\title{
A QUALITATIVE STUDY OF TEACHER LEADERSHIP \\ IN SECONDARY SCHOOLS \\ IN CENTRAL MISSOURI
}

\author{
A Dissertation \\ presented to \\ the Faculty of the Graduate School \\ at the University of Missouri-Columbia
}

In Partial Fulfillment

of the Requirements for the Degree

Doctor of Education Leadership and Policy Analysis

by

JULIE A. CARTER

Dr. Sandy Hutchinson, Dissertation Supervisor

JULY 2018 
(C) Copyright by Julie A. Carter, 2018 All Rights Reserved 
The undersigned, appointed by the Dean of the Graduate School, have examined the thesis or dissertation entitled

\section{A QUALITATIVE STUDY OF TEACHER LEADERSHIP IN SECONDARY SCHOOLS IN CENTRAL MISSOURI}

presented by Julie Carter, a candidate for the degree of Doctor of Educational Leadership and Policy Analysis, and hereby certify that, in their opinion, it is worthy of acceptance.

Dr. Sandy Hutchinson

Dr. Barbara Martin

Dr. Steve Ritter

Dr. Doug Thomas 


\section{Dedication}

I would first like to thank God for giving me strength and guidance every step of the way on this journey. Feeling His comforting presence and knowing He is in control of all things has helped to keep me grounded, gave me motivation, and provided me piece of mind in order to persist and see this endeavor through to the end.

I would like to dedicate this work to my husband Steven. Your enduring love and sweet words of encouragement helped me persevere and finish strong. Thank you for being there for me and believing wholeheartedly in me when I needed motivation, support, and reassurance. You always help to keep me grounded and consider the big picture. You were there two decades ago when I first promised myself I would one day achieve this goal, and I certainly could not have realized this dream without you. You are always my inspiration!

I would also like to thank my family for their love, support, and encouragement. Dad, you have always told me I could do anything I set my mind to. You always support me and say just the right thing to keep me going. Mom, you have always believed in me and you inspire me to keep moving forward with your own energy and zest for life. To my son Zackary, thank you for being there for me, loving me, reminding me what is important in life, and encouraging me along the way. You continually help me to see different points of view. To my daughter Elizabeth, I greatly appreciate your love and support. I also am grateful for your assistance when I needed ideas or was at a loss for words during different stages of writing. It has been an unforgettable experience being college students together! My granddaughter Evelyn, you are always a light in my life 
and motivate me to keep going with your sweet spirit. To my sisters Carol and Susie, thank you for your love, support, and enthusiasm during the completion of this project.

Finally, I would like to express gratitude for my dear friends. Thank you for believing in me, comforting me, encouraging me, and for providing much needed breaks during this journey. Your friendship is truly a blessing 


\section{Acknowledgments}

First, I would like to personally acknowledge and extend heartfelt gratitude to my professor, Dr. Sandy Hutchinson. She has been there every step of the way and has made this experience meaningful and worthwhile. I have learned so much under your tutelage about research, leadership, and life. Thank you for being such an inspiring role model!

I wish to extend a special thank you to members of my dissertation committee. I appreciate your personalized attention and ideas for my research. I am grateful for your advice and inspired by your knowledge and experience. You are each an excellent resource, and I am quite fortunate to have had you on my team.

I would also like to thank my classmates in Cohort 10 for your support and comradery. I have grown quite fond of you over the past three years. I am so grateful for our meaningful discussions, moments of discovery, laughter, and even tears. I feel as though I am a better person for having known each of you. Thank you for being so supportive and kind. Thank you for your friendship.

I am grateful for the administration, staff, and students of the Odessa R-VII School District for your continued support and encouragement during this endeavor. You helped to make this dream a reality. I have enjoyed celebrating our educational milestones together.

While conducting my research in the field, I was introduced to some outstanding individuals in leadership positions. I wish to extend a heartfelt thank you to all of the participants who assisted me in my research. I appreciate your candidness and willingness to take the time to share your thoughts about leadership in education. I have 
learned a great deal, and I have been personally inspired by your professionalism and level of commitment to education. 


\section{TABLE OF CONTENTS}

ACKNOWLEDGMENTS ..........................................................

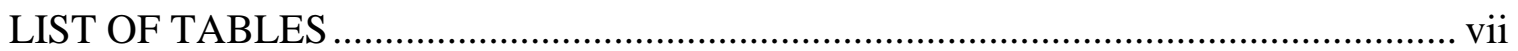

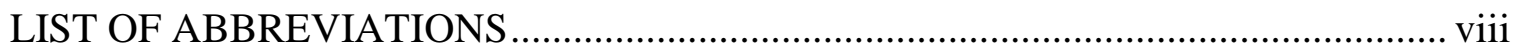

ABSTRACT

Section

1. INTRODUCTION TO THE DISSERTATION IN PRACTICE ......................

Background........................................................2

Statement of Problem..................................................

Problem of practice............................................... 3

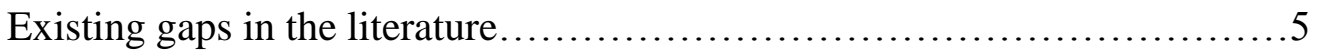

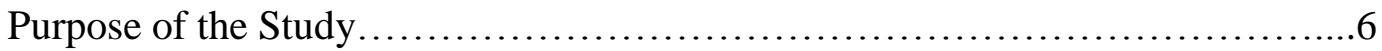

Research Questions...................................................8

Conceptual/Theoretical Framework $\ldots \ldots \ldots \ldots \ldots \ldots \ldots \ldots \ldots \ldots \ldots \ldots \ldots \ldots \ldots$

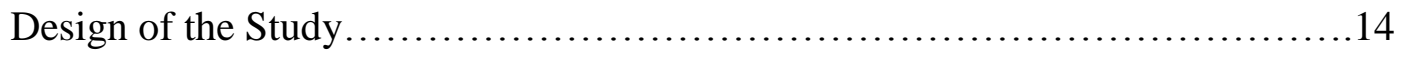

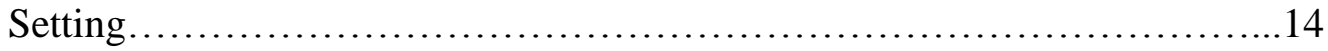

Participants................................................... 15

Data Collection Tools............................................... 16

Data Analysis................................................... 19

Limitations, Assumptions, and Design Controls...........................20

Definitions of Key Terms...........................................22

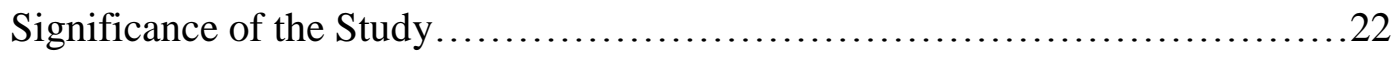

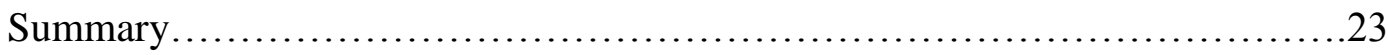




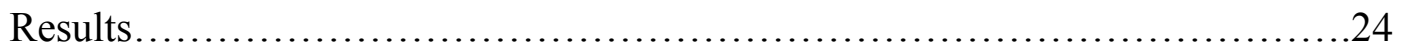

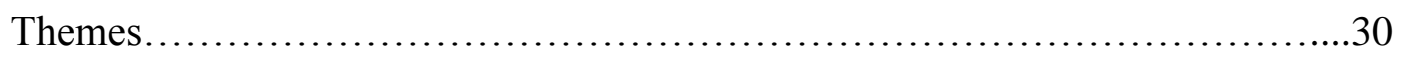

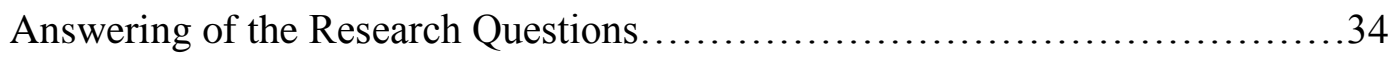

Implications for Practice.................................................66

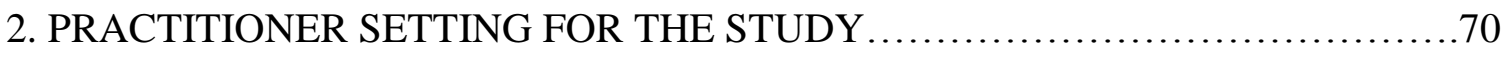

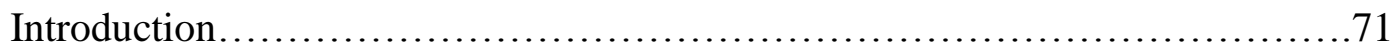

History of the Organization............................................... 71

Organizational Analysis.................................................. 74

Leadership Analysis.................................................... 76

Implications for Research in the Practitioner Setting...........................79

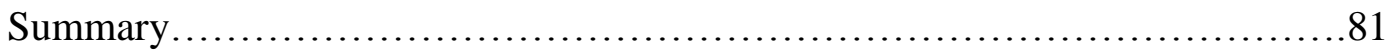

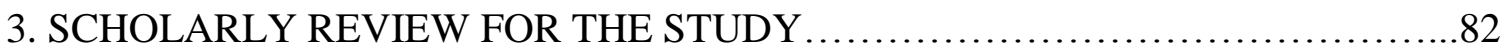

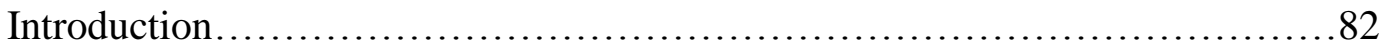

Teacher Leaders: A Description............................................ 83

Seminal Research: Teacher Leadership ...................................84

Formal and Informal Roles of Leadership..................................86

Why Teachers Make Good Learning Leaders.................................88

Teacher Leadership Concerns..............................................91

Need for Professional Development......................................93

Professional Learning Communities (PLCs) ................................99

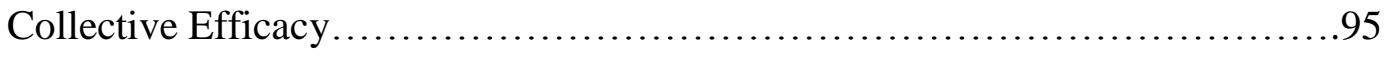

Effective Teacher Leadership Among Peers..................................96

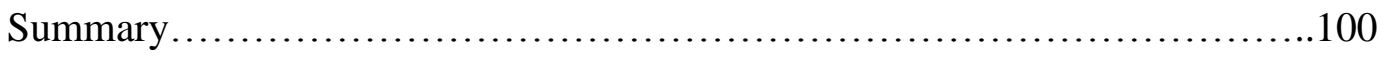


4. CONTRIBUTION TO PRACTICE............................................. 101

Presentation............................................................ 102

References..................................................... 123

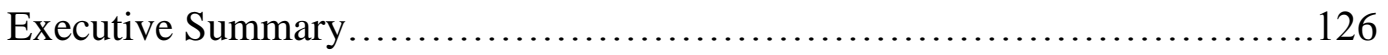

References..................................................... 128

5. CONTRIBUTION TO SCHOLARSHIP .................................. 130

Abstract........................................................... 131

Journal-Ready Article...............................................132

References........................................................... 147

6. SCHOLARLY PRACTITIONER REFLECTION.............................. 150

REFERENCES ......................................................... 160

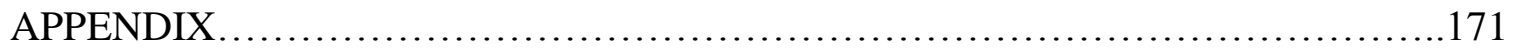

A. Demographic Survey for Principals.................................... 171

B. Principal Interview Questions...................................... 172

C. Teacher Interview Questions............................................ 173

D. Waiver of Documentation of Consent Form for Principal Survey.................174

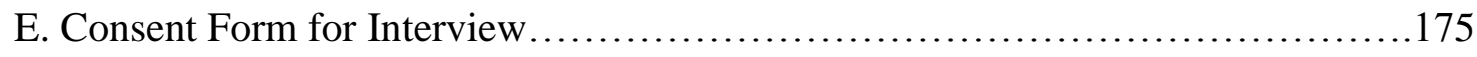

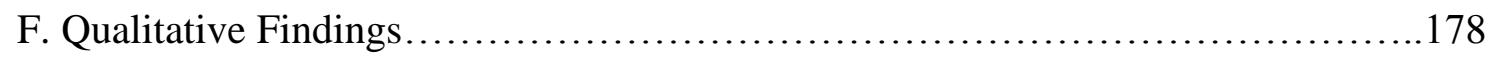

G. Themes.......................................................... 330

H. Answering of the Research Questions.................................... 361

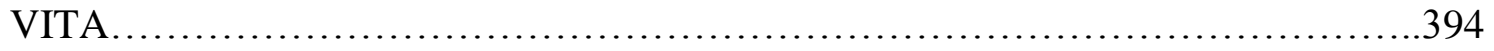




\section{List of Tables}

Table 1. Teacher Pseudonyms, Subject, and Grade Level, Alphabetical

Table 2. Principal Pseudonyms and Grade Level, Alphabetical 
BIST: Behavior Intervention Support Team

BLT: Building Leadership Team

CSIP: Comprehensive School Improvement Plan

CTA: Community Teachers Association

DI: Direct Instruction

EOC: End of Course (Exams)

FACS: Family and Consumer Sciences

FBLA: Future Business Leaders of America

FCCLA: Family, Community and Career Leaders of America

MSTA: Missouri State Teachers Association

NEA: National Education Association

NCES: National Center for Education Statistics

NHS: National Honor Society

NJHS: National Junior Honor Society

PBIS: Positive Behavior Interventions and Supports 
PLC: Professional Learning Community

RTI: Response to Intervention

STARR: Standardized Test for the Assessment of Reading

TAC: Teacher Advisory Committee 


\begin{abstract}
This qualitative study examined teacher leadership with the purpose of gaining knowledge and insight as well as adding to existing research about teacher leaders. Research was conducted in the form of surveys and interviews. Ten principals and their ten selected teacher leaders were interviewed. The researcher discovered characteristics teacher leaders possess, how their respective principals view them as leaders, and how they view themselves as leaders. Several subthemes emerged from the overarching theme of "Let's go." Results from the study revealed teachers, when given opportunities for leadership roles, impact the school in many positive ways and this distributive leadership helps alleviate pressure from principals.
\end{abstract}


SECTION ONE

INTRODUCTION TO THE DISSERTATION IN PRACTICE 


\section{Introduction to the Background of Study}

A pressing need and a sense of urgency has dominated the system of American education in terms of providing effective leadership and direction in a fast-paced global economy ever since the turn of the century. Furthermore, there is a significant demand to prepare students for the future with highly qualified teachers. However, stresses and demands of the job have rendered a mass exodus of teachers leaving the field (Cosenza, 2015; Mihans, 2009). According to Womack-Wynne et al. (2011), 40-50\% of teachers leave the field within the first five years. The need for teacher leadership is ever prevalent and significant. Perhaps not unrelated, schools have been burdened with an immense amount of responsibility coupled with unprecedented levels of accountability mandates (Mangin \& Stoelinga, 2010; Mihans, 2009; Singh, 2012). The significance of leadership within the context of the public school seems to be at an all-time high.

Incidentally, since the early 2000 s there has been a resurgence in the focus and study of leadership, specifically teacher leadership (Browne-Ferrigno, 2016; Cosenza, 2015; Lukacs, 2015; Muijs, Chapman, \& Armstrong, 2013; Singh, 2012). Traditionally, leadership within schools was reserved primarily for the principal, but this paradigm has shifted, and it is in the process of a transformation (Cosenza, 2015; Lukacs, 2015; Ross, Lutfi, \& Hope, 2016; Singh, 2012). Teachers often claim that they feel unsupported by their principals (Mihans, 2009). In some cases, teacher leaders have assumed such leadership roles. This is a compelling time, as teachers are rising above expectations and are taking on greater responsibilities, fulfilling increased roles, and affecting change both within and beyond their classrooms in meaningful ways (Akert \& Martin, 2012; Cosenza, 2015; Edwards \& Hineuber, 2015; Lukacs, 2015; Martin, 2007; Nappi, 2014; Stanulis, 
Cooper, Dear, Johnston, \& Richard, 2016). For these reasons, the time is right to examine what the literature reveals about this resurgence in leadership and more specifically, about the concept of teacher leaders, including a better understanding of who they are, what they do, and the impact that they have on the districts where they teach. A grand challenge exists to tap into one of the greatest resources of all time in relation to leadership - a challenge to include teachers as leaders in further capacities beyond the classroom.

\section{Statement of the Problem}

\section{Problem of Practice}

Given increased demands for leadership in schools, it is both important and troubling to note that teachers are an untapped potential regarding leadership in school districts (Hanuscin, Cheng, Rebellow, Sinha, \& Muslu, 2014; Lukacs, 2015; Mangin \& Stoelinga, 2010; Margolis \& Deuel, 2009; Ross, Lutfi, \& Hope, 2016). According to Hanuscin et al. (2014), “...few teachers consider themselves leaders. Teachers may fail to recognize the need for multiple leaders" (p. 207). Even when teachers assume leadership roles, they often "do not see themselves as leaders, reserving the term 'leader' for those who take on formal roles such as principals or district supervisors" (p. 143). Furthermore, teachers may not even realize opportunities for leadership that surround them (Sinha, Hanuscin, Rebello, Muslu, \& Cheng, 2012). On the administrative side, according to Foster and Wiseman (2015), "Many leaders, having spent years being rewarded for their intelligence, never look beyond their own capability to see and use the full genius of their team" (p. 47). 
Why should teachers share in this leadership role? Teacher leaders work alongside their peers, they are respected by their peers, and they can be a model and a source of inspiration for them. They provide "mastery experiences which can impact the collective beliefs of the faculty in a positive manner" (Angelle \& Teague, 2014, p, 748). According to Spillane and Kim (2012), teacher leaders can help establish a more collaborative work environment, creating situations where it is easier for teachers to garner support and glean both skill and mastery in education. School districts often utilize experts in the field of education for improvement efforts in professional development, but Nappi (2014) contended "teachers have a pragmatic understanding of the needs of the school and the school community that outsiders frequently do not. In addition, outside consultants and teaching experts often do not have experience in education or in public schools" (p.31). Buchen (2000) expressed the importance of teachers engaged in leadership roles: "The only leadership that will make a difference is that of teachers. They alone are positioned where all the fulcrums are for change. They alone know what the day-to-day problems are and what it takes to solve them" (p. 35).

Reeves (2006) maintained teachers are "islands of excellence," isolated in their own classrooms and not fully utilized by school leaders. He discussed enthusiasm for change initiatives on the part of school leaders where efforts for improvement are all too often unrealized:

You have witnessed it dozens of times: A leader becomes enthusiastic about a change initiative. Senior management attends an off-site retreat. Groups generate vision statements . . . and spend extraordinary levels of time and resources to extend the initiative throughout the organization, and ... nothing happens. A few 
people embrace the initiative, but the leaders don't admit that these enthusiastic few had already been implementing similar strategies without direction from headquarters. These isolated individuals who carry out the desired change are the islands of excellence, and their isolation is the reason that more than two-thirds of reform initiatives are never fully implemented. (p. 33)

Reeves (2006) postulated that a few outstanding individuals - teacher leaders - are at the ready, and they could have an extraordinary impact for helping to create and sustain change.

\section{Existing gaps in the literature}

Gaps in the literature exist related to this problem of practice. One such gap is that an educational leadership focus has traditionally been geared toward administrators and not teachers (Hanuscin, et al., 2014; Lukacs, 2015; Nappi, 2014; Singh, 2012). The capacity for teacher leadership is underrepresented and underexplored. There is a need for merging perceptions in terms of leadership within the literature. Division of leadership in the research further propagates the mentality that leadership is a formal role reserved solely for the principal. The voice of the teacher as leader is severely lacking in the research, especially in the form of qualitative research (Angelle \& Dehart, 2011; Cosenza, 2015; Lukacs, 2015; Neumerski, 2016; Singh, 2012; Struyve, Meredith, \& Gielen, 2014; Wenner \& Campbell, 2016). By examining the problem of unfulfilled teacher leadership, this study will contribute to the literature in the field.

Another gap in the literature is the absence of examples where teachers have taken on meaningful leadership roles. Although there is a smattering of examples of teachers fulfilling leadership roles in school districts in the literature, the scope is limited 
and the number of instances is few. Lukacs (2015) asserted, "The role of the teacher in educational change is shifting from recipient to initiator, but little is known about the teachers who fulfill that latter role" (p. 39). Also, teacher leadership scenarios are too often focused on extracurricular pursuits and specific, predictable roles teachers are likely to assume as characteristic of the profession, and are less likely to be meaningful endeavors such as those affiliated with meaningful problem solving, decision making, and implementation of initiatives and change. In direct association with administrative officials in schools, Reeves (2006) claimed, "Leaders seeking change must abandon the fantasy that human organizations function as hierarchies - and recognize the value of networks," (p. 32) and that leaders can be a valuable resource within this network.

\section{Purpose of the Study}

Although the presence of research is extensive in the realm of administrative leadership, very little research has been conducted on the topic of teachers as leaders (Angelle \& Dehart, 2011; Cosenza, 2015; Lukacs, 2015; Neumerski, 2016; Singh, 2012; Struyve et al., 2014; Wenner \& Campbell, 2016). The purpose of this study was to gain knowledge and insight as well as add to existing research about teacher leaders. What are the perceived qualities of a true teacher leader? What are the actual qualities of a teacher leader? The researcher conducted research to discover from principals the teachers they would identify as leaders. After identifying these individuals, the researcher discovered characteristics teacher leaders possess, how their respective principals view them as leaders, and how they view themselves as leaders. Variations about these discrepancies were notated and explained. 
Another component of the research covered ways principals utilize those teachers with leadership qualities within their respective districts. Are the identified teachers currently fulfilling roles outside the classroom? If so, what are those roles? What does this look like in day-to-day practice? The researcher wishes to discover to what extent teacher leaders are being utilized, as well as discover whether teacher leaders are being used to their potential (Angelle \& DeHart, 2011; Cosenza, 2015; Wenner \& Campbell, 2016).

Yet another area of interest is that of professional development, specifically in learning about the ways principals support and encourage leadership roles among faculties (Cosenza, 2015; Gordon, Jacobs, \& Solis, 2014; Mangin \& Stoelinga, 2010; Wenner \& Campbell, 2016). It would be beneficial to know how much professional development involves leadership specifically intended for teachers, whether or not teachers are informed about specific leadership opportunities, and the number of teachers pursuing these opportunities. Finally, of pressing importance would be the steps administrators can take to better recognize and encourage teacher leaders in order to more adequately discover and take advantage of this invaluable potential that is unrealized, ever present, and within reach.

With this study, the researcher discovered the qualities, both perceived and real, of teacher leaders, the ways in which teacher leaders are utilized, and how professional development is used or could be used in order to better recognize and utilize teachers as leaders. Considering the demands placed upon administration in education during such turbulent times and ever-increasing responsibilities, the importance of effective leadership cannot be underestimated, nor can it be underutilized (Gordon et al., 2014; 
Nappi, 2014; Ross et al., 2016). Teachers themselves often do not view themselves as leaders, nor do they recognize opportunities for leadership that surround them (Sinha, Hanuscin, Rebello, Muslu, \& Cheng, 2012). This study offered information and recommendations for how to effectively utilize teacher leadership as well as provided a more established sense of voice of teachers as leaders, all while adding qualitative research to the field.

\section{Research Questions}

The research questions guiding this study were:

1) How are teacher leaders identified and utilized in school districts?

2) How are teacher leaders perceived by teachers and principals?

3) What types/characteristics of leadership are exhibited by teacher leaders?

4) How can schools more effectively identify and engage teacher leaders?

5) How is teacher leadership encouraged by teachers and principals?

6) How are elements of distributed leadership exhibited by principals and teachers?

\section{Conceptual/Theoretical Framework}

When examining the need for increased teacher leadership in education, it is valuable to explore distributed leadership (often used synonymously or in conjunction with shared leadership) as a conceptual framework to see how this concept relates to teachers as leaders within the grand scope and study of leadership. Distributed leadership occurs when more than one person assumes a leadership role and shares administrative responsibility (Ross et al., 2016). Bush (2013) contended that "leadership may arise anywhere in the organization and is not confined to formal leaders" (p. 543). Models of 
distributive leadership involve interactions between people of different levels and roles in the workplace. Singh (2012) described this interaction as:

collaborative, dynamic, mutually accountable, and based on a match between organizational need and individual expertise...This allows participants to share passion for their work, pursue a common vision, take advantage of expertise within the group, and optimize collaboration. (p. 16)

When leaders in formal roles decide to operate with the distributive leadership model in place, "they demonstrate that the organization values the contributions of its members and affirm their belief that all individuals should have a voice" (Singh, 2012, p. 16).

Interest in distributed leadership has been on the rise since the early 2000s (Muijs et al., 2013). Gronn (2000) presented distributive leadership as a conceptualization of leadership by which the construct could be viewed more holistically and fluidly instead of a collection of individual pursuits. He voiced,

I synthesized current trends and developments in leadership and considered whether the field was on the cusp of a fundamental rethink - driven mainly by the need to accommodate new organizational change and restructuring imperatives which would supersede all that had gone before it, and which would alter forever our view of leadership. (p. 317)

Spillane (2005), another leading contributor to distributive leadership, stated that other leaders besides principals have a role in leadership: "School principals, or any other leader for that matter, do not single-handedly lead schools to greatness; leadership involves an array of individuals with various tools and structures" (p. 143). The responsibility of leadership in schools was traditionally placed on administrative officials 
such as superintendents and principals; however, of recent there has been a shift towards including teachers in leadership capacities beyond the classroom, given that principals are overwhelmed with leadership tasks (Gordon et al., 2014; Nappi, 2014; Ross et al., 2016).

Since the beginning of the $21^{\text {st }}$ century, significant growth has occurred from educational practitioners and researchers in the study of distributed leadership, which has been attributed to increased demands placed on schools (Muijs et al, 2016). Bush posits that "distributed leadership has become the normatively preferred leadership model in the $21^{\text {st }}$ century" (p. 543). Teacher leadership is recognized as a subset of distributed leadership. The concept of teacher leaders, when viewed through the lens of distributed leadership, represents a more cooperative view of authority between teachers and principals (Gordon et al., 2014; Margolis \& Deuel, 2009; Muijs et al., 2013; Nappi, 2014; Peterson \& Conway, 2011; Singh, 2012; Sinha et al., 2012). With this cooperative view of authority, teachers are "empowered to work collaboratively" (Peterson \& Conway, 2011); this approach fosters empowerment of the individual rather than the sense of being controlled.

In practical application, the process of distributed leadership occurs when an administrator makes an intentional decision to let go of some control, "moving from isolationist to a shared mode of operating" (Singh, 2012, p.16). Individuals in the group naturally assume leadership roles and they "work in diverse configurations, involving varying degrees of interdependence or sequences of interactions, according to the task" (Singh, 2012, p.16). An example of distributive leadership is that of PLC (Professional Learning Community). In this scenario, principals and teachers rally together individual strengths, knowledge bases, and levels of expertise in order to analyze information 
related to a problem and make an informed decision together (DeMatthews, 2014; Singh, 2012). Distributed leadership can occur in many contexts in a school setting. According to Ross et al., (2016):

During the adoption of DL, a school experiences transformation into a multidirectional flow of influence that entwines the principal, teachers, counselors, and other organization members ... Essentially, experiences arising from the distribution of leadership prepare teachers to become leaders. (p.160)

In taking a closer look at distributed leadership, Devos, Fuytens, and Hulpia (2014) analyzed the relationship between the leadership of principals and teacher. Their findings indicated that "the school principal remains a pivotal player who should stimulate distributed forms of leadership in the school" (p. 225), and teachers' levels of commitment rise when opportunities for leadership roles are presented. Other benefits of shared leadership were "group cohesion, role clarity, and goal orientedness" (p. 225). It was concluded that "principals should stimulate assistant principals and teacher leaders to take part in leading the school, lead the school in a collegial way with other members of the leadership team, and where teachers can participate in school decision making" (p. 205).

Stegall and Linton (2012) presented an example of distributed leadership in action that transpired in the Newton-Conover City Schools in North Carolina, where a "problems-up, solutions-down" approach to leadership changed to a "problems-down, solutions-up" approach. Practically speaking, shared decision making and leadership became a reality, as the districts put shared leadership to the test: 
School-level teacher teams are empowered to put these strategies into practice throughout the school, create a monitoring system, and study the effect of improvement efforts before deciding if more changes are needed. School leaders become more of a resource to the teacher teams, helping them identify gaps and possible areas for improvement instead of defining the work that needs to be done. . This approach empowers teachers and school stakeholders to make decisions and address solutions to problems instead of waiting on the leader to tell them what needs to be done. (p. 62)

School priority and goal teams replaced traditional meetings for shared decisions. Different teams of teacher leaders focused on improvement goals through data analysis, and the teams influenced decision-making regarding best practices, initiatives, community needs, school processes, and student needs. Different goal teams included: student academic performance and growth, teacher growth and development, technology, and parent and community stakeholder needs. Essential to the process, the school leader provided "a vision and the structure" and monitored "implementation to ensure the fidelity of the process" (Stegall \& Linton, 2012, p. 63). Collaboration through PLCs was also cited as important in this endeavor. After implementation of shared leadership practices, the district saw an increase in academic growth. The graduation rate increased from $63.3 \%$ in 2006 to $88.6 \%$ in 2010 . Regarding student achievement, during the same four-year span, third through eighth graders increased in reading proficiency from $63 \%$ to $86 \%$. High school student achievement increased $68.9 \%$ proficiency to $85.5 \%$. Following the study, the district looked forward to sustainable gains beyond the principal's leadership. 
Woods and Gronn (2009) recommended a multi-faceted approach when implementing distributive leadership which includes a careful, intentional approach "on the grounds of its potential contribution to effectiveness, accompanied by critical evaluation of how it plays out in practice" (p. 447). Also included in the recommendation are taking into account the democratic health of the organization and a re-emphasis of the single-leader construct. Gronn (2008) has voiced concern for "a scholarly ignorance that denies distributed leadership's continuity with intellectual precedence" (p. 155), and has voiced the need to more seriously consider the domains of power and democratic leadership in organizations. It is for these reasons Gronn (2008) has considered the term "hybrid" as a better representation of distributed leadership.

According to Kezar, Carducci, and Contreras-McGavin (2006), "Social constructivism is the belief that reality is developed through one's interpretation of the world .. .reality is a social and cultural construction" (p. 19). The constructivist worldview guided the research in the study. Constructivism or social constructivism is a perspective in which "individuals seek understanding of the world in which they live and work" (Creswell, 2014, p. 8); therefore, context is of high importance (Creswell, 2014; Kezar et al., 2006). According to Creswell (2014), this process of comprehending the world can be complex and varied, and the researcher will place great emphasis on the views of the participants. Many questions will be open-ended and general in nature in order to capture subjective meanings shared by participants about their unique lives and experiences (Creswell, 2014; Kezar et al., 2006). Also congruent with constructivism is the element of the researcher. As researchers interpret information collected by participants, "their own backgrounds shape their interpretation, and they position 
themselves in the research to acknowledge how their interpretation flows from their personal, cultural, and historical experiences" (Creswell, 2014, p. 8). The researchers then, through the process of induction, establish meaning.

\section{Design of the Study}

The overarching design of this study about teacher leaders was phenomenological, which is described as the "lived experience" or "a study of people's conscious experience of their life world" (Merriam \& Tisdell, 2016, p. 26). This was a qualitative study, given that the researcher's general objective was to learn more about the personal stories and experiences of principals and teachers in regard to teacher leadership. Merriam and Tisdell (2016) presented characteristics of qualitative research: "The focus is on process, understanding, and meaning, the researcher is the primary instrument of data collection and analysis; the process is inductive; and the product is richly descriptive" (p. 15). The nature of this method of research allows a more comprehensive understanding of "how people interpret their experiences, how they construct their worlds, and what meaning they attribute to their experiences" (Merriam \& Tisdell, 2016, p. 15). A concern emphasized by the authors is for researchers of qualitative research to understand the subject of interest from the participants' perspectives and not the researcher's.

\section{Setting}

The setting was a representative sample (Creswell, 2016) of ten rural public secondary schools located in the Central RPDC (Regional Professional Development Center) region of the state of Missouri, as established by DESE (Department of Secondary and Elementary Education). For this study, rural schools were defined based 
on their proximity to a metropolis, as classified by the National Center for Education Statistics (NCES). School districts sampled were located more than twenty-five miles from an urbanized area (National Center for Education Statistics). Counties in this region include: Bates, Benton, Carroll, Cass, Henry, Hickory, Johnson, Lafayette, Morgan, Pettis, Ray, St. Clair, Saline, and Vernon. School districts in the study ranged in size from 175 to 3,400 enrolled students. Four middle schools, four high schools, and two middle/high school combinations were included in the study.

The researcher chose secondary education because her teaching experience of twenty-five years has occurred in both middle school and high school, so she is better informed and has a working knowledge about the educational system and its functionality at this level. Furthermore, she felt as though she would be better able to understand and appreciate, as well as provide insight and analysis more competently at this level, as a result of her own experience.

\section{Participants}

Participants included ten secondary principals and their selected teachers from the Central RPDC region who agreed to participate and contribute to the study. The Central RPDC region consists of 71 school districts. Secondary principals for this research study included those administering any combination of grades 6-12. Before IRB approval, the researcher contacted superintendents of schools within the Central RPDC region by phone and requested written permission to conduct research in their respective schools. After receiving the written permission to conduct research from the superintendents as well as IRB approval, the researcher obtained a list of names and emails for these respondents from the DESE website, explained by Creswell (2016) as a sampling frame. 
Surveys via email were sent to these principals in an effort to find out which individuals were willing to participate and were the best fit for the purpose of the study. These surveys consisted of multiple choice and open-ended questions which determined demographic information as well as whether or not potential participants had a case relevant to the research (Appendix A). Specifically, did the principals have teachers they would name as a leader based on the presented criteria, and were the principals and teachers willing to participate in the study?

The researcher analyzed demographic and qualitative statistics in order to determine which district principals and their teachers could participate. The researcher employed a strategy called purposeful sampling to "discover, understand, and gain insight ... and select a sample from which the most can be learned" (Merriam \& Tisdell, 2016, p. 96). Participants were contacted by phone or email to set up personal interviews. In the actual study, participants consisted of ten secondary principals along with the teacher each principal identified as a teacher leader according to the definition and presented criteria, so the sample equaled 20 participants total.

\section{Data Collection Tools}

After Institutional Review Board (IRB) approval from the University of Missouri, which ensures sound, ethical research, information was collected in the form of surveys, personal interviews, observations, and documents, all strategies concurrent with qualitative research (Creswell, 2016; Merriam \& Tisdell, 2016). Since qualitative research is about studying how people make sense of their world (Merriam \& Tisdell, 2016), these processes helped to gain a deeper understanding and appreciation of the teacher leaders that principals named as well as how those teachers viewed themselves. 
These data collection tools helped to shed light on "understanding the meaning people have constructed" (Merriam \& Tisdell, 2016, p. 15) about their world, and utilizing multiple sources of data rather than relying on a single source (Creswell, 2016; Merriam \& Tisdell, 2016).

Surveys. Data collection tools included an initial survey of principals in order for the researcher to determine participants suited for the study. Since the researcher went outside of her own educational setting and community, chances were better to ensure validity (Fink, 2017). A pilot test was administered to individuals not located in the area of study to help guarantee reliability and validity. For reliability, content and ordering of questions were revised for clarity and continuity. For validity, items were revised to stimulate full expression of participant views. After revision, surveys were created and distributed by email for the sake of cost and convenience using Google survey and consisted of qualitative statistics for general demographics and open-ended questions. Responses were captured by the Google survey software and organized by item into a Google spreadsheet. These responses were the first responses and impressions in gathering information about the proposed research questions.

Personal Interviews. For data analysis, face-to-face interviews were conducted, audio recorded, and transcribed to effectively capture original meanings and quotes. An interview protocol was used to document and organize demographics and other related notes (Creswell, 2014). Interviews were semi-structured with a predetermined list of questions asked in a flexible order for best flow, researcher response, and emerging ideas (Merriam \& Tisdell, 2016). Interviews were selected as a research tool because of the level of depth that occurs when having individuals reflect on their related human 
experience and the sense that they have made from it; language is a powerful element for making meaning of this experience (Seidman, 2013). Additionally, utilizing multiple cases of interviews strengthens the validity and generalizability of findings (Merriam \& Tisdell, 2016). Interviews were first pilot tested to ensure questions "support the objectives of the study" (Seidman, 2013). A total of 20 interviews were conducted, including 10 principal interviews (Appendix B) and 10 teacher interviews (Appendix C). The duration of the interviews was approximately 45 minutes in length. Both the researcher and the interviewee signed a consent form (Appendix E) to clearly communicate permission to conduct the research, the researcher's intentions, and confidentiality of the information captured. The researcher de-identified information as well as assigned pseudonyms to keep the process and related information confidential (Merriam \& Tisdell, 2016; Seidman, 2013).

Observation. Observation notes were taken to capture a more complete picture of the location as well as actions and behaviors, both verbal and nonverbal, of those interviewed. Of special importance is describing careful, systematic observations during the interview to seize a more complete, firsthand view of the event (Creswell, 2014; Merriam \& Tisdell, 2016). The researcher made notes of behaviors or other related happenings in the margins of the interview question sheet to track their time and progression for a more accurate, complete understanding of the context. The researcher did her best to make sure this process did not interfere with the progression and flow of the interview. Several benefits of observations are that any unusual occurrences can be recorded, and "they are useful in exploring topics that may be uncomfortable for the participants to discuss" (Creswell, 2014, p. 191). These written observations were 
considered field notes, "which are analogous to the interview transcript" (Merriam \& Tisdell, 2016, p. 149). These were recorded soon after the interview to ensure accuracy (Merriam \& Tisdell, 2016).

\section{Data Analysis}

As part of the analysis process with qualitative data, it is critical to segment and disassemble the data as well as piece it all back together (Creswell, 2014). It is essential that the researcher "review all of the data, make sense of it, and organize it into categories or themes that cut across all data sources" (Creswell, 2014, p. 186). Interviews were transcribed and hand coded in order to capture and record the prominent themes (Creswell, 2014; Merriam \& Tisdell, 2016). The researcher meticulously read through transcriptions and noted common trends and themes, "working back and forth between the themes and the database" until a "comprehensive set of themes" surfaced (Creswell, 2014, p. 186). These themes were assigned a code and were labeled when they occurred on the transcripts. Specifically, lean coding was used to create a list of the codes in a document that was then formulated into a smaller grouping, a culmination of approximately five to seven themes (Creswell, 2016). Notes to augment description and discussion of themes were taken in order to interpret and reflect upon the data. Selected quotes were extracted from transcripts and organized according to their respective themes. The researcher completed this process so the researcher could both systematically and meaningfully conclude the findings.

Data were then validated by means of triangulation, member checking and rich description, presenting information that varied from the themes, peer debriefing, and reflexivity (Creswell, 2014). Triangulation is important to qualitative study because 
multiple data sources are examined, and this information is used "to build a coherent justification for themes," which enhances the validity of the study (Creswell, 2014, p. 201). Comparing and crosschecking data at different intervals was also integral to triangulation (Merriam \& Tisdell, 2016). Member-checking was important to double check recorded information with those interviewed. Thick, rich description also adds to the authenticity of findings in that the results are more realistic with the provided details. Presenting information that varies from the presented themes demonstrates transparency, which strengthens the credibility of the researcher. Peer debriefing is recommended, as the researcher presents findings to someone else "so that the account will resonate with people other than the researcher" (Creswell, 2014, p. 202). Reflexivity occurs when the researcher presents any possible bias that s/he brings to the situation that could stem from elements such as gender, background experiences, and socioeconomic origin (Creswell, 2014; Merriam \& Tisdell, 2016). Once the researcher had employed these methods, the findings were recorded into a cohesive document.

\section{Limitations, Assumptions, and Design Controls}

In this research study, certain limitations were present, such as those occurring as a result of the setting, the design of study, including the nature of the interview questions, the participants themselves and possible limited responses, and the process of analysis. A limitation of the setting may be that the data collected represented responses from teachers and principals from rural schools in the Midwest, so the information may not be completely generalizable for other areas of the country or for urban schools. Another limitation may include researcher bias toward perspectives of teachers, given that the researcher is a classroom teacher. The researcher did her best to remain objective in her 
interpretation and analysis of data and to not allow personal bias to interfere with results. The interview questions themselves could prove faulty and not render the type of response expected, but the researcher pilot tested the questions in an alternate setting, taking into account feedback from pilot participants, and revised accordingly.

A philosophical assumption of the researcher is identification with the constructivist worldview. The constructivist worldview guided the research in the study, which is characteristic in qualitative research. Given that the researcher was a part of the research process with her own background and experiences, as she interpreted the data, which was complex and varied, she did her best to remain objective and to keep the emphasis on the views of the participants.

Regarding design control, since the research was a qualitative study, the researcher collected data in the natural setting. Interviews were conducted face to face in the environment where the participants were employed so that the researcher could observe behaviors and actions of the participants in their own context (Creswell, 2014). The researcher developed data collection tools such as surveys and interviews. Many sources of data were used such as interviews, surveys, and observations. Data were organized inductively by building and organizing patterns and themes from responses and then deductively to determine whether themes were justified (Creswell, 2014). The research process was an emergent design, also consistent with qualitative research. The plan for the research was flexible as phases of the process can shift or change (Creswell, 2014). Therefore, the researcher "has to be comfortable with the ebb and flow of a qualitative investigation and trust in the process" (Merriam \& Tisdell, 2016, p. 18). 


\section{Definitions of Key Terms}

Defined are the following terms to guide in understanding this inquiry:

Collective efficacy: A process by which group members believe in their

collaborative efforts to accomplish goals and achieve success (Angelle \& Teague, 2014).

Distributed (Shared) Leadership: A more holistic or fluid view of leadership which occurs when more than one person assumes a leadership role and shares administrative responsibility, especially of different levels and roles. Distributed leadership may be used interchangeably with shared leadership (Bush, 2013; Gronn, 2000; Ross, Lutfi, \& Hope, 2016; Spillane, 2005).

Social Constructivism: The worldview or perspective that individuals seek understanding from the world in which they live which results in a complex viewpoint; people attribute meaning to their reality (Creswell, 2014; Kezar, Carducci, \& ContrerasMcGavin, 2006).

Teacher Leader: A teacher that functions as a leader beyond the classroom in ways meaningful to the betterment of the school; one who shapes school culture and builds school resilience; one who leads by example and has credibility and expertise (Green \& Kent, 2016; Martin, 2007).

\section{Significance of the Study}

The study contributed to educational leadership by providing more information about how teachers can serve as leaders within their districts, the importance and rationale for such an endeavor, and ways administrators can more effectively realize this potential. Teachers are the ultimate leaders (Buchen, 2000; Edwards \& Hinueber, 2015), and better utilizing their talents for the betterment of education is both necessary and 
ideal, especially considering the landscape of education and the level of demand placed on administrators (Mangin \& Stoelinga, 2016; Mihans, 2009; Singh, 2012).

This study could be used to increase awareness and utilization of teacher leaders within school districts. Findings could be presented to administration and teachers and, ultimately, more teachers could be encouraged and inspired to become leaders.

This qualitative research will add to the area of teacher leadership, a concept that is scant in the literature (Angelle \& DeHart, 2011; Cosenza, 2015; Lukacs, 2015). The voice of teachers is severely lacking in the research; this study will help to propagate the mentality that teachers are viable leaders and ultimately can make a difference, both within and beyond the classroom.

\section{Summary}

A pressing need exists for effective leadership in public schools, and principals cannot do it alone (Akert \& Martin, 2012; Gordon et al., 2014; Miles, 2016; Nappi, 2014). Though extensive research is available for leadership related to administration, only a scant amount of research exists with a focus on teachers as leaders. Furthermore, there is untapped potential in teachers serving as leaders, as teachers do not always know about leadership opportunities that surround them, nor do they consider themselves leaders (Hanuscin, 2014; Sinha et al., 2012). The purpose of this study is to gain knowledge and add to existing research which may better explain teacher leaders.

This proposed study is qualitative, comprised of descriptive statistics (surveys), field notes, and interviews. The end goal is to contribute to educational leadership by providing more information about how teachers currently serve and can serve as leaders within their districts, the importance and rationale for such an endeavor, and how 
administrators can tap into this potential, which would yield a more comprehensive approach to leadership in school districts.

\section{Results}

The results from the qualitative study were captured from the responses of principal surveys and both teacher and principal personal interviews. Principals who were interviewed had specifically selected a teacher leader in their districts, as indicated by the survey they completed. Areas of focus included: how teacher leaders are identified and described, how they are utilized by administration, how they are encouraged to take on leadership roles, how they evolve, and the impact they have on schools.

A total of twelve principals were surveyed, with ten qualifying for the study. Ten secondary principals and their selected teacher leaders (one leader per principal) from seven different districts were interviewed from the Central RPDC region in Missouri, which includes the following counties: Bates, Benton, Carroll, Cass, Henry, Hickory, Johnson, Lafayette, Morgan, Pettis, Ray, St. Clair, Saline, and Vernon. These schools and the towns in which they resided varied in size, but due to the geographical location of the Central RPDC region, the schools were rural communities. Both principals and teachers had different ranges of experience in education, from two years to twenty-eight years. Pseudonyms of participants are located in Appendix E, Tables 1 and 2.

According to the study, teacher leaders are identified and utilized in various ways. Often times, these individuals rise to the top on their own or would inevitably show themselves in various ways as "emergent leaders" (Northouse, 2016). They do not wait for a formal request or role from the principal, but offer their expertise to others they collaborate with (Akert \& Martin, 2012). Principal Warren shared: 
The way I identify them is basically how they model for other teachers, their willingness to help others, their constant drive to get better in the classroom, and the fact that they're always looking at ways to make their environment better and instruction better.

Other times, the principal would seek out leadership traits or potential in certain teachers and question or encourage them to take on leadership roles. These people are often viewed as activators or initiators. They have a desire to lead. They step up and take an active role. They are highly motivated, take on challenges, are problem solvers, and actively seek out opportunities to improve themselves and the school, all for the greater good (Cooper et al., 2015; Green \& Kent, 2016; Wenner \& Campbell, 2016).. They lead by example, and they serve students, teachers, and administrative personnel as an invaluable resource.

Another point gleaned from the research is teacher leaders are passionate about their work, they have a strong sense of pride, and they have a vested interest for the culture of their school and community. They are perceived as having integrity. Ms. Marigold, a teacher leader, stated, "Always have integrity. Make sure that you understand that it's not about collecting accolades; it's about staying true to what we started this profession for - why - we got into this to help kids." These teachers are conscientious, and this is often revealed through their high expectations and a constant desire for betterment and growth. They tend to be listeners and learners themselves.

Teacher leaders are involved in a plethora of different roles and contribute in many different capacities; they are multi-talented and multi-faceted individuals. They collaborate well with others, including those with whom they are directly involved, such 
as students, teachers, and principals, and these people often gravitate towards them. They act as a voice for both teachers and principals, often as a powerful liaison for either or both. They are instrumental in carrying out the articulated mission and in leading the school in a desired direction. Principal Finnegan articulated:

I'd say the practices of our school were developed by our teacher leaders through the years ... my philosophies are throughout this school, but the teacher leaders are the ones who are leading us in the direction that we need to be going. Roles fulfilled by teacher leaders include: mentor, instructional leader and strategist, professional development leader, liaison, and problem solver.

Teacher leaders were also found to be innovative, often unafraid to try new things and take risks; these endeavors often occur outside their comfort zone. Principal Munstermann spoke of his teacher leaders:

You know, I think that it's so hard to answer, but I think you see teachers who are very innovative, not afraid to try things, who question and ask others what works, what doesn't work, how can I get better? And I think people are naturally drawn to those inquisitive people. And I think that just kind of sets that whole thing in motion. And we see that, when something new comes down the pike, who do teachers gravitate towards? She's relatively young in the game, but they flock her direction right now. I think that it's almost courage to try something and to fail and then I think the reflection piece is huge on that, whether it's internal, or just bouncing things off. 
These undertakings are researched and well-planned; the aim is to revise and improve teaching strategies and to enhance learning. In both success and failure, reflection is a compulsory part of this process in order for these teachers to evolve and advance.

Both principals and teachers emphasized the importance of discovering who the teacher leaders are. Being present in classrooms and in meetings is important on the part of administration, especially when teachers are engaged in collaboration such as in focus groups or leadership team meetings. This way, the administrative team can see which teachers emerge as leaders among their peers. Another essential part of this identification process is getting to know each individual teacher so that principals can become better aware of personal strengths. This transpires through conversations with teachers. The understanding and appreciation for complex social structures was also cited as important. Teachers taking on leadership roles in an effective manner were often described as not afraid of disagreement, and they saw the value in different individuals providing diverse perspectives and in moving forward, even collaborating and learning from people who think differently than they do. Ms. Williams provided an example of a co-worker she sees as a teacher leader:

She is a good public relations person as far as let's try to see the other side of things, which I don't always do... She brings out the other balance of let's look at the other perspective and consider that. She's good about kind of bringing people together on the same page when we're not always like that. Engaging teacher leaders often happened in increments. Principals played a crucial role in this process, as they encouraged and provided opportunities for leadership by way of decision making, committee involvement, and time for collaboration among 
peers and with the principal. Principals often requested the teacher's input, in some cases on a regular basis. Enlisting teachers to help make important decisions that impact many, to seek out and present professional development, and to take on additional responsibilities were components of this process.

Teacher leaders played a supporting role, especially when the occasion was related to problem solving, brainstorming for ideas, or helping with the day to day profession of teaching. This process was welcomed by both principals and teachers. Teacher leaders were continually noted as being active listeners, inviting the confidence of both principals and teachers. As trusted mentors and companions, these teacher leaders would often hear multiple, diverse perspectives which could potentially become instrumental in handing issues or offering solutions. In this manner, teacher leaders were perceived as having a voice for others. These teachers were encouraged by this process, as they expressed satisfaction in taking ownership by supporting and promoting individual members' needs as an integral part of the collective team.

Distributed leadership was observed as an important component to utilizing teacher leaders for greatest impact. In order for principals to, in effect, share leadership with teachers, principals had to trust them and relinquish some control. Only then did they maximize their own leadership potential and truly benefit from the abundant resource that was just within reach. Teacher leaders were seen as trusted advisors to the principal. They were seen as instrumental in starting new initiatives as well as enforcing change, with an emphasis in assisting with teacher buy-in. Principal Hyde expressed how he relies on his teacher leader: 
Honestly just trying to get them to kind of get on board with some of the things that we are trying to do. Because if I don't have buy-in from a certain percent of the teachers, it really doesn't matter. What initiatives I want to happen aren't going to happen. So you really just got to make certain that you have some of those teachers that are willing to kind of maybe help try to do those things.

Several principals voiced that change with the assistance of their teacher leaders was much more likely to result in a positive experience, simply because these leaders were on the same level of and respected by their peers.

Another example of distributed leadership was principals relying on teacher leaders as a resource for instruction, given that these teachers were viewed as experts in their content field. These teachers were academic leaders, and they were provided opportunities to lead other teachers through data teams, research, professional development, leadership committees, strategic planning committees, and in other ways. Ms. Stephens explained,

When I think of academic leaders, I think of our two title teachers and they are so strong in their content. I mean, we just look to them like crazy for help and ideas. You know, because they can kind of see maybe how programs should be run from what's best for the student as opposed to, you know, administration has to see what works on paper, but you really look to those two ladies to see how does it really work for teachers and kids. . They're very conscientious, they have the utmost integrity. If they say they're going to do something, they do it. I mean, they're not ones that just give you the talk that you want to hear because a lot of us are good at the talk, but the really getting down and doing the work. 
These teachers guided, directed, and mediated their peers, as well as aided the principal in holding them accountable. They were also perceived as effective in encouraging, challenging, and pushing teachers beyond the status quo to higher standards.

This process of distributed leadership both empowered and enriched the team concept and dynamic. By sharing leadership roles and delegating responsibility, principals recognized and effectively realized the value in the collective. This increased sense of ownership greatly benefitted the school and the individual.

\section{Themes}

The purpose of the study was taken into serious consideration as well as the guiding research questions, and survey responses and transcriptions from personal interviews were considered and analyzed for emerging patterns and trends. One overarching, comprehensive theme emerged: "Let's Go." Stemming from this prominent theme, four sub-themes emerged: 1) "I'm Here for You," 2) "You Can Count on Me," 3) "Let's Go Together," and 4) "Let's Keep our School Moving Forward". These personal statements capture the collective essence of the responses. They were concurrent across the data and occurring in all participant responses.

Let's Go. The prominent theme of "Let's go" was echoed throughout the research, cutting across all responses, indicating a level of support as well as a strong sense of motivation and enthusiasm for teacher leadership in general and in having the initiative to get things done. Ms. Carroll spoke of this sense of motivation and energy of teacher leaders:

It's much like that teacher who comes out of school initially. They are motivated.

They lean towards leadership somehow by nature. It could be that that's their-it's 
just the way that they are or in some instances I feel like there's others like me who realize when you are put in that position you have to step up. They're flexible, they are responsive, they are perceptive. . They are still active. They're not passive; they don't sit back. They communicate with you but you can see that behind them is this energy that's visible in the hallways, in their classroom, in their interactions with their colleagues.

I'm Here For You. Along with being motivated to action, the theme "I'm Here For You" emerged. This theme was detected over and over again in the research, and it addresses the components of meaningful relationships, involvement, and devotion, which were often used interchangeably within participant responses. When asked how Principal Hyde identified teacher leaders in his building, he claimed:

A lot of it just comes from initiative. I think being a leader you just have to have a little bit of self-motivation to want to do what's best for whatever the situation is, what's best for kids, best for the program, best for the district, whatever it is. There has to be a little bit of initiation there or motivation on the teacher's part. And other times I try to see, you know, there may not be always people that are always putting themselves out in the front, but then through conversations they have a desire to maybe want to improve so then trying to find ways to see if they would be willing to take the next step and maybe put themselves out in front and take the initiative to make a difference.

You Can Count on Me. On several occasions, the sentiment "You can count on me" was captured by participant responses. This happened in the context of teachers 
relying on other teachers, teachers relying on principals, principals relying on teachers, and students relying on teachers. Principal Garrison explained:

Sometimes I'm not always the best at this myself because I have a vision, I want to share my vision, and I usually do but sometimes it's hard. A lot of times I will have to go to these people and ask them, "So this is the message I want to convey, and it's very clear to me that it's not being conveyed in that fashion, you know what I mean? Like, I'm seeing something and I know that's not how people see it. That's not the message that I'm trying to send. This is the message that I'm trying to send." And so a lot of times I will use them in that capacity. Not necessarily as that, but also in that sense of I need input to understand what I need to change to make this maybe more palatable, more... how do we need to craft a plan here that's actually going to be successful.

Let's Go Together. A theme of working together for a common purpose also emerged from participant responses. These teacher leaders are willing to work alongside others and solve problems. They understand relationships and social structures, as well as how to motivate others to work together to accomplish tasks and make decisions. Ms. Robbins voiced:

I've helped another teacher sponsor science Olympiad and they do competitions. I would just go out and help. Let me help you with that or help with this... I have planned school-wide - we had a solar eclipse day and so I kind of got that started in a plan and then encouraged people to help with that. We also have done crime scene investigation day. Just kind of take a little idea and bump it off a few people and if they agree it's a good idea say help me; we've planned that. 
Let's Keep Our School Moving Forward. Ensuring that progress is an ongoing consideration and mission surfaced as a prominent theme of "Let's keep our school moving forward". Teacher leaders were involved in multiple capacities with growth and change. Ideas in this category include having a growth mindset and seeking improvement and change. A willingness to try new things and be innovative, as well as pushing and challenging both self and others, are behaviors attributed to this theme. Ms. Weston explained:

Try new things is the big thing. Last year we got really into the technology and I went to a tech conference and they were like, "So do you want to try Chromebooks all the time in your room? What do you think?" And I was like, “Sure!" So a week later I had a whole set of Chromebooks for my kids. I've got eighteen Chromebooks in my room all the time and so it was like, well, let's just do it and see what happens. So the next week it was like Google Classroom, Google certified. It was like okay, let's just jump in and let's go! So it's been very nice to have that flexibility and that well, we'll just see how it goes. This year all of the middle school classrooms have our own sets of Chromebooks. All four of the middle school classrooms do and then we have two mobile carts for the high school to use. But all of our dual credit kids - so half of our juniors and seniors have Chromebooks with them that they take home with them and that kind of thing. We still have an actual computer lab, too, and then our business still has a lab, too. But it has been a world of difference now. And with the flexible seating, my textbook is online, now, Google Classroom. 


\section{Answering of the Research Questions}

The following questions were answered as a result of collecting and analyzing responses representing multiple perspectives from both teachers and principals in the Central RPDC region in the state of Missouri. These responses were captured in the form of principal surveys as well as principal and teacher interviews. Teachers interviewed were specifically selected as teacher leaders on the part of the principals.

\section{Research Question One}

Research question one of this study was "How are teacher leaders identified and utilized in school districts?" Teacher leaders are identified in various ways. Often times, these individuals rise to the top on their own or inevitably show themselves in many different scenarios, which Northouse (2016) termed “emergent leadership”. Principal Warren indicated,

The way I identify them is basically how they model for other teachers, their willingness to help others, their constant drive to get better in the classroom, and the fact that they're always looking at ways to make their environment better and instruction better. So that's how I identify them and usually it doesn't take a whole lot of prodding. They will rise to the top, and you'll find them pretty darn quick. So those are quick and easies for me to figure out who they are.

Principal Hall shared the following about his selected teacher leader:

Well, I know a couple like Ms. Carroll, for example, would be one, that, you know, she is an art teacher. She impressed us obviously to hire her. She was a very impressive person. But just in her desire to improve herself is what really drove me to her and so we started working together on the leadership team. 
Other times, the principal will see leadership traits or potential in certain teachers and will question or encourage them to take on leadership roles. Elizabeth indicated that this was the case with her leadership as a teacher:

I think for me the biggest thing has been being given some opportunities and being put in some positions where I'm a little uncomfortable. And so, like, I did not want to present to the faculty this fall, and so my principal says you're standing in front of a group of 80 people, most of which are older than you and have way more experience, but to put me out there in that position made me like, well, holy cow, I can do this, and so afterwards, encouraging people, whether it went great or whether it went poorly, and so I presented, and before I had even gotten back to my classroom, Mr. Munstermann had sent me an email that said, "Hey, great job presenting today. That's a tough thing to do. Keep it up. .." So I think giving people an opportunity to do something and then encouraging them to keep trying it or that it was good when they did it.

These people are the activators and initiators. They step up and take an active role. They are highly motivated, take on challenges, are problem solvers, and actively seek out opportunities to improve themselves and the school, all for the greater good. They lead by example, and they serve students, teachers, and administrative personnel as an invaluable resource. Principal Hyde mentioned such characteristics:

A variety of things, but honestly I think it just goes back to the initiative piece. I think the real teacher leaders are the ones that are just constantly almost to the point of bugging I think at times just because they see that there is a need here and they want to move forward and they want to make a change, you know. And it 
may not be a drastic change, it just may be a tweak, it may be a minor thing, but they just see a need and they would like to attack it. And they know how to get people on board to kind of make those changes.

Alexandria discussed her own motivation and responsibility as a teacher leader: I would say yes, with the getting things done. I'm kind of the one that will start the email, like here's what's coming up next month and what we need to get going, just the proactiveness of it because I don't want to wait until the last minute. And then we have to throw something together. I don't know. That's just how I am. Luckily, they all are okay with it. . .I am the department head for ELA for the school, so we are taking on some curriculum writing. So I've had to go to some summer trainings and then tomorrow during our early out is the day when ELA is meeting to kind of vertically reassess and make sure we're all on the same page of what grade level is doing what. So but again, I think it just takes just the motivation and the organization to put that together and that's just where I think I kind of thrive on that kind of stuff.

Teacher leaders are involved in a plethora of different roles and contribute in many different areas; they are multi-talented and multi-faceted individuals. They collaborate well with others, and those with whom they are directly involved, such as students, teachers, and principals, and these people gravitate towards them. Principal Quick contended, "Those are more just the teachers that other teachers want to follow. . .and they are teacher leaders by students ... .kid magnets. . .students are flocking to them and want to be around them and yet still learn ...” They act as a voice for both teachers and 
principals, often serving as a powerful liaison for both. As principal, Garrison spoke of this meaningful role of teacher leaders:

But you see a lot of things differently when you move into administration because you're just viewing all the systems at the same time. And so things look so different. And sometimes you want to impress that on people, but it's hard for you to impress that because you are different. And so, to have that person who is the teacher leader, that person can step in and basically, like I said, they can take the message and they can translate it. And when I say translate, I mean it's nothing different. It's nothing amazing, it's nothing new. It's just they trust that perspective of that person because they're respected as the leader.

They are receptive to input and feedback from the principal and other teachers, and they reciprocate this interaction by providing valuable input to both parties in return. They are instrumental in carrying out the articulated mission and in leading the school in a desired direction. Principal Finnegan articulated,

I'd say the practices of our school were developed by our teacher leaders through the years. I think it's sustainable leadership ... .my philosophies are throughout this school, but the teacher leaders are the ones who are leading us in the direction that we need to be going.

These are ways they show themselves or are identified by principals.

Teacher leaders are utilized in so many different ways and fulfill vital roles. One such role is that of mentor, both to students and teachers. These mentors go above and beyond, and they are on a personal mission to help others. They are instructional leaders and effective strategists. Principal Warren discussed: 
I think it starts with a mentoring process, like a teacher who demonstrates by action and by voice, and then other people think, hey, it's okay if I do that. We do have way different teaching experiences in the middle school and levels of ability; however, we are always willing to share - I don't want to say a spotlight - but share a lead in something.

Ms. Carpenter spoke of these teacher mentors:

We have a couple of teachers here in the middle school that they have their master's degrees in specialized math and so they're taking on leadership, going out to other classrooms and kind of being an instructional coach so we have a couple of those here in the middle school. . .Again I think it's just doing it. Going out and doing it and taking the leap of faith, a step ahead of everybody else just to show that it can be done. I think that's one of the things is just, you lead by example so, if you want to get it...if you want other people to do it you have to do it first so that they will follow.

Another important way these teachers are utilized is through professional development. They not only lead professional development, but they also seek out professional development, both for themselves and others as well as for the district. These pursuits are often self-driven. Principal Chrisley elaborated on the topic of professional development and teacher leaders:

Confident but willing to follow as much as they are to lead. They're a good team player. So they listen to other people's opinions... not a know-it-all because they have to be respected by others so it's got to be somebody with a good work ethic 
and someone who values professional development and learning and wants to grow as an educator so we need them to be a model to other teachers.

Ms. Weston provided information about her own involvement with leading professional development:

Well, my colleague next door. She's been here for two years, but she has been teaching for fifteen years. She is my co-chair for professional development, and the way that works is that we lead all of the professional development for the district. So we are the ones finding it, we are the ones teaching it, and we're the ones doing it. We're spending a lot of extra time together . . .for the betterment, I mean, yes ourselves, but the betterment of forty teachers that we have here. We're trying to figure out K-12, so we're even trying to figure out elementary, like what it is they want and what they need and all of that so that tends to be a little time consuming.

Principals also rely on these teacher leaders to relay important messages, to rally support and teacher buy-in for upcoming initiatives, and to help solve important problems.

Principal Garrison shared his experience with relying on teacher leaders for such matters: And so we try really hard to encourage people if they want to take on things, absolutely, but I really try hard not to just craft a committee, you know what I mean ... You know, and then, within that meeting, like I said, you carry that in who do you give the research to? You give that research to the teacher leaders. You know what I mean? I mean, if you want me to do the research that's fine, but I still need an advocate. So you go and you give it to them and so that way you don't overburden them but you still empower them . . . Right now we're basically 
moving into a competency-based grading system over the course of like the next seven years, so we started it in the elementary and it's just going to grow to us. And so a lot of what we're doing right now is basically preparing teachers to understand the shifts in how you approach education. It's in these moments where, I mean, I definitely am going to need to use more of them than I am even right now. I mean because we're talking about major shifts in thinking and for some teachers who use it as a personal affront to using what I'm doing is bad, I think that what we've been doing hasn't changed in a long time.

Several principals indicated a need for teachers to help with such messages being relayed to staff, explaining that the role of teacher leader makes this transition smoother.

\section{Research Question Two}

Research Question Two of this study was "How are teacher leaders perceived by teachers and principals?" Both teachers and principals perceive these teacher leaders as having initiative or an innate desire to lead. Ms. Carpenter expressed this desire:

You know, at one point we had done RTI (Response to Intervention) and I was on the team for that so figuring out what interventions would work best and how do we go about doing that and so I think part of it is that, just stepping forward and taking that initiative and then like I said, anytime there's something new just jumping in and doing it and then being able to lead others in the process.

Principal Hyde spoke of this initiative as well:

A lot of it just comes from initiative. I think being a leader you just have to have a little bit of self-motivation to want to do what's best for whatever the situation is, what's best for kids, best for the program, best for the district, whatever it is. 
There has to be a little bit of initiation there or motivation on the teacher's part... to take the next step and maybe put themselves out in front and take the initiative to make a difference.

These teacher leaders are passionate about their work; they have a strong sense of pride and a vested interest for the culture of the school and the community in which it resides. Mr. Hawthorne illuminated this idea:

And you just want your school to be the best. You want the experience for the kids to be the best. I don't know whether you'd call that dedication or whatever, but I think that's probably the primary. Every single one of us has something to offer. The English teacher here who was a former student of mine, you know, she came here and was like, we don't do speech. Why don't we do speech? When she was here she did speech, but the person that did speech retired and then nobody did speech, so now we don't do speech anymore. I didn't even really realize it...so why don't we do speech anymore? That teacher left. I guess. So nobody did it. So now she does it. She's got a young lady going to regional speech championships. That just happened. Somebody just came in and made it happen, changed some kid's life. So that's really what I feel is the clearest answer I can give is who's going to be dedicated to put in those hours.

These teacher leaders are perceived as having integrity. Ms. Marigold reflected upon her own profession:

Always have integrity. Make sure that you understand that it's not about collecting accolades; it's about staying true to what we started this profession for-why we got into this to help kids and it doesn't matter what award you can 
put under your belt or what titles you can add to it - it still goes back to the core of you wanted kids to have those aha moments like you did when you were a learner. And so I think remembering that, remembering that we are a team, and that even if you are lucky enough or are honored enough to be put into a position where you have a title, learning that it's just that and it only carries as much value as you put into it.

Teacher leaders are conscientious, and this is often seen through their high expectations and a constant desire for betterment and growth.

These teacher leaders are highly knowledgeable in their content. They are intelligent critical thinkers and teaching strategy specialists, and they are viewed as experts in their fields. They are often described as "informal instructional coaches," and they collaborate with others. They are often sought out for practical advice. Principal Chrisley declared:

I have a couple of other teachers who have gone and gotten their specialist degree in math instruction which is kind of a new thing that's just started in the last couple of years, so they're among the first ones at UCM to earn that degree. So they've been ones, then again, with tons of encouragement, and they support one another. I think that's been kind of a neat part of that is that they work really closely together and they push each other to be better and better all the time. So they're the ones that are always willing when I go to them and say I want you to present what I saw you doing at the faculty meeting. They're always willing to jump in and help other teachers. We worked it out this year that each one of them can have an extra hour-it's different hours, different quarters, but they each have 
an extra hour when they can go down to the elementary and kind of do some instructional coaching - informally. Nothing super formal, but that's been really well received, so they just kind of hung their hat on a passion and we just keep encouraging it and they keep growing and growing.

These teacher leaders have meaningful interactions with others. They are described as caring and compassionate. They not only help others, but they are known for their level of effort and engagement. Principal Hyde voiced:

But again it's kind of that desire inside to want to see a change and see something positive for our kids. Some of my other teacher leaders, like Cara . . but her desire to always want to do what's best and try to evaluate what's going on is probably stronger so than my other staff members. You've got to have a sense of compassion and caring because if you didn't care, then obviously you're not wanting to see things get better; you're okay with the status quo. Then again, just going back to a little bit of initiative and being able to grab the reins and go with it.

Teacher leaders follow through with their words, and they work alongside both teachers and principals to see that things come to fruition. Ms. Robbins indicated:

There's a little area of expertise. And they're comfortable doing it and they're willing to help. So they're helpers, they're leaders, they've got expertise in that area, and some are just the people that never say no. They will help you no matter what. I don't know what you're doing, I don't understand a word of it, but I will help you. 
They are listeners and learners themselves. They are results-driven and detail-oriented. They are problem solvers and mediators. Williams shared about a co-worker:

She is a good public relations person as far as let's try to see the other side of things, which I don't always do. Sometimes it's my way is the only way I think, so she brings the other balance of that of let's look at the other perspective and consider that. She's good about kind of bringing people together on the same page when we're not always like that.

Another perception of teacher leaders is they are innovative. They are unafraid to try new things and take risks, often stepping outside their comfort zone. These new undertakings are researched and well-planned - the aim is to revise and improve teaching strategies and to enhance learning. In both success and failure, reflection is seen as a compulsory part of this process in order for these teacher leaders to evolve and advance. Principal Munstermann spoke of his teacher leaders:

You know, I think that it's so hard to answer, but I think you see teachers who are very innovative, not afraid to try things, who question and ask others what works, what doesn't work, how can I get better? And I think people are naturally drawn to those inquisitive people. And I think that just kind of sets that whole thing in motion. And we see that, when something new comes down the pike, who do teachers gravitate towards? She's relatively young in the game, but they flock her direction right now. I think that it's almost courage to try something and to fail and then I think the reflection piece is huge on that, whether it's internal, or just bouncing things off. 


\section{Research Question Three}

Research Question Three of this study was "What types/characteristics of leadership are exhibited by teacher leaders?" Specific types of leadership that emerged from the data were servant leaders and transformative leaders (Northouse, 2016). Principal Warren shared of servant leadership:

Someone who's willing to put themselves out in front, someone who understands what it means to be a servant leader, and I think that's most important. And here in (name of school) we're blessed with a lot of people who come back and are alumni from here, (selected teacher leader) being one of them. Just the fact that they have pride in the school, especially the school district, and they know what the school did for them and so they want to come back and give in return. And so that to me, definition of servant leader. I love it. They want to serve our community and serve our kids and that's awesome.

Principal Finnegan also noted:

You know that they are - when I am leaving here at 4:30 and we dismiss at 2:30, their car is still around back because they are doing that much more. They are the ones who, when asked to serve, serve, and other times they volunteer to serve. And those teacher leaders aren't power hungry; they are just wanting to make the place better.

Principal Munstermann spoke of transformative leadership in response to characteristics of teacher leaders:

Gosh, almost transformative. And by that I think just bringing other people along with them, maybe even unintentionally. If I look at Ms. Sparlding, she has people 
follow her that she probably doesn't even realize. And I think that's okay. But I think that, I know that there's some that sit back and watch what she does and things that she says. She makes us better every time she presents something or questions something. Right now they're in data teams and she has really kind of taken a lead role with her data team. I think, you know, specifically in terms of her, and I think that's probably broad and global, she makes others better just through the natural conversations they have. Nothing fake about it - just genuine concern for how do we make this a better place for our kids. I don't know if I can quantify that. I'm not aware of any words per se, but when I think transformative, that's what I think of.

Major leadership traits that surfaced, as outlined by Northouse (2016) were: sociability, integrity, and confidence. Principal Chrisley reported:

And we do have some really strong people in the middle school that are willing to jump in, be on the committees, be on the PD committee, help out with the superintendent's advisory council, they do like to jump in there and they do it with a positive voice. What I have heard is when they are in those committees, they're not there to complain, they're not there to say this is really messed up and I'm here to make a change; they come into it with a positive attitude. And I think that's huge. They have a growth mindset, I guess, and they know we are doing great but we can do better, and I think that attitude is a little bit contagious throughout the district. They learn a lot from each other being this close together. 
Based on interview responses of both teachers and principals, other characteristics of leadership exhibited by teacher leaders that arose were: influential, inspiring, guiding, positive, determined, and confident.

\section{Research Question Four}

Research Question Four of this study was "How can schools more effectively identify and engage teacher leaders?” As indicated by both teachers and principals, discovering who the teacher leaders are is paramount, and this happens by being present. Spending time in classrooms and in meetings is helpful, especially when teachers are engaged in collaboration such as in focus groups or leadership team meetings. This way the principal can see who emerges as a leader. Ms. Stephens reflected on the importance of this presence:

Well, I think it has to do maybe with just seeing how teachers operate in their classrooms and being present - if administrators are present when teams are meeting to see who can kind of keep the group at bay and keep them going. I think that their presence in those areas would kind of help other teachers come out as leaders.

Another important part of this identification process is in getting to know each individual teacher so that principals can become better aware of his/her strengths. This happens through personal conversations with teachers. Ms. Stephens elaborated:

Just being aware and taking an interest in who you have employed and what their strengths are and playing on them. Because like I said, you know, with my R2 Title teachers, they would never want to be pushed out there in the limelight and our administration knows that which is good, but they still go to them privately 
for advice or for help and then the principal knows that I'm not afraid to - here's what we need to do. So he knows that he can ask me and he can rely on me and I can do things that I'm stronger at and I think just playing on those strengths and getting people more confident, like those teachers that they see as leaders, just building their confidence. . .

Principal Quick also discussed the importance of identifying teacher leaders and of having these conversations:

Well, I think you've got to know who they are, for good or bad. I mean, you have to know who they are. If you don't know who your teacher leaders are or you think you have none, you know. . . I think you'd be just absolutely wrong to say I don't have any teacher leaders. Maybe you don't have any positive ones, I guess, you could be put in a position where there are some negative teacher leaders, but then you still need to know who those are, too. You know, and I would always think that everything's relative so even in the worst of schools is going to have some teachers that are the highest level comparatively to everybody else, and you've got to find them and start with them. You've got to use them somehow. You've got to find out what their strengths are; you've got to use them.

Principals often look for teachers who: show initiative, share and collaborate well with others, and are willing to present professional development before their peers. Principal Shackles verbalized this sentiment in relation to the teacher leader he chose:

Willingness to get in front of their peers... . I mean, there's plenty that would like to say yes, I'm a leader. Plenty that you think would be a leader, but it's fewer when you go hey, would you put a 15-minute presentation together or a 1-hour 
presentation at our next PD day on a certain instructional strategy or whatever. The ones who are willing to do that, well, you've found a leader. If they're not willing to do it then you go, well, you're all right. But you're not going to be the leader of the pack. The young lady that you interviewed before me, Ms. Marigold, she had not been here more than 60 days - it might have been less than that when I talked to her, but I asked her to put on at our first PD day of the fall ... I asked her to put on a half hour to one hour demo of the Socratic seminar method running a discussion and debate. I was going to do it with her, but then my wife fell down so I couldn't do it with her, but she went ahead and did it on her own. Which, you know, that's kinda cool.

These teacher leaders understand social relationships and social structures. They are not afraid of disagreement and they see the value in providing diverse perspectives and in moving forward and even collaborating and learning from people who think differently than they do.

Ms. Carroll described her experiences:

I am most often acknowledged by the few people that I've talked to personally and on some of the stuff that we do on the leadership teams when we do evaluations is that I hear people out and I'm not quick to make a statement about a particular movement we're trying or change we are trying to implement. I'm not quick to shoot it down or say let's go for it. I perceive multiple sides and I'm one of those people who sits back first to hear it all before making any decisions. Principal Garrison conveyed: 
I'll just kind of give you an anecdote. The other day I was having a discussion with another staff member about relationships within the building and I was just like, I go, "I think we all know that Ms. Williams is the ultimate team player. And she's from here, she played basketball here, she's our basketball coach now, but it's so much more than just an athletic mindset. . She's the team player because in meetings, she's the one who's going to stand up and say, 'We need to hear that person's opinion because all of our opinions matter because when you're truly the ultimate team player, everybody's voice on the team should be heard,"' you know, and when you're the ultimate team player, you stand up for other people's opinions because you want your own opinions to be stood up for as well and there should be value in the collective. And so she truly embodies that ... Several principals indicated that often times teacher leaders emerge organically, as a natural progression. Finding willing participants is quite important in the process. These individuals are driven by high expectations and have their focus on success. Principal Garrison emphasized, "And the teachers who evolve, they see that. They take the time to reflect. . her goals are more about expectations so it's not about failure." As far as engaging these teachers, principals indicated that it often happens in increments. Principal Hall communicated:

I've got another teacher who's been here eleven years and slowly but surely, she started becoming a team leader. She didn't feel comfortable being in charge of anything but I put her on some committees because I knew that she wanted to be involved. And then I talked her into getting her specialist degree in reading, and so once she got her specialist degree she feels more confident in leading now that 
she has something to say, and so now she's in charge of her leadership committee. So she wouldn't have done that eleven years ago; she wouldn't have felt strong enough to do that. I could tell that she just needed some time to develop. It really kind of depends on the teacher.

Principals engage these teacher leaders by encouraging and providing opportunities for leadership through decision-making, committee involvement, and collaboration.

Ms. Silvers claimed:

Well, I think you have to give them the opportunity. You have to -you just have to jump in. And making the teachers responsible through committees, I've seen that, that's been a huge improvement, at least as far as our PLC and our PBIS committees here. Our administrators are part of it, but they don't run it. They're a part of the team; everybody does it together. And so I think creating those opportunities, understanding and seeing the importance of teacher time to work together, to do things together, because the benefits are huge. And you don't see it right away; but you see it over time. I think they're on a three or four year process here, but they've seen a huge change in student behavior, in the way the teachers communicate with one another and you know, they just have to jump in and do it.

Principals often enlist the teachers to make important decisions that impact many. Teacher leaders present professional development to the building and even school wide. These teachers are often included to help share the vision of the school and the principal. Principal Garrison explained,

Yeah, so, sometimes I'm not always the best at this myself because I have a vision, I want to share my vision, and I usually do, but sometimes it's hard. A lot 
of times I will have to go to these people and ask them, "So this is the message I want to convey, and it's very clear to me that it's not being conveyed in that fashion, you know what I mean? Like, I'm seeing something and I know that's not how people see it. That's not the message that I'm trying to send. This is the message that I'm trying to send." And so a lot of times I will use them in that capacity. Not necessarily as that, but also in that sense of I need input to understand what I need to change to make this maybe more palatable, more... how do we need to craft a plan here that's actually going to be successful? Principal Hall claimed, “. . . You need to find people you trust and you feel like they can support your vision."

Principals also delegate responsibilities to these teachers. Ms. Stephens shared:

Todd definitely looks to me to schedule for us, I mean anything from just our basic daily schedule to our MAP testing to our benchmark testing to putting groups together for things, so I really feel like he definitely looks to me just to kind of take care of us down here.

Ms. Carroll mentioned:

Mostly the only ways in which I have influence is in that leadership committee with others and it's ultimately making decisions together. . .I am currently the facilitator of the group, so there is a responsibility there that has been offered to me in that position, an accountability piece, that I think is used to keep others accountable ... I'm keeping my colleagues accountable in there. .. so when we are initiating change, for example, a focus on literacy across the building, I can share what it may look like within this classroom and other performance-based 
classes where individuals who don't necessarily have that built into the curriculum as quickly as others may or as easily as others may. So it would be ultimately just be being a voice for those who don't have a voice on a normal dayto-day basis when we meet with him.

Ms. Spalding claimed:

... this year is my first year on the PLC committee, which that kind of helps plan all of our PD and ...monitors our school's progress. I did my first faculty presentation at the beginning of this school year, and so starting to be more of a vocal person is challenging, but it's exciting to think about continuing on. . .And if you need help or have questions...I feel very supported by Mr. Munstermann and our other administrators, and so I think they want people to step up and do better.

Mr. Hawthorne also mentioned:

I think that's an area where the administration has utilized me and other people in the building — getting teachers into a situation where we're learning from each other. I would say, I don't know if the administration agrees, one of my strengths is like classroom management. I have students that I have never had a problem with that other teachers do. And maybe vise versa. You know, I've had a positive experience more than negative. And so the administration has done a good job of saying, "Look, you have a student - you've never written this student up, sent them away, they're passing. They're totally, they're not making it in this other class. Can you talk to that teacher? Can they come into your room a little bit? Can they see and find out what you're doing? Share some strategies to get success 
across the board with the student?' I think that is a way that is a lot of times just organic and not exactly part of a program or a plan, but one way that they've utilized me and other leaders in the building to try to do positive...It is something they've made a priority and they've found different ways to make that happen, and I think that that's positive impact for the school. I've gotten things out of it and I think other teachers have. That's one thing that comes to mind that I think administrators have positively used different leaders including me.

Principal Hall answered, "If I think a teacher is not stepping up to a leadership role and I feel they need to, I will go and talk to them personally. I'll assign them some type of leadership role."

Another significant way the principals rely on the teacher leaders is to help implement initiatives or change. They are instrumental in rallying support and teacher buy-in during such times, making the transition smoother and more effective. Principal Munstermann indicated:

I think if you talk to central office, the high school, I think with most districts it's the face of the district. We have started a lot of the initiatives that the district has taken on. The PLC - this was the first building to go the PLC route and we were that way several years before that became a district philosophy. And so I think that those teacher leaders have been the ones to implement the change process here that has gone district wide. Not just PLC, but the whole data team piece and everything else is that all originated with us here.

Principal Finnegan relayed-- 
... both are well-respected by their peers. You know, as a principal, if I'm trying to implement something, I'm going to talk to the two of them before I even try to do anything because I know that their influence will be helpful as far as things go. Principal Hyde felt similarly:

...It's not something that I can just come in and say this is something we're going to do. So trying to utilize those teacher leaders that I know maybe have the same philosophy and then trying to work them in a way to start making those changes happen. Because if I don't have buy-in from a certain percent of the teachers, it really doesn't matter. What initiatives I want to happen aren't going to happen. So you really just got to make certain that you have some of those teachers that are willing to kind of maybe help try to do those things ... It's really not going to change unless I have a teacher leader that's willing to tackle it. . . if you don't just have a person that's willing to take initiative and drive, it doesn't really matter how much I really want that program to improve - it doesn't really matter. The ideas that we throw out there; if they're not willing to really just grab the bull by the horns and tackle the problem, they're never really going to see it. So just trying to figure out what teachers' strengths are and how I can utilize them to create things to happen in whatever capacity it is.

\section{Research Question Five}

Research Question Five of this study was "How is teacher leadership encouraged by teachers and principals?" Teachers encourage leadership by example, primarily by modeling their own leadership behaviors for other teachers.

Ms. Stephens expressed: 
Everybody just kind of has their own niche ... and mine is the voice of reason. I don't really know why, but we've got a lot of personalities in our group and some are more likely to have big opinions really quickly, and, you know what I mean? And there are some negatives and some that are really just hyper and it's just like somebody has to be that voice, okay, but here's what we need to do. Here's what our goal is. I don't know. I've just always been like that. I don't have a lot of patience in a meeting when we're not talking about what we're supposed to be talking about because we've all got stuff to do and so I just kind of lead things in that way.

Principal Chrisley described how both she and her teacher leader encouraged leadership development in a different teacher who was not very involved but had leadership potential:

Last year we went to a middle school conference and I had asked people and said, "Hey, who wants to go with me? I'd love to take several teachers," and he hadn't said anything but I went to him and said, "You know what? I'd like for you to be a part of this," and when he came and had the opportunity to visit with these other teachers that he didn't normally talk with, just people we had taken from our school, he got really excited. He actually fed off of Ms. Carpenter, and . . .they, they had gone to a brain-breaks workshop and got really excited about it. I got him then to present to the faculty meeting, so I needed other people - I needed him to buy in to middle school concept and then I needed other people to see him buying in. So anyway, and he's just a very, very respectful young man and just with the work ethic, I mean I guess that's just the key thing you look for is really 
somebody that's going to get things done and take it seriously whatever they do, but still be willing to have a little fun.

On leadership teams, teacher leaders encourage other teachers to step up, take initiative, and self-advocate. Teacher leaders play a supporting role, especially when it comes to problem solving, brainstorming for ideas, or helping with the day-to-day profession of teaching. This process is welcomed by both principals and teachers, and it helps to create an environment that is rich in support and resources. Teacher leaders are often active listeners, inviting the confidence of both principals and teachers. They hear multiple, often diverse perspectives which may later become helpful components used to gather ideas, handle issues, or offer solutions. In this way, teacher leaders are seen as a voice for others. This process is encouraging to teacher leaders, as they are inspired to take ownership by supporting and promoting individual members' needs as a part of the team.

An important aspect of encouraging teacher leadership, as noted by several principals, is to first build relationships with faculty members by getting to know them through personal conversations. The teachers will feel as though what they have to say as well as what they do matters. Principal Quick discussed:

You've got to, if nothing else, ask their input. And I think you can ask everybody's input, but specifically and maybe more often, you ask those (teacher leaders) more intentionally.... And to add to that characteristic, often those teachers do that. They are intentional. They don't come - they don't fly by the seat of their pants very often ...they've got a plan . . .you've got to find those teacher leaders - you've got to ask the advice. You should. . .base your decisions 
on what they would say more often than not and use them. Just put them to work. I think continue to praise them for what they do because they need to know that not everybody is doing that.

Principal Hall commented:

...you just get to know teachers. You are looking for anybody that's really going to be a good teacher in the classroom is where we start having those conversations. Find people who have a niche for something like RTI, or organization, or after school programs and then try to connect their passion to that need, so ...that's how we kind of do it here.

Through relationships that are built and opportunities for leadership, principals better know who their most effective teacher leaders are, and they will then be able to encourage them in more direct, personal ways, maximizing their strengths, deliberately working compatibly with their passions and interests, while building confidence along the way. This focus on communication helps to create a positive school culture, which is encouraging to teachers. Principal Quick shared, "Hey, I have this thing I want to do, this project, whatever, who am I going to ask? Well, I'm going to ask my teacher leaders. . .I think it's a culture thing - and a relationship between the principal and the teacher."

Both principals and teachers emphasized the importance of providing opportunities for these teacher leaders to exercise leadership roles as well as to grow as leaders. Teachers underscored that awareness of these opportunities is key, as well as clearly articulating the purpose and intentions of the teacher leaders acting in leadership roles to help diminish effects of the stigma of teachers in leadership roles. Ms. Stephens, when mentioning other teacher leaders, mentioned the issue: "I don't think either one of 
them would be comfortable saying they're a leader. They don't want to be a leader, because that takes on a whole new monster in itself." Ms. Carroll also helped to clarify this point:

I think there's a stigma towards leadership teams and thinking if I'm on this committee I am making decisions for people and so others see that as a negative thing. So finding a way to communicate to all staff that if you're in that situation you may find out it's not exactly that would be a major benefit so it's communicating the intentions of a leadership team or any leadership positions so it comes down to not assuming that they understand the process to get through that and again the intentions... Knowing how to let the staff know how to take the path to get to a position of leadership would be definitely helpful.

As teachers try out new leadership endeavors, flexibility and openness on the part of the principal was cited as critical for improvement and growth. Room for making mistakes was a necessary ingredient for these teachers' success. Principals who show vulnerability and admit their own mistakes was also encouraging to the teachers, showing them that this is not only acceptable, but a necessary part of growth. Ms. Carpenter shared:

Just doing it, just go ahead and take the leap and know that you may make mistakes, you know, in leading others or even in doing whatever it is that you're going to lead at and just not worry about necessarily that you might make mistakes but that's a part of learning. So I think just telling them that they should go ahead and do it. 
Ms. Weston revealed, "I think the important thing is giving teachers some flexibility and some room. . I think it really helps to let the teachers have their flexibility and space to make mistakes and correct mistakes and try again." Trust was also an essential component in this process; the teacher trusted that the principal would provide support and back up while in the role as leader, and the principal trusted that the teacher would be a conscientious leader.

Several principals indicated a tendency to go to the same teacher leaders time and time again, but this was often viewed as a personal shortcoming on their own part, in that these teachers may become burned out because it is likely that they apply additional pressure to themselves given their strong work ethic and level of involvement and because so many people are potentially using them as resources. Because of these occurrences, the importance of rotating teacher leadership and giving many individuals the chance at leadership opportunities was verbalized. This decision of involving many helps to boost morale and cultivates a climate of leadership and professionalism. Principal Finnegan discussed this:

You try not to get your favorites. And every building will tell you that's one of his favorites. Well, why is it one of my favorites? Cause she stays late... there may be reasons that administrators have favorites, but I honestly have to say you can't go to the well too many times because you spread yourself too thin, so you've got to try to have those conversations with people in the hallways, about hey, have you ever thought about helping out with this? Helping out with that? Let me tell you pretty much everything I do I try to do by committee. We switched from BIST to PBIS this year. We're trying to marry the two 
together...so forming that committee to help lead us into that next phase of things. Grading practice. Have the teachers help develop it because I can tell you what to do, but I think until they have ownership in that... I don't want to say leadership by committee, but have those teacher leaders on committees to help guide the building in the right direction.

Ms. Spalding also elucidated:

We almost have a hierarchy of administrators, leaders of the teacher leaders, teacher leaders, and then like everybody else, which is not a whole lot of people . . And it's like the leader of each team that we have, so we have like a data team and a PLC team and so on ... and then all of our individual groups meet. . .So it's almost like a big pyramid. There's an overall idea. The administrators are kind of like facilitating some of it, but it's a lot ... I feel like our teachers are mostly deciding the direction that we're wanting to go. And I'm sure that like our administrators have an idea, but like they're consulting with... I feel like it's very teacher-friendly ... so. I think that's cool and I'm sure it's not like that at every district, so it's a cool district to be a part of.

Another important part to growing teachers as leaders is to never lose sight of the personal aspect of the individual who is the leader. This will support the process of teacher growth by empowering the teacher as an individual and celebrating the personal strengths and aspects of each teacher. Principal Munstermann illuminated, "I think it's just encouraging them to express their freedoms and creativity. We don't want to put the ratchet on anybody. We want to allow them to grow." Principal Warren shared, "Identify 
them, celebrate them, let them take risks, let them be who they are meant to be - not only inside the classroom but outside the classroom."

\section{Research Question Six}

Research Question Six of this study was "How are elements of distributed leadership exhibited by principals and teachers?" In order for distributed leadership to occur, that is, principals sharing leadership with other individuals, principals feel that they must relinquish some control and get help from the abundant resource of leadership that is all around them every day: teachers. When this occurs, teacher leaders are seen as trusted advisors to the principal, and there are many situations in which leadership is shared. Principal Chrisley echoed this sentiment:

I think the teacher leaders are even maybe more important than the leadership of the principal, and that being, I really learned that because my unique experience was being here as a teacher, and I was that teacher leader, and I was the one that if I would say here's a great strategy; you should try this in your classroom and everybody would latch onto it and oh, Karla thought that was a good idea; let's try it. It was really good. We had some good stuff going on, and then when I moved to the principal's office I tried to do the same things but it didn't go over as good enough. Am I going to get a bad score? And they just were always wondering what I was up to... and I was like, no, I just want to help, I just like instruction and I want to keep helping you. So that's when I realized right away, okay, I have to get these people like I was. I pulled out of that mix, and we were left with not a lot of teacher leadership. I've got to start planting those seeds and get the people under me so I can give to them, hey, this is my idea, this is what I'm thinking, and 
let them take ownership and run with it. It's just better received from the teachers. And it was just interesting, because I am the same exact person I was three months ago...but it says "principal" over my door, so that changed things. And now, they've developed more trust and I'm kind of back, it's come full circle, but I mean it's because of those teacher leaders; that's huge. . . Trust your teachers. I think that's one problem with a lot of administrators is they want to be in charge, which obviously, that's why you get the degree. You want to be the leader, but at the same time, you don't have to do everything ., ,

Principal Warren attested to this point:

Don't be afraid to let go. I don't mind letting go. We have enough on our plate as it is. I have enough. I don't need to do everything, so let some of it go and let them do it and run with it. They will always surprise us in a positive way and they have the gift to be in school...that's why we hired them.

One way leadership is shared is through problem solving and decision making. Principals often rely on teacher leaders to help them solve important problems that affect many people. By considering this trusted teacher's opinion, the principal is able to better understand different viewpoints among the faculty and make more well-informed decisions that more people will embrace and be able to implement. Ms. Wheatley shared some of her experiences with problem solving:

I've even taken some big steps into learning more about data collection and then integration into what we're doing ... so far we've kind of narrowed it down to our reading and math. We've got to figure out what our foundational issues are within those two areas. So I'm starting on the high school end, trying to figure out 
why the certain kids that we have keep landing in our DI all the time and we're trying to figure out if this is a can we do this and just not want to, or do we really not understand what we're learning, so that's kind of where we're starting.

Principal Garrison also relayed information about getting help with problem solving: You have to demonstrate that you are willing to allow your ideas to be changed just like you're probably going to change their ideas, you know? And it's in that sense that, I mean, I've worked with people who are like that, I mean, I've worked with people who basically are like, I'm not the $10^{\text {th }}$ smartest person in this room, but my job is to let the $11^{\text {th }}$ or $12^{\text {th }}$ smarter person in this room succeed and they made no qualms about that. And I respected that, you know what I mean? It's like these are the things I know, and these are the things I'm good at, and these are the things I don't know and I'm not very good at, and I'm going to lean on you, you know.

Related to decisions implemented, principals rely on teachers to help them begin new initiatives for improvement or to help enforce change. These teacher leaders are seen as instrumental at bringing improvement or change, especially in helping with teacher buy-in. Principal Quick emphasized:

And I think the biggest need for them would be change. Even if you're on the right track, you've got to be moving, and so you know, as good as we think we are, we've got to be looking for ways to improve. Which means change, plain and simple, that just means we're going to have to change something. Don't know what, and we're not going to change just to change, but there will have to be some kind of change and that's tough for a lot of people, teacher leaders included, but if 
I can get teacher leaders on board, or if I can even get their input on how to change, you know, whatever we're trying to change, I think that's the biggest necessity for those teacher leaders.

Principals who share leadership often rely on teacher leaders as a resource for instruction, given that these teachers are viewed as experts in their content field. In this way, these teachers are academic leaders. These teacher leaders are provided opportunities to lead other teachers through data teams, research, professional development, leadership committees, strategic planning committees, and in other ways. These teachers often guide, direct, and mediate their peers, as well as aid the principal in holding them accountable. They are also effective in encouraging, challenging, and pushing teachers beyond the status quo and to higher standards. Principal Munstermann spoke of his selected teacher leader in this role:

When we paired her it naturally happened with common classes. We had a teacher that we were working quite hard with to improve some things and once they got paired up in a common curriculum, that other teacher, I mean, it was like a light switch went on. I mean, it was night and day the difference in the performance of that teacher in front of the classroom. I can't tell you what was said behind those closed doors or anything, I have no idea, but I know that individual relies on her, yet she has cut them loose a little bit but is always there. As a matter of fact, they're in a team right now together. But I think that is my Ms. Spalding story, if you will. Just because of the growth in one year's time that we saw in that other teacher. Because that's someone - we were seriously considering hey, this is not 
working and then now, they're a fantastic teacher, I mean holy smokes, I do attribute that to Ms. Spalding and her leadership.

This process of distributed leadership enriches and empowers the team concept and dynamic. By sharing leadership roles and delegating responsibility, principals recognize the value in the collective, and in the words of Ms. Carroll, "with multiple brains more things can be considered to achieve greatness." This increased sense of ownership benefits both the school and the individual. Principal Garrison added, "Not only are you empowering teacher leaders, but you are empowering that concept of the team where everyone is valued and we're real with one another".

\section{Implications for Practice}

Given the influx of research about distributed leadership in public schools and the willingness of teacher leaders to help burden the responsibility, principals should be encouraged and inspired by these possibilities. This practice of shared leadership is not to diminish or undermine a principal's leadership, but to bolster and empower it. In today's shifting educational landscape inundated with immense amounts of responsibility, teachers are stepping up and sharing the responsibility, whereby alleviating the mounting pressure that principals are experiencing.

Teacher leaders in many schools are currently taking a step forward to fulfill yet another calling and assume more leadership roles. These roles include but are not limited to: mentor, instructional leader and strategist, professional development leader, liaison, problem solver, and change agent. These teachers thrive on leadership experience both within and beyond the classroom. Meaningful leadership opportunities increase teachers' levels of satisfaction and sense of ownership, and they feel more empowered in their 
profession of education. This experience, in turn, is motivating to others that come into contact with that teacher, such as other faculty members, students, and even principals. In order for principals to better identify and utilize teacher leaders in their respective buildings, it is recommended that principals should:

- Be diligent about identifying teacher leaders in each building, realizing that sometimes these leaders will rise to the top and stand out, while at other times they may need to be discovered and encouraged. This process could be prioritized as an important component of a principal's annual goals.

- Formulate a list of teachers who have shown themselves as good leaders and be intentional about actively increasing that number. Realize the value in other leaders, even if opinions differ from the principal, and their potential.

- Engage in personal conversations with teachers to get to know them as individuals in order to better understand their strengths, interests, and passions. This knowledge can be used to position teachers in leadership roles as well as to help foster each individual teacher's leadership style.

- Tie teacher leadership to the climate and the culture of the building for a greater sense of empowerment, ownership, and cohesiveness within the district.

- Observe faculty during collaboration times and meetings to identify which teachers effectively lead the group, generate ideas, mediate others, and solve problems. 
- Offer meaningful leadership opportunities to all staff, being intentional and clear about expectations and level of commitment. These opportunities can take many forms, including teacher mentoring, professional development (seeking out and implementing), leading focus teams, advisory council member to administrative personnel, instructional facilitator, liaison, data coach, and curriculum specialist, just to name a few. Types and roles of leadership are as unique as each individual district. Offering leadership opportunities incrementally with each teacher may work best.

- Highlight the importance of as well as the need for shared leadership and becoming a teacher leader in professional development. Follow through with decisions for shared leadership, and reflect and revise as needed.

Given the impact and benefits of teacher leadership, perhaps a greater emphasis should be placed on shared leadership in both principal and teacher preparation programs. Increasing awareness of distributed leadership as well as providing practical examples and success stories for how this process could be implemented would be beneficial for principals in their leadership roles as well as the teachers training and working with them.

\section{Summary}

Teachers have an innate desire to lead, as is characteristic of their profession. Some have a desire to expand their sphere of influence. Some will step up, but others may need to be discovered and encouraged. A greater emphasis should be placed on identifying and encouraging potential teacher leaders to keep them engaged and challenged so that more will stay in the profession and others may experience their 
positive impact. Teachers need to be made aware of leadership opportunities that exist, and leadership training needs to happen for these possibilities to become a reality.

\section{Future Studies}

The transferability of the findings from this study could be enhanced by collecting data from a greater number of samples. Additional schools from more geographically diverse locations may render different results. Furthermore, the researcher surveyed school principals who currently utilize and support teacher leaders in different ways and degrees. More could be learned by also including schools where teacher leadership is not supported or utilized. Further studies could provide a more complex understanding of teacher leadership, including how teacher leaders are perceived, identified, supported, and utilized. 


\section{SECTION TWO}

\section{PRACTITIONER SETTING FOR THE STUDY}




\section{Introduction}

Historically, public schools have advanced a great deal over the years since the first one opened in New England in 1635. Significant changes have been made regarding their structure, organization, curriculum, design, and function. Leadership in public schools is varied in terms of approach and style. As schools increase in complexity and administrators tackle dilemmas that constantly seem to multiply by number and degree, the responsibility of leadership becomes ever more daunting. Involving teachers to help realize the responsibility of educational leadership is an ultimate opportunity to enhance the experience of education for many involved.

\section{History of the Organization}

Historically, in 1635, the first Latin Grammar school, The Boston Latin School, was established. These schools were solely for sons of certain social rank who intended to acquire leadership positions in the church, state, or court system. The only schooling women received was the education they got from home, unless they were wealthy enough to have a private tutor (American public, 2013; Sass, 2018). In the same year, the first free school in Virginia opened. In 1690, the first New England Primer was printed and almost two centuries later, the first public high school, the Boston English High School, opened. Six years later, Massachusetts produced a law requiring towns of 500 or more families to open a public high school to all students (Sass, 2018). Throughout the $18^{\text {th }}$ Century, by the time of the American Revolution, colonies such as Georgia were partially funding schools (American public, 2013).

The $19^{\text {th }}$ Century brought about increased change. In 1837, Horace Mann became the Secretary of the Massachusetts State Board of Education. Mann, an advocate of free 
public schools, increased funding and quality teacher training. Curriculum became standardized in public schools during this time (Sass, 2018). He also introduced separating students based on age, and then other schools adopted this method of restructuring (American public, 2013). Another innovation attributed to Mann was standardized curricula:

Theoretically, this ensured that children could expect the same high-quality education from any school, district-wide. Prior to this reform to model American schools after the Prussian "common school" system, public education varied dramatically between schools. Once it was instituted, the American student population, one of the most internationally diverse in the world, came one step closer to achieving equal access to high-caliber educations. (American public, 2013, para. 5)

In 1837, Louisville, Kentucky, appointed the first superintendent. The first state-funded school for teacher education was in Lexington, Massachusetts. The first kindergarten opened in Columbus, Ohio (Sass, 2018).

In the $19^{\text {th }}$ and early $20^{\text {th }}$ Centuries, the majority of American children attended school in a one-room schoolhouse. One teacher would have instructed all students in first through eighth grades, totaling anywhere from six to forty students. The youngest children sat in front, while the oldest sat in the back. Subjects taught include reading, writing, math, history, and geography (Library of Congress).

Public schools have evolved significantly since the one-room school houses in the $19^{\text {th }}$ Century. Contemporary public schools are generally organized into districts by county, and they are controlled by locally-elected officials and superintendents appointed 
by the respective school board. Principals follow next in the chain of command, followed by assistant principals, teachers, and support staff. Schools "provide both educational and extracurricular activities for young people and a center for social, political, and cultural community events" (Social organization, 2017, para. 2).

A current day school district is typically composed of a kindergarten and grades first through 5 or 6, middle grades (6-8) or junior high grades (7-9) and high school (grades 9 or 10-12). Elementary schools generally house between 300-1,000 students, while middle/junior high schools are larger, with the enrollment of several different elementary schools in the area. Often times, communities will only have one high school, so enrollment size is substantially larger (Social organization, 2017).

Curriculum pursuits have gone far past the core subjects of the early $17^{\text {th }}$ Century. Subjects range from basic core subjects to advanced classes within the core areas; practical arts such as business and marketing, fine arts such as music, band and art appreciation; and even dual credit courses where students can earn college credit before ever leaving high school. Access to technology has caused vast changes in public schools:

Today's schools are marked by changes as significant as the technology that populates them. In many places, particularly rural communities where populations are shrinking, school districts are being consolidated in order to stay fiscally sound while providing students with all of the necessary and desirable modern facilities. While students in these consolidated districts have longer travel times, they are also able to avail themselves of the Wi-Fi, tablets, laptops, and computer labs enjoyed by students in metropolitan districts. 
The hi-tech devices enjoyed by our students are fostering a digital revolution in the classroom. Enabling more engaging distance learning and bringing the world to students, digital learning is transforming modern instruction. With access to other cultures and translation devices, the woes of early eras, such as teaching the growing Hispanic population and other non-native English speakers, are

eliminated with a few keystrokes. (American public, para. 18-19)

Public schools have changed in a myriad of ways since the first one opened in 1635 . They have grown from isolated one-room structures to diverse, expansive networks where change is only just beginning.

\section{Organizational Analysis}

When analyzing public schools, it is beneficial to examine them through an organizational frame. According to Bolman and Deal (2013), because organizations are complex and ambiguous, a frame is a "coherent set of ideas or beliefs forming a prism or lens that enables you to see and understand more clearly what goes on from day to day" (p. 41), and this frame helps one make sense of the world. Analyzing public schools through the structural frame makes sense because of division of labor, formal specialized roles, routines such as a schedule organized in set increments of time, and a focus on both process and product (Bolman \& Deal, 2013). A hierarchical structure of authority exists, from the school board to the superintendent, principal(s), teachers, and staff. Goals, objectives, rules, and policies are an integral part of the structural frame, as they are in schools. The school itself functions around a mission statement and a core set of rules, as do the administration, teachers, and students. Maintaining specified levels of quality is also a major undertaking in schools (Bolman \& Deal, 2013). 
Another element congruent with the structural frame is that of standards.

According to Bolman and Deal (2013), "A standard is a benchmark to ensure that goods and services maintain a specified level of quality" (p. 52). School boards hold schools to a specific standard, superintendents hold principals to certain standards, teachers are evaluated according to a specified set of standards, and teachers uphold their students to prescribed standards or benchmarks prevalent in curriculum, lesson planning, and testing. With school reform and the No Child Left Behind Act of 2001, standards, assessment, and accountability became a crucial focus, as test results became a part of the accreditation formula for schools. The use of planning and control systems, yet another component of the structural frame (Bolman \& Deal, 2013), is also heavily utilized in schools. Forecasting how students will perform and then measuring those results, as well as making efforts for improvement, are all part of the job description of teachers in public education.

Though it is easy to become absorbed in the structural aspects of public schools, fortunately this is not entirely what education is about. The human element must be prioritized as the most important aspect of education; after all, the goal is to educate children. Therefore, the human resource frame is another lens through which schools can be examined. Bolman and Deal (2013) stated "Organizations exist to serve human needs rather than the converse" and "people and organizations need each other" (p. 117). One focus of the human resource frame is that humans have needs, and basic needs must be met before people can advance to higher levels. When viewing the relationship between people and organizations, Bolman and Deal (2013) contended "When the fit between people and organizations is poor, one or both suffer; individuals may feel neglected or 
oppressed, and organizations sputter because individuals withdraw their efforts or even work against organizational purposes" (p. 135). This is especially relevant and important given the context of education, where the quality of individuals is paramount.

Furthermore, organizations that are highly successful have invested in people (Bolman \& Deal, 2013).

\section{Leadership Analysis}

Effective leadership is of utmost importance to any organization. Leaders come in all kinds of levels, styles, and types, and people exhibit many different traits of leadership, as well as employ various strategies depending on the context of the situation, the group being led, and the goals to be achieved (Bolman \& Deal, 2013; Goleman, 1996; Levi, 2014; Northouse, 2016). According to Northouse (2016), "Leadership is a highly sought-after and highly valued commodity" (p. 1). This is highly pertinent for educational leaders, whether they be administrators or classroom teachers. No matter the role of leadership in public schools, by examining leadership theory and practice and applying sound researched methods, a more comprehensive, in-depth understanding, appreciation, and application of leadership can evolve and flourish.

\section{Approaches to Leadership}

Levi (2014) explained the nuances of leadership by categorizing it into four different approaches: trait or personality, behavioral, situational, and contingency. The trait or personality approach supports the notion that good leaders exhibit certain characteristics. These characteristics may include: trustworthiness, motivation, intelligence, self-confidence, flexibility, creativity, and business sense, "yet no one trait can predict good leadership" (Levi, 2014, p. 187). Effective leaders in education exhibit 
all sorts of different traits, just as there are all sorts of different people with their own strengths. The behavioral approach focuses on how good leaders act, which in theory could be used to train other people to emulate these behaviors. This approach focuses on whether people are task oriented or people oriented (Bolman \& Deal, 2013; Northouse, 2016). Both would be applicable to leaders in education. The situational approach is all about context. Levi (2014) provides examples of situations that would call for different types of leaders; with important personal issues, one might need a charismatic leader, yet in times of worldly crisis, one might need a globally conscious leader.

\section{Styles of Leadership}

In harmony with situational leadership, various styles of leadership have been discussed amongst scholars (Bolman \& Deal, 2013; Levi, 2014; Northouse, 2016). Some of the prominent styles presented by Northouse (2016) that would more heavily involve educators are transformational, authentic, and servant. Each style is unique by definition, characteristics, and application.

Transformational. Transformational leadership has been heavily researched since the 1980s (Northouse, 2016). The focus of this type of leadership is the change and transformation of people. According to Northouse (2016), “Transformational leadership involves an exceptional form of influence that moves followers to accomplish more than what is usually expected of them . . .It includes assessing followers' motives, satisfying

their needs, and treating them as full human beings" (p. 161). It is all about charisma and vision. It is a reciprocal process, in that both leader and follower are inspired and motivated to reach the highest levels of achievement (Northouse, 2016). 
Transformational leadership is cited often in literature centered on education, and it is often referenced as a conceptual framework.

Authentic. Authentic leadership, one of the more newly explored styles of leadership, "hinges on whether leadership is genuine and real" (p. 9). No universal definition exists for authentic leadership; instead, researchers have formulated their own descriptions (Northouse, 2016). Determining authenticity can be both intriguing and challenging. It develops gradually over a person's life and may be triggered by a critical event such as a near-death experience or the birth or loss of a child. Other leadership analysts have called this event a crucible event, "a point of deep reflection that forced them to question who they were and what mattered to them. . .they emerged from the crucible stronger and more sure of themselves and their purpose - changed in some fundamental way" (p. 99). This new outlook propels authentic leaders, and they are inspired to lead with confidence, hope, optimism, and resilience (Northouse, 2016). Authentic leaders in the field of education at any level are inspiring, greatly sought after, and their impact affects many; this impact has great potential as it can continue on through others.

Servant. The goal of servant leadership is to assist and serve others. This type of leadership seems synonymous with that of a caring educator. Northouse advances this description, claiming that "servant leadership emphasizes that leaders be attentive to the concerns of their followers, empathize with them, and nurture them . . empower them" and "are ethical" (p. 225). Serving others comes first, and along with their selflessness, servant leaders are known to have high moral values and behavior. Northouse (2016) extends the following traits exhibited by servant leaders: listening, empathy, healing, 
awareness, persuasion, conceptualization, foresight, stewardship, commitment to growth of people, and building community. According to Bolman and Deal (2013), the servant leader's ultimate gift is love.

\section{Implications for Research in the Practitioner Setting}

The demands of leadership are at an all-time high, and it is unrealistic to think that principals can assume the weight of this responsibility alone. Stressors that weigh heavily on educational leaders include accountability mandates, a fast-paced global economy, a myriad of student issues, and teachers leaving the field of education in droves (Cosenza, 2015; Mangin \& Stoelinga, 2010; Mihans, 2009; Singh, 2012). The need for effective leadership is great, as the school itself evolves into an ever-increasingly complex organization of divergent interests, which are often political.

In order for teachers to develop their potential and be more fully recognized, trained, and utilized as leaders, more attention and research needs to be applied to this concept for increased awareness and growth to happen on this front (Angelle \& DeHart, 2011; Cosenza, 2015; Lukacs, 2015). Currently, teachers are too often isolated in classrooms with little to no idea about how they can expand their opportunities and experience in the area of leadership and make an even greater difference. Classroom teachers often do not even consider themselves leaders, having a very limited outlook on leadership.

This research study was aimed at helping alleviate such pressures from administrators as well as enhancing the educational experience by tapping into a resource that is ever present and ever ready: the teacher. Teachers are in a prime position for this opportunity: "They alone are positioned where all the fulcrums are for change" (Buchen, 
2000, p. 35). Teachers know the climate and the culture, they know the day-to-day rhythms of the schools, and they are in the trenches right along with the students and other teachers. Teachers, if motivated to do so, can have further impact on students, other teachers, other buildings, and other schools, given the tools, guidance, and support.

Even though research has been conducted on teacher leadership and a renewed sense of focus has occurred since the early 2000s, the research has been broad, the challenges of bureaucracy have prevailed, and the need for teachers in leadership positions is huge (York-Barr \& Duke, 2004). The voice of the teacher leader is insufficient in the research; qualitative studies on this topic are minimal but necessary for increased awareness and the likelihood of teachers leading and making change beyond the classroom.

In addressing the need to access the rich resource of teachers as leaders, the research addressed how administrators in a public school district, primarily principals, utilize teachers as leaders. The intention is that this knowledge will inspire other administrators to more seriously consider teachers as resources for leadership. Another area addressed by the research are the characteristics and leadership styles principals observe in their teacher leaders. This knowledge could help principals in other districts recognize potential leadership in their own faculties. Additionally, knowledge gleaned from the research will provide insight as to how teachers view themselves as teacher leaders as well as how to encourage this process. Another focus was placed on how schools can more effectively employ teachers as leaders, as well as how to promote leadership among staff, such as through professional development. 


\section{Summary}

As public schools have evolved over the centuries, they have become increasingly complex organizations. The need for effective leadership has become exponentially important if schools are to keep up with the changing tides and demands of education. This qualitative study involves the practice of including teachers in leadership positions beyond the classroom. 
SECTION THREE

SCHOLARLY REVIEW FOR THE STUDY 


\section{Introduction}

The next section provides a scholarly review of the research and covers the range of definitions and descriptions of teacher leaders, seminal work on teacher leadership, formal and informal roles of teacher leadership, and concerns about teacher leadership. Professional development needs are also covered, as well as collective efficacy in teacher leadership. The section concludes with discussion of teacher leadership among peers with a focus on making meaning from modeling and the importance of reflection.

\section{Teacher Leaders: A Description}

Since the research study focuses on teacher leaders, it is important to note the range of definitions of "teacher leader" that exist. A teacher leader is difficult to conceptualize, in that there are a myriad of definitions prevalent in the research (Cosenza, 2015; Nappi, 2014; Struyve, Meredith, \& Gielen, 2014; Wenner \& Campbell, 2016). Some descriptions include: One who shapes school culture and builds school resilience or a person who leads by example, has credibility and expertise, is a problem solver, and relates well to others...may or may not have a formal leadership role in the school (Martin, 2007); one who shifts from recipient to initiator (Lukacs, 2015); those who "get to engage with their work in new ways" while "their colleagues receive relevant, actionable professional learning" (Edwards \& Hinueber, 2015, p. 27). Other researchers list roles fulfilled by a teacher leader, including: resource provider, instructional specialist, curriculum specialist, classroom supporter, learning facilitator, mentor, school leader, data coach, catalyst for change, learner (Harrison \& Killion, 2007; Nappi, 2014); teachers contributing to the decision-making process (Cosenza, 2015); or "leading change from within" (Stanulis, Cooper, Dear, and Johnston, 2016, p. 54). Angelle and DeHart 
(2011) maintained "the concept of teacher leadership is defined by the context in which it is experienced" (142). This range of definitions and inconsistency is a gap in the literature, in that more cohesiveness of thought could exist with a more precise, universal definition.

Green and Kent (2016) depicted teacher leaders as having “ 'something extra” that sets them apart from just being a good teacher" (p. 1). Qualities and descriptions of such leaders include strong work ethic and persona; teacher leadership going beyond classroom walls; involved in policy and/or decision making at some level; and working toward improvement and change for students, their schools, or for the whole school organization; to determine, transcend a school wide vision for instruction (Cooper et al., 2015; Green \& Kent, 2016; Wenner \& Campbell, 2016).

\section{Seminal Research: Teacher Leadership}

York-Barr and Duke (2004) contributed seminal research on the topic of teacher leadership. Within their research, these authors identified a gap regarding how teacher leadership develops and the subsequent information about its effects. They claimed teacher leadership was ill defined both "conceptually and operationally" (para. 1). YorkBarr and Duke (2004) indicated “...the concept of teacher leadership suggests that teachers rightly and importantly hold a central position in the ways schools operate and in the core functions of teaching and learning" (para. 2). The researchers expressed that there was much to be learned about the specific paths related to teacher leadership, and whatever the path, the result is increased student achievement. The authors referenced reform initiatives in 1980, the teacher professionalism movement, and concerns of teachers operating in isolation. Upon conducting a literature review from 1980 to the time 
of publication of their article in 2004 , they concluded that the coverage of teacher leadership was quite broad, considering the complex nature of the topic. York-Barr and Duke (2004) explained that leadership was not restricted to one person elevated in the hierarchy, but could potentially be filled by both teachers and administrators. They noted challenges of teacher leadership in education such as a traditionally bureaucratic structure in education, physical structures themselves, and insufficient time. The researchers underscored the need for more teachers in active leadership roles.

Wenner and Campbell (2016), after referencing York-Barr and Duke (2004), explained that while the seminal research was important and provided fresh perspective and a new focus for teacher leadership, "much has changed since 2004; teacher quality mandates have been implemented in several states, and Teacher Leader Model Standards have been created" (p. 2). These included seven domains promoted by the Teacher Leadership Exploratory Consortium in 2008, and were meant to encourage and promote teachers in leadership roles:

Domain I: Fostering a Collaborative Culture to Support Educator Development and Student Learning

Domain II: Accessing and Using Research to Improve Practice and Student Learning Domain III: Promoting Professional Learning for Continuous Improvement Domain IV: Facilitating Improvements in Instruction and Student Learning Domain V: Promoting the Use of Assessments and Data for School and District Improvement

Domain VI: Improving Outreach and Collaboration with Families and Community Domain VII: Advocating for Student Learning and the Profession 
The authors continued their discussion, noting that the educational landscape has been in a state of constant change with continual shifts in policy. Additionally, research on teacher leadership has had a limited, narrow focus.

\section{Formal and Informal Roles of Leadership}

Also prevalent in the research inquiry is the idea of formal and informal roles of leadership. Formal leadership would entail roles that are specifically assigned to teachers or those that would occur outside the confines of the classroom, such as department head, subject coordinator, team leader, peer coach, or instructional facilitator (Martin, 2007). Informal roles of leadership would include those limited to the classroom, including planning, communicating goals, or regulating activities (Angelle \& DeHart, 2011; Margolis \& Deuel, 2009; Muijs, Chapman, \& Armstrong, 2013; Sinha, Hanuscin, Rebello, Muslu, \& Cheng, 2012; Struyve et al., 2014). Martin (2007) explained a third, informal layer of leadership of teachers who provide a successful learning environment, where teacher leaders, formal or informal, are placed into these broad areas: Influencing the school culture, building and maintaining a successful team, equipping other potential teacher leaders, and enhancing or improving student achievement. In the literature, more can be learned in terms of teacher leaders and this layer of leadership where teachers impact the school on a grander scale (Angelle \& DeHart, 2011; Cosenza, 2015; Lukacs, 2015).

Within the literature, there is a need for merging perceptions in terms of leadership. Traditionally, leadership has been examined under the canopy of administration, specifically the principal (Hanuscin, Cheng, Rebellow, Sinha \& Muslu, 2014; Lukacs, 2015; Nappi, 2014; Neumerski, 2013; Singh, 2012). When leadership is 
examined in education, teachers and administrators have been segmented in the research; therefore, it is important to more comprehensively understand and more effectively apply leadership practices (Neumerski, 2013). According to Neumerski (2013):

... instead of a cohesive conversation around leading the improvement of instruction, we have created separate bodies of knowledge, each typically published in its own subset of academic journals ... The result (not withstanding a handful of exceptions) is a body of literature on what principals should do to lead instruction, a separate body on what teacher leaders should do, and still another on what instructional coaches should do. (p. 312)

Division of leadership in the research further propagates the traditional mentality that leadership is a formal role reserved solely for the principal, which may help to explain the fact that teachers often do not consider themselves leaders (Angelle \& Dehart, 2011; Hanuscin, et al., 2014; Sinha et al., 2012; Wenner \& Campbell, 2016). Furthermore, in considering research conducted by Tichnor-Wagner, Harrison, and Cohen-Vogel (2016), when administrators do not support leadership pursuits among teachers, the results can pervade school culture negatively. When "teachers noted that district officials did not value shared decision-making at the school level," they described the leadership structure with phrases such as "hierarchy", "chain of command", and "top-down"; and teachers "expressed dissatisfaction with top-down mandates about curriculum, instruction, and the budget" (p. 627). In addition, "these top-down mandates hindered teachers from taking leadership and having autonomy over instructional practices" (Tichnor-Wagner et al., 2016). 


\section{Why Teachers Make Good Learning Leaders}

As noted previously, so much potential has yet to be realized in terms of teacher leadership. According to Buchen (2000), teacher leadership makes all the difference in a school setting:

They alone are positioned where all the fulcrums are for change. They alone know what the day-to-day problems are and what it takes to solve them. They, not the principals, should be the ones to hire new teachers. They know what is needed, and if they make a mistake they have to live with it. They should run the schools, the classes, the halls, the extracurricular activities. But, alas, they are brainwashed, they are fearful, they are dependent. They don't know how good some of them can be as managers of learning. But sadly, unless they are forthcoming, the vacuum will be filled by the old leaders who helped create the paralysis in the first place. (p. 36)

Edwards and Hinueber (2015) claimed that teachers make good learning leaders, and when they are encouraged to assume these roles, everyone benefits. The teachers themselves "engage with their work in new ways . . their colleagues receive relevant, actionable professional learning. Principals leverage the benefits of teacher collaboration...District officials see the pipeline of school and district leaders expand" (p. 27). The authors led to and emphasized the people who benefit the most: the students (Edwards \& Hinueber, 2015).

Teacher leaders are especially important in promoting educational reforms (Angelle \& DeHart, 2011; Cosenza, 2015; Gilad, 2014; Margolis \& Deuel, 2009; Nappi, 2014; Ross, Lutfi, \& Hope, 2016; Sinha et al., 2012; Stanulis, et al., 2016). Angelle and 
DeHart (2011) contended "increasing the extent of teacher leadership in a school can bring positive change to schools" (p. 142), and both student and adult learning can flourish. Margolis and Deuel (2009) underscored the impact teacher leaders can have on instructional change. For this reason, the literature revealed many educators who hold the viewpoint that teachers should be actively involved in important decision-making scenarios which include but are not limited to: class scheduling, textbook selection, communicating and leading instruction about best practices, mentoring novice teachers (first year or student teachers), providing classroom coaching to peers, managing resources, and building community support (Cosenza, 2015; Margolis \& Deuel, 2009; Nappi, 2014; Sinha et al., 2012; Stanulis, et al., 2012).

Further illuminating the reform path, the literature revealed the importance of teacher leaders and teacher retention. According to Sinha et al. (2012), "Leadership is viewed as an essential component in the initial success and long-term sustainability of such reforms" (p. 12). Retention of employees is important in any organization, considering how expensive the process is to replace them; larger school districts spend tens of thousands of dollars to recruit and train new teachers (Ross et al., 2016). In the literature, the concept of teacher retention was covered in two ways with respect to teacher leadership: retaining teachers because they were involved in leadership opportunities beyond the classroom and retaining novice teachers because of the quality leadership they received as a result of teachers in leadership positions. When teachers are involved in leadership opportunities in school decision making, they feel as if they have more control, are more personally invested, and are more likely to stay (Angelle \& DeHart, 2011; Cosenza, 2015; Margolis \& Deuel, 2009; Ross et al., 2016; 
Sinha et al., 2012). This sense of control teachers feel as a result of higher levels of leadership increases feelings of empowerment, which increases levels of commitment and may potentially advance school improvement (Angelle \& DeHart, 2011; Cosenza, 2015; Gilad, 2014; Nolan \& Palazzolo, 2011; Ross et al., 2016; Sinha et al. 2012; Struyve et al. 2014). On the opposite side, "When teachers were deprived of decision-making abilities, they reported greater dissatisfaction, more stress, and less loyalty to the principal" (Angelle \& DeHart, 2011, p. 145).

Seasoned teachers in leadership positions are a powerful influence on novice teachers who can benefit from their expertise and experience (Angelle \& DeHart, 2011; Mihans 2009; Sinha et al, 2012). According to Angelle and DeHart (2011), teacher competency and expertise is of utmost importance in effective leadership. Depending on the size of the school district, principals must oversee between 30-100 teachers. Experienced teacher leaders may assist in this role by easing the principal's load and managing small groups of teachers (Miles, 2016). According to Nappi (2014), teachers more naturally collaborate with other teachers than with principals or other outside professionals. Teacher leaders who collaborate with classroom teachers are thought to have the greatest chances of changing instruction in the context of schools, yet the research is scant in this area (Neumerski, 2013). Margolis and Deuel (2009) contended when expert teachers assume leadership roles, the professional culture is enhanced and "that increases meaningful conversations between veteran and novice teachers. This increased professional support and commitment then facilitates better retention rates amongst new teachers and wards off the pervasive maladies of teacher isolation and attrition" (p. 267). The benefits of teacher leadership are reciprocal, in that the process of 
mentoring new teachers also benefits the mentor teacher; teachers who served as mentors to other teachers might experience "a personal and professional satisfaction . . . a sense of instrumentality, and new learning” (Gilad, 2014, para. 2).

The importance of teachers working collectively in the name of effective leadership, with both the administration and each other, was cited often in the literature. Angelle and DeHart (2011) emphasized the importance of collaboration and teachers learning from each other in order to reach their potential. Miles (2016) maintained that teaming "is the collaboration and support structures that help all teachers grow" (p. 17). Peterson and Conway (2011) relayed "teachers are empowered to work collaboratively and have a say in the decision making so that a collective sense of responsibility for improving student outcomes occurs" (p. 176). Sterrett and Irizarry (2014) noted that principals could encourage teacher leadership by promoting time for meaningful collaboration. Principals may also help to foster teacher leadership by providing adequate and timely professional development in leadership training (Cosenza, 2015; Gordon, Jacobs, \& Solis, 2014; Mangin \& Stoelinga, 2010; Muijs et al., 2013; Wenner \& Campbell, 2016). Mangin and Stoelinga (2010), expressing great confidence in the potential for teacher leadership, posited "teachers, in interaction with one another, have the potential to lead instructional improvement efforts despite a lack of positional leadership authority" (p. 50).

\section{Teacher Leadership Concerns}

A concern about teacher leadership uncovered in the literature focused on principals who were unwilling to share the role of leadership and lose their authority, which could pose problems for teachers trying to rise as leaders (Cosenza, 2015). 
Logically, principals are essential deciding factors in whether to encourage or discourage teacher leadership. They can discourage leadership by "withholding, controlling, or limiting power from teachers, placing teachers in isolation rather than in collaborative situations; or focusing too much on micromanaging the details of work" (Sterrett \& Irizarry, 2014, p. 7). Another concern is that some teachers in leadership roles experience isolation or backlash from their fellow teachers (Struyve et al., 2014), while some avoid leadership responsibilities and prefer to work alone to avoid such challenges (BrowneFerrigno, 2016). Other deterrents to teacher leadership include time constraints, unhealthy relationships with co-teachers and administration, school climate issues, selfdoubt, and other personal characteristics (Lukacs, 2015; Wenner \& Campbell, 2016).

Trust at all levels, laterally and vertically, was an important component underscored in the literature in fostering meaningful teacher leadership (Edwards \& Hinueber, 2015; Gilad, 2014; Mangin \& Stoelinga, 2010; Ross et al., 2016; Singh, 2012; Stanulis, et al., 2016). Singh (2012) discussed the importance of trust in shared leadership situations: "If teachers perceive unfair and dishonest treatment, trust will not develop, and teachers will choose not to collaborate" (p. 19). Ross et al. (2016) emphasized how critical trust is in the context of the teacher functioning in various roles: "When in the role of follower, teachers must trust the leader's vision and distribution of tasks. When in the role of leader, teachers must trust their peers to be team players" (p. 162). In considering multiple layers of trust, Edwards and Hinueber (2015) contended "teachers need to be able to trust that their leaders will represent their interests; school administrators must have confidence that teacher leaders will implement initiatives with fidelity; and teacher leaders need to trust that administration will support them" (p. 27). 


\section{Need for Professional Development}

Teachers do not necessarily automatically possess the knowledge, skills, and experiences that correlate with teacher leadership. Hence, "some form of leadership development is often necessary to enable teachers to take on leadership roles effectively, and in those cases where teacher leadership has been most successful, school management has usually either put some form of leadership development programme in place or encouraged and supported staff in enrolling on existing teacher leadership programmes” (Muijs et al., 2016, p. 770).

Teacher leader roles are fostered and explored by opportunities for effective professional development (Mangin \& Stoelinga, 2010; Muijs et al., 2013) which schools and leaders need to provide (Muijs et al, 2016). Professional development is most beneficial when instruction and collaboration are components and it is sustained over a period of time (Mangin \& Stoelinga, 2010). Mangin and Stoelinga posited such professional development may increase instructional capacity, resulting in improved practice and contributing to overall school improvement. These benefits have led to a growing emphasis on the development of quality training opportunities for teachers to enhance their skills, deepen their knowledge, and improve their practice. In theory, instructional leader roles can facilitate instructional improvement by providing teachers with contextualized, sustained, instructionally focused, and thus effective professional development. (p. 51)

\section{Professional Learning Communities (PLCs)}

A Professional Learning Community (PLC) is a model of school reform that centers on the following fundamental principles: ensuring that students can learn, 
fostering a culture of collaboration, and focusing on results to set and reset goals as progress occurs (DuFour, 2004). According to DeMatthews (2014):

Professional learning communities demand a school organization that features shared values, collective responsibility, an inquiry-minded orientation, and a school culture that promotes reflection, collaboration, and dialogue. Rooted in these organizational elements is an assumption that teachers and other stakeholders have particular knowledge, expertise, and experience that contribute to the teacher learning, innovative teaching pedagogies, and improved student achievement. (p. 178)

Even though schools are complex, in PLCs teachers are "capable of creating structures that promote their own improvement and collective success...such communities can take advantage of the varied capacity, expertise, and experience of teachers by pulling these people together in ways that facilitate learning, reflection, and group problem-solving" (DeMatthews, 2014, p. 180).

PLCs provide a unique opportunity for teacher leaders to act as effective leaders (Nicholson, Capitelli, Richert, Bauer, \& Bonetti, 2016). According to Nicholson et al. (2016), “The success of actualizing this image of teacher leadership is contingent on having both a school culture and the requisite structures that allow it to develop" (p. 31). One component to support such a culture is collaboration. Protected collaboration time for allowing teachers opportunities for roles in leadership is important (Tichnor-Wagner, Harrison, \& Cohen-Vogel, 2016). PLCs can be especially instrumental in developing teacher leadership because PLCs, by nature, are enhanced by teachers coordinating elements that run the communities (DeMatthews, 2014; Nicholson et al., 2016). PLCs can 
help illuminate the pathways toward becoming a teacher leader in a cohesive community of teachers (Luft, Dubois, Kaufmann, \& Plank, 2016). Luft et al. (2016) emphasized the power of professional learning communities and the unique "opportunity to discuss personal and professional experiences" as well as "an opportunity to make sense of the challenges and opportunities that exist with learning" (p. 8). This "collaborative culture" is essential as teachers move into positions of leadership (Nicholson et al., 2016).

\section{Collective Efficacy}

Collective efficacy is described as "a teacher's belief in the faculty as a whole to accomplish goals ... associated with persistence and tenacity ... .teachers who believe they can be successful in a task redouble their efforts in the face of failure to achieve their goals" (Angelle \& Teague, 2014, p. 740). Linked to shared decision making, collective efficacy is viewed as a possible result of collaborative efforts as well as building meaningful relationships (Angelle \& Teague, 2014). According to Goddard, Goddard, Eun, and Miller (2015), “Collective efficacy beliefs thus arise from a metacognitive process in which group members assess the relationship between their competence and the nature of the task they face" (p. 507).

Going beyond the confines of the classroom as a teacher leader is associated with collective efficacy and is conceptualized as an "extra role behavior" or "organizational citizenship behavior" (Angelle \& Teague, 2014, p. 741). This collective willingness to collaborate with others and share learning and expertise represents a multidirectional flow of influence and the experience increases credibility with peers. The school setting is advanced as a place for adult learning as well as children's learning. This practice of 
sharing in expertise "is an element of collaboration where most of the work of teacher leadership is conducted" (Angelle \& Teague, 2014, p. 741).

Stemming from their research, Angelle and Teague (2014) found a "clear and strong relationship between collective efficacy and the extent of teacher leadership" (p. 741). Another important finding is that teachers place more importance on informal roles of leadership such as collaboration or extra role behaviors than formal roles of leadership delegated by the principal, such as department chairs, grade level chairs, and instructional coaches. Therefore, "empowering teachers in informal ways such as teacher-led collaborative units or shared responsibility for budgeting, scheduling, and interdisciplinary project in their unit may be more effective in increasing collective efficacy" (Angelle \& Teague, 2014, p. 748). Results from Angelle and Teague's (2014) study also showed that teachers are willing to lead beyond the classroom in situations where principals encourage this leadership, thus strengthening the concept of shared leadership.

\section{Effective Teacher Leadership Among Peers: Modeling and Reflection}

Nicholson et al. (2016) elaborated upon the notion of teacher leaders by addressing how to "empower teachers to be primary catalysts in their own leadership development" as well as "facilitate leadership development among their own colleagues" (p. 32), while emphasizing the significance of teachers going beyond formal leadership roles. In a study of teacher leadership by Luft et al. (2016), the researchers discovered the significance of teachers and how they learned and developed individually as leaders, noting the challenge of leadership development: 
There are a variety of skills, abilities, and levels of impact to consider. More importantly, teachers are individuals with different interests, knowledge levels, and opportunities to practice their leadership skills. (p. 7)

Given these differentiated characteristics as evolving leaders, the researchers indicated the need of an individual professional learning plan with specific learning objectives for “optimizing teacher learning” (Luft et al., 2016, p. 8) in the role of flourishing leader. This individual plan would offer guidance for personalized professional development as well as provide time for further collaboration and learning.

The notion of leading one's colleagues naturally brings to mind the act of modeling. In examining modeling as a vehicle for teacher leader-facilitated professional development, Margolis and Doring (2012) differentiated between Level 1 and Level 2 modeling. Level 1, or the studio classroom, occurs when teachers observe other teachers in the classroom with students present. Level 2 modeling involves "instances where teacher leaders share openly about their teaching” (Margolis \& Doring, 2012, p. 862) where students are not present. This sharing can occur in person or online, and can be related to teaching lessons, planning, strategies, and individual strengths and weaknesses. Level 1 modeling, though potential benefits are copious in the literature, has its downfalls. Lessons from the studio classroom are viewed by teachers as "requiring practice for replication rather than as a venue to stimulate discussion of problems of practice to promote teacher learning" (Margolis \& Doring, 2012, p. 864). Because of these limitations, reflection is encouraged instead of replication in regard to teaching. This lends credence to the "acknowledgment that any lesson is to some degree an experiment; and that even a 'best practice' will require much fine-tuning when 
manifested with particular students on a particular day in a particular classroom" (Margolis \& Doring, 2012, p. 864). Each lesson, regardless of how polished the content or method of delivery, will be received differently depending on the day or the specific class.

This concept of modeling transcends to the area of teacher leaders. The importance of leadership lies in the learning, and not in the perfection of the experience (Margolis \& Doring, 2012). Accordingly, "in dismantling the search for the holy grail of the 'perfect lesson,' a new vision of leadership can emerge where the teacher leader is the best teacher learner" (Margolis \& Doring, 2012, p. 878). This sentiment is inspiring, as the goal of the perfect lesson is discarded, yet the element of reflection becomes paramount, which is more realistic and consistent with real-life experience. The practice of teaching through revising, improving, and providing feedback to others becomes the focus (Margolis \& Doring, 2012). Further, Level 1 modeling would become less daunting and more useful in this scenario. Margolis and Doring (2012) recommended using classroom observations to learn rather than to evaluate and in this process to reward reflection instead of perfection.

Nicholson et al. (2016) emphasized teachers as reflective learners in the context of teacher leadership as well, claiming it is "a process of influencing others to improve their educational practice and exemplifying a learning stance" (p. 30). Teacher leadership is both interpersonal and intrapersonal, and this process of reflection is key (Nicholson et al, 2016). Merriam and Bierema (2004) also discussed the importance of reflection in adult learners, or "reflective practice" (p. 115). The authors presented two concepts regarding reflective practice: reflection-on-action and reflection-in-action. Reflection-on- 
action is congruent with experiential learning, where a person has the experience and purposefully thinks and reflects upon it after the fact. Reflection-in-action takes place while the experience is occurring: "Reflection-in-action is what distinguishes the more expert practitioner from the novice. It characterizes the practitioners who 'think on their feet', who experiment, change direction, and immediately respond to a changing context of practice" (p. 116). Upon further consideration of the concept of reflection, Caffarella and Daffron (2013) claimed "A number of authors view reflective practice as a critical aspect of learning from experience (p. 54) and that "getting to the essence of who individuals are and how they perceive the world is at the heart of reflective practice" ( $\mathrm{p}$. 56).

Gill (2010) underscored the importance of reflection within the context of individual learning, explaining individual learning as a social process, and how "it is difficult to do without feedback from others and reflection with others" (p. 55). Reflection is a process by which an individual finds practical meaning by answering the following questions:

- What happened?

- What were you trying to do?

- What results did you want?

- What were the actual results?

- What could have been done better?

- $\quad$ How would you improve things next time? (Gill, 2010, p. 55)

Reflecting on the answers to these questions and thinking about the learner in the data as a part of the equation helps turn this information about specific behavior "into knowledge 
and wisdom" (Gill, 2010, p. 55). Seeing our reflection clearly without our own bias and judgment of ourselves can be daunting and ambiguous. Taking the next step and including others in this reflection is more "likely to produce more accurate and useful learning (Gill, 2010, p. 55). Kahneman, Lovallo, and Sibony (2011) explained reflective thinking as "slow effortful and deliberate" (p. 22) and emphasized the importance of moving from the individual to the collective when making decisions.

\section{Summary}

A pressing need exists for effective leadership in public schools, and principals cannot do it alone (Gordon et al., 2014; Nappi, 2014; Ross et al., 2016). Though extensive research is available for leadership related to administration, only a scant amount of research exists with a focus on teachers as leaders; it is "emerging" and "yet to be fully realized" (Margolis \& Deuel, 2009, p. 283). Furthermore, there is untapped potential in teachers serving as leaders, as teachers do not always know about leadership opportunities that surround them, nor do they consider themselves leaders (Angelle \& DeHart, 2011; Hanuscin et al., 2014; Sinha et al., 2012). The purpose of this study is to gain knowledge and add to existing research, which may better explain teacher leaders. This is a qualitative study comprised of qualitative statistics (surveys) field notes, and interviews. The end goal is to contribute to educational leadership by providing more information about how teachers serve and can serve as leaders within their districts, the importance and rationale for such an endeavor, and how administrators can tap into this potential, which would yield a more comprehensive approach to leadership in school districts. 
SECTION FOUR

CONTRIBUTION TO PRACTICE 


\section{Presentation for Principals of Secondary Schools}

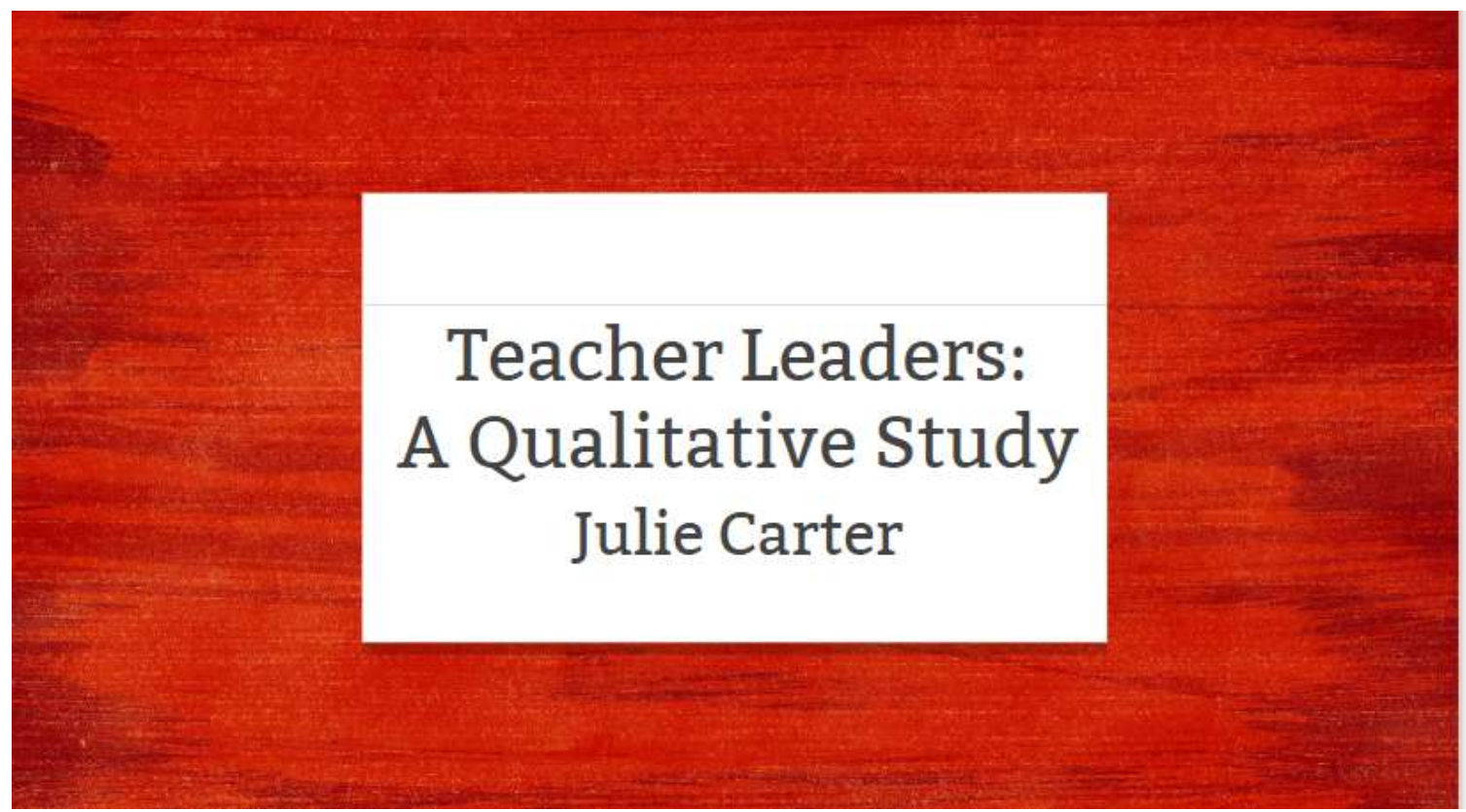

Notes: Research in the field for this study was conducted during the Spring Semester of 2018.

\section{Quotes From Principals}

\section{"I have this thing I want to do, this project ... who am I going to ask? I'm going to ask my teacher leaders."}

Notes: Time and time again, principals echoed this sentiment in relation to making decisions, implementing new ideas, and enforcing change. 


\section{Quotes From Principals}

"Sometimes I'm not always the best at this myself because I have a vision, I want to share my vision ... but sometimes it's hard. A lot of times I will go to these people and ask them, 'So this is the message I want to convey.' I need input to understand what I need to change to make this more palatable."

Notes: Often times, because of their position as leader of the school, principals indicated that teacher leaders worked as liaisons to help convey messages to other teachers.

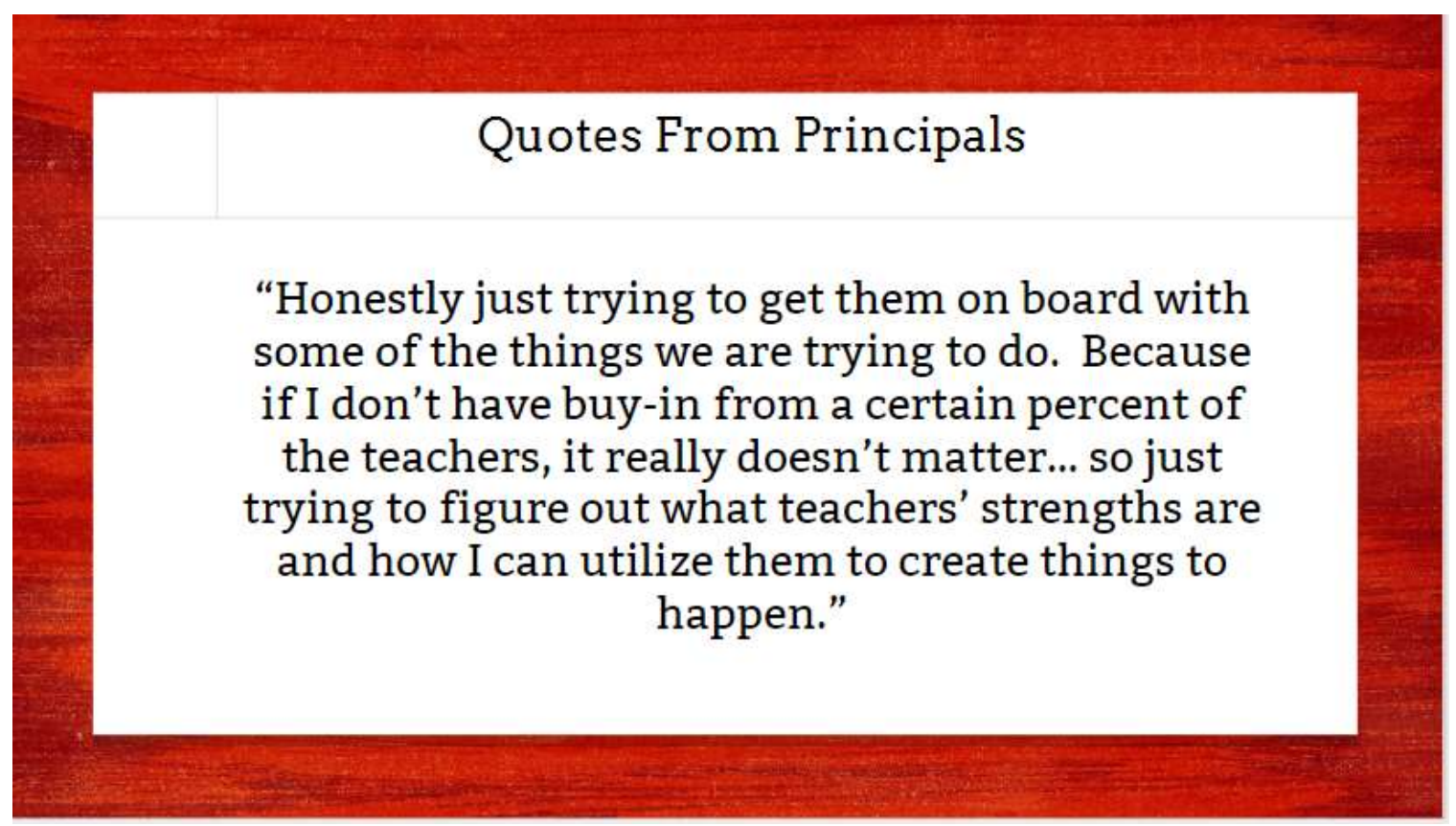

Notes: Teacher buy-in was voiced as an essential component to advancing and implementing change. 


\section{Introduction}

A pressing need in American education regarding leadership

A mass exodus of teachers leaving the field (Cosenza, 2015; Mihans, 2009).

Schools have immense amount of responsibility coupled with accountability mandates

(Mangin \& Stoelinga, 2010; Mihans, 2009; Singh, 2012)

\section{Notes:}

The need for leadership has caused a sense of urgency for effective leadership. There is a significant demand to prepare students for the future with highly qualified teachers, even though $40-50 \%$ of teachers leave the field within the first 5 years. Stresses and demands of the job have been a factor in the amount of teachers leaving. The significance of leadership within the context of the public school seems to be at an all-time high.

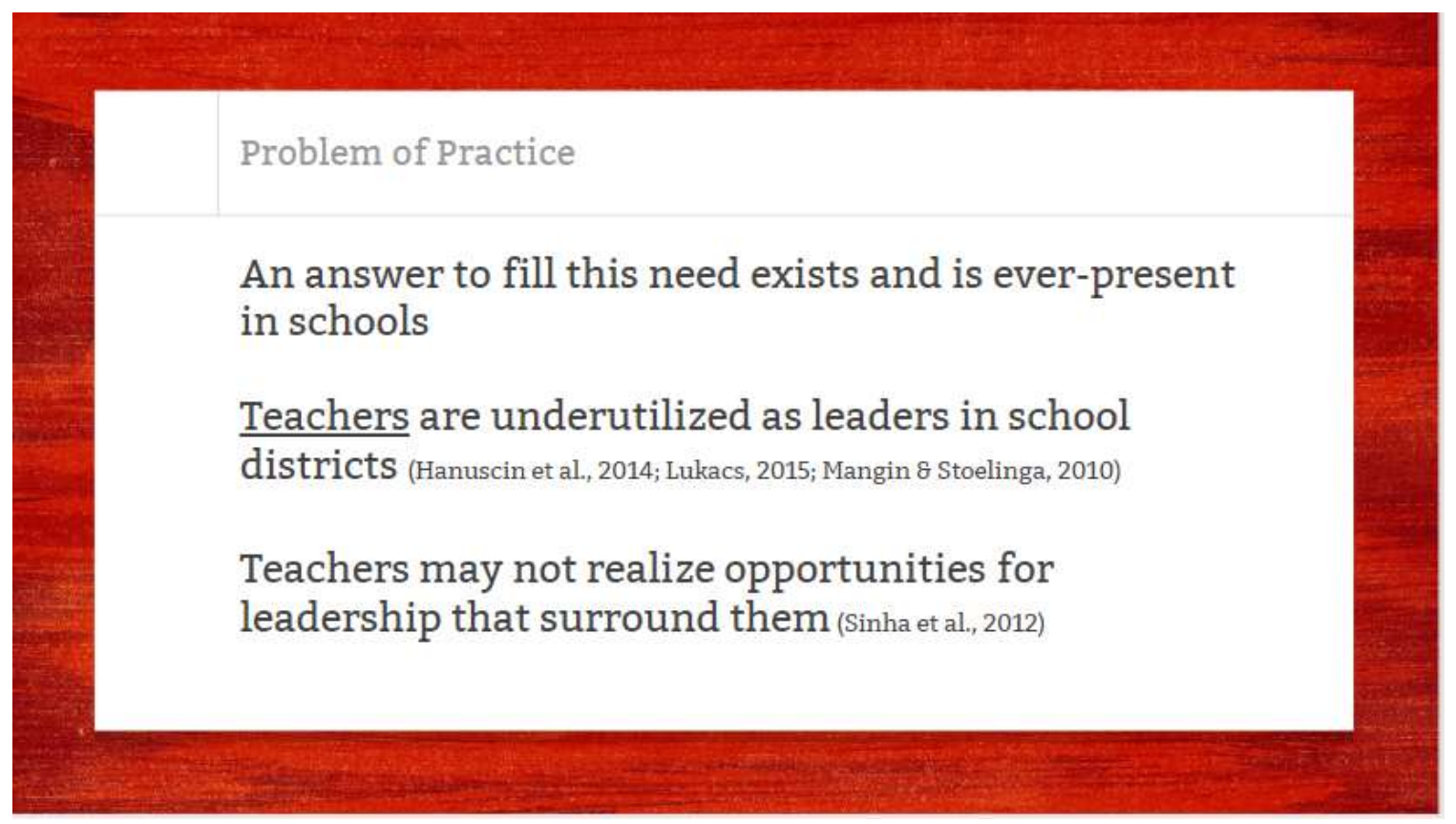


Notes: Teachers have been referred to as "islands of excellence," isolated in their own classrooms and not fully utilized (Reeves, 2006).

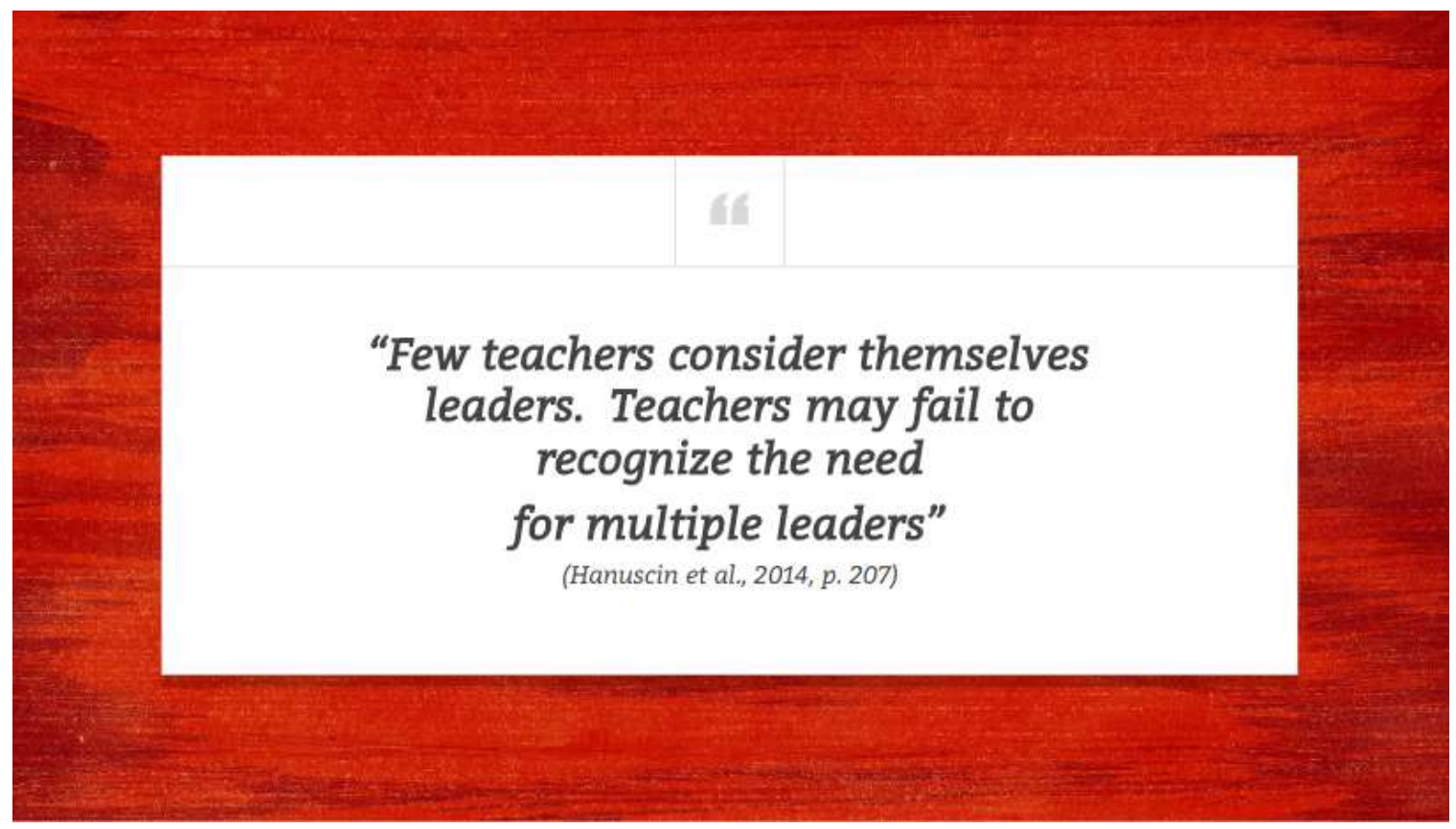

Notes: This quote from the literature rang true in my research. Teachers, even though they had been specifically chosen by their principals as outstanding leaders in their district, had difficulty referring to themselves as leaders.

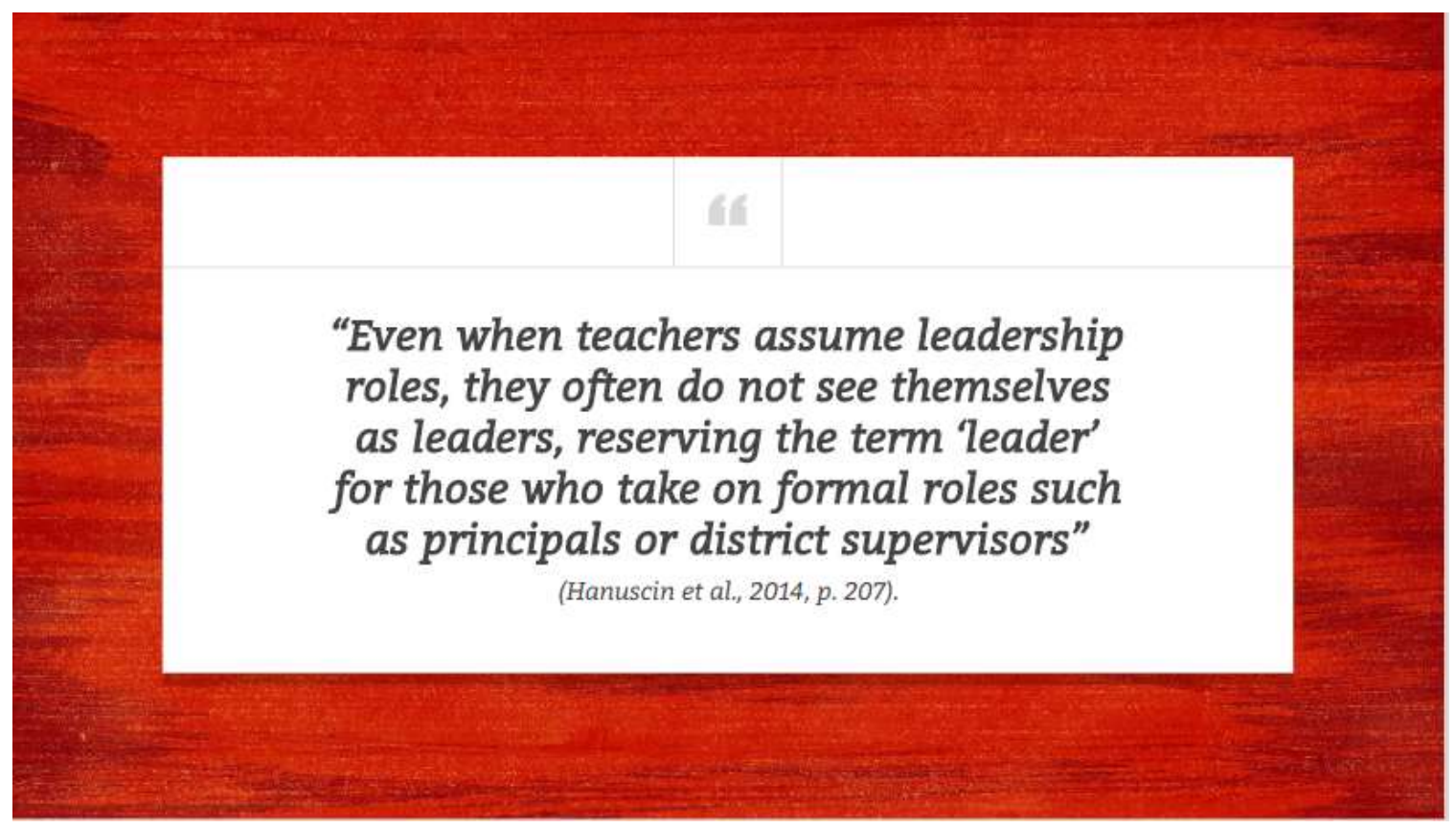




\section{Literature Review}

A range of definitions for "teacher leader" exists, so it is difficult to

conceptualize (Cosenza, 2015; Nappi, 2014; Struyve, et al., 2014; Wenner \& Campbell, 2016)

Seminal research: York-Barr and Duke (2004):

Teacher leadership ill-defined "conceptually and operationally" (para. 1)

Leadership not restricted to one person elevated in the hierarchy; does

not have to be a formal leadership role

Challenges exist regarding teacher leadership in education due to traditionally bureaucratic structure in education, physical structures, and time

(York-Barr \& Duke, 2004)

Notes: Some definitions include: A) One who shapes school culture and builds school resilience; B) A person who leads by example, has credibility and expertise, is a problem solver, and relates well with others; C) One who shifts from recipient to initiator

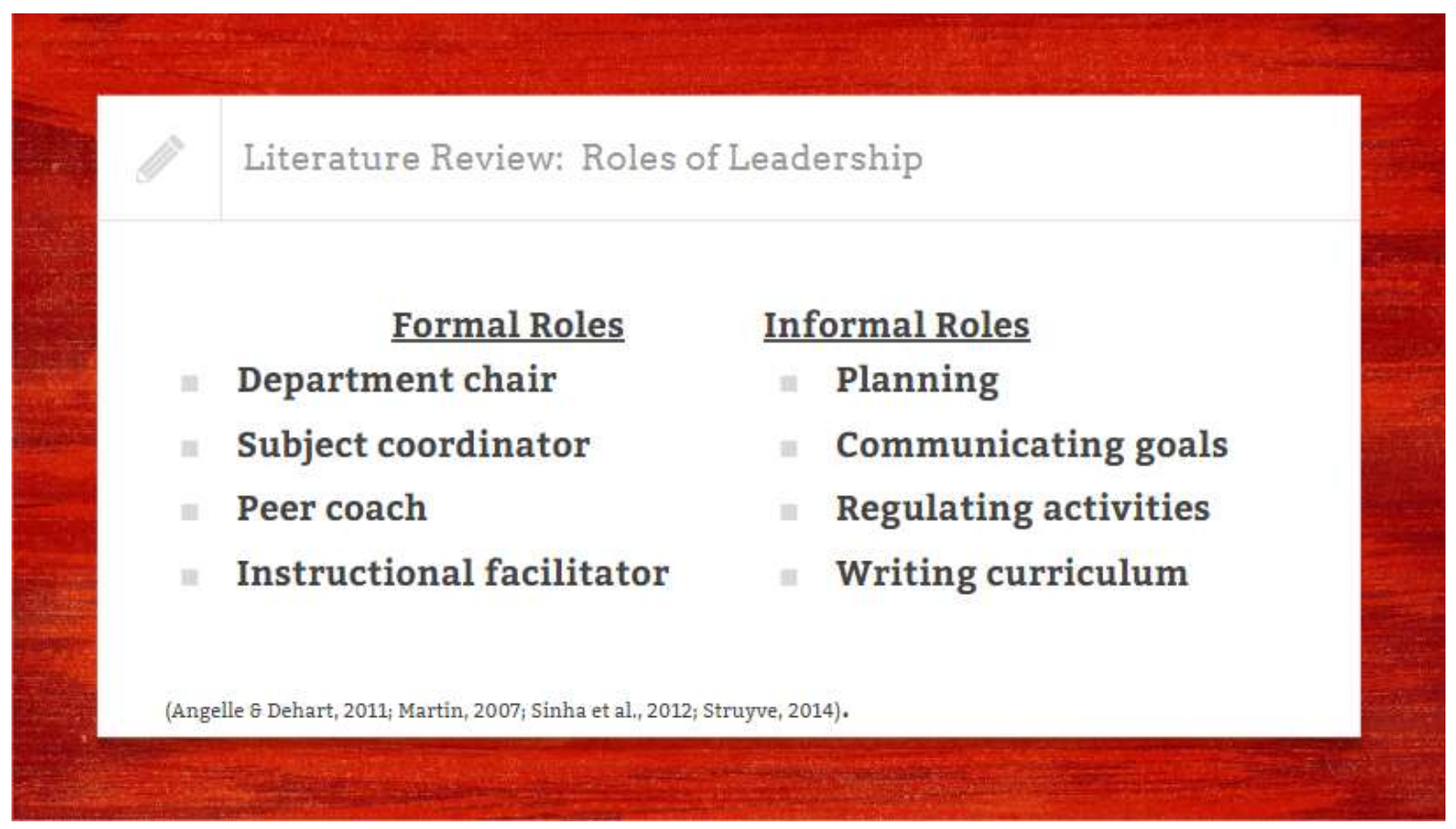

Notes: Other researchers' categorize leadership by formal and informal roles Teachers "contributing to decision making," "leading change from within" were other descriptions

The way it is defined also depends on the context in which it is happening 


\section{Literature Review}

Division of leadership propagates the mentality that leadership is a formal role reserved solely for the principal

(Angelle \& DeHart, 2011; Hanuscin, et al, 2012; Wenner \& Campbell, 2016).

May help to explain why teachers often do not consider themselves leaders

Often times, "top-down mandates hindered teachers from taking leadership and having autonomy over instructional practices"

(Tichnor-Wagner et al, 2016, p. 627).

Notes: Within the literature, several scholars expressed the need to merge perceptions in terms of leadership.

Traditionally, leadership has been examined under the canopy of administration, specifically the principal.

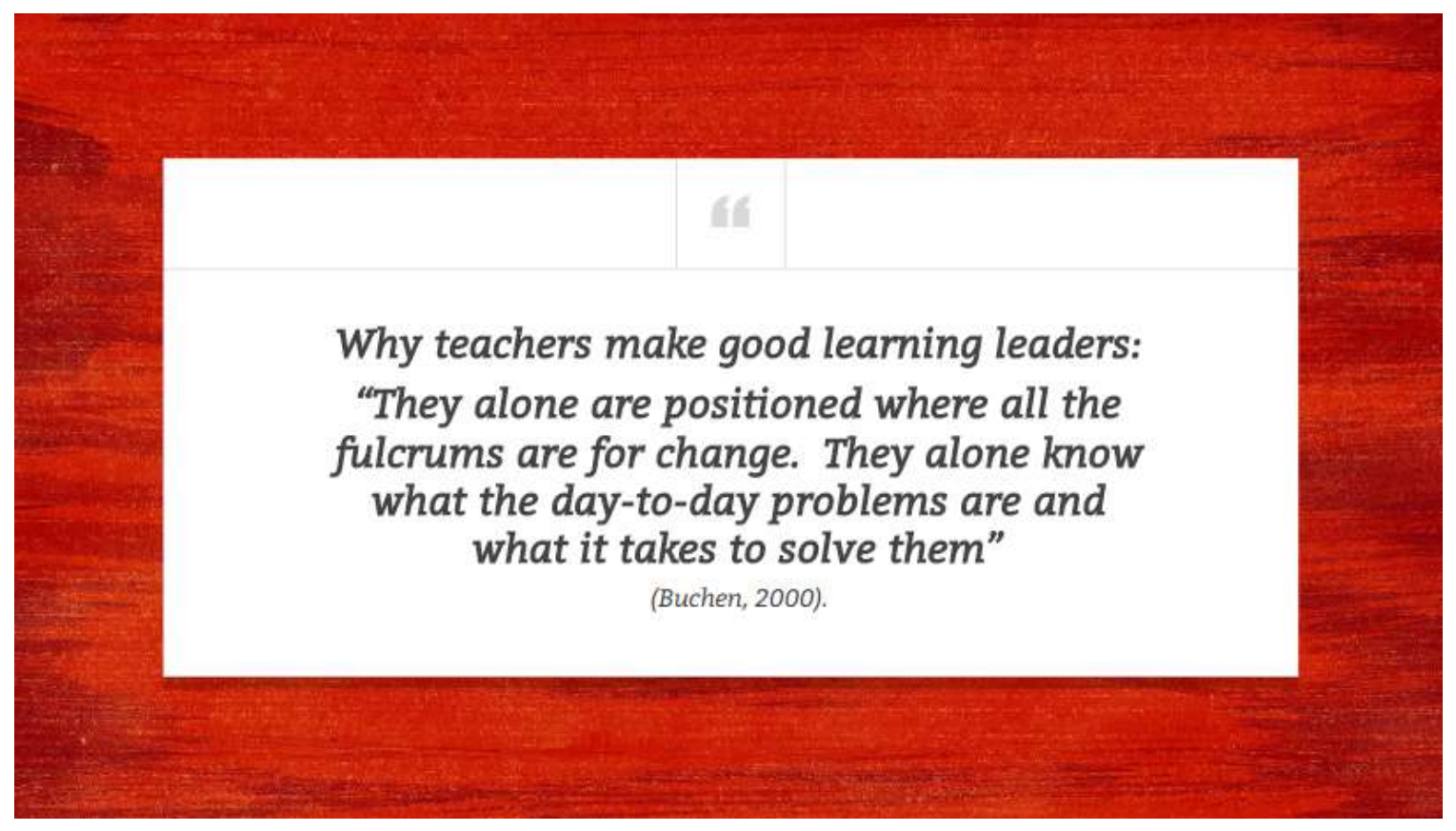




\section{Literature Review}

Teacher leaders are especially important in promoting educational

reforms (Angelle \& DeHart, 2011; Gilad, 2014; Margolis \& Deuel, 2009; Ross et al., 2016; Stanulis, et al., 2016)

Teacher leaders are important in regard to teacher retention

(Angelle \& DeHart, 2011; Cosenza, 2015; Margolis \& Deuel, 2009; Ross et al., 2016; Sinha et al., 2012)

Principals foster teacher leadership by providing adequate and timely professional development in leadership training

(Cosenza, 2015; Gordon et al., 2014; Mangin \& Stoelinga, 2010; Muijs et al., 2013; Wenner \& Campbell, 2016)

Notes:

Increasing the extent of teacher leadership can bring positive changes to schools, and both student and adult learning can flourish.

Increasing retention occurs because teacher leaders are involved in leadership beyond the classroom and retaining novice teachers because of the quality leadership they received as a result of teachers in leadership positions.

When teachers are involved in leadership opportunities in school decision making, they feel as if they have more control, are more personally invested, and are more likely to stay.

The sense of control leads to increased feelings of empowerment, which increases levels of commitment and may advance school improvement. 


\section{Purpose of the Study}

To gain knowledge and insight as well as add to existing research about teacher leaders

In general:

- What does a teacher leader look like?

II How are teacher leaders utilized in school districts?

Purpose of the Study

1. Offer information and recommendations for effectively utilizing teacher leadership

Provide a greater sense of voice for teachers who are active leaders

Add qualitative research to existing data, which is limited (Neumerski, 2013). 


\section{Significance of Study}

Contribute to educational leadership:

How teachers can serve as leaders Importance of the endeavor

Ways administrators can utilize these strengths Ways teachers can be encouraged as leaders Betterment of education

Notes: This study contributed to educational leadership in these ways. How teachers can serve as leaders within their districts How administrators can more effectively realize the potential of teacher leadership Teachers are the ultimate leaders, and better utilizing their talents for the betterment of education is both necessary and ideal, especially considering the landscape of education and the level of demand placed on administrators.

\section{Research Questions}

1) How are teacher leaders identified and utilized in school districts?

2) How are teacher leaders perceived by teachers and principals?

3) What types/characteristics of leadership are exhibited by teacher leaders? 


\section{Research Questions}

\section{4) How can schools more effectively identify and engage teacher leaders?}
5) How is teacher leadership encouraged by teachers and principals?

\section{6) How are elements of distributed leadership exhibited by principals and teachers?}

\section{Conceptual/Theoretical Framework}

\section{Distributed or Shared Leadership:}

Among scholars, viewed as helpful when examining the need for increased leadership in education.

Occurs when more than one person assumes a leadership role and shares administrative responsibility (Ross, et al., 2016).

Notes: Distributed and Shared Leadership are often used synonymously in the research as a conceptual framework to see how the concept relates to teachers as leaders within the grand scope and study of leadership.

Leadership not confined to formal leaders. 
Interactions under shared leadership:

"Collaborative, dynamic, mutually accountable. . This allows participants to share passion for their work, pursue a common vision, take advantage of expertise within the group, and optimize collaboration"

(Singh, 2012, p. 16).

\section{Conceptual/Theoretical Framework}

Interest in distributive leadership has been on the rise since the early 2000 s.

Gronn (2000) \& Spillane (2005):

A more holistic, fluid view of leadership as opposed to a collection of individual pursuits. 


\section{Design of the Study}

Overarching design is phenomenological:

"The lived experience or study of people's conscious experience of their life world" (Merriam \& Tisdell, 2016).

Qualitative study: General objective to learn more about the personal stories and experiences of teachers and principals (regarding teacher leadership)

\section{Design of the study: Setting}

Purposeful sample of 10 rural public secondary schools in the Central Regional Professional Development Center (RPDC) region in Missouri

Counties in this region include:

Bates, Benton, Carroll, Cass, Henry, Hickory, Johnson, Lafayette, Morgan, Pettis, Ray, St. Clair, Saline, 8 Vernon

This region is comprised of 71 school districts

Notes: The researcher selected secondary education because her teaching experience of 25 years has occurred in both middle school and high schools. 


\section{Design of the study: Participants}

Participants:

10 secondary (6-12) principals and 10 teacher leaders

Called superintendents for permission to conduct research

Obtained principal email addresses accordingly

Surveys via email sent to these and other principals in region to determine which individuals would be willing to participate and would be the best fit for the purpose of the study

Notes: Received written permission from each superintendent before contacting principals.

\section{Data Collection Pending IRB Approval}

\section{Personal Interviews:}

Face-to-face interviews were conducted with 10 principals and their selected teacher leaders (10), so 20 interviews in total

Interviews were semi-structured with a predetermined list of questions asked in a flexible order for best flow, researcher response, and emerging ideas (Merriam 8 Tisdell, 2016)

Audio recorded and transcribed 


\section{Data Analysis}

Interviews were transcribed, meticulously reviewed, and hand-coded to capture and record prominent themes (Creswell, 2014; Merriam 8 Tisdell, 2016).

Lean coding was used to create a list of codes in a document which was then formulated into a smaller grouping of themes (Creswell, 2014).

Notes were taken to augment description and discussion of themes

Selected from transcripts and organized according to respective themes

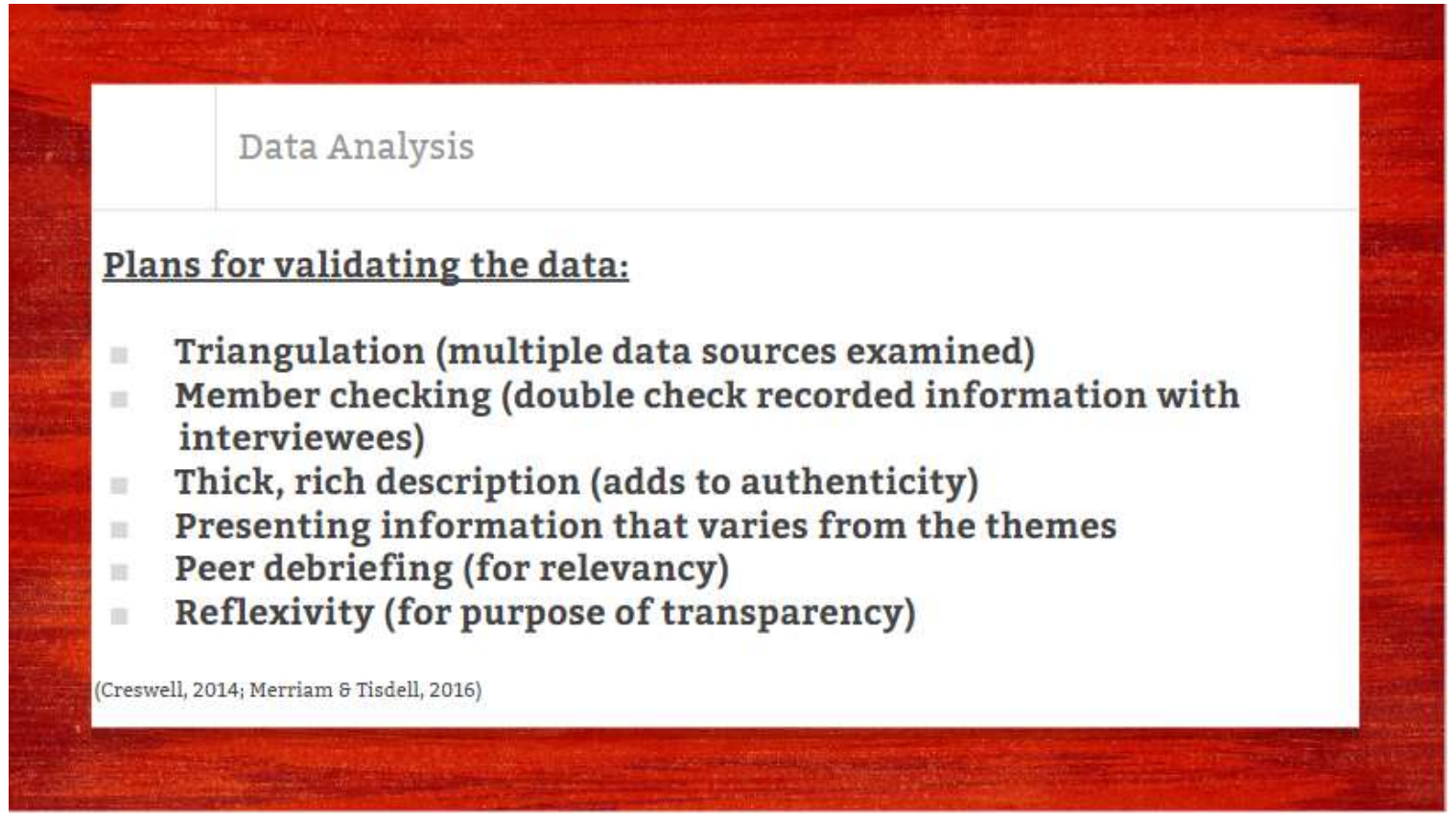




\section{Limitations}

Possible limitations:

Setting

Teachers and principals from rural schools in the Midwest

Design of the study

- Nature of interview questions

Participants themselves

Limited responses

Process of analysis

Researcher bias toward perspectives of teachers

Notes: Because of the geographic location of schools in the Central RPDC, the schools were predominantly rural.

Information may not be completely generalizable for other areas of the country or for urban schools.

Though the researcher is a teacher herself, she did her best to remain objective.

\section{Results: Themes that Emerged}

\section{Overarching Theme: "Let's Go."}

Notes: This overarching theme indicated a level of support as well as a strong sense of motivation and enthusiasm for teacher leadership in general and in having the initiative to get things done. 


\section{Results: "Let's Go."}

\section{"It's much like that teacher who comes out of school initially. .you realize when you are put in that position you have to step up. . . they are responsive; they are perceptive." \\ -Ms. Carroll, teacher}

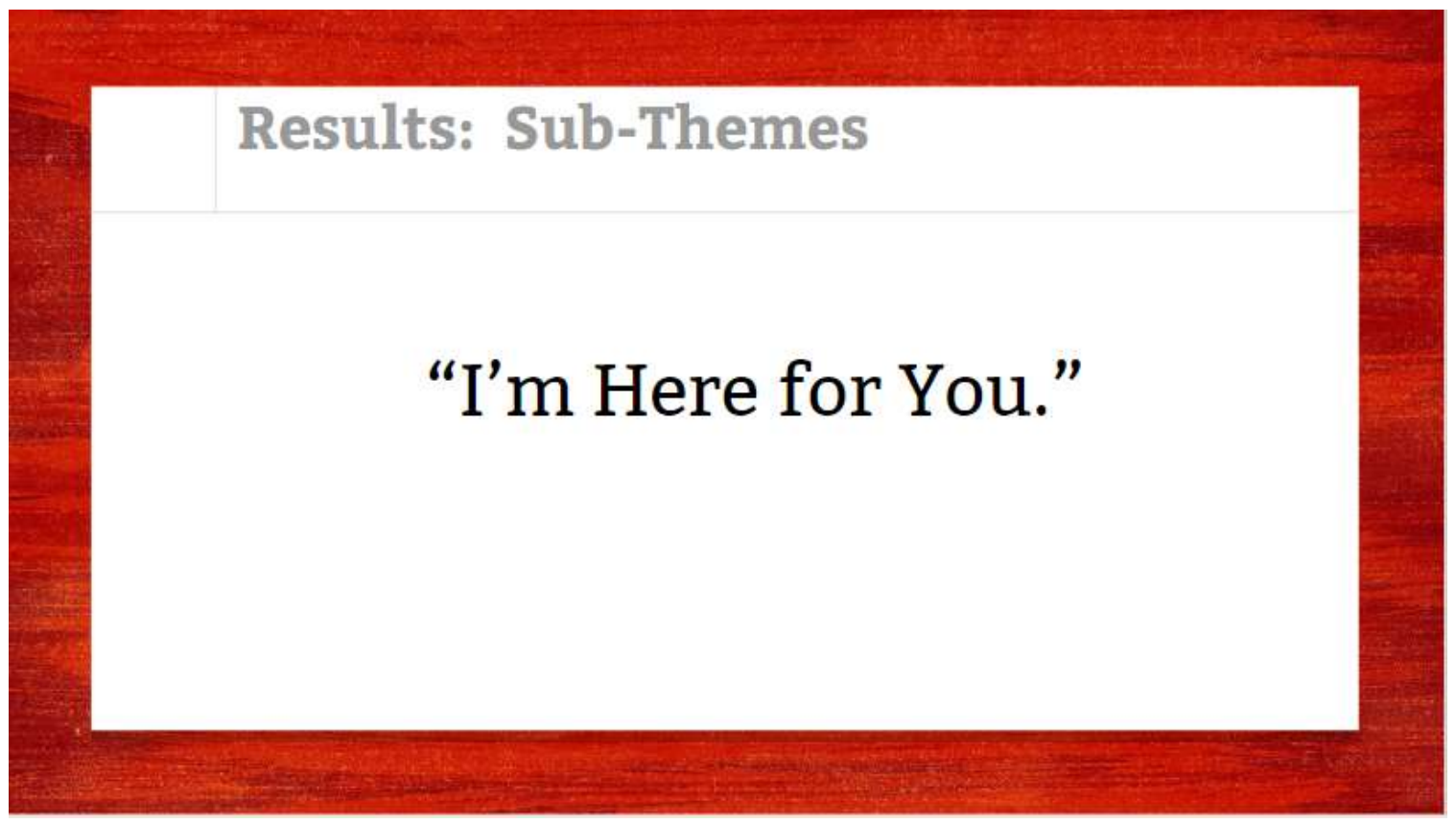

Notes: Along with being motivated to action, this theme emerged. It addresses the components of meaningful relationships, involvement, and devotion, which were often used in coordination within participant responses. 


\section{Results: "I'm Here for You."}

“...the willingness to be devoted. . to go all in. . our whole lives -- our pride, our identity...The other leaders are the people who also do that. They're just here all the time. The kids know it."

-Mr. Hawthorne, teacher

\section{Results: Sub-Themes}

\section{"You Can Count on Me."}

Notes: This sentiment happened in the context of teachers relying on other teachers, teachers relying on principals, principals relying on teachers, and students relying on teachers. 


\section{Results: "You Can Count on Me."}

"She's very good at brainstorming and she's really receptive of just sitting down with me and just talking shop. She's a huge resource and it really comes down to mostly that she sees what needs to get done and she just gets out there and does it without having to have a lot of direction." -Principal Chrisley

\section{Results: Sub-Themes}

\section{"Let's Go Together"}

Notes: This theme of working together for a common purpose emerged from participant responses. These teacher leaders are willing to work alongside others and solve problems. They understand relationships and social structures, as well as how to motivate others to work together in order to accomplish tasks and make decisions. 


\section{Results: "Let's Go Together."}

"She's good about bringing people together on the same page when we're not always like that ...just being able to talk and then agree to disagree and see other viewpoints."

-Ms. Williams, teacher

\section{Results: Sub-Themes}

\section{"Let's Keep our School Moving Forward"}

Notes: Ensuring that progress is an ongoing consideration and mission surfaced as a prominent theme. Teacher leaders were involved in multiple capacities with growth and change. A willingness to try new things and be innovative, as well as pushing and challenging both self and others are behaviors attributed to this theme. 


\section{Results: "Let's Keep our School Moving Forward."}

"Well, the ones that are evolving, you know, they continue to have an enthusiasm for improvement that drives them ... they are the ones that really kind of keep it going, so. . .I just try to find people who are passionate about those changes." -Principal Hall

\section{Implications for Practice}

* Hopefully, principals are encouraged by the possibilities of teacher leadership

* Teacher leaders in many schools are currently taking a step forward to assume more leadership roles. 


\section{Implications for Practice}

* Meaningful leadership opportunities increase teachers' levels of satisfaction and sense of ownership, and they feel more empowered in their profession of education.

\section{Implications for Practice}

* A greater emphasis should be placed on identifying, encouraging, and training potential teacher leaders to keep them engaged and challenged so that more will stay in the profession and others may experience their positive impact. 


\section{Click to add title}

\section{Discussion: \\ Q \& A}

\section{References}

Angelle, P. S. \& DeHart, C. A. (2011). Teacher perceptions of teacher leadership: Examining differences by experience, degree, and position. National Association of Secondary School Principals.NASSP Bulletin, 95(2), 141-160. Retrieved from

https:/login cyrano, ucmo edulogin? url=http:/ 3 earch, proquest com doctiew 892570986 ? accountid $=6143$

Buchen, I.H. (2000). The myth of school leadership. Education Week (19)38, 35-36. Retrieved from http:/ wwww edweek org ew articles/2000/05/31/38buchen.h $19 \mathrm{html}$

Cosenza, M. N. (2015). Defining teacher leadership: Affirming the teacher leader model standards. Issues in Teacher Education, 24(2), 79-99. Retrieved

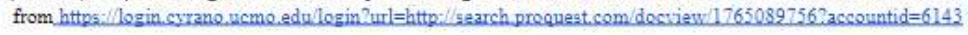

Crestvell, J. W. (2014), Research Design: Qualitative, Quantitative, and Mixed Methods Approaches (4th ed.). Thousand Oaks: SAGE.

Gilad, E. (2014). A management practicum programme in teacher education: From teacher to teacher-leader. International Jounal of Learning and Development, 4(3). Retrieved from www lexisnexis.com.cyrano.tucmo.edu

Gordon, S. P., Jacobs, J., \& Solis, R. (2014). Top 10 learning needs for teacher leaders. Journal of Staff Development, 35(6), 48-52. Retrieved from https:/login.cyrano.ucmo.edu login?url=http:/search. proquest.com/docview $/ 1628379519$ ? accountid=6143

Hanuscin, D.L., Cheng, Y., Rebellow, C., Sinha, S., \& Muslu, N. (2014). The affordances of blogging as a practice to support ninth-grade science teachers identify development as leaders. Journal of Teacher Education, 65(3), 207-222. Retrieved from http://journals.sagepub.com.cyrano.ucmo.edu:2048/doi full $10.1177 / 0022487113519475$ 


\section{References}

ukacs, K., P.H.D. (2015). 'For me, change is not a choice': The lived experience of a teacher change agent. American Secondary Education, 44(1), 38-49. Retrieved from

https://login.cyrano.ucmo.edu/login?url=http://search.proquest.com/docview/1746603926?accountid=6143

Mangin, M. \& Stoelinga, S. (2010). The future of instructional teacher leader roles. The Educational Forum, 74(1), 49-62. doi: $10.1080 / 00131720903389208$

Margolis, J. \& Deuel, A. (2009). Teacher Leaders in Action: Motivation, Morality, and Money. Leadership \& Policy In Schools, 8(3), 264-286. doi: $10.1080 / 15700760802416115$

Martin, B. (2007), Teacher leaders: Qualities and roles. The Journal for Quality and Participation, 30(4), 17-18. Retrieved from https:/login cyrano,ucmo.edu/login?url=http://search proquest.com/docview/219149826?accountid=6143

Merriam, S. B., \& Tisdell, E. J. (2016). Qualitative research: A guide to design and implementation (4th ed.). Jossey-Bass.

Mihans, R. (2009). Can teachers lead teachers? The Education Digest, 74(5), 22-25. Retrieved from https://login.cyrano,ucmo.edu/login?url=http://search.proquest.com/docview/218195759?accountid=6143

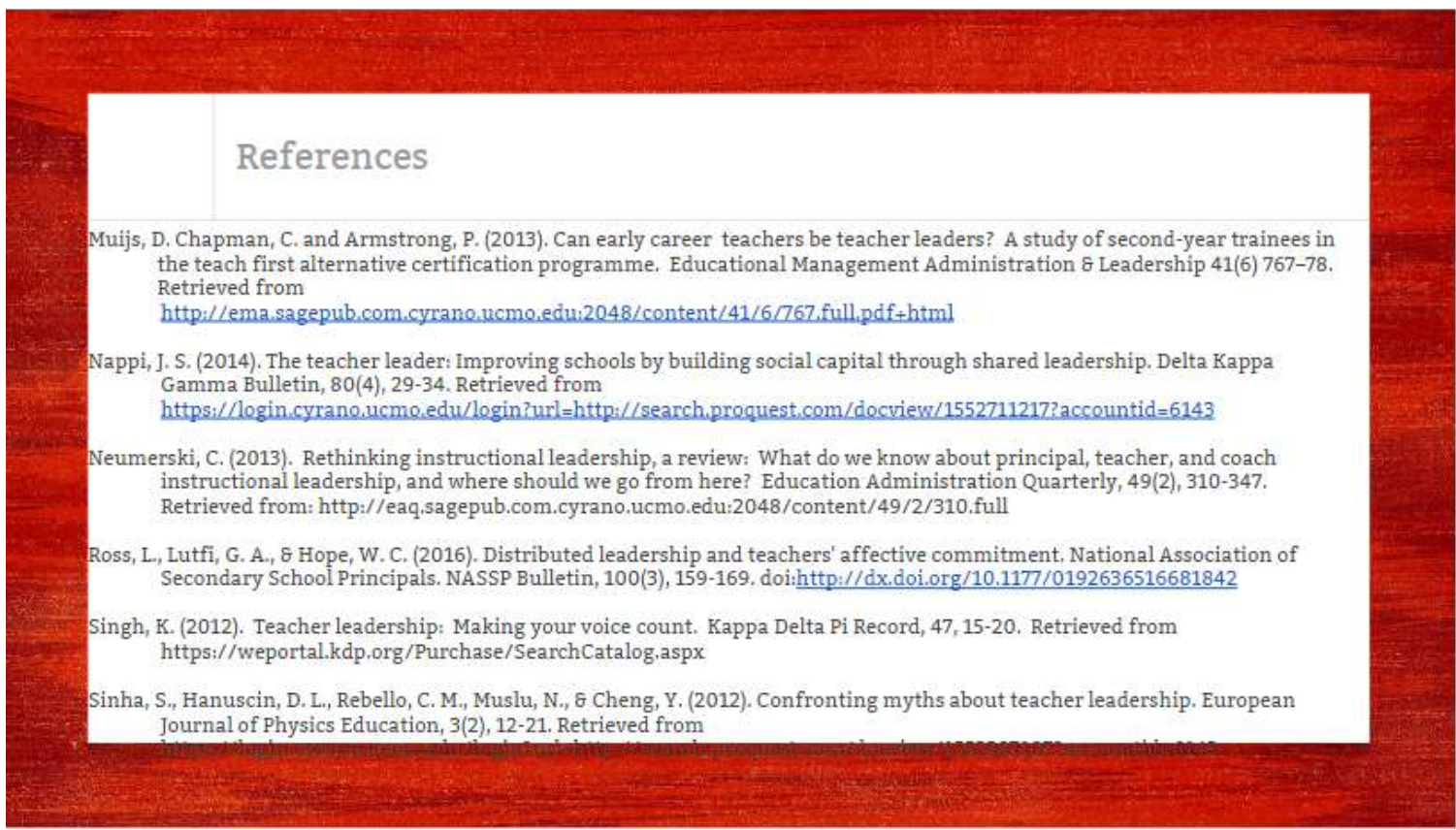




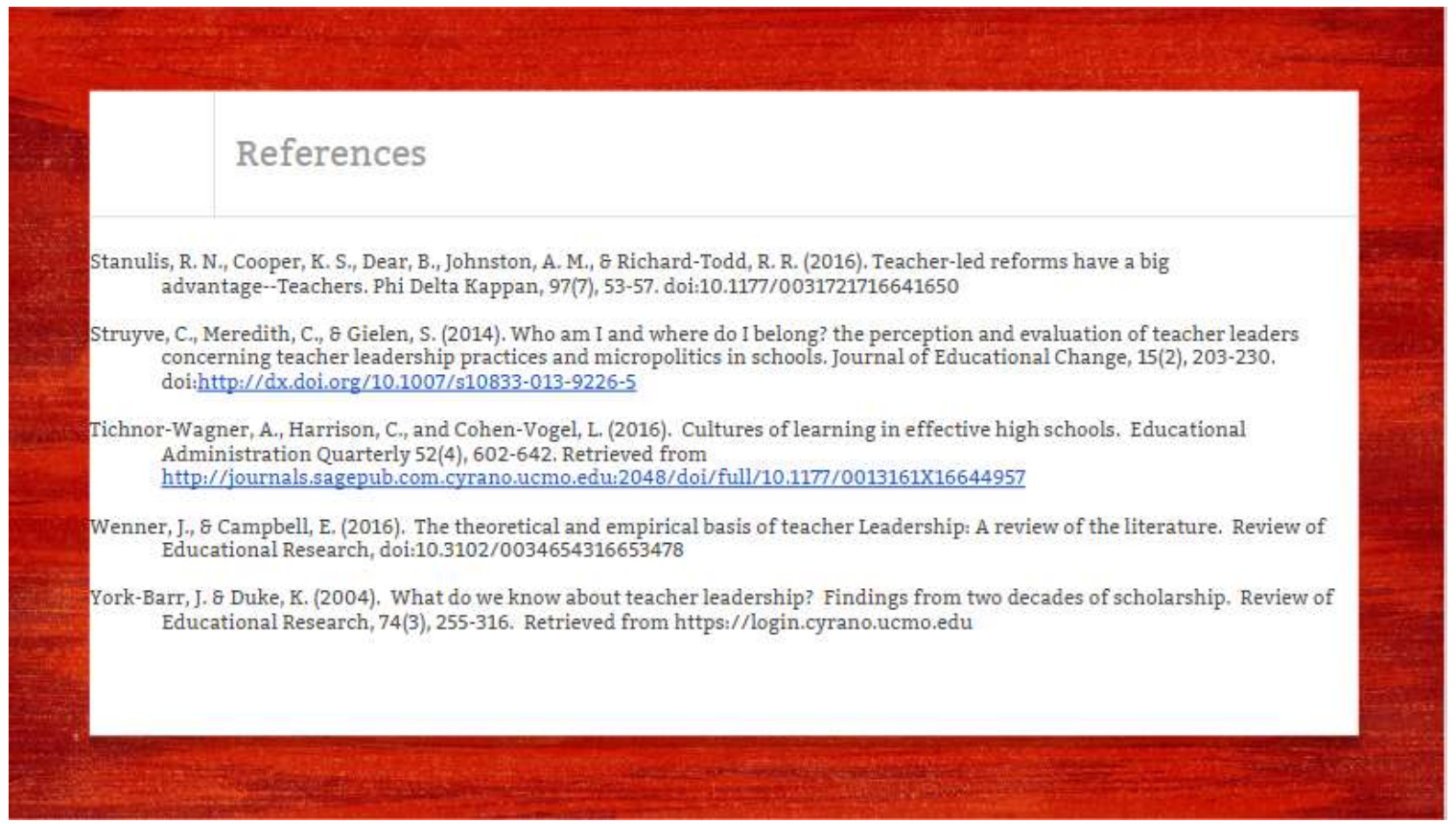




\section{Executive Summary}

Abstract: This qualitative study takes a closer look at teacher leadership. The purpose of this study was to gain knowledge and insight as well as add to existing research about teacher leaders. Research was conducted in the form of surveys and interviews. Ten principals and their ten selected teacher leaders were interviewed. The researcher discovered characteristics teacher leaders possess, how their respective principals view them as leaders, and how they view themselves as leaders. Several subthemes emerged from the overarching theme of "Let's go." Results from the study showed that teachers, when given opportunities for leadership roles, impact the school in many positive ways and employing distributive leadership helps alleviate pressure from principals.

\section{Key words: distributed leadership, teacher leaders}

Introduction: A pressing need and a sense of urgency has dominated the system of American education in terms of providing effective leadership and direction in a fastpaced global economy ever since the turn of the century. The need for teacher leadership is ever prevalent and significant. This is a compelling time, as teachers are rising above expectations and are taking on greater responsibilities, fulfilling increased roles, and affecting change both within and beyond their classrooms in meaningful ways (Cosenza, 2015; Edwards \& Hineuber, 2015; Lukacs, 2015; Nappi, 2014; Stanulis, Cooper, Dear, Johnston, \& Richard, 2016).

Conceptual Framework: When examining the need for increased teacher leadership in education, it is valuable to explore distributed leadership (often used synonymously or in conjunction with shared leadership) as a conceptual framework to see how this concept relates to teachers as leaders within the grand scope and study of 
leadership. Distributed leadership occurs when more than one person assumes a

leadership role and shares administrative responsibility (Gronn, 2000; Ross, Lutfi, \& Hope, 2016).

\section{Research Questions:}

1) How are teacher leaders identified and utilized in school districts?

2) How are teacher leaders perceived by teachers and principals?

3) What types/characteristics of leadership are exhibited by teacher leaders?

4) How can schools more effectively identify and engage teacher leaders?

5) How is teacher leadership encouraged by teachers and principals?

6) How are elements of distributed leadership exhibited by principals and teachers?

Design \& Data Collection: Qualitative study of ten secondary school principals (Central RPDC region) and their selected teacher leaders; principal surveys, teacher and principal interviews

Data Analysis: Discover emerging themes from participant responses; lean coding

\section{Findings:}

- 1 overarching theme of "Let's go."

- 4 subthemes:

-"I'm here for you."

-"You can count on me."

-"Let's go together."

-"Let's keep our school moving forward."

-"I'm here for you." 


\section{Implications:}

- Hopefully, principals are encouraged by the possibilities of teacher leadership and are diligent about identifying and utilizing them in their buildings.

- Teacher leaders in many schools are currently taking a step forward to assume more leadership roles. Perhaps more teachers will be inspired to become leaders. Professional development highlighting the importance of shared leadership would be beneficial.

- Meaningful leadership opportunities increase teachers' levels of satisfaction and sense of ownership, and they feel more empowered in their profession of education.

- A greater emphasis should be placed on identifying, encouraging, and training potential teacher leaders to keep them engaged and challenged so that more will stay in the profession and others may experience their positive impact.

\section{References}

Cosenza, M. N. (2015). Defining teacher leadership: Affirming the teacher leader model standards. Issues in Teacher Education, 24(2), 79-99. Retrieved from https://login.cyrano.ucmo.edu/login?url=http://search.proquest.com/docview/1765 $\underline{089756 ? \text { accountid }=6143}$

Edwards, B., \& Hinueber, J. (2015). Why teachers make good learning leaders. Journal of Staff Development, 36(5), 26-29,70. Retrieved from https://login.cyrano.ucmo.edu/login?url=http://search.proquest.com/docview/1732 $\underline{758487 ? \text { accountid }=6143}$

Gronn, P. (2000). Distributed properties: A new architecture for leadership. Educational Management \& Administration, 28(3), 317-338. doi:10.1177/0263211X000283006

Lukacs, K., P.H.D. (2015). 'For me, change is not a choice': The lived experience of a teacher change agent. American Secondary Education, 44(1), 38-49. Retrieved 
from

https://login.cyrano.ucmo.edu/login?url=http://search.proquest.com/docview/1746 603926? accountid=6143

Nappi, J. S. (2014). The teacher leader: Improving schools by building social capital through shared leadership. Delta Kappa Gamma Bulletin, 80(4), 29-34. Retrieved from

https://login.cyrano.ucmo.edu/login?url=http://search.proquest.com/docview/1552 $\underline{711217 ? \text { accountid }=6143}$

Stanulis, R. N., Cooper, K. S., Dear, B., Johnston, A. M., \& Richard-Todd, R. R. (2016). Teacher-led reforms have a big advantage--Teachers. Phi Delta Kappan, 97(7), 53-57. doi:10.1177/0031721716641650 


\section{SECTION FIVE}

CONTRIBUTION TO SCHOLARSHIP 


\begin{abstract}
This qualitative study takes a closer look at teacher leadership. The purpose of this study was to gain knowledge and insight as well as add to existing research about teacher leaders. Research was conducted in the form of surveys and interviews. Ten principals and their ten selected teacher leaders were interviewed. The researcher discovered characteristics teacher leaders possess, how their respective principals view them as leaders, and how they view themselves as leaders. Results from the study showed that teachers, when given opportunities for leadership roles, impact the school in many positive ways and employing distributive leadership helps alleviate pressure from principals.
\end{abstract}

Key words: distributive leadership, teacher leaders 


\section{Teacher Leaders: Rising to the Occasion}

\section{A Pressing Need for Leadership in Public Schools}

A pressing need and a sense of urgency has dominated the system of American education in terms of providing effective leadership and direction in a fast-paced global economy ever since the turn of the century. The demand is great to adequately prepare students for the future. Stresses and demands of the job have rendered a mass exodus of teachers leaving the field (Cosenza, 2015; Mihans, 2009). An estimated 40-50\% of teachers leave the field within the first five years (Womack-Wynne et al., 2011). This statistic is staggering and unfortunate.

The need for teacher leadership is ever prevalent and significant. Perhaps not unrelated, schools have been burdened with an immense amount of responsibility coupled with unprecedented levels of accountability mandates (Mangin \& Stoelinga, 2010; Mihans, 2009). The significance of leadership within the context of the public school seems to be at an all-time high. Traditionally, leadership within schools was reserved primarily for the principal, but this paradigm has shifted, and it is in the process of a transformation (Cosenza, 2015; Lukacs, 2015; Ross, Lutfi, \& Hope, 2016; Singh, 2012). This is a compelling time, as teachers are rising above expectations and are taking on greater responsibilities, fulfilling increased roles, and affecting change both within and beyond their classrooms in meaningful ways (Cosenza, 2015; Edwards \& Hineuber, 2015; Lukacs, 2015; Nappi, 2014; Stanulis, Cooper, Dear, Johnston, \& Richard, 2016). For these reasons, the time was right to examine teacher leadership, as a grand challenge exists to tap into one of the greatest resources of all time in relation to leadership - a challenge to include teachers as leaders in further capacities beyond the classroom. 


\section{Definition of a Teacher Leader}

It is important to note that a range of definitions for "teacher leader" exists. Green and Kent (2016) depicted teacher leaders as having " " something extra' that sets them apart from just being a good teacher” (p.1). Qualities and descriptions of such leaders include strong work ethic and persona; teacher leadership going beyond classroom walls; involved in policy and/or decision making at some level; and working toward improvement and change for students, their schools, or for the whole school organization; to determine, transcend a school wide vision for instruction (Cooper et al., 2015; Green \& Kent, 2016; Wenner \& Campbell, 2016).

\section{Purpose of the Study}

Although the presence of research is extensive in the realm of administrative leadership, very little research has been conducted on the topic of teachers as leaders (Angelle \& Dehart, 2011; Cosenza, 2015; Lukacs, 2015; Neumerski, 2016; Singh, 2012). The purpose of this study was to gain knowledge and insight as well as add to existing research about teacher leaders. What are the perceived qualities of a true teacher leader? What are the actual qualities of a teacher leader? The researcher conducted research in the form of a qualitative study to discover from principals examples of teachers they would identify as leaders. After identifying these individuals, the researcher discovered characteristics teacher leaders possess, how their respective principals view them as leaders, and how they view themselves as leaders.

\section{Participants of the Study}

A total of twelve principals were surveyed, with ten qualifying for the study. Ten secondary principals and their selected teacher leaders (one leader per principal) from 
seven different districts were interviewed from the Central RPDC region in Missouri. These schools and the towns in which they resided varied in size, but due to the geographical location of the Central RPDC region, the schools were rural communities. Both principals and teachers had different ranges of experience in education, from two years to twenty-eight years.

\section{Research Questions}

The research questions that guided this study were:

1) How are teacher leaders identified and utilized in school districts?

2) How are teacher leaders perceived by teachers and principals?

3) What types/characteristics of leadership are exhibited by teacher leaders?

4) How can schools more effectively identify and engage teacher leaders?

5) How is teacher leadership encouraged by teachers and principals?

6) How are elements of distributed leadership exhibited by principals and teachers?

\section{Conceptual Framework: Distributed Leadership}

When examining the need for increased teacher leadership in education, it is valuable to explore distributed leadership (often used synonymously or in conjunction with shared leadership) as a conceptual framework to see how this concept relates to teachers as leaders within the grand scope and study of leadership. Distributed leadership occurs when more than one person assumes a leadership role and shares administrative responsibility (Ross et al., 2016). Bush (2013) contends that "leadership may arise anywhere in the organization and is not confined to formal leaders" ( $p$ 543). Gronn (2000) presented distributive leadership as a conceptualization of leadership by which the construct could be viewed more holistically and fluidly instead of a collection of 
individual pursuits. Spillane (2005) stated that other leaders besides principals have a role in school leadership.

*Note: Pseudonyms were used in place of actual names.

\section{Results of the Study}

\section{Answering of Research Questions One and Two}

The following questions were answered as a result of collecting and analyzing responses representing multiple perspectives from both teachers and principals in the Central RPDC region in the state of Missouri. These responses were captured in the form of principal surveys as well as principal and teacher interviews. Teachers interviewed were specifically selected as teacher leaders on the part of the principals.

\section{Research Question One}

Research question one of the study was "How are teacher leaders identified and utilized in school districts?" Teacher leaders are identified in various ways. Often times, these individuals rise to the top on their own or inevitably show themselves in many different scenarios, which Northouse (2016) termed "emergent leadership". Principal Warren indicated,

The way I identify them is basically how they model for other teachers, their willingness to help others, their constant drive to get better in the classroom, and the fact that they're always looking at ways to make their environment better and instruction better. So that's how I identify them and usually it doesn't take a whole lot of prodding. They will rise to the top, and you'll find them pretty darn quick. So those are quick and easies for me to figure out who they are.

Principal Hall shared the following about his selected teacher leader: 
Well, I know a couple like Ms. Carroll, for example, would be one, that, you know, she is an art teacher. She impressed us obviously to hire her. She was a very impressive person. But just in her desire to improve herself is what really drove me to her and so we started working together on the leadership team. Other times, the principal will see leadership traits or potential in certain teachers and will question or encourage them to take on leadership roles. Elizabeth indicated that this was the case with her own leadership as a teacher:

I think for me the biggest thing has been being given some opportunities and being put in some positions where I'm a little uncomfortable. And so, like, I did not want to present to the faculty this fall, and so my principal says you're standing in front of a group of 80 people, most of which are older than you and have way more experience, but to put me out there in that position made me like, well, holy cow, I can do this, and so afterwards, encouraging people, whether it went great or whether it went poorly, and so I presented, and before I had even gotten back to my classroom, Mr. Munstermann had sent me an email that said, “Hey, great job presenting today. That's a tough thing to do. Keep it up. .." So I think giving people an opportunity to do something and then encouraging them to keep trying it or that it was good when they did it.

These people are the activators and initiators. They step up and take an active role. They are highly motivated, take on challenges, are problem solvers, and actively seek out opportunities to improve themselves and the school, all for the greater good. They lead by example, and they serve students, teachers, and administrative personnel as an invaluable resource. Principal Hyde mentioned such characteristics: 
A variety of things, but honestly I think it just goes back to the initiative piece. I think the real teacher leaders are the ones that are just constantly almost to the point of bugging I think at times just because they see that there is a need here and they want to move forward and they want to make a change, you know. And it may not be a drastic change, it just may be a tweak, it may be a minor thing, but they just see a need and they would like to attack it. And they know how to get people on board to kind of make those changes.

Alexandria discussed her own motivation and responsibility as a teacher leader:

I would say yes, with the getting things done. I'm kind of the one that will start the email, like here's what's coming up next month and what we need to get going, just the proactiveness of it because I don't want to wait until the last minute. And then we have to throw something together. I don't know. That's just how I am. Luckily, they all are okay with it. . .I am the department head for ELA for the school, so we are taking on some curriculum writing, so I've had to go to some summer trainings and then tomorrow during our early out is the day when ELA is meeting to kind of vertically reassess and make sure we're all on the same page of what grade level is doing what. So but again, I think it just takes just the motivation and the organization to put that together and that's just where I think I kind of thrive on that kind of stuff.

Teacher leaders are involved in a plethora of different roles and contribute in many different areas; they are multi-talented and multi-faceted individuals. They collaborate well with others, and those with whom they are directly involved, such as students, teachers, and principals, and these people gravitate towards them. Principal Quick 
contended, "Those are more just the teachers that other teachers want to follow. . . and they are teacher leaders by students ... kid magnets. . . students are flocking to them and want to be around them and yet still learn ...” They act as a voice for both teachers and principals, often serving as a powerful liaison for both. As principal, Garrison spoke of this meaningful role of teacher leaders:

But you see a lot of things differently when you move into administration because you're just viewing all the systems at the same time. And so things look so different. And sometimes you want to impress that on people, but it's hard for you to impress that because you are different. And so, to have that person who is the teacher leader, that person can step in and basically, like I said, they can take the message and they can translate it. And when I say translate, I mean it's nothing different. It's nothing amazing, it's nothing new. It's just they trust that perspective of that person because they're respected as the leader.

Teacher leaders are receptive to input and feedback from the principal and other teachers, and they reciprocate this interaction by providing valuable input to both parties in return. They are instrumental in carrying out the articulated mission and in leading the school in a desired direction. Principal Finnegan articulated,

I'd say the practices of our school were developed by our teacher leaders through the years. I think it's sustainable leadership ... my philosophies are throughout this school, but the teacher leaders are the ones who are leading us in the direction that we need to be going.

These are ways they show themselves or are identified by principals. 
Teacher leaders are utilized in so many different ways and fulfill vital roles. One such role is that of mentor, both to students and teachers. These mentors go above and beyond, and they are on a personal mission to help others. They are instructional leaders and effective strategists. Principal Warren discussed:

I think it starts with a mentoring process, like a teacher who demonstrates by action and by voice, and then other people think, hey, it's okay if I do that. We do have way different teaching experiences in the middle school and levels of ability; however, we are always willing to share - I don't want to say a spotlight - but share a lead in something.

Ms. Carpenter, a selected teacher leader, spoke of these teacher mentors:

We have a couple of teachers here in the middle school that they have their master's degrees in specialized math and so they're taking on leadership, going out to other classrooms and kind of being an instructional coach so we have a couple of those here in the middle school. . .Again, I think it's just doing it. Going out and doing it and taking the leap of faith, a step ahead of everybody else just to show that it can be done. I think that's one of the things is just, you lead by example so, if you want to get it...if you want other people to do it, you have to do it first so that they will follow.

Another important way these teachers are utilized is through professional development. They not only lead professional development, but they also seek out professional development, both for themselves and others as well as for the district. These pursuits are often self-driven. Principal Chrisley elaborated on the topic of professional development and teacher leaders: 
Confident but willing to follow as much as they are to lead. They're a good team player. So they listen to other people's opinions... not a know-it- all because they have to be respected by others, so it's got to be somebody with a good work ethic and someone who values professional development and learning and wants to grow as an educator so we need them to be a model to other teachers.

Ms. Weston, a teacher leader, provided information about her own involvement with leading professional development:

Well, my colleague next door. She's been here for two years, but she has been teaching for fifteen years. She is my co-chair for professional development, and the way that works is that we lead all of the professional development for the district. So we are the ones finding it, we are the ones teaching it, and we're the ones doing it. We're spending a lot of extra time together .. .for the betterment, I mean, yes ourselves, but the betterment of forty teachers that we have here. We're trying to figure out K-12, so we're even trying to figure out elementary, like what it is they want and what they need and all of that so that tends to be a little time consuming.

Principals also rely on these teacher leaders to relay important messages, to rally support and teacher buy-in for upcoming initiatives, and to help solve important problems. Principal Garrison shared his experience with relying on teacher leaders for such matters: And so we try really hard to encourage people if they want to take on things, absolutely, but I really try hard not to just craft a committee, you know what I mean ... You know, and then, within that meeting, like I said, you carry that in who do you give the research to? You give that research to the teacher leaders. 
You know what I mean? I mean, if you want me to do the research that's fine, but I still need an advocate. So you go and you give it to them and so that way you don't overburden them but you still empower them ... Right now we're basically moving into a competency-based grading system over the course of like the next seven years, so we started it in the elementary and it's just going to grow to us. And so a lot of what we're doing right now is basically preparing teachers to understand the shifts in how you approach education. It's in these moments where, I mean, I definitely am going to need to use more of them than I am even right now. I mean, because we're talking about major shifts in thinking and for some teachers who use it as a personal affront to using what I'm doing is bad, I think that what we've been doing hasn't changed in a long time.

Several principals indicated a need for teachers to help with such messages being relayed to staff, explaining that the role of teacher leader makes this transition smoother.

\section{Research Question Two}

Research Question Two of this study was "How are teacher leaders perceived by teachers and principals?" Both teachers and principals perceive these teacher leaders as having initiative or an innate desire to lead. Ms. Carpenter, teacher leader, expressed this desire:

You know, at one point we had done RTI (Response to Intervention) and I was on the team for that, so figuring out what interventions would work best and how do we go about doing that and so I think part of it is that, just stepping forward and taking that initiative, and then like I said, anytime there's something new just jumping in and doing it and then being able to lead others in the process. 
Principal Hyde spoke of this initiative as well:

A lot of it just comes from initiative. I think being a leader you just have to have a little bit of self-motivation to want to do what's best for whatever the situation is, what's best for kids, best for the program, best for the district, whatever it is. There has to be a little bit of initiation there or motivation on the teacher's part...to take the next step and maybe put themselves out in front and take the initiative to make a difference.

These teacher leaders are passionate about their work; they have a strong sense of pride and a vested interest for the culture of the school and the community in which it resides. Mr. Hawthorne, teacher leader, illuminated this idea:

And you just want your school to be the best. You want the experience for the kids to be the best. I don't know whether you'd call that dedication or whatever, but I think that's probably the primary. Every single one of us has something to offer. The English teacher here who was a former student of mine, you know, she came here and was like, we don't do speech. Why don't we do speech? When she was here she did speech, but the person that did speech retired and then nobody did speech, so now we don't do speech anymore. I didn't even really realize it...so why don't we do speech anymore? That teacher left. I guess. So nobody did it. So now she does it. She's got a young lady going to regional speech championships. That just happened. Somebody just came in and made it happen, changed some kid's life. So that's really what I feel is the clearest answer I can give is who's going to be dedicated to put in those hours. 
These teacher leaders are perceived as having integrity. Ms. Marigold reflected upon her own teaching profession:

Always have integrity. Make sure that you understand that it's not about collecting accolades; it's about staying true to what we started this profession for, why we got into this to help kids and it doesn't matter what award you can put under your belt or what titles you can add to it - it still goes back to the core of you wanted kids to have those aha moments like you did when you were a learner. And so I think remembering that, remembering that we are a team, and that even if you are lucky enough or are honored enough to be put into a position where you have a title, learning that it's just that and it only carries as much value as you put into it.

They are conscientious, and this is often seen through their high expectations and a constant desire for betterment and growth.

These teacher leaders are highly knowledgeable in their content. They are intelligent critical thinkers and teaching strategy specialists, and they are viewed as experts in their fields. They are often described as "informal instructional coaches," and they collaborate with others. They are often sought out for practical advice. Principal Chrisley declared:

I have a couple of other teachers who have gone and gotten their specialist degrees in math instruction which is kind of a new thing that's just started in the last couple of years, so they're among the first ones at UCM to earn that degree. So they've been ones, then again, with tons of encouragement, and they support one another. I think that's been kind of a neat part of that is that they work really 
closely together and they push each other to be better and better all the time. So they're the ones that are always willing when I go to them and say I want you to present what I saw you doing at the faculty meeting. They're always willing to jump in and help other teachers. We worked it out this year that each one of them can have an extra hour-it's different hours, different quarters, but they each have an extra hour when they can go down to the elementary and kind of do some instructional coaching - informally. Nothing super formal, but that's been really well received, so they just kind of hung their hat on a passion and we just keep encouraging it and they keep growing and growing.

These teacher leaders have meaningful interactions with others. They are described as caring and compassionate. They not only help others, but they are known for their level of effort and engagement. Principal Hyde voiced:

But again it's kind of that desire inside to want to see a change and see something positive for our kids. Some of my other teacher leaders, like Cara ... but her desire to always want to do what's best and try to evaluate what's going on is probably stronger so than my other staff members. You've got to have a sense of compassion and caring because if you didn't care, then obviously you're not wanting to see things get better; you're okay with the status quo. Then again, just going back to a little bit of initiative and being able to grab the reins and go with it.

Teacher leaders follow through with their words, and they work alongside both teachers and principals to see that things come to fruition. Ms. Robbins, a teacher leader, indicated: 
There's a little area of expertise. And they're comfortable doing it and they're willing to help, so they're helpers, they're leaders, they've got expertise in that area, and some are just the people that never say no. They will help you no matter what. I don't know what you're doing, I don't understand a word of it, but I will help you.

They are listeners and learners themselves. They are results-driven and detail-oriented. They are problem solvers and mediators. Williams, a teacher leader, shared about a coworker:

She is a good public relations person as far as let's try to see the other side of things, which I don't always do. Sometimes it's my way is the only way I think, so she brings the other balance of that of let's look at the other perspective and consider that. She's good about kind of bringing people together on the same page when we're not always like that.

Another perception of teacher leaders is they are innovative. They are unafraid to try new things and take risks, often stepping outside their comfort zone. These new undertakings are researched and well-planned - the aim is to revise and improve teaching strategies and to enhance learning. In both success and failure, reflection is seen as a compulsory part of this process in order for these teacher leaders to evolve and advance. Principal Munstermann spoke of his teacher leaders:

You know, I think that it's so hard to answer, but I think you see teachers who are very innovative, not afraid to try things, who question and ask others what works, what doesn't work, how can I get better? And I think people are naturally drawn to those inquisitive people. And I think that just kind of sets that whole thing in 
motion. And we see that, when something new comes down the pike, who do teachers gravitate towards? She's relatively young in the game, but they flock her direction right now. I think that it's almost courage to try something and to fail and then I think the reflection piece is huge on that, whether it's internal, or just bouncing things off.

\section{Summary}

Results from the qualitative study showed that the practice of distributive leadership in schools has the power to render some truly positive benefits. Principals sharing leadership with their trusted teacher leaders empowers and enriches the team concept and dynamic. By sharing leadership roles and responsibility, principals recognize the value in the collective, and in the words of a teacher leader, "With multiple brains more things can be considered to achieve greatness." This increased sense of ownership benefits both the school and the individual. In the words of a principal: "Not only are you empowering teacher leaders, but you are empowering the concept of the team where everyone is valued and we're real with one another." 


\section{References}

Angelle, P. S. \& DeHart, C. A. (2011). Teacher perceptions of teacher leadership: Examining differences by experience, degree, and position. National Association of Secondary School Principals.NASSP Bulletin, 95(2), 141-160. Retrieved from https://login.cyrano.ucmo.edu/login?url=http://search.proquest.com/docview/8925 $\underline{70986 ? \text { accountid }=6143}$

Bush, T. (2013). Distributed leadership: The model of choice in the $21^{\text {st }}$ century. Educational Management Administration \& Leadership, 41(5), 543-544. Retrieved from doi: $10.1177 / 1741143213489497$

Cooper, K.S., Stanulis, R.N., Brondyk, S.K., Hamilton, E.R., Macaluso, M, \& Meier, J.A. (2015). The teacher leadership process: Attempting change within embedded systems. Journal of Educational Change, 17, 85-113. Retrieved from https://search-proquest-com.cyrano.ucmo.edu/docview/1761627184?pqorigsite=summon

Cosenza, M. N. (2015). Defining teacher leadership: Affirming the teacher leader model standards. Issues in Teacher Education, 24(2), 79-99. Retrieved from https://login.cyrano.ucmo.edu/login?url=http://search.proquest.com/docview/1765 089756?accountid $=6143$

Edwards, B., \& Hinueber, J. (2015). Why teachers make good learning leaders. Journal of Staff Development, 36(5), 26-29,70. Retrieved from https://login.cyrano.ucmo.edu/login?url=http://search.proquest.com/docview/1732 $\underline{758487 ? \text { accountid }=6143}$ 
Green, A. M. \& Kent, A. M. (2016). Developing science and mathematics teacher leaders through a math, science and technology initiative. The Professional Educator, 40(1) Retrieved from https://search-proquest-com.cyrano.ucmo.edu/docview/1805720343?pqorigsite $=$ summon

Gronn, P. (2000). Distributed properties: A new architecture for leadership. Educational Management \& Administration, 28(3), 317-338.

doi:10.1177/0263211X000283006

Lukacs, K., P.H.D. (2015). 'For me, change is not a choice': The lived experience of a teacher change agent. American Secondary Education, 44(1), 38-49. Retrieved from https://login.cyrano.ucmo.edu/login?url=http://search.proquest.com/docview/1746 $\underline{603926}$ ? accountid $=6143$

Mihans, R. (2009). Can teachers lead teachers? The Education Digest, 74(5), 22-25. Retrieved from https://login.cyrano.ucmo.edu/login?url=http://search.proquest.com/docview/2181 95759? accountid $=6143$

Nappi, J. S. (2014). The teacher leader: Improving schools by building social capital through shared leadership. Delta Kappa Gamma Bulletin, 80(4), 29-34. Retrieved from https://login.cyrano.ucmo.edu/login?url=http://search.proquest.com/docview/1552 $\underline{711217 ? \text { accountid }=6143}$ 
Neumerski, C. (2013). Rethinking instructional leadership, a review: What do we know about principal, teacher, and coach instructional leadership, and where should we go from here? Education Administration Quarterly, 49(2), 310-347. Retrieved from: http://eaq.sagepub.com.cyrano.ucmo.edu:2048/content/49/2/310.full

Singh, K. (2012). Teacher leadership: Making your voice count. Kappa Delta Pi Record, 47, 15-20. Retrieved from https://weportal.kdp.org/Purchase/SearchCatalog.aspx

Spillane, J. P. (2005). Distributed leadership. The Educational Forum, 69(2), 143-150. doi:10.1080/00131720508984678

Stanulis, R. N., Cooper, K. S., Dear, B., Johnston, A. M., \& Richard-Todd, R. R. (2016). Teacher-led reforms have a big advantage--Teachers. Phi Delta Kappan, 97(7), 53-57. doi:10.1177/0031721716641650

Wenner, J., \& Campbell, E. (2016). The theoretical and empirical basis of teacher Leadership: A review of the literature. Review of Educational Research, doi:10.3102/0034654316653478

Womack-Wynne, C., Dees, E., Leech, D., LaPlant, J, Brockmeier, L., Gibson, N. (2011). Teachers' perceptions of the first-year experience and mentoring. International Journal of Educational Leadership Preparation 6 (4). Retrieved from http://files.eric.edu.gov/fulltext/EJ974328.pdf 


\section{SECTION SIX}

\section{SCHOLARLY PRACTITIONER REFLECTION}




\section{How has the dissertation influenced your practice as an educational leader?}

The dissertation process has greatly influenced my practice as an educational leader. To begin, I have been affected on a daily basis by how I view interactions and communication. I have been more cognizant of leadership around me and have felt a greater sense of responsibility in terms of being an effective leader. I feel more aware and in tune with the process and dynamics of leadership. It seems I am continuously analyzing people in leadership roles, taking in the decisions they make, how people are treated, responses from those individuals, and effects of that leadership.

As a classroom teacher, I believe wholeheartedly that the dissertation process has made me a better educator. I have always been conscientious and diligent and have taken my career seriously, but I genuinely believe I have and still am changing in some fundamental ways. The interviews I conducted of both principals and teachers as well as conversations I have had with superintendents have left a positive, lasting impression on me. I am more aware of the big picture. I no longer feel a sense of isolation, but instead, I feel like I am a part of something greater and I can make a difference no matter what role I am in. I feel as though I belong a spectrum of educators and for the most part, intentions of the others involved are pure and worthwhile. I feel a greater sense of responsibility to my students to fill my role as a teacher by consistently giving my best effort, even when I am tired, frustrated, or begin to feel as though my efforts really are not that important. My faith in education as well as my passion for the profession have been rejuvenated, and for that I am grateful.

The dissertation process has also made me stronger as a mentor. As I lead and assist new teachers, whether it is a teacher new to the profession or new to my district, I feel better equipped to teach and influence them in more positive, productive ways. With 
my heightened sense of awareness and boost of confidence, I feel smarter and more adequately prepared for the profession. I have a more comprehensive view of education. I attribute this to building relationships and garnering support from my cohort at UCM, reading scholarly, current literature, conducting research with other stakeholders in the field, and periodically reflecting upon these endeavors. I feel as though I have more practical advice and wisdom to offer newer educators that transcends what I knew before the experience. In looking to the future, I have a renewed sense of purpose. I have a more positive outlook, and I believe because of the experiences from the dissertation process, I will be more diligent about seeking out opportunities to continually grow and develop myself as well as to more intentionally help others.

I believe the experience of the past several months and even three years will also affect my role as a leader in my department at work. Though I do not currently hold a formal role as leader such as department head or instructional coach, I am indeed a leader in my department, and I have an even stronger resolve about that. I have interviewed both principals and teachers who have provided numerous examples of teacher leaders who were integral to the functionality and effectiveness of their department, their district, and beyond. These people were encouraging, diligent, influential, intentional leaders of integrity who were known for problem solving, caring, and inspiring others. They were the go-to people in the department who thrived on helping others at every level and at any capacity they could, yet they remained humble. Their presence and influence was felt in huge ways. These findings are enlightening and inspiring to me. Consequently, I wish to be more like those teacher leaders. I feel a certain sense of comradery with them. I hope 
that I can be a more positive team player and leader within my current department, or in any department to which I am a contributor in the future.

The dissertation process has given me a greater sense of admiration and a deeper respect for individuals in leadership positions. Because of the process of learning more about leadership through the coursework of the program, conducting research and case studies with peers on the subject of leadership, and then personally meeting and interviewing practitioners in the field, I have a better understanding of those people and what they do on a daily basis, including challenges, involvement with stakeholders, and the call for making a positive difference in education. Administrators juggle so much often with so little, and their need for support and encouragement cannot be underestimated. The need for quality individuals to step up and be leaders themselves to share in this responsibility and to make a difference is ever present.

As a result of my experiences from the dissertation and the program, I feel less restrained and more empowered to be that person who steps up. In the past I have felt left out or even offended when those in positions of leadership did not ask for my advice or input, especially when I had first-hand knowledge or experience about an issue or a topic that could benefit them. However, I have learned some important lessons. This is not the mindset to have, as it benefits no one. First, administrators or others in leadership may not even be aware that one of their faculty members has this knowledge, even if it seems obvious. Second, these people may believe teachers are not willing to share or assist, and often times the expectation is that the leaders will naturally rise to the top and provide input or assistance if they are willing to. Teachers should always try to share this information or knowledge when it may benefit others, even when they are not sure if it 
will be used or implemented. Teachers who were active leaders in the field often times disregard such feelings of limitation and try anyway, making a big difference in the end. Not all input and ideas are used, yet such notions and concepts seem to always be considered. Because of these observations and reflections, I will more actively seek out opportunities to confer with and assist administrators, especially when I feel like I have something worthwhile to offer for the benefit of the cause, whereas before I may have had more of a tendency to hold back.

As I look to the future, I hold a different view than when I started this program. I feel more secure about myself and in considering any future positions I may hold as leader. I believe I am better prepared. The need for effective leaders is great, and I have seen several examples of such leadership in action. When one holds a position of leadership, so much is at stake and there are so many layers to consider. A clear, wellconceived vision is essential in order for everyone in the organization to be working on the same page with the same goals and fundamental principles, and clear, consistent communication at all levels is a must for the establishment to function smoothly. I have both first-hand experience as well as experiences shared by participants in my research to extend this understanding. Gathering input from all stakeholders on a continual basis is a key component to effective leadership. In situations where this process was prioritized, the teachers practicing under those leaders expressed feelings of greater satisfaction and fulfillment in their profession, as did that respective leader. Also, the functionality of the organization itself was more streamlined. There was a greater sense of morale when this was the case, and feelings of trust and respect were more frequently declared. An acute sense of responsibility to do what was right culminated in trust. This trust and mutual 
respect was cited by both principal and teacher. The principal would entrust the teacher with more opportunities in meaningful leadership, and the teacher would trust in the principal for continued support and encouragement in taking on such endeavors.

No matter what position of leadership I may find myself in in the future, whether this be in secondary or higher education or in a completely different organization, I now more fully understand and appreciate the importance of solid leadership - how to be a better, more effective leader, the interworking of relationships, and the potential results of this leadership because of the experience of the doctoral program and the dissertation process.

\section{How has the dissertation process influenced you as a scholar?}

The dissertation process has undoubtedly influenced me as a scholar. Since I was young and in elementary, I have always loved school and learning. I have always enjoyed the thrill of learning new concepts, embracing challenges, and taking it to the next level. Even in difficulty, even when learning and growing as an individual, even when it became frustrating, I have always pushed through to that next assignment, certification, or degree. At the time it may not have always felt like enjoyment, but when looking at the big picture, the sense of satisfaction and reward I feel as a scholar is difficult to put into words. The dissertation process has certainly elevated and magnified my educational experience to a whole new level!

In a more practical sense, the experience has increased my knowledge base and awareness of research. I feel caught up and current not only from the standpoint of leadership, but also in terms of how to research appropriately in the most expedited manner to render the best results. Though I teach research to my students, my pedagogy 
has been more focused on specialized databases as those that our school subscribes to. I am certainly more confident with accessing information through a major library, such as that of a university. There was definitely a learning curve with this experience. I had not been a student for fifteen years, and so much has changed. The mere concept of peerreviewed scholarly articles published within the last five years was certainly a new concept for me. Some guidance and practice was definitely necessary, and it took a while to feel confident about the research process. At first the idea was overwhelming. Patience in this process as well as showing myself some grace was important. As a result of this experience, I feel less daunted and more proficient about conducting research myself as well as teaching others about it. I am even excited about sharing my knowledge with others. I feel empowered because of this process.

Along with researching scholarly articles, I can definitely better understand and appreciate a multi-faceted, layered approach to research, such as the process the dissertation offered. I more fully comprehend aspects and purposes for both quantitative and qualitative research, after having experience with each type of method during the program. As my method for research for the dissertation was qualitative, I have additional insight and appreciation for the value of seeking out individuals for personal response and experience. The significance of collecting data first hand from these participants was eye-opening for me, and it enhanced my experience and understanding as a scholar. Although there were moments when I had my doubts about finding all of the participants I needed in a timely manner, and also moments of frustration and feeling vulnerable knowing I was completely dependent upon these individuals to respond and follow through, after some patience and persistence, everything worked out in the end. 
The process was not easy. Some individuals agreed to help on the phone but then did not follow through. I have a greater respect and sense of appreciation for researchers who collect data first hand in the field. As a scholar, the end result is truly rewarding, as I take away a sense of ownership, empowerment, and pride from the experience.

These proud, self-assured moments are humbling, however. Seeing evidence of solid leadership and the knowledge and work behind it and realizing that I still have much to learn through experience is overwhelming at times. My hope is that I will always hold this knowledge in perspective and use it to stay grounded and focused as a scholar and as a leader. This is the best way, I feel, to evolve and to grow.

Another area of growth for me as a scholar is that of time management. I have learned that much can be accomplished in a short period of time with some strong selfdiscipline and diligence. Even when a task, problem, or project seems mammoth and its undertaking seems impossible, setting small manageable goals and methodical planning with a clear sense of direction are important. Revising the master plan and redrawing the mental map when things go awry or fail is also necessary at times. On several occasions, challenges arose. I had to revise time frames when specific tasks were not completed. Efficient time management became increasingly important. When things did not go as I had originally planned, I had to shift my mental focus, remain positive, and focus my efforts on a different component or section of the dissertation in order to make the best use of time.

Yet another take away is the power of multiple minds working together for a common purpose. To this end, I learned a lot about letting go of control for this process to happen, which was certainly a moment of growth for me. Moments when this was the 
clearest were when working with IRB, my professor, and my committee, primarily because I was so accustomed to working individually, especially in regard to scholarly work. With IRB, I can better understand and appreciate the desired end: to ensure soundminded research which protects subjects and oversees research to make sure that it is ethical and valid. Keeping this in mind made it easier to move forward, even in stages of revision or amendment. With my committee, though it was daunting to propose my research proposal to knowledgeable professors, I was able to put feelings of intimidation behind me while at the same time relinquishing control, take the constructive criticism and suggestions with poise, and willingly accept the feedback and help from my committee. Even though I felt intimidated in the beginning, the overall experience was enlightening and inspiring. Finally, my professor helped me to grow as a scholar in meaningful ways.

Getting to know and to collaborate with my professor Dr. Sandy Hutchinson has truly been a rewarding, uplifting experience. She has not only influenced me, but she has inspired me as a scholar and as a person. She has been an excellent model for me as a teacher and as a leader, and her impression and influence on me will be lasting. On several occasions, both during the program and during the dissertation process, I have contemplated and reflected upon effective leadership and teaching, and she always comes to mind. I have been inspired by her knowledge, compassion, positivity, willingness to help, dedication, and commitment. She has been a constant source of encouragement, a voice of reason, and an abundant wellspring of knowledge and ideas. Any moment I began to feel the slightest concern or worry, I knew without a doubt that she would be there for me, encouraging me. I would leave her energized and rejuvenated, feeling as 
though I could accomplish anything. She has taught me that it is acceptable and even a positive thing to ask for and receive help from others. The rewards reaped from that experience are even bigger, and sharing that with others even transcends the experience. I hope that I am able to remember this experience and change for the better because of her influence.

The dissertation process has been transformative for me as a scholar. I recognize the importance of continual learning throughout one's life, and I feel as though not only has my knowledge been extended, but my mind has been expanded. I feel as though I have been challenged, my limits have been tested, and I have been pushed as a person, excelling to a higher degree. I feel that this was not only important for me, but also healthy. I set this goal many years ago as an undergraduate. I made an intentional promise to myself to achieve this level of accomplishment in education - this dream. It is surreal and even at times difficult to believe, but the journey has been well worth it. 


\section{References}

Akert, N. \& Martin, B. N. (2012). The role of teacher leaders in school improvement through the perceptions of principals and teachers. International Journal of Education, 4(4), 284-299.

American public education: An origin story. Education News. (2013). Retrieved from http://www.educationnews.org/education-policy-and-politics/american-publiceducation-an-origin-story/

Angelle, P. S. \& DeHart, C. A. (2011). Teacher perceptions of teacher leadership: Examining differences by experience, degree, and position. National Association of Secondary School Principals.NASSP Bulletin, 95(2), 141-160. Retrieved from https://login.cyrano.ucmo.edu/login?url=http://search.proquest.com/docview/8925 $\underline{70986 ? \text { accountid }=6143}$

Angelle, P. S. \& Teague, G. M. (2014). Teacher leadership and collective efficacy: Teacher perceptions in three U.S. school districts. Journal of Educational Administration, 52 (6), 738-753. Retrieved from https://search-proquest-com.cyrano.ucmo.edu/docview/1633968074?pqorigsite $=$ summon

Bolman, L.G. \& Deal, T.E. (2013). Reframing organizations: Artistry, choice, and leadership ( $5^{\text {th }}$ ed). San Francisco, CA: Jossey-Bass.

Browne-Ferrigno (2016). Developing and Empowering Leaders for Collective School Leadership. Journal of Research on Leadership Education, 11(2), 151-157. Retrieved from http://journals.sagepub.com/doi/abs/10.1177/1942775116658820 
Buchen, I.H. (2000). The myth of school leadership. Education Week (19)38, 35-36. Retrieved from http://www.edweek.org/ew/articles/2000/05/31/38buchen.h19.html

Bush, T. (2013). Distributed leadership: The model of choice in the $21^{\text {st }}$ century. Educational Management Administration \& Leadership, 41(5), 543-544. Retrieved from doi: $10.1177 / 1741143213489497$

Caffarella, R.S. \& Daffron, S. R. (2013). Planning programs for adult learners: A practical guide ( $3^{\text {rd }}$ ed). San Francisco: Jossey-Bass

Cooper, K.S., Stanulis, R.N., Brondyk, S.K., Hamilton, E.R., Macaluso, M, \& Meier, J.A. (2015). The teacher leadership process: Attempting change within embedded systems. Journal of Educational Change, 17, 85-113. Retrieved from https://search-proquest-com.cyrano.ucmo.edu/docview/1761627184?pqorigsite=summon

Cosenza, M. N. (2015). Defining teacher leadership: Affirming the teacher leader model standards. Issues in Teacher Education, 24(2), 79-99. Retrieved from https://login.cyrano.ucmo.edu/login?url=http://search.proquest.com/docview/1765 $\underline{089756}$ ? accountid=6143

Creswell, J. W. (2014). Research design: Qualitative, quantitative, and mixed methods approaches (4th ed.). Thousand Oaks: SAGE.

DeMatthews, D. (2014). Principal and teacher collaboration: An exploration of distributed leadership in professional learning communities. International Journal 
of Educational Leadership and Management 2(2), 176-206. Doi:

10.4471/ijelm.2014.16

Devos, G., Tuytens, M., \& Hulpia, H. (2014). Teachers' organizational commitment: Examining the mediating effects of distributed leadership. American Journal of Education, 120(2), 205-231. doi:10.1086/674370

DuFour, R. (2004). What is a professional learning community? Educational Leadership, 61(8), 6-11. Retrieved from http://www.ascd.org/publications/educationalleadership/may04/vol61/num08/What-Is-a-Professional-LearningCommunity\%C2\%A2.aspx

Edwards, B., \& Hinueber, J. (2015). Why teachers make good learning leaders. Journal of Staff Development, 36(5), 26-29,70. Retrieved from https://login.cyrano.ucmo.edu/login?url=http://search.proquest.com/docview/1732 $\underline{758487 ? \text { accountid }=6143}$

Fink, A. (2017). How to conduct surveys: A step-by-step guide. Los Angeles, CA: Sage

Foster, E., \& Wiseman, L. (2015). Multiplying is more than math - it's also good management. Phi Delta Kappan, 96(7), 47-52. doi:10.1177/0031721715579040

Gilad, E. (2014). A management practicum programme in teacher education: From teacher to teacher-leader. International Journal of Learning and Development, 4(3). Retrieved from www.lexisnexis.com.cyrano.ucmo.edu

Gill, S. J. (2010). Developing a learning culture in nonprofit organizations. Los Angeles: Sage 
Goddard, R., Goddard, Y., Kim, E. S., \& Miller, R. (2015). A theoretical and empirical analysis of the roles of instructional leadership, teacher collaboration, and collective efficacy beliefs in support of student learning. American Journal of Education, 12, 501-530.

Goleman, D. (1996). What makes a leader? In HBR's 10 must reads: On leadership, (121). Boston: Harvard Business School Publishing Corporation.

Gordon, S. P., Jacobs, J., \& Solis, R. (2014). Top 10 learning needs for teacher leaders. Journal of Staff Development, 35(6), 48-52. Retrieved from https://login.cyrano.ucmo.edu/login?url=http://search.proquest.com/docview/1628 $\underline{379519 ? \text { accountid }=6143}$

Green, A. M. \& Kent, A. M. (2016). Developing science and mathematics teacher leaders through a math, science and technology initiative. The Professional Educator, 40(1) Retrieved from https://search-proquest-com.cyrano.ucmo.edu/docview/1805720343?pqorigsite $=$ summon

Gronn, P. (2000). Distributed properties: A new architecture for leadership. Educational Management \& Administration, 28(3), 317-338. doi:10.1177/0263211X000283006

Gronn, P. (2008). The future of distributed leadership. Journal of Educational Administration, 46(2), 141-158. doi:10.1108/09578230810863235 
Hanuscin, D.L., Cheng, Y., Rebellow, C., Sinha, S., \& Muslu, N. (2014). The affordances of blogging as a practice to support ninth-grade science teachers' identify development as leaders. Journal of Teacher Education, 65(3), 207-222. Retrieved from

http://journals.sagepub.com.cyrano.ucmo.edu:2048/doi/full/10.1177/0022487113 $\underline{519475}$

Harrison, C. \& Killion, J. (2007). Ten roles for teacher leaders. Educational Leadership, 65(1), 74-77

Kahneman, Lovallo, \& Sibony (2011). Before you make that big decision. In HBR's 10 must reads: On making smart decisions, (21-40). Boston: Harvard Business School Publishing Corporation.

Kezar, Adrianna J., Ed.; Carducci, Rozana, Ed.; Contreras-McGavin, Melissa, Ed. (2006). Rethinking the "L" word in higher education. ASHE Higher Education Report, 31 (6), 15-29. Retrieved from https://search-proquestcom.cyrano.ucmo.edu/docview/216588326/fulltextPDF/A21BDC3BF16742D4P Q/1?accountid=6143

Levi, D. (2014). Group dynamics for teams ( $4^{\text {th }}$ ed.). Thousand Oaks, CA: Sage. Library of Congress (1997). “One-Room Schoolhouse.” Retrieved from http://www.americaslibrary.gov/es/ny/es_ny_school_1.html

Lukacs, K., P.H.D. (2015). 'For me, change is not a choice': The lived experience of a teacher change agent. American Secondary Education, 44(1), 38-49. Retrieved from 
https://login.cyrano.ucmo.edu/login?url=http://search.proquest.com/docview/1746

\section{$\underline{603926 ? \text { accountid }=6143}$}

Luft, J. A., Dubois, S. L., Kaufmann, J., and Plank, L. (2016). Science teacher leadership: Learning from a three-year leadership program. Science Educator, 25(1), 1-8. Retrieved from https://search-proquest-com.cyrano.ucmo.edu/docview/1812542161?pqorigsite=summon

Mangin, M. \& Stoelinga, S. (2010). The future of instructional teacher leader roles. The Educational Forum, 74(1), 49-62.

doi: $10.1080 / 00131720903389208$

Margolis, J. \& Deuel, A. (2009). Teacher leaders in action: Motivation, morality, and money. Leadership \& Policy In Schools, 8(3), 264-286.

doi:10.1080/15700760802416115

Margolis, J. and Doring, A. (2012). The fundamental dilemma of teacher leaderfacilitated professional development: Do as I (kind of) say, not as I (sort of) do. Education Administration Quarterly, 52(4), 859-882. Retrieved from http://journals.sagepub.com.cyrano.ucmo.edu:2048/doi/pdf/10.1177/0013161X12 452563

Martin, B. (2007). Teacher leaders: Qualities and roles. The Journal for Quality and Participation, 30(4), 17-18. Retrieved from https://login.cyrano.ucmo.edu/login?url=http://search.proquest.com/docview/2191 $\underline{49826 ? \text { accountid }=6143}$ 
Merriam, S. B., \& Tisdell, E. J. (2016). Qualitative research: A guide to design and implementation (4th ed.). Jossey-Bass.

Mihans, R. (2009). Can teachers lead teachers? The Education Digest, 74(5), 22-25. Retrieved from https://login.cyrano.ucmo.edu/login?url=http://search.proquest.com/docview/2181 95759? accountid=6143

Miles, K.M. (2016). Effectively integrating teacher leadership into the system. The Education Digest, 81 (9), 17-22. Retrieved from https://www.erstrategies.org/news

Muijs, D. Chapman, C. and Armstrong, P. (2013). Can early career teachers be teacher leaders? A study of second-year trainees in the teach first alternative certification programme. Educational Management Administration \& Leadership 41(6) 76778. Retrieved from http://ema.sagepub.com.cyrano.ucmo.edu:2048/content/41/6/767.full.pdf+html

Nappi, J. S. (2014). The teacher leader: Improving schools by building social capital through shared leadership. Delta Kappa Gamma Bulletin, 80(4), 29-34. Retrieved from https://login.cyrano.ucmo.edu/login?url=http://search.proquest.com/docview/1552 $\underline{711217 ? \text { accountid }=6143}$

National Center for Education Statistics (NCES). "Rural education in America." Retrieved from https://nces.ed.gov/surveys/ruraled/definitions.asp 
Neumerski, C. (2013). Rethinking instructional leadership, a review: What do we know about principal, teacher, and coach instructional leadership, and where should we go from here? Education Administration Quarterly, 49(2), 310-347. Retrieved from: http://eaq.sagepub.com.cyrano.ucmo.edu:2048/content/49/2/310.full

Nicholson, J., Capitelli, S., Richert, A.E., Bauer, A., \& Bonetti, S. (2016). The affordances of using a teacher leadership network to support leadership development: Creative collaborative thinking spaces to strengthen teachers' skills in facilitating productive evidence-informed conversations. Teacher Education Quarterly. Retrieved from https://search-proquest-com.cyrano.ucmo.edu/docview/1850121388?pqorigsite $=$ summon

Nolan, B. \& Palazzolo (2011). New teacher perceptions of the "teacher leader" movement. NASSP Bulletin 95(4), 302-318. doi: 10.1177/0192636511428372

Northouse, P. G. (2013). Leadership: Theory and practice (7th ed). Thousand Oaks: Sage.

Petersen, S., \& Conway, J. M. (2011). I can see clearly now: Teacher leaders invoking reaction. International Journal of Pedagogies \& Learning, 6(3), 175-186.

Retrieved from https://login.cyrano.ucmo.edu/login?url=http://search.proquest.com/docview/1022 $\underline{032564 \text { ? accountid }=6143}$

Reeves, D. B. (2006). Of hubs, bridges, and networks. Educational Leadership, 63(8), 32-37. 
Ross, L., Lutfi, G. A., \& Hope, W. C. (2016). Distributed leadership and teachers' affective commitment. National Association of Secondary School Principals. NASSP Bulletin, 100(3), 159-169. doi:http://dx.doi.org/10.1177/0192636516681842

Sass, E. (2018). American educational history: A hypertext timeline. Retrieved from http://www.eds-resources.com/educationhistorytimeline.html

Seidman, I. (2013). Interviewing as qualitative research: A guide for researchers in education \& the social sciences ( $4^{\text {th }}$ ed.). NY: Teachers College Press

Singh, K. (2012). Teacher leadership: Making your voice count. Kappa Delta Pi Record, 47, 15-20. Retrieved from https://weportal.kdp.org/Purchase/SearchCatalog.aspx

Sinha, S., Hanuscin, D. L., Rebello, C. M., Muslu, N., \& Cheng, Y. (2012). Confronting myths about teacher leadership. European Journal of Physics Education, 3(2), 12 21. Retrieved from https://login.cyrano.ucmo.edu/login?url=http://search.proquest.com/docview/1553 $\underline{387107 ? \text { accountid }=6143}$

Social organization of schools - American public schools in context, the purposes of schooling, defining organizations and bureaurocracies (2017). Retrieved from http://education.stateuniversity.com/pages/2430/Social-OrganizationSchools.html

Spillane, J., \& Kim, C. (2012). An exploratory analysis of formal school leaders' positioning in instructional advice and information networks in elementary schools. American Journal of Education, 119(1), 73-102. doi:10.1086/667755 
Spillane, J. P. (2005). Distributed leadership. The Educational Forum, 69(2), 143-150. doi:10.1080/00131720508984678

Stanulis, R. N., Cooper, K. S., Dear, B., Johnston, A. M., \& Richard-Todd, R. R. (2016). Teacher-led reforms have a big advantage--Teachers. Phi Delta Kappan, 97(7), 53-57. doi:10.1177/0031721716641650

Stegall, D., \& Linton, J. (2012). Teachers in the lead: A district's approach to shared leadership. The Phi Delta Kappan, 93(7), 62-65. doi:10.1177/003172171209300715

Sterrett, W. \& Irizarry, E. (2015). Beyond "autopsy data": Bolstering teacher leadership, morale, and school improvement. Journal of Cases in Educational Leadership, 18(1), 3-13. doi: 10.1177/1555458914551828

Struyve, C., Meredith, C., \& Gielen, S. (2014). Who am I and where do I belong? the perception and evaluation of teacher leaders concerning teacher leadership practices and micropolitics in schools. Journal of Educational Change, 15(2), 203-230. doi:http://dx.doi.org/10.1007/s10833-013-9226-5

Tichnor-Wagner, A., Harrison, C., and Cohen-Vogel, L. (2016). Cultures of learning in effective high schools. Educational Administration Quarterly 52(4), 602-642. Retrieved from http://journals.sagepub.com.cyrano.ucmo.edu:2048/doi/full/10.1177/0013161X16 644957

Wenner, J., \& Campbell, E. (2016). The theoretical and empirical basis of teacher leadership: A review of the literature. Review of Educational Research, doi:10.3102/0034654316653478 
Womack-Wynne, C., Dees, E., Leech, D., LaPlant, J, Brockmeier, L., Gibson, N. (2011). Teachers' perceptions of the first-year experience and mentoring. International Journal of Educational Leadership Preparation 6 (4). Retrieved from http://files.eric.edu.gov/fulltext/EJ974328.pdf

Woods, P. A., \& Gronn, P. (2009). Nurturing democracy: The contribution of distributed leadership to a democratic organizational landscape. Educational Management Administration \& Leadership, 37(4), 430-451. doi:10.1177/1741143209334597

York-Barr, J. \& Duke, K. (2004). What do we know about teacher leadership? Findings from two decades of scholarship. Review of Educational Research, 74(3), 255316. Retrieved from https://login.cyrano.ucmo.edu 


\section{Appendix A}

\section{Demographic Survey for Principals}

1. In which school district are you currently employed?

2. Is this a junior high or high school?

3. Which grade levels does your building encompass?

4. In what ways to do you encourage teacher leadership?

5. What are the characteristics of an effective leader?

6. What are the characteristics of a teacher leader?

7. Is there a certain teacher that comes to mind as a predominant leader (who does not already have a formal role as leader)? Yes or no.

8. In what ways does the teacher that came to mind as a leader show leadership? 


\section{Appendix B}

\section{Principal Interview Questions}

1) How do you identify teacher leaders in your building? (RQ1) (RQ3)

2) What comes to your mind first when I say "teacher leaders"? Please tell me about these teacher leaders. What are their characteristics? Do you have particular stories that come to mind? (RQ2) (RQ3)

3) Considering the teacher leader you have named, why did you select him/her specifically? What impact have they had on the school? What impact had they had beyond the classroom? (RQ1) (RQ2) (RQ3) (RQ5) (RQ6)

4) Please talk to me about some of the best ways you have utilized teacher leaders. (RQ1) (RQ2) (RQ4) (RQ5) (RQ6)

5) How do teacher leaders evolve in your building. What impact have these individuals had on the school? What does this leadership look like outside the classroom? What impact have they had on the building, district, and beyond? (RQ1) (RQ2) (RQ3)(RQ5)(RQ6)

6) How do you encourage or provide opportunities for teachers in leadership roles? (RQ4) (RQ5)(RQ6)

7) What advice would you give other administrators about discovering and encouraging teacher leaders in their respective buildings? (RQ4) (RQ5) 


\section{Appendix C}

\section{Teacher Interview Questions}

1) Why do you think your principal named you as a prominent teacher leader? (RQ1) (RQ2) (RQ3)(RQ5)

2) What are some of the most important ways you have been a leader? Talk to me about how you are a leader beyond the classroom. (RQ2) (RQ3) (RQ6)

3) How have your leadership skills been utilized by the administration? (RQ1) (RQ4) (RQ5) (RQ6)

4) Please describe for me other teachers in leadership roles who do not have a formal leadership title. How are they leaders beyond the classroom? What characteristics do they have? (RQ1) (RQ2) (RQ3)

5) What advice would you give teachers who are potential leaders? (RQ4) (RQ5)

6) Does the administration support teacher leadership endeavors? Please tell me what this looks like. (RQ1) (RQ5) (RQ6)

7) How can schools more effectively identify and engage teacher leaders? (RQ4) 


\title{
APPENDIX D \\ WAIVER OF DOCUMENTATION OF CONSENT
}

\author{
INVESTIGATOR'S NAME: JULIE A. CARTER \\ ProjeCT \#
}

\section{STUDY TITLE: A QUALITATIVE STUDY OF TEACHER LEADERSHIP IN SECONDARY SCHOOLS IN CENTRAL MISSOURI}

1. I would like to ask you to participate in a study that involves research.

2. Participation is voluntary and your decision not to participate will not involve any penalty or loss of benefits. You may withdraw from the study at any time without any penalty or loss of benefits.

3. This study involves being asked questions about your experiences related to the education profession as a principal in regard to teacher leadership. You will be asked to participate in a survey via email in google forms. The survey will consist of 8 open-response questions. This survey will take approximately 15 minutes to complete. You can stop participating at any time without penalty.

4. The purpose of this research is to investigate the shared experiences of principals and teacher leaders.

5. I am asking approximately 20 subjects to participate in this study.

6. The researcher may withdraw you from the study at any time after explaining to you the reason for withdrawal.

7. While in the study, the risks are similar to the risks of everyday life discussions.

8. If you agree to take part in this study, your participation may benefit teacher leadership programs by increasing the understanding of teacher leaders in the profession of education. You may also enjoy sharing your experiences.

9. There are no alternative procedures for this study.

10. If you choose to participate, surveys will be emailed to you and results will be confidential. You will be assigned a pseudonym as an additional safeguard in your confidentiality. The researcher will maintain confidentiality in all individual surveys. Information produced by this study will be stored on the researcher's password protected computer and hard copies will be stored in the investigator's file cabinet in a locked office. Participants will only be identified by a pseudonym. Information contained in your records may not be given to anyone unaffiliated with the study in a form that could identify you without your written consent, except as required by law.

11. There is no compensation given to you for participation in this study.

12. If you have any questions regarding your rights as a participant in this research and/or concerns about the study, or if you feel under any pressure to enroll or to continue to participate in this study, you may contact the University of Missouri Institutional Review Board (which is a group of people who review the research studies to protect participants' rights) at (573) 882-3181.

13. If you have any questions or concerns, you may contact Julie Carter, primary investigator, at jcarter@ odessar7.net. Additionally, you may ask questions or voice concerns to Sandy Hutchinson, Dissertation Chair at hutchinson@ucmo.edu.

14. You may print a copy of this script for your records. 


\title{
Appendix E
}

\section{Consent Form}

\section{Individual Interview Consent Form CONSENT Form to PARTICIPATE IN A RESEARCH STUdy}

\author{
Researcher's Name(s): Julie A. Carter
}

Project Number: 2009793C

Project Title: A qualitative study of teacher leadership in secondary schools in central Missouri

\section{INTRODUCTION}

You are being asked to participate in a research study. This research is being conducted to investigate the experiences of principals and teachers in education, specifically in regard to teacher leadership. When you are invited to participate in research, you have the right to be informed about the study procedures so that you can decide whether you want to consent to participation. This form may contain words that you do not know. Please ask the researcher to explain any words or information that you do not understand. You have the right to know what you will be asked to do so that you can decide whether or not to be in the study. Your participation is voluntary. You do not have to be in the study if you do not want to be. You may refuse to be in the study and nothing will happen. If you do not want to continue to be in the study, you may stop at any time without penalty or loss of benefits to which you are otherwise entitled.

\section{WHY IS THIS STUDY BEING DONE?}

The purpose of this research is to investigate the shared experiences of principals and teachers in education in an effort to better understand teacher leaders.

\section{WHAT AM I BEING ASKED TO DO?}

This research involves being asked questions about your experiences related to being a principal or a teacher in secondary education. You will be asked to participate in an individual interview. During the individual interview, I may take notes and I will audio record the discussions.

\section{HOW LONG WILL I BE IN THE STUDY?}

This study will take approximately 45 minutes for an individual interview in which you will take part. You can stop participating at any time without penalty. 


\section{WHAT ARE THE BENEFITS OF BEING IN THE STUDY?}

Your participation may benefit education by increasing the educators' understanding of teacher leaders in secondary schools. You may also enjoy sharing your experiences.

\section{WHAT ARE THE RISKS OF BEING IN THE STUDY?}

The risks to this study are similar to the risks of everyday life discussions.

\section{WHAT ARE THE COSTS OF BEING IN THE STUDY?}

There is no cost to you.

\section{CONFIDENTIALITY}

The interviews will take place behind closed doors to maintain confidentiality. You will be assigned a pseudonym as an additional safeguard in your confidentiality. The researcher will maintain confidentiality in all individual interviews.

Information produced by this study will be stored on the researcher's password protected computer and hard copies will be stored in the investigator's file cabinet in a locked office. Participants will only be identified by a pseudonym. Information contained in your records may not be given to anyone unaffiliated with the study in a form that could identify you without your written consent, except as required by law.

\section{WILL I BE COMPENSATED FOR PARTICIPATING IN THE STUDY?}

You will receive no payment for taking part in this study.

\section{WHAT ARE MY RIGHTS AS A PARTICIPANT?}

Participation in this study is voluntary. You are not required to participate in this study. You will also be informed of any new information discovered during the course of this study that might influence your health, welfare, or willingness to be in this study.

\section{WHO DO I CONTACT IF I HAVE QUESTIONS, CONCERNS, OR COMPLAINTS?}

Please contact Sandy Hutchinson, Dissertation Chair, at hutchinson@ucmo.edu if you have questions about the research. Additionally, you may ask questions and voice concerns or complaints to the researcher.

\section{WHOM DO I CALL IF I HAVE QUESTIONS OR PROBLEMS?}

If you have any questions regarding your rights as a participant in this research and/or concerns about the study, or if you feel under any pressure to enroll or to continue to 
participate in this study, you may contact the University of Missouri Campus Institutional Review Board (which is a group of people who review the research studies to protect participants' rights) at (573) 882-9585 or umcresearchcirb@missouri.edu.

You may ask more questions about the study at any time. For questions about the study, contact Julie Carter at 660-238-7357 or jcarter@ odessar7.net and Sandy Hutchinson 660543-4341 or hutchinson@ucmo.edu.

A copy of this Informed Consent form will be given to you before you participate in the research.

\section{SIGNATURES}

I have read this consent form and my questions have been answered. My participation means that I do want to be in the study. I know that I can remove myself from the study at any time without any problems.

Subject-

Date 
Appendix F

\section{Qualitative Findings}

Table 1: Teacher Pseudonyms, Subject, and Grade Level, Alphabetical

\begin{tabular}{|l|}
\hline Teacher Pseudonym/Subject \& Grade Level Taught \\
\hline Denise Carroll, MS/HS Art \\
\hline Kylie Carpenter, MS Lang. Arts \& Social Studies \\
\hline Zackary Hawthorne, HS Social Studies \\
\hline Marie Marigold, HS English \\
\hline Cindy Robbins, MS Science \\
\hline Elizabeth Spalding, HS Science \\
\hline Alexandria Stephens, MS Lang. Arts \\
\hline Anne Wheatley, HS English \& Tech \\
\hline Cara Weston, MS/HS Social Studies \\
\hline Bonnie Williams, HS Health \& PE \\
\hline
\end{tabular}

Table 2: Principal Pseudonyms and Grade Level, Alphabetical

\begin{tabular}{|l|}
\hline Principal Pseudonym/Grade Level \\
\hline Karla Chrisley, MS \\
\hline Michael Finnegan, MS \\
\hline Steven Garrison, MS/HS \\
\hline Matthew Hall, MS \\
\hline Brandon Hyde, MS/HS \\
\hline David Munstermann, HS \\
\hline Max Quick, HS \\
\hline Jenny Silvers, MS/HS \\
\hline Chad Shackles, HS \\
\hline Todd Warren, MS \\
\hline
\end{tabular}




\section{Survey Results}

1) In which school district are you currently employed?

12 responses

2) Is this a junior high or high school?

12 responses

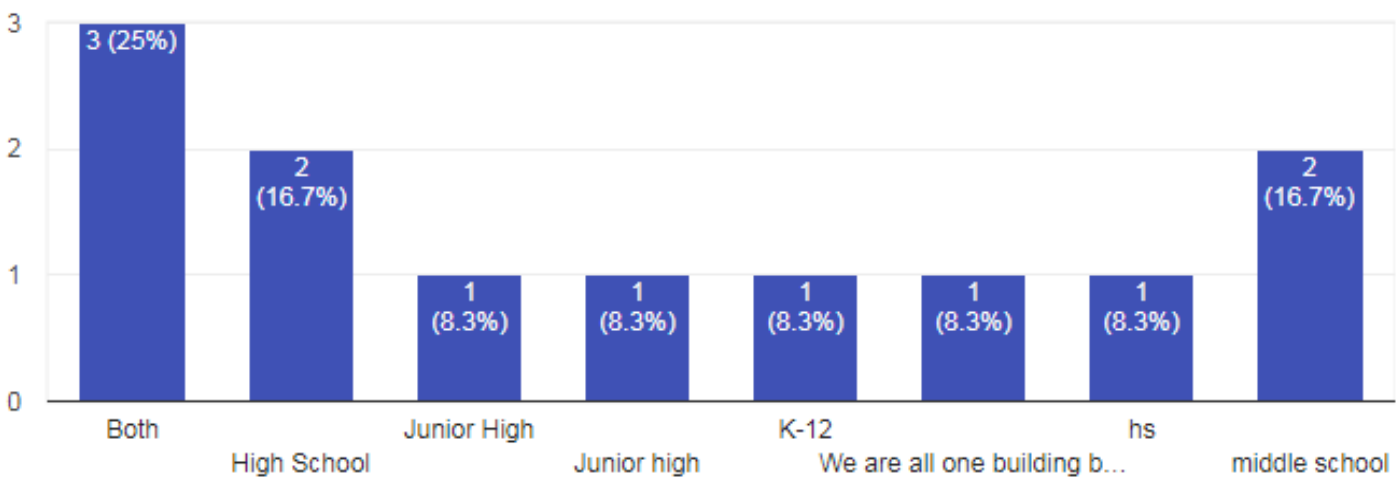

3) Which grade levels does your building encompass?

12 responses

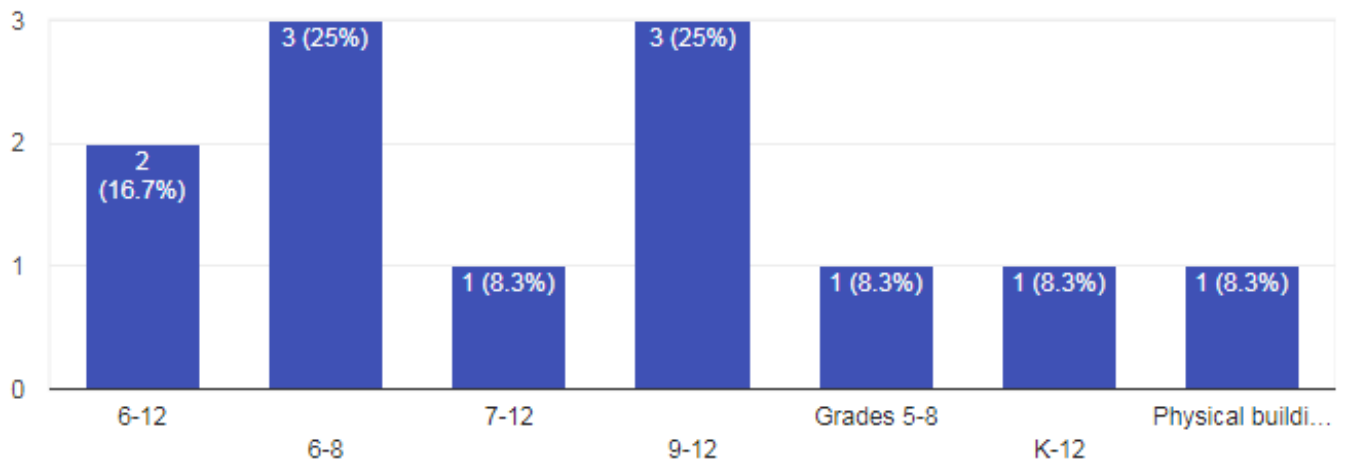

4) In what ways do you encourage teacher leadership? 
12 responses

We try to allow for large swaths of autonomy within a framework of big picture goals and ideas. Typically, teachers are all leaders in their own right but some show this as a predominant trait. Giving them a purpose and then allowing them to work with independence is great way to see who is capable of what.

I have teachers as leaders on all of my teams, including Building Leadership Team. I have had several teachers go on to be administrators

We give teachers opportunities to be on a variety of committees. If I feel a teacher has the qualities necessary to be successful, I go to them individually and let them know they should volunteer for open positions. I also believe in being positive and supportive of giving teachers the autonomy to try new things. If a teacher feels a program or idea will be best for students I allow them the freedom to get outside the box and try it.

I believe it is important to allow teachers to lead, they are the experts in the building and have the day to day experiences to make decisions that impact their classrooms.

committee/team membership (PLC, data, etc), collaborative groups, informal settings

1) Grade level chairs are selected with the responsibility of organizing the annual field trip and serving as representative for the grade level for various purposes. 2) Teachers are often asked to present best practices at faculty meetings. 3) Encourage teachers to participate in PD outside of the district so that they can learn new things to be shared with other teachers in the district. 4) Praise teachers privately and publicly when I see them exhibiting leadership qualities.

We are a PLC school. We have a leadership team that is comprised of one member of each PLC team. This person serves as the liaison of the collaborative team. We strive to include a good mix of teachers so that we have well-rounded discussions and ideas during our meetings. We encourage veterans, new teachers, elective teachers, etc to step up as the leader. I also encourage teachers to lead in other ways. My focus is to support the teacher-leader, but to ultimately give him/her ownership and autonomy of their task.

We are involved in both PLC and PBIS programs. Both of these programs have teacher leadership teams. We also have teacher associations which offer committee assignments and leadership opportunities. Teachers have a voice in our district and we work very hard to build an atmosphere of trust and collaboration.

brainstorming,presentations

I ask for regular teacher input, structure team meetings so they are teacher-led. Provide multiple opportunities to share best practices, celebrate successes, let them have the flexibility to develop their own classroom culture.

We empower our teachers throughout many levels of the building. We have a building leadership team. We also have a district Aspiring Leader Academy. This academy give training and opportunities for teachers leaders to serve. 
I try to delegate the planning of certain events to my teacher leaders. In a small school almost every teacher is needed to sponsor some type of extracurricular group and those always present times of needed leadership. I think asking for input through conversations, especially from current teacher leaders, is a good way to slowly spread the idea of teacher leadership with regard to teaching philosophy and practices. We do not have any PLC collaboration time or even common plan time so I ask each teacher to perform peer observations once per quarter, then comment on some of the positives they saw via our HS faculty google classroom.

\section{5) What are the characteristics of an effective leader?}

12 responses

Honesty (both to oneself and others), integrity (beyond the ethical considerations, can never expecting another to do something one is unwilling to do), courage (can't shy from conflict and tough conversations), and lastly is to be a consensus builder.

Clear vision, ability to listen to others, collaborative problem solving, patience.

There are many characteristics which define an effective leader, but I think the most important characteristics are positive/encouraging, truly having the idea of every student every day, and being able to reflect on on themselves and how they are leading the building.

organized, listens, communicates effectively, leads by example

visionary, innovative, relational, reflective

1) positive/optimistic attitude 2) willing to follow when needed 3) lifelong learner 4) good communication skills (both input and output) 5) forward thinking 6) motivational 7) organized

1. Relationships are key 2. Ability to prioritize time effectively and efficiently 3. Be Available 4. Love to learn. 5. Willing to have difficult conversations

Listener, Open Minded, Dedicated, Focused, Empathetic, Humorous, Caring, Problem Solvers

decision making.energy

Having a servant/service mindset. We are servant-leaders. Our job is to serve those with whom we impact.

Passion for their profession, flexibility, change agent

A effective leader is one that accomplishes what he set out to do. That means there must be a goal and to be long term effective those goals should be based on a larger vision. That leader asks for input from those doing the work and through the application of that feedback may adjust the goals. A leader must be a solid communicator which includes follow through, a good listener, 
open to feedback/criticism, and able to realize weaknesses in himself in order to mitigate them with other's strengths.

\section{6) What are the characteristics of a teacher leader?}

\section{2 responses}

Teacher leaders are those who can not only do the above list with students but can do this with their fellow teachers. People who are effective leaders bring others into the fold and work for the benefit of all.

Dedicated to their craft, see above for others

I think the characteristics of an effective teacher leader are the same. If you are not positive/encouraging, believe in every student every day, or if you don't have the ability to evaluate your skills and develop a plan to improve, you will not be successful in any capacity of education or leadership.

organized, listens, communicates effectively, leads by example

visionary, innovative, relational, content expert, collaborative

1) positive/optimistic attitude 2) willing to follow when needed 3) lifelong learner 4) good communication skills (both input and output) 5) enthusiastic 6) organized 7) trusted by other staff

same as above, but perhaps not as "amped" up.

Open Minded, Dedicated, Willing to Adapt, Listener, Passionate, Strong Communicator

same as above

Would be the same an effective leader. When you develop a service mindset you encompass all those intangible qualities for leadership. When you slip out of this mindset you become selfserving. This leads to conflict, cultural discord, and loss of focus on what the mission/vision would be for our building.

\section{Same as above}

A good teacher leader is one that other teachers gravitate toward or listen to when they talk. They have the respect, not fear, of their peers so that when a decision is made a large portion of the group will follow the teacher leader's example. Teacher leaders will complete tasks on their own with minimal guidance. That could include everyday teaching tasks or more complicated special events that need to be planned for the first time. They are always willing to provide advice/input. They are confident in their abilities. 


\section{7) Is there a certain teacher that comes to mind as a predominant leader (who does not already have a formal role as a leader)?}

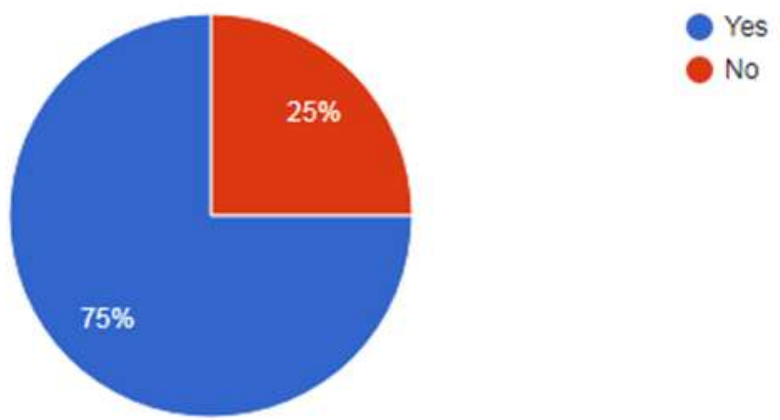

\section{8) In what ways does the teacher that came to mind as a leader show leadership?}

12 responses

I have several who show leadership in different ways, but I would point to one of my teachers who is a graduate of the district (extremely loyal to the district and the community), is great at being a team player (everyone's opinions matter, we all have value to contribute to the cause), is an incredibly hard worker, and is not afraid to say the things that matter, even when it may be uncomfortable. She is a natural leader.

She is the head of our BLT, she seeks opportunities to help improve the school, she listens to others.

This teacher takes the initiative to best help her students in any capacity she can and volunteers her programs any chance she gets the opportunity as she knows it will be completed. She also takes feedback and criticism well and works on the skills she is lacking to better help serve our students.

Sees a problem, identifies a solution, lets administration know of problem and possible solutions, completes task in timely manner

innovative, reflective, collaborative 
1) She is willing to share new instructional strategies with other teachers informally and at organized meetings. 2) She has taken the initiative to set up systems for managing building level tasks. (such as chromebook cart checkout) 3) She strives to develop her skills more every year. 4) She supports other teachers when they need help with technology and instruction.

NA 


\section{Identification of Teacher Leaders}

\section{Discovering Them}

Teacher perceptions. When asked why she was named as a prominent teacher leader by her principal, Ms. Carroll explained:

I came in as a brand new teacher out of college and so I think it probably was the fresh eyes concept of a new person. With many schools, there are the schools that have veteran teachers, teachers that stay within a district for quite an amount of time He's one of those leaders that believes in kind of big changes and so I feel like he probably saw the aspect of a new teacher, preservice teacher, coming in with maybe potential concepts that are new, or strategies, anything really. And then, of course, there's that drive I think when you initially start that gives you that passion that makes you want to like really push for greatness, so I think by having those characteristics he probably saw that as a good characteristic for a leadership team member. That's my guess. It was kind of referred to me that way when he had asked me to join the leadership committee. So I felt like there was probably a bit of me seeing it that way, my own motivations behind it and then him seeing it, too.

Ms. Williams answered:

Well, I've been here awhile. I've been here eleven years, but I think it goes along with being a coach and being a leader for my girls. A lot of just able to give people direction on their purpose and what we're trying to achieve and then you know, steps on how to get there and then motivating them along the way, so. I feel like I'm pretty good at connecting with relationships with the kids and then 
that leads to having a good purpose and then staying on path for that. I'd assume that's why.

\section{Ms. Weston answered:}

Well, I'm also, volunteer wise, I co-chair the professional development committee for the district, I am the chair of our salary and welfare for the district, I volunteer as the MSTA rep for the district so I do that. I have some teachers that don't...I don't know. I have a very strong personality, like I tend to like getting things done my way. It takes a lot of convincing for someone to be like, no, we should do it this way, and I'm like, okay, prove to me why your way is better than my way, like is it going to be easier, faster, quicker, you know, more productive, that kind of thing. But I've figured this year that I have a lot of teachers that come and observe me and I guess I never really paid attention to how many teachers actually come into my room to watch me teach.

Ms. Robbins explained:

Oh, wow, hopefully you have to be positive about the environment of your school. Every rule or procedure is not going to be exactly the way you would do it, but, you know, looking at the bigger picture, is it better for the school? Better for the students? Can you buy into what we plan as a faculty and be okay with that? I think just having a positive outlook on everything - to change or whatever is new coming down the pike. I think you have to be strong in your classroom management. You have to have good relationships with students and love what you do, you have to. The best teachers, if you think back, the ones that you either connected with or you just liked going to their class, you didn't know why, it was 
because they loved what they were teaching. They were excited about I get to be here, this is what I get to share with you, and I hope you love it as much as I do. Ms. Carpenter relayed:

I don't know. I think I just jump in when there's something new. I jump in and I get the hang of it and then I'm able to - if other teachers have questions or what not I'm really able to point them in the right direction because I've already gone and made all the mistakes... I'm also the - it used to be NJHS, but it's not here anymore because they wanted so much money, so we changed it. I'm the sponsor for the junior honor club. We do some service projects mainly; we do a rock-athon where students rock in rocking chairs all day long and it's fundraising so then we donate portions of the money different places. So then we do some babysitting nights, some free babysitting nights like while there's music programs going on so parents don't have to worry about their little ones.

\section{Ms. Spalding explained:}

He talks a lot about that I try new things in the classroom so like new strategies and stuff; he says that I'll try anything in the classroom, which I don't know how accurate that is, but he sees me as that. I don't know, I like to take on challenges when it comes to like working with certain kids that are just like a struggle, and like I want to get them to learn something. I'm more stubborn than the kids sometimes and so I just keep like beating at it and trying to like, okay, we're going to get this, so I guess probably like that. He talks about me coaching in the classroom because I'm a coach as well. So he talks about that I have a teaching style that's like coaching, that I've kind of used that. He mentions that sometimes. 
Ms. Stephens shared:

I would say probably because I take initiative to kind of get things done. There's six of us that work fifth, sixth grade. I don't know. From the first year he came he's more of a big picture kind of guy and the details aren't really where his strength is and so that is a strength of mine is kind of a passion - I really enjoy taking care of the details, so it just kind of started that way. When he first came it was, I think my second year here, and he would just kind of throw an idea out there and I would make it happen for us, and so it just kind of kept growing from there, so it was just kind of where my strength was and maybe not his strength.

Mr. Hawthorne discussed why he believed his principal named him as a prominent leader:

That's a good question. I don't know. I feel like I'm probably involved in a lot of different aspects of the school probably. I coach two sports and I'm a curriculum leader, which we call department heads here since we're a smaller district. I am student council sponsor and we recently had a, we went through like a CSIP process. I was part of that. So probably just a diversity of experiences involved in the school, probably... I'm sure I'm forgetting some stuff. I do a lot of stuff. It's a small district so we do tend to do a lot.

Ms. Wheatley answered:

Well, I'm not afraid to take on challenges. My personality, at least in the way that I think other people see it, is I'm one of those people that's very calm and I assess the situation, and you know, I don't jump into things and I'm prepared, and I think that's why she sees me that way. 


\section{Ms. Marigold responded:}

I think because I am able to understand that teaching has so many different facets and there's not one correct way to teach or to bring instruction across. It has to be personal to the teacher, but they also have to differentiate to each student. So I think that was one of the aspects. Often times I'm a very good judge of character, but I'm also a very good judge of if a student is learning or not.

When asked important ways teachers have been leaders, Ms. Carroll explained: I am most often acknowledged by the few people that I've talked to personally and on some of the stuff that we do on the leadership teams when we do evaluations is that I hear people out and I'm not quick to make a statement about a particular movement we're trying or change we are trying to implement. I'm not quick to shoot it down or say let's go for it. I perceive multiple sides and I'm one of those people who sits back first to hear it all before making any decisions on my end, so as a participant of a leadership team I think that's probably what he could have seen too. My guess is the same thing, what my peers have said about me, my colleagues just due to that nature where you can be very fired, very passionate about something and not see others' points of view. I think that is really probably my major aspect to bring to the table that people perceive too. I feel like naturally choosing the teacher path, you already have some of that instilled in you, so I can't say if it was a nurture thing, but it's the path that I have chosen and so by the nature of my upbringing and the choices I have made for jobs prior to this as a preservice teacher to then a teacher, I think they have all offered me those opportunities. A lot of it has been leadership in the way of 
guiding others, so the specifics, the attributes I guess would be relative to those experiences that I have had so putting myself in the place of leadership, so knowing the advisory process and how to communicate to others and hearing their wishes and helping them along that path. The general acknowledgment that you are not the only one with the solid idea. I'm a generally positive person who tries to communicate my points of view along with others acknowledging empathy in their conversations and not necessarily trying to fix people's issues but hearing them out and being willing to assist them and noticing when there are concerns I try to be aware of things that could be changed or manipulated or reviewed to benefit a group of people. Really what it comes down to is not seeing yourself as an individual who's making the influence; it's realizing that there's a collaborative effort there and so being consistently aware that it's a team effort. When you are making decisions I think it's kind of a major thing because there are plenty of people who don't see it that way.

Ms. Williams answered:

As far as staff themselves, I don't know that I consider myself leading in education just because I'm of the PE department, but as far as public relations stuff, community stuff, we do...we just got done with a cancer benefit. We raised almost $\$ 6,000$ in the fall during homecoming week and we just did a basketball night where we raised over $\$ 3,000 \ldots$. so we do a Hoops for Hope night, which was that night, and rally around people who currently have or had it, so kind of more of that aspect as far as the PR of good things happening and teaching our kids how to treat others so to speak, and so I'd say that would be more of where I 
am better as a leader is how our school as a whole is, so not just necessarily how we teach or anything like that but just being positive influences. The decisions a lot of times he asks because I went to school here and then I left for seven years, so I was gone to another district and I came back, so I think he likes to check with me because I have a feel on what does work and doesn't work, and then I also like to challenge people a little bit. I like to challenge my teams to give their best. . . And so I think he likes to do that also. He likes to have feedback on that.

\section{Ms. Weston replied:}

I have a lot of people that come and they're like, well, I don't really like this. Can we change it? And they're like, but I don't really want to go and say anything, don't want to rock the boat, and I'm like okay, well, let me get a notepad and I'll write it down and I'll go ask. So I'm not afraid. Once again, why are we doing it this way? Why can't we do it this way? I think this way would be better. Well, did you come up with that and I'm like, no I didn't. This person did or you know, that kind of thing. . . when I became the MSTA liaison person here, that was four years ago and since then, every person in the district staff wise, everyone in the district is MSTA now. We don't have a single NEA member anymore everyone's MSTA now. So last year at convention for MSTA, I got the leadership award for MSTA for member numbers and that kind of thing. I think it has a lot to do with because on my end of the building down here, there's only myself and two other teachers that have been here longer than ten years. I have two other teachers. One has been here twelve and the other sixteen. Everyone else is new. I'm the only tenured teacher in my hallway. There are only, like down this way 
and that way, there are only three of us that are tenured. We have a lot of new staff. . . I think the thing is that I'm consistent. . And I'm willing to listen.

Ms. Robbins also discussed important ways she's been a leader:

I have written curriculum...I'm not sure about hierarchy of what's most important, but I have written curriculum, I have been a department chair, I have shared lessons with other teachers and other ideas, I have mentored other people, I have mentored student teachers. At the middle school we have this team approach where six of us in our different core areas work together as a team and we do a pretty good job of everybody just takes a certain responsibility and we all work together, so I like to think that all of us are leaders, you know, and if somebody needs a helping hand, you jump in and help them or if you need help you don't feel bad asking for help because we're all on this team and kind of working together. . I guess, every day expectations to a high standard. You know, holding yourself to a high standard as well as your students. Those expectations are keep them high. I've gone to lots of different conferences and I've come back and shared with my colleagues, things that I've learned I've implemented that I like or think will be effective with particular students. And I've helped another teacher sponsor science Olympiad and they do competitions. I would just go out and help. Let me help you with that or help with this. I'm trying to think. I have planned school-wide - we had a solar eclipse day and so I kind of got that started in a plan and then encouraged people to help plan that. We also have done crime scene investigation day. Just kind of take a little idea and bump it off a few people and if they agree it's a good idea say help me, so we've planned that. In the elementary 
years I have written several foundation grants and have taken students out owling at night and we've done worm compost bins, just different things to enrich the classroom, but you know you had to write a grant to get funding to go do those little things, some things like that along the line.

Ms. Carpenter responded:

You know, at one point we had done RTI and I was on the team for that so figuring out what interventions would work best and how do we go about doing that and so I think part of it is that, just stepping forward and taking that initiative and then like I said, anytime there's something new just jumping in and doing it and then being able to lead others in the process.

Ms. Spalding shared:

Well, this year, I've started taking on more of a role, because we are a PLC and so I've started taking on more of a role in my individual collaboration group. I've started probably in the last two years I've really kind of co-led my instructional data team, the IDT group, and so we have a sophomore science small group that I've kind of helped pushed along. I've taken over as the cross country coach, so I've kind of stepped up outside the classroom. And so like in the cross country world I've been named to like the MSHHA cross country advisory committee so that's kind of like I'm being more of a voice. I think like for me, more being is like speaking up more than anything else is probably the way that I'm helping. I don't know. And I'm hoping to be more of an instructional leader as I continue on in my career. I don't want to be like I've been teaching for five years. I am the expert because I'm not. And so I try to learn from other people and willing to 
share when new people come along. I really enjoy having the practicum students and stuff. Well, they're not called practicum students anymore but whatever they are from the college, I enjoy having them and passing on things that I have learned. Because I feel like I'm still pretty fresh in the world of teaching and so I remember what it was like to be a new clueless teacher.

Ms. Stephens discussed her leadership:

I would say for us, I mean, I think, when I think of leader, I don't consider myself a teacher leader for the whole school because I'm very much, this is my life is fifth and sixth grade and we're kind of our own little island it feels like sometimes. I just feel like in most ways with scheduling, I don't know how to describe it. It just seems like that's where everybody just kind of has their own niche with us and mine is just more of the - I don't know -- the details, kind of the voice of reason. I'm not sure - I don't really know why, but we've got a lot of personalities in our group and some are more likely to have big opinions really quickly, and, you know what I mean? And there are some negatives and some that are really just hyper and it's just like somebody has to be that voice, okay, but here's what we need to do. Here's what our goal is. I don't know. I've just always been like that. I don't have a lot of patience in a meeting when we're not talking about what we're supposed to be talking about because we've all got stuff to do and so I just kind of lead things in that way.

When asked if she were a leader to other teachers in her building, Stephens added: I would say yes, with the getting things done. I'm kind of the one that will start the email, like here's what's coming up next month and what we need to get 
going, just the proactiveness of it because I don't want to wait until the last minute. And then we have to throw something together. I don't know. That's just how I am. Luckily, they all are okay with it. . I am the department head for ELA for the school. . we are taking on some curriculum writing, so I've had to go to some summer trainings and then tomorrow during our early out is the day when ELA is meeting to kind of vertically reassess and make sure we're all on the same page of what grade level is doing what. So but again I think it just takes just the motivation and the organization to put that together and that's just where I think I kind of thrive on that kind of stuff.

Mr. Hawthorne reflected on his own leadership when taking on roles and projects:

Uh well, I think, I don't know. Different ways that I've been a leader. I think that probably one of the biggest ways is just being willing to step into a lot of these different roles. Certainly not all of them I would have described as within my comfort level first coming out of college. So I think that over the years it's like a general willingness to take on roles and projects that were not necessarily ones for which I was trained or even necessarily originally comfortable.

I'll give you an example. You know, we have a Veteran's Day assembly. Schools are mandated to have some kind of Veteran's Day recognition assembly. When I first started, they had a real nice one and I was very impressed with it. The gentleman that ran it he moved on, he left. And so you know at that time I realized that when I first started at the district I thought that, I don't know, maybe every school does that, and maybe it's like a general format that all schools are doing. And I realized after he left that it was not. We did a lot of things the way 
that we did them simply because that's the way that he did them. He had built this up; he had built the expectations up a lot and made it a really, really excellent thing the school did, and so when he left, you know how things are. Now you're in kind of danger of it going away, I had to step up and take that thing. So I kind of stepped into that role. I don't really know, why. I'm in the military, so I guess it felt like the right thing to do. So they're like hey, will you do this Veteran's Day assembly thing? So I tackled that thing. Not alone - with a lot of help or whatever, obviously. You know, each year we try to make it even better and better and it's something that I'm really proud of. It's an opportunity for us to showcase the district, the whole community, we bring a lot of community members in here and different things like that... We've had a big focus on trying to get as many community members as possible. We also turned the experience into a fundraiser for veterans. We raised money for Show-Me Honor Flight through it and the last couple of years we raised a pretty good little hunk of money for Show-Me-Honor Flight, which is really fantastic, and we really focused on having a key-note speaker here that could kind of deliver something to the student body and community that really mattered. So we've brought a lot of focus on that, bringing in really valuable key-note speakers.

Mr. Hawthorne discussed the CSIP process:

When we went through that CSIP process, I spent a lot of time with some other teachers and just other people, patrons of the district so we rewrote the mission statement and developed a plan there and so I felt like my contribution to that was pretty positive. That CSIP process developed into focus area groups. We created 
focus area groups and along with a teacher from the elementary I was a focus group leader, I guess. And so we were organizing those meetings as well, and that's something that as you know well that's totally outside of anything that's necessarily a stipend or anything like that. We just - are you willing to spend a whole bunch of time in meetings with people and wrestle with the wording of goals and mission statements and how you're gonna measure that and all that different stuff. Something that was valuable, I think, I felt like I got a lot out of it, but also kind of like refocused a lot of things in school we were doing, so pretty proud of the work we did there.

Mr. Hawthorne explained some of the focus groups that evolved from the CSIP process: So, the focus group that I led was called "relevant learning". So just trying to focus on what we were teaching, and I think the biggest thing which was really hard to do was what are we not teaching that we need to be teaching? And bringing in patrons of the community, employers, and different types of people like that, that we don't always have a good dialogue with and like what do you see with kids, young adults, what are we not teaching kids that we need to be teaching them? And so how do you do that? How do you measure it? How do you make goals in those areas? That was the one that we led was relevant teaching, but we had one that was like School and Community Pride. And we had one like Buildings and Grounds, our infrastructure, I guess, you know, how to improve that, so retaining staff and getting recruiting quality staff was one as well. There were five total.

Ms. Wheatley told about her leadership experiences: 
At least within this school district they've done a lot of work with PLC which I actually had some experience with before I came here. So I kind of think I've been with PLC since the beginning and I know that they've made a lot of progress here, but there have been a lot of things at least particularly this year with data collection and understanding how to integrate technology with what they're doing and so I have some experience. And so they've been able to pick my brain a little bit but at the same time send me out to go learn some new things and then come back in and teach them to them and they even had me go to the consortium this year and do a whole technology session. It was so much fun. They know that that's a passion I have and so they allow me to work with them and to teach them and so that's been a great experience.

Ms. Wheatley spoke of more leadership experiences:

A lot of those sessions that I try to do for everybody around here with professional development. I've even taken some big steps into learning more about data collection and then integration into what we're doing. I went to a huge conference in December...it was fantastic, and I would recommend it to anybody because there were professionals from all over the country. There was a contact that I made at Microsoft. It was phenomenal but at the same time thought wow, this his heavy... when I came back and tried to talk to everybody about it, I felt like it was incredibly overwhelming, but I narrowed it down to what I thought we needed to do here, and you know, everybody was really positive about okay, let's do something with this, so that was something that I really just kind of saw a need for and I said okay, how about I just do this because I think this is important and I 
think it will benefit us. . . so far what we've kind of narrowed it down to is with our reading and math. We've got to figure out what our foundational issues are within those two areas. So I'm starting on the high school end, trying to figure out why the certain kids that we have keep landing in our DI all the time and we're trying to figure out if this is a can we do this and just not want to, or do we really not understand what we're learning, so that's kind of where we're starting.

Ms. Marigold discussed her experiences with leadership:

I think I've been a leader through my positivity and showing that although teaching in our profession definitely has frustrations, if you can always find the positive or you can find those students that are able to have the aha moments, it keeps you going. I think I have done this long enough that I know sort of what works the best and that's what I usually go with first although it always needs a different variation and needs a different tweak on it, so I think that's a real benefit. I also think showing students leading through positivity and not the screaming and the yelling and the demanding, but leading through respect is something that I'm able to show, and I think that that has been a benefit for me as well. Also, just being resilient and showing that yes, you have bad days but the kids have bad days, too and surviving those bad days, that's really the key. . . I think I'm a leader beyond the classroom - I think, again, it just goes back to respect, positivity, and being resilient. I've had many hardships in my life, and each of those hardships I've taken as a gift - and as a learning tool to better myself and I think I'm not shy about my past or about my parents and their situation and coming out of ...my father was in jail, my mother is addicted to 
drugs, and surviving out of all of that and still being able to be a productive citizen in society is something I can give them to show them. Because not-a small fraction have perfect home lives. And it's so important to show them that you still get to decide what your life is going to look like, if that makes sense. Principal perceptions. When principals were asked how teacher leaders were identified in their buildings, they provided a range of responses. Principal Hall said, Well, you know, you just get to know teachers. You are looking for anybody that's really going to be a good teacher in the classroom is where we start having those conversations. Find people who have a niche for something like RTI, or organization, or after school programs and then try to connect their passion to that need, so ...that's how we kind of do it here.

When asked to describe them further, Principal Hall answered,

Good instructional leaders, passionate about education, great relationship builders, good team worker . . is a person who is not ever satisfied with what they are doing, so they are always looking to improve. I know a couple like Ms. Carroll, for example, would be one, that, you know, she is an art teacher. She impressed us obviously to hire her. She was a very impressive person. But just in her desire to improve herself is what really drove me to her and so we started working together on the leadership team and I could tell that she was really passionate about becoming a PLC, and we're trying to get exemplary status and that's something that's really driving her. She wasn't a part of that so I made her in charge of BLT. We felt like she had a great way of organizing and facilitating meetings, and instead of the principal myself being in charge, we felt like I was 
directing too much about the conversation and people were afraid to express their opinions. We turned that over to Mrs. Carroll so that it could be a little more innocuous and she could feel a little more comfortable, and she's done a great job leading that so far so...

Principal Garrison remarked,

Typically speaking from a teacher-leader standpoint, we're looking for the attributes, basically in a teacher especially, do they understand what the kids are going through? You know what I mean? Because that's basically what we as administrators are expected to do is make sure you remember what it was like to be a teacher, and so if you're the teacher, I really need somebody who remembers and understands what it's like to be a kid, and so that's one of the first things you're looking for. You know, sound judgment making, like typically speaking they're not going to be the ones where you are asking them questions like walk me through this because I don't know why you would do what you did. And you know, just the normal honesty, integrity, you know, are you - can you work with others, are you cooperative. Those are the types of things.

We have to varying degrees - we have a number of leaders. Obviously, everybody has their flaws. It's hard to find somebody who's great in all areas, like there are some who are very organized and very on top of things but they aren't always the best at working with others, etc. etc., so those are the things you try to look for, though, I mean it's just the attributes that would make someone good in charge of other people. When I think of teacher leaders I basically think of that role of those teachers who are in your building that ...Y You trust them to take care 
of things with students and students see that in them as well. So when you have the teacher, or you have the kid who comes to that teacher for help with homework and they're not...it shows that they have an attribute of this person's a problem solver, this person cares about me, this person... and the same thing amongst the staff.

So let's say we put out a new staff initiative and we give some direction, but there's some work that they have to do and then you watch to see what happens next. People know who they can go to, and so when I think of teacher leaders, those are the people that are really kind of the ones that...they...they can translate, they can understand, they're willing to ask the questions especially like in meetings and stuff like that, when there may be some confusion. Maybe they're not confused, but maybe they can sense some of that confusion thinking about problems, you know. They're going to be the one who raises their hand and says, "Hey, I need to ask this question," you know?

Those are some of the attributes that I look for in teacher leaders and then in terms of like the day to day, I mean those are the people that you can go to and you can say, "Tell me what you think about this," you know? Because they have the ear of the other teachers, they have the respect of the other teachers, and same thing... You typically see the kids know who they are and the teachers know who they are. And so those are the kind of things that you see and you are looking for and I view as a teacher leader - the people who are capable of doing those things for you, so...

When asked to share a story of a teacher leader, Principal Garrison added, 
Well, yeah, so right now, I mean, and this is an example of someone who has basically kind of moved into more of a leadership role. Our curriculum advisor, she started in that role in my first year here, and she had been teaching and so she moved into that role because whenever we were doing anything in that area - and she actually - she doesn't even work here anymore. Now she works in another district and she just comes back and works with us on professional development days and things like that, but basically when somebody had a curriculum question, they would go to her because they knew that she would listen, they knew that she would work through them, they knew that they could find a solution for them because she wasn't the party line, so to speak, she was kind of the go-between, which is what all leaders should be. You know what I mean?

Like but when you have that in a teacher - because the reality of it is, I mean, I taught for ten years. I remember what it's like. But you see a lot of things differently when you move into administration because you're just viewing all the systems at the same time. And so things look so different. And sometimes you want to impress that on people, but it's hard for you to impress that because you are different.

And so, to have that person who is the teacher leader, that person can step in and basically, like I said, they can take the message and they can translate it. And when I say translate, I mean it's nothing different. It's nothing amazing, it's nothing new. It's just they trust that perspective of that person because they're respected as the leader. And so they offer something at times that, you know, your regular leaders just can't offer. I mean, she's a good example of that. . . 
And so, you know, when you take the time to think about it like that and then one of your jobs as a leader is to develop leaders amongst you and you know, like, my assistant principal - before she was assistant principal she had been in the classroom and when we were going to reorganize and cut positions and hers were some of the ones we were going to move to the elementary because she was teaching at the middle school level, and it's like these are more elementary skills now, like computer applications and stuff, and so you take those people - they are problem solvers, you know, they can take what you are saying, compute it, tell you the aspect, the viewpoint of, how this will be responded to and, you know, offer that back. So those are the things, like, to me those are some of the characteristics I've seen that embody that person that really has the respect and the ear of the other teachers because they know that they can get things done. Principal Garrison also shared an anecdote to illustrate why he selected his teacher leader:

The other day I was having a discussion with another staff member about relationships within the building and I was just like, I go, "I think we all know that Bonnie is the ultimate team player. And Bonnie's from here, she played basketball here, she's our basketball coach now, and I'm like, but it's so much more than just an athletic mindset." I go, "She's the team player because in meetings, she's the one who's going to stand up and say, 'We need to hear that person's opinion because all of our opinions matter because when you're truly the ultimate team player, everybody's voice on the team should be heard,' you know, 'and when you're the ultimate team player, you stand up for other people's 
opinions because you want your own opinions to be stood up for as well and there should be value in the collective"". And so she truly embodies that, and like that's...to me, that's the reason, you know, I mean she has her arena, and she will never likely become an administrator or anything like that, which is another reason why I picked her because she's not - she doesn't do it to groom herself for something else. She does it because she cares about it, you know what I mean? And she leads by example. And like when I need something done on a curriculum level, like the PE department is going to be with me, which is awesome because you might know that that's not always the way it goes and so I mean it's that sort of thing, but to me that's her greatest attribute and it's an attribute that's really hard to find and it's amazing to me because even amongst your coaches who should definitely understand what it means to be a team player, they sometimes don't translate that into the team that is the school. And she's always on mission and she understands doing what's best for kids and so in that regard, those are the reasons why I picked her.

Principal Hyde shared,

A lot of it just comes from initiative. I think being a leader you just have to have a little bit of self-motivation to want to do what's best for whatever the situation is, what's best for kids, best for the program, best for the district, whatever it is. There has to be a little bit of initiation there or motivation on the teacher's part. And other times I try to see, you know there may not be always people that are always putting themselves out in the front, but then through conversations they have a desire to maybe want to improve, so then trying to find ways to see if they 
would be willing to take the next step and maybe put themselves out in front and take the initiative to make a difference.

When asked to further describe teacher leaders, he responded, A variety of things, but honestly I think it just goes back to the initiative piece. I think the real teacher leaders are the ones that are just constantly almost to the point of bugging I think at times just because they see that there is a need here and they want to move forward and they want to make a change, you know. And it may not be a drastic change, it just may be a tweak, it may be a minor thing, but they just see a need and they would like to attack it. And they know how to get people on board to kind of make those changes. . .

Honestly, I don't know if there's a one size fits all model to being a teacher leader, kind of going back to, because I do have some really good teacher leaders that are not quite as vocal. But again it's kind of that desire inside to want to see a change and see something positive for our kids. Some of my other teacher leaders, like Cara, she is very vocal. I don't necessarily think that makes her a better teacher leader than the others, but her desire to always want to do what's best and try to evaluate what's going on is probably stronger so than my other staff members. You've got to have a sense of compassion and caring because if you didn't care, then obviously you're not wanting to see things get better; you're okay with the status quo. Then again, just going back to a little bit of initiative and being able to grab the reins and go with it.

Principal Hyde provided an example of another teacher leader: 
We have a wonderful FACS teacher. Again, she just sees a need of how she can best suit kids. She comes and asks if this idea is going to be okay. I try to be very hands off and release the reins you know if a teacher wants to try something new, something different and they think it's going to impact the kids, then go ahead and jump on it, and so giving teachers the freedom and the ability to do the things that they want to do, but anytime...I would say that she's another good example of hey, I want to try this. I think it's going to be best for our kids and our school and she's really turned the program around that really didn't have a whole lot of participation last year, but just through her desire to kind of just want to take things on and face those challenges has led to...I mean we had the highest participation rate at the state conference this year for FCCLA. You know, first year here, I mean, she's been in education for a few years so it's not like it's her first go around or anything, but she still is just highly motivated and wants to do what's best for her kids.

Principal Hyde explained more in depth about why he selected the teacher leader that he did:

Obviously because I can rely on her. Just the other day we had a fundraising idea - the elementary was doing it. My secretary caught wind and asked if we could hop on and I said yeah, but I know that I'm not going to be the best to get those kids kind of motivated and organized to do something and so I know that she is very effective in utilizing her resources, communicating with kids, kind of getting an idea across to them and getting things done. She's very organized, like I said, kind of going back to - any time there's something going on, whether it's 
professional development - if it's a teacher issue, if it's a student issue, hey, she has no problems with trying to find ways to improve, maybe she doesn't have the time, energy, or the ability to fix a problem but she at least recognizes the problem and maybe kind of direct other teachers to me and say, hey, we're all seeing this problem. Maybe you need to go and have a conversation, so she does a very good job of you know, organizing, delegating - there's a variety of things that she just does well. But she really just goes back to having that initiative and that desire.

Principal Finnegan discussed how he identifies teacher leaders:

You know, I try to give everybody opportunities to serve and lead the individuals that stand out, and what does "stand out" mean? I think so much of our stuff has to be teacher-driven. Supported by administration but teacher driven, so letting them take the reins. We're using PBIS right now, for example, and there's five individuals I would call them teacher leaders - coaches - whatever you want to call them and then there's a committee on top of that to spread the word throughout the building of what we're trying to accomplish at different times, so how do I identify them? I think it's just they kind of show themselves a lot of times.

Principal Finnegan further described teacher leaders:

I think what I would say is well-respected. That's what comes to my mind. By everybody in the building. They're that individual that takes on roles and responsibilities. You know that they are - when I am leaving here at 4:30 and we dismiss at 2:30, their car is still around back because they are doing that much 
more. They are the ones who, when asked to serve, serve, and other times they volunteer to serve. And those teacher leaders aren't power hungry; they are just wanting to make the place better.

The one you are going to interview is retiring this year. There's another one that's retiring this year. Both are teacher leaders - very different ways that I would say that that they lead. But both are well respected by their peers. You know, as a principal, if I'm trying to implement something, I'm going to go talk to the two of them before I even try to do anything because I know that their influence will be helpful as far as things go. They're highly organized, they are tenacious, not in a mean way but as in we're going to get this done, we're going to get this done, we're going to get this done. We aren't going to accept anything but getting it done. One of them is a talker; the other one is a listener. The one you're going to talk with is a listener. She hears and then she is able to go from there with it. You know, an interesting thing that I will tell you is to me, all that wrapped up into one, sometimes there are people that are offended by them. And the offense is they're just trying to make the unit better, and it's not meant to be a put down to you - you have personalized it thinking they are coming at you - that's not the right way to put it... and so I would tell you I would say that through my time, I try to absorb that because I don't want it to be they're just doing Michael's dirty work because that's not what it is. You're saying I think it's a good thing, but you guys have to implement it.

Principal Finnegan discussed why he picked Ms. Robbins specifically: 
I recruited her to come over here. She was in elementary. This is her $30^{\text {th }}$ year. She was in elementary until probably until 2006-7. None of my kids had ever had her; I just knew the reputation as far as a classroom teacher was and I thought what a great sixth grade science teacher she would be. And just having worked with her now for twelve years, I selected her, just because I think she's the epitome of what a teacher is and always has been. I was just talking today and I think the younger generation of teachers - they come to school and they leave. Well, I don't do paperwork at home. I do that at school. We get out at 2:30 and if you try to call... this building you can get in until 2:45 but if you drive up you'll see Mrs. Jones and I here until 4:30 or 5:00 because we can't get it done during the day and I'm always amazed at principals that can walk out about twenty minutes afterwards and I'm just like, wow, I can't do that, but she's here, she's here late, she's here early. If we ask for volunteers she's always one of those people that's like yeah, I'll come up. Because it's good for the cause. We were short-handed big time one day earlier this week. I sent out an email saying, hey, it'd be appreciated if you could come for lunch duty. . . and so that's that individual that always comes up and knows that, hey, they're asking because they need help, not because they just don't want to do it. She's what I think of when I think of teacher.

Principal Chrisley explained how she identifies teacher leaders in her building: Well, I'm looking for people that other teachers are going to respect. For one reason or another, other teachers listen to them and value their opinions. And you met with Carpenter. With her, it really was she had been transferred from the 
elementary to the middle school. Things were okay down in the elementary, but she just kind of was struggling a little bit and she got up here and kind of just started to find a niche and so, I don't know. I just saw something in her that maybe she could be contributing more and I sat her down one day and said, "I believe in you. I think that you could be contributing a lot more and I think you are a leader." That's been about four years ago and she has run with it. She just... and I think you build those leaders by giving them encouragement and letting them know you do believe in them.

Chrisley further described teacher leaders:

Confident but willing to follow as much as they are to lead. They're a good team player. So they listen to other people's opinions... not a know-it-all because they have to be respected by others so it's got to be somebody with a good work ethic and someone who values professional development and learning and wants to grow as an educator, so we need them to be a model to other teachers.

She elaborated on other teacher leaders:

I have a couple of other teachers who have gone and gotten their specialist degrees in math instruction which is kind of a new thing that's just started in the last couple of years, so they're among the first ones at UCM to earn that degree. So they've been ones, then again, with tons of encouragement, and they support one another. I think that's been kind of a neat part of that is that they work really closely together and they push each other to be better and better all the time. So they're the ones that are always willing when I go to them and say I want you to present what I saw you doing at the faculty meeting. They're always willing to 
jump in and help other teachers. We worked it out this year that each one of them can have an extra hour-it's different hours, different quarters, but they each have an extra hour when they can go down to the elementary and kind of do some instructional coaching - informally. Nothing super formal, but that's been really well received, so they just kind of hung their hat on a passion and we just keep encouraging it and they keep growing and growing.

What I noticed when I first got here fifteen years ago, you didn't see a lot of leadership among the faculty. And I was used to that atmosphere where I had been before that it wasn't just the principal leading; it was the teachers jumping in and leading and so I kind of tried to start bringing that in as a teacher and going to the principal and saying, "Hey, I'd like to lead this PD," or "I'd like to get a group together and do a study" and different things like that, and then I think it grows. It's contagious. Other teachers start going, "Oh, I want to be kind of like that," and so now we've gotten to a point where it was actually kind of hard to pick when you asked who I would think of as a teacher leader...there are several...and I have one teacher that is a second year teacher. But again, you can see that leadership in him and so he's being groomed to step in and take over a lot of things, too.

I think the teacher leaders are even maybe more important than the leadership of the principal, and that being, I really learned that because my unique experience was being here as a teacher, and I was that teacher leader, and I was the one that if I would say here's a great strategy; you should try this in your classroom and everybody would latch onto it and oh, Karla thought that was a good idea; let's try 
it. It was really good. We had some good stuff going on, and then when I moved to the principal's office I tried to do the same things but it didn't go over as good enough. Am I going to get a bad score? And they just were always wondering what I was up to... and I was like, no, I just want to help, I just like instruction and I want to keep helping you. So that's when I realized right away, okay, I have to get these people like I was. I pulled out of that mix, and we were left with not a lot of teacher leadership, I've got to start planting those seeds and get the people under me so I can give to them, hey, this is my idea, this is what I'm thinking, and let them take ownership and run with it. It's just better received from the teachers. And it was just interesting, because I am the same exact person I was three months ago...but it says "principal" over my door, so that changed things. And now, they've developed more trust and I'm kind of back, it's come full circle, but I mean it's because of those teacher leaders; that's huge.

Chrisley then discussed why she chose the teacher leader she did:

Because, number one, she has grown so much over the course of four or five years. She's just flourished when I said you can do this. All of a sudden she could, even better than I thought she could. And then she doesn't hold an official sixth grade team leader title or anything like that right now, but she is the one, that for example, when we said how are we going to get all these Chromebooks checked out and keep track of it? She said, I've got it, I'm going to create a Google Calendar, she got it connected to the website, she just, she has that ability to see that there's something that needs to be done and just jump in and do it. So, I've learned seeing that happen a few times, that if I'm stumped on something in how 
we might make this work, especially if it relates to technology I can go to her and say, "Hey, what do you think? Do you have any ideas?" And she's very good at brainstorming and she's really receptive of just sitting down with me and just talking shop. She's a huge resource and it really comes down to mostly that she sees what needs to get done and she just gets out there and does it, without having to have a lot of direction.

Principal Munstermann discussed how he identifies teacher leaders:

You know, I think that it's so hard to answer, but I think you see teachers who are very innovative, not afraid to try things, who question and ask others what works, what doesn't work, how can I get better? And I think people are naturally drawn to those inquisitive people. And I think that just kind of sets that whole thing in motion. And we see that, when something new comes down the pike, who do teachers gravitate towards? She's relatively young in the game, but they flock her direction right now. I think that it's almost courage to try something and to fail and then I think the reflection piece is huge on that, whether it's internal, or just bouncing things off.

Munstermann further described teacher leaders:

Fearless. You know again, I go back to that innovative piece. That willingness to try anything that you think is going to help kids. You know, I look at they're very student focused, what's working, what isn't working and it doesn't matter - it might work in one classroom but not the other. So it's that never-ending quest to get everybody on the same page and knowing you may have to do something 
different for each of there are six blocks that they have to teach. So those six sections.

He elaborated with more characteristics:

Gosh, almost transformative. And by that I think just bringing other people along with them, maybe even unintentionally. If I look at Elizabeth, she has people follow her that she probably doesn't even realize. And I think that's okay. But I think that, I know that there's some that sit back and watch what she does and things that she says. She makes us better every time she presents something or questions something. Right now they're in data teams and she has really kind of taken a lead role with her data team. I think, you know, specifically in terms of her, and I think that's probably broad and global, she makes others better just through the natural conversations they have. Nothing fake about it - just genuine concern for how do we make this a better place for our kids? I don't know if I can quantify that. I'm not aware of any words per se, but when I think transformative, that's what I think of.

Munstermann shared a story about Ms. Spalding's leadership:

Well, I can look at her. She came to us as a student teacher and there was something very different about her as a student teacher. It was you're a lot farther along in this game than most people we see even after a year or two. And so, she was just very confident, comfortable. She would probably tell you just the opposite, but that's not what we saw projected. And we knew right away we wanted her and we had an opening and actually, we received permission to cut her student teaching short to come in as a long-term sub for us. We had an opening 
due to a military deployment, and so one of the unique things we get to deal with in the area as you well know.

But I think, when we paired her, it naturally happened with common classes. We had a teacher that we were working quite hard with to improve some things and once they got paired up in a common curriculum, that other teacher, I mean it was like a light switch went on. I mean, it was night and day the difference in the performance of that teacher in front of the classroom. I can't tell you what was said behind those closed doors or anything, I have no idea, but I know that individual relies on her, yet she has cut them loose a little bit but is always there. As a matter of fact, they're in a team right now together. But I think that is my Elizabeth story, if you will. Just because of the growth in one year's time that we saw in that other teacher. Because that's someone - we were seriously considering hey, this is not working and then now, they're a fantastic teacher, I mean holy smokes, I do attribute that to Elizabeth and her leadership. She's one of those that every administrator, every teacher wants to work with. There's others in our building, but I've been with her as her evaluator since she came in. That's my department and I'm an old science guy, which is where that falls, so that's helped a little bit in that regard. But you know, she, from the very beginning was always asking what she could do to get better. I mean, probably calling her perfectionist might do her some injustice, but I think it's just she wants to be as good as she possibly can and will take whatever feedback you can give. It's just, you can't give her enough feedback; she soaks it in and then moves along. 
Principal Warren weighed in on why he chose his teacher leader:

The way I identify them is basically how they model for other teachers, their willingness to help others, their constant drive to get better in the classroom, and the fact that they're always looking at ways to make their environment better and instruction better. So that's how I identify them and usually it doesn't take a whole lot of prodding. They will rise to the top, and you'll find them pretty darn quick. So those are quick and easies for me to figure out who they are.

He provided in greater depth a description of these teachers:

Someone who's willing to put themselves out in front, someone who understands what it means to be a servant leader, and I think that's most important. And here, we're blessed with a lot of people who come back and are alumni from here, Alexandria being one of them. Just the fact that they have pride in the school, especially the school district, and they know what the school did for them and so they want to come back and give in return. And so that to me, definition of servant leader. I love it. They want to serve our community and serve our kids and that's awesome.

They want to be the best in their profession - that does not mean it's a competition kind of thing. It's just the fact of they're always willing to try to get better. They're very reflective on their process and their practices, and they know, hey, this did not work out very well, so how can I change it to make it better? They're also willing to help others who may be in need. There is no silo approach here, which I really like that in our school district. In middle school we really pushed hard for that. We used to be pretty segregated not only geographically, but 
since that side of the building was so different from elementary school, they're almost like shunned to a corner somewhere, so it was a different kind of environment.

Also, what I appreciate most about them is their willingness to communicate with adults. Our stakeholders, our board, and especially our parents. And once again, a lot of our teachers are embedded in the community, so they have that relationship to begin with, walking in the door. But there is no fear and insecurity about speaking and communicating. I believe for a middle school that's our strength. We are always communicating with parents, sometimes over-communicating. I don't mind that whatsoever. When I hear, hey, you're sending me a lot of messages, I don't take that too bad. I just want you guys to know, so.

Principal Warren addressed why he named the teacher leader that he did: All of those characteristics that I told you about - she embodies that. And she's only been teaching for five years, so when people have it, I mean she has it. She has a God-given gift - to teach, and to be with kids, and to love them and nurture them and just, her content - I mean she's a master at it. Just five years teaching, she is a true master at it. She takes a concept, puts it in her class, and it is rock star stuff. But she just has that. You know, I can't put my finger on it. Kids are drawn to her. She's specifically sixth grade for a reason because that's a major transition for us. And I'm sure you've been through this. Every year you hear, hey, this group is rough. Watch out for them. They're not going to be good. But she just has a way of bringing them in, making them feel comfortable, you will be okay, and get to know them. And so I could just mention a kid's name and she could tell 
me top to bottom, everything about that kid: not only academically but socially, all about their parents, everything. She just has that. And people are drawn to her. I have a huge amount of respect for her. I go to her quite a bit. I throw quite a bit on her. She's just that personality to where this is where she's meant to be and that doesn't happen a whole lot. We all have a calling, but she is truly blessed. I mean, it is awesome to be here.

Principal Quick discussed how he identifies teacher leaders:

I don't know, that's one of those things, it's kind of - they have it, you know. I think being a self-starter helps. If you're motivated and a self-starter, you're probably going to do things, you know, quote right. Because if you aren't going to do them right, then you wouldn't want to do them anyway. So people that come to and me, say, hey can I X,Y,Z, usually the answer is, yeah, let's try it and that's a pretty good identifier of who's going to be the leader in the building is the one that wants to step up and do it on their own.

Quick also presented examples of different types of teacher leaders:

Others, you know, they don't have to do that. Others are kind of silent leaders and maybe those aren't teacher leaders, maybe those are more just the teachers that other teachers want to follow, so maybe they're quiet leaders - you know, I'm not sure what to title them. Or maybe they're not active in the fact of they come up with ideas and they want to do different things. They just quietly go about their business and do everything, again, the right way and then other teachers tend to follow that. So, by definition, if other teachers are following 
them, I guess they would be leaders, but they don't seek to do that. So I mean, there's a couple of different ways I think that it could surface.

And then I think maybe a third way is they are teacher leaders by students. You know, there are some students who just flock to. We call those kid magnets. You know, whenever we're hiring I just look for kid magnets. You know, are you a kid magnet? So there are some teachers that don't necessarily set out to be a teacher leader. That is not their goal - leading other teachers, but the sheer fact that students are flocking to them and want to be around them and yet still learn, because there's a fine line there, too. Other teachers see that and then want to emulate that also. So again, if other teachers are trying to do what they're doing, then by definition that would be a teacher leader, but I think the most direct answer to your question is my first one of they will come to me and say, hey, can I try this? Absolutely let's try that or can we start this club? Yes, or can I - I'm really tired of using this book - can I just not use the book anymore? Yes, absolutely. You know, so stuff like that.

There is a fine line or two where I flip those questions where somebody comes and says, "Hey, my book is outdated. Can you buy me a new book?" So just because somebody's asking if they can do something doesn't necessarily mean that they're a teacher leader, but it's something different. Can they do something different? If the question involves change or improvement, you know. I want to try something different because I think what we're doing we can get it better, so I think that's the easiest thing that they're doing.

Quick elaborated further on his selected teacher leader: 
Yeah, I don't know if it comes up in your questions here or not but to speak to him, I've asked him about that before, about why he coaches and his answer honestly I don't know how you would make a better answer, but his answer is he coaches, I'll sum it up - it's a big philosophy, but his answer to me was I coach because then I can get a relationship with kids in a way that I can't get any other way, and then when I have them in class, then I can exploit that relationship and make them to learn what I need them to learn. I can use that relationship for what I need it to be academically, so I coach and I spend all that time so that it still comes back to academics. I can still use it for academics.

So he's almost offended at times when he doesn't get every kid. He teaches American History - and that's every sophomore - he thought up until a couple of years ago. He just thought truly it was every sophomore. Well, there are some special education students that aren't in his class. There at that time what brought this to light was there was a student that could not fit - they had a couple other, you know, band and, they wanted to go to a Career and Technical College. They had major scheduling conflicts that it was truly going to be - they were going to have to give up either Ag which was their future career or give up band, which they had been in since fifth grade and had gone to state several years, so it was a big deal for them just to be in history class, you know. And so I say just, and so, like gosh, we really don't want to make this kid choose - we really don't want to have to do that, so we came up with an alternative plan which was not in his classroom. And that really, I mean like I said, almost offended him. And that's what really brought that to light. Since then, he's had a little bit different of a - I 
think maybe like an aha moment of okay, maybe I don't have every kid. But until then, certainly his thought was, okay, he has every single kid and so he needs to have a relationship with every single kid in the school and so that was his goal and I think he did a real good job with it. And he still does.

The kids love him. The kids have a high amount of respect for him. You know, he was past military - I guess still is, National Guard, and so I'm not sure if that just raises the respect level of the kids, knowing that he still does that, you know, one weekend a month he's gone. He was deployed so he was truly gone for a full year, and so I think the kids that are still around - that was four or five years ago, so the juniors and seniors that were around that happened - they know that that happened, so I think there is a level of respect there, too that just. You know, naturally, you don't have to earn that, you don't have to know me at all, but I walk in with a uniform and our kids are pretty respectful anyway and so, you know, they see that and know that instantly. He gets some of that, too.

Principal Quick provided more description about teachers in leadership:

I think again, particular characteristics - just the big one is the self-starter. They have a tendency - I don't know if it's a characteristic or - but they have a tendency to overwhelm themselves, where you can see them being overwhelmed. Then again, I'm not sure if that's a characteristic, a positive characteristic, but you can look at the workload of all the people and again, there are some that are overwhelmed, not doing what they're supposed to do. So that alone not just a characteristic, but I think it's maybe a red flag kind of thing. Like hey, that teacher is overwhelmed, maybe go check on them and find out, hey, they are 
overwhelmed because they are grading stacks of paper every night compared to hey, they're overwhelmed because they are doing ten different things. All are positive and they're just trying to do too much. So I think it is a single characteristic, but it's not a single characteristic. I don't think you can judge just based on that. Because there's always counter examples, but I think they do that. I think teacher leaders, we were just talking about this the other day - they have a tendency to think that everybody else operates like they do. That's not accurate and so they get really frustrated when somebody doesn't do what they do naturally.

Again, to Mr. Hawthorne, he'll spend hours planning lessons. He is a primarily lecture teacher, which you know, research would say is probably not the best thing. However, if you go into his lecture class, somehow, he is just absolutely engaging. He can tell stories, he has, again, that relationship with kids where it's back and forth, it's interaction with them and it still works somehow. And I would not encourage others to try and do it because I don't know how he does it. You know, I don't know how to duplicate that. Back to my first comment, he just kind of has it. But he will spend hours looking at his standards making sure he's going to teach the right things. His Power Points are not the same old yellow transparency things. Every class period, every Power Point he goes back and updates the pictures that he has everywhere with current pictures to make it relevant for these kids for today. He'll change things left and right if it's not quite working. So all of that to go back to the point of that's what he expects every teacher is doing with every lesson, but that's not accurate. They don't all do that. 
And I mean, they probably can't. If everybody did that, we wouldn't have time for anything else because it is a lot of time that he invests. I think that's part of it. You know, we're working on curriculum right now and I think those teacher leaders - another one that comes to mind that we're not talking about does the same thing, just expects - the one you interviewed yesterday, I would expect her to have the same - she does a lot of behind the scenes work and just expects that that's what everybody does - it's what teachers do. And teachers probably should, but don't.

So I think they have a hard time understanding when somebody says something like, "Well, gosh, when did you find time to do that, or how did you do that? You know, how am I supposed to do X,Y,Z?”, and that teacher says, "Well, what do you mean how are you supposed to? Aren't you doing that every day?" "Well, no, no, I'm not. What do you mean?" And so, again, a counter example is teachers who don't do that every day. They think everyone's doing it just like that, too. You know, so, anyway, one of my favorite phrases is "everybody's normal is different". And so, that teacher that comes in and it's just a job, comes in and does day to day, that's what they think everybody is doing. The teacher that comes in and busts their tail until 5:00 or 5:30 and then takes a stack of stuff home, that's what they think everybody is doing, or wonder what they're doing wrong. Why am I here until 5:00? I think that could add to some of that frustration. Why am I here until 5:00 every night when there's only three of us in the building at that time? How are they getting done so quickly? And they think that they're doing 
something wrong, when in actuality, they're probably one of the few doing it right, so.

Principal Silvers explained her philosophy behind identifying teacher leaders:

First we start with looking for people who are just willing to step up and are looking for some extra involvement, first of all. And then we try and decide where would they fit in with that involvement and how have they contributed to different things in the past. I do look for some of my veterans that I know have been very proven teachers and I'm lucky there. I've got a really great staff here and I'm very lucky with the fact that they embrace things.

We started PLC and PBIS (Positive Behavior Intervention System) the same year, three years ago and we were crazy to do that, but we did it. And we've had a lot of change here in the last three years. Before Mrs. Benning, the elementary principal and myself started, teachers were just basically in their classrooms and we didn't do a lot of teacher leadership or shared leadership or anything like that, and we decided we needed to change. Our kids, our scores had tanked, our scores had gone down.

We had one principal. We went back to two; our board made a good decision there, and so, anyway. I'm off the track of how you identify those folks, so the teachers that have been here a while, the teachers that are veteran teachers, the teachers that want to be involved, and then the teachers that are just really good classroom teachers because they can share their knowledge with the rest of the staff, and real honesty of it is the teachers that don't want to sit in the back, have side conversations, and try and run the show in a different way. We want the 
teachers that are very open to change and open to helping other teachers. That's how I look at it. Like I said, I'm very lucky because we don't have a lot of that side conversation.

Principal Silvers elaborated on the teacher leader she selected:

Well, with Anne that you're going to speak to, she is just willing to try anything new and she's willing to share her ideas so she's been to a couple of things and she's a very tech-savvy person anyway, but data. You know, people who are willing to use data to drive your decisions and willing to just put themselves out there and try something new. Those are the people that I really try to look for because you can't be stuck in a rut in education anymore. You have to be willing to change and try new things. We do have a few folks on our staff that are veteran teachers that have been at this a while, and for them - and it was hard for me at first, too, because I was used to that, too. I stay in my classroom and I do my thing and you know, I don't want to be interrupted or whatever, so those are the folks that I think make the biggest difference for our kids.

Well, with Anne, this is just her first year back here. . . I think hers is just how she relates to the kids and how she can draw things out of the kids. She builds relationships with kids. That is amazing and being able to show that to other teachers. That's something that she does that I think is really great. Another example, Mr. Bentley, who is another veteran teacher here. He's our history teacher. Watching him over the last three years change his teaching style he's embraced some of the new things that we've done. He used to be very more textbook oriented, we're going to follow the text, we're going to do this, and his 
leadership has started to grow, where he's trying new things in his room and he's gotten outside of his classroom to work with other teachers.

And then I guess one of our best teachers here is our middle school English teacher, Bella, and she can teach about anything. She's just one of those ladies that when she was born she wanted to be a teacher, I think. Examples that she she will pull people in for critical thinking and she's on our English, you know like our grade-level reading team and STARR reading team and watching her develop systems to help kids learn how to read. It's just that - and I don't know if that's what you were looking for, but they really work hard around here.

She discussed why she selected Anne:

I've known Anne a very long time. We taught together while she was here the first time and I went after her, basically, to bring her back when I knew we were going to have the position because of the way she does work with kids and the way she just is able to draw them in to what she's teaching. And so they just love to learn from her and seeing the change in her as well since she was here before to how much she's grown to now as far as curriculum. She went back and got her master's in technology so all of this - technology stuff - we have a tech company but she will manage all these Chromebooks as well. Just her willingness to learn new things and to share those things with staff - she's really going to grow into a great teacher leader here. And she's not on our PLC. That's why I picked her, because I do have several teacher leaders on the PLC team I thought about, but with her, I want to build her up into a new teacher leader so that would be why I picked her. 
Principal Shackles discussed how he identifies teacher leaders:

Passion is a large part of it. Willingness to get in front of their peers. That may be the toughest hump to get over, I guess you might say. I mean, there's plenty that would like to say yes, I'm a leader. Plenty that you think would be a leader, but it's fewer when you go hey, would you put a fifteen-minute presentation together or a one-hour presentation at our next PD day on a certain instructional strategy or whatever. The ones who are willing to do that, well, you've found a leader. If they're not willing to do it then you go, well, you're all right. But you're not going to be the leader of the pack. . . Besides the passion and willingness to get up front, are they in it for themselves, or are they in it for the students? You know, I mean, generally, we all make assumptions. Everybody's given that free pass until you prove the free pass is wrong. $95 \%$ are in it for the kids. And actually I don't think I've ever met a strictly classroom teacher that isn't in it for the kids. You do have a few coaches that aren't in it for the kids and those are men and women who are natural born leaders for the sometimes wrong reasons and you have to weed them out.

Shackles provided more explanation about these teachers: Are they chipper? Are they always struggling time management wise? I can understand some struggles. But one thing that I always look for - are they here early and are they here afterwards. That's another biggie.

He provided more specifics about teachers he views as leaders:

The young lady that you interviewed before me, Marie, she had not been here more than sixty days - it might have been less than that when I talked to her, but I 
asked her to put on at our first PD day of the fall, now I'm not talking the ones in August, I'm talking the ones after school got started, which I think was October. I asked her to put on a half hour to one hour demo of the Socratic seminar method running a discussion and debate. I was going to do it with her, but then my wife fell down so I couldn't do it with her, but she went ahead and did it on her own. Which, you know, that's kinda cool. A lot of people - even teacher leaderswould have backed out, because you know, in sixty days, you know their names, you know what they look like, but you don't always know all your colleagues yet. Because life is just so busy in a high school. And so she was still brave enough to do that and I think that's pretty cool.

I've had a couple of others who have done similar things. Ms. Hammond, my biology teacher, she has done a lot of work with the rest of the staff on Kagan strategies. She took it upon herself - before she became a fully certified teacher she was a sub and she paid for Kagan training on her own. You wouldn't know this, but I recruited her out of St. Louis. And her and her husband quit their jobs, sold their house, and moved. They heard the call, manifest destiny. Go west. And I tell her every once in a while, "Go west, young lady, go west," and she smiles at me. You know that's a lot of courage, which would be another. Are they willing to take some risks and have courage? I feel pretty good about the teacher leaders that I have. You put me on the spot with who is it, and I was like, Marie. I actually have three or four.

Shackles discussed why he picked Marie specifically: 
Well, the main thing there was the courage, like I told you about the - within sixty days and then her passion for teaching. And I tell the staff, I say it about three times a year, the beginning, the middle, and the end, and all the rookies, I just throw it in their face all the time - you're never going to be rich, but you're never going to be bored in this profession.

\section{Teacher Leader Impact/Influence}

Teacher perceptions. Ms. Carroll described how her skills have been utilized by the administration:

Mostly the only ways in which I have influence is in that leadership committee with others and it's ultimately making decisions together, so I wouldn't say I have an individual influence. I am currently the facilitator of the group, so there is a responsibility there that has been offered to me in that position, an accountability piece, that I think is used to keep others accountable, so I would say that I'm not necessarily an influencer, but it would be in that sense that I'm keeping my colleagues accountable in there. In minor instances, my point of view as a teacher who teaches a topic without others to collaborate with we call them exploratory or singletons. I hold the position as the one individual on the committee who sees that perspective so when we are initiating change, for example, a focus on literacy across the building, I can share what it may look like within this classroom and other performance-based classes where individuals who don't necessarily have that built into the curriculum as quickly as others may or as easily as others may. So it would be ultimately just being a voice for those who don't have a voice on a normal day-to-day basis when we meet with him. It has 
also sparingly offered me times to be a leader on other committees, too, just based off the performance from the leadership team performance. So nothing specifically direct from me saying here's what I think, But it does allow for a voice to get to that point if I felt like that was necessary. But it's more still you are an individual amongst many making decisions together.

She mentioned other committees she's served on:

I am currently in a committee that is based off it is called Bright Futures where we try and have communal interactions, well, with the community that is, in making positive changes helpful to the kids involved so service learning activities, donations, giving back to the community. That's a committee I've been put on. Another one is our PLC committee or Professional Learning Community in which we take those concepts trying to improve our school and bring them into the leadership committee. Another is behavior and struggling student support team in which we are looking at those things that keep students from feeling like they want to achieve greatness on the things that are not necessarily academic-based but relate to attendance or general interest or rewards based things that can help them improve that. There will be a new committee next year for a new Behavior Intervention System and that will be the next one that I will be on. And they all have stemmed from being on a leadership team just because of how I've interacted on that one. Those invites have come due to that.

Next, Mrs. Carroll described other teachers in leadership roles and the impact they have: I think you're going to often see that. From my perspective of still a fairly young teacher, this is the sixth year for me and in one district. From my perspective, I 
see it as the leaders are found more among the young teachers. So they are the veterans who have previous experience in multiple areas and they can guide, basically. They feel much more apt to reach out and have quick pieces of advice for other teachers so I see it as more of a mentor situation, mentoring their colleagues. In other ways it's general understanding of relationships. They can perceive student to teacher relationships quicker, they notice the small things I think better just from experience with maybe a kid who has come to school wearing the same shirt three days in a row. They have quick eyes to notice things beyond the academics so they are leaders in the sense of how to have those relationships with students. It might be even small, and I feel non-veteran teachers there are a few who take certain aspects of leadership upon them that maybe others wouldn't, so being like a second-hand man in the hallway so much like security or the assistant principal who might say, "Hey, you need to stop running," and have a discussion with the kids so they are playing the watch guard. I don't know how else you would describe that. Other ways there are leadership positions without having the proper title. There are plenty, I think, teachers are basically like teaching strategy specialists. I feel like they just naturally have found the stuff, not naturally, maybe they have researched what works in the classroom and what doesn't so they're leaders on the academic side by how they implement stuff. There are plenty who are solid at collecting data, using it to guide their instruction so I would say if you can make that a title, whatever would relate to that. I feel like from my perspective, those are probably the main ones that I see. 
It's much like that teacher who comes out of school initially. They are motivated. They lean towards leadership somehow by nature. It could be that that's their-it's just the way that they are or in some instances I feel like there's others like me who realize when you are put in that position you have to step up. They're flexible, they are responsive, they are perceptive. On the more literal situation I would say they are the teachers who have been around a little bit longer than maybe ten years plus. I feel like those are the stronger ones that I see. Then the other ones would be the fresh eyes, the new teachers. They are still animated. They are still active. They're not passive; they don't sit back. They communicate with you but you can see that behind them is this energy that's visible in the hallways, in their classroom, in their interactions with their colleagues.

Ms. Williams relayed ways the administration has utilized her skills:

Yeah, I think the questions a lot - he comes in for feedback. There's times in meetings when I'll answer his questions with my opinion even if it doesn't relate to PE. Just to be like why are we doing this? Just kind of feedback because you can tell he wants feedback from teachers and a lot of them are scared to give it. And I'm not because I know that he respects me and so, I know we might not always agree and we can always agree to disagree, but there's a respect there so I'm not afraid to say things. He might like it, he might not.

She also talked about other teachers in leadership roles without a formal title:

Well, Coach Delaney Steele, she just became a formal leader but until now she really wasn't. But she's been big on kind of in-between the teacher and the administration in the past. And then, we had a principal a few years back. He was 
a PE teacher that used to be a principal. And he was interesting because he taught me a lot. Because he's a PE teacher for me and had been a principal for two different districts in the past so he gave a different perspective, but he left a couple of years ago. We have some really good teachers, like Mr. Ray is a really good teacher that - I think they look to him a lot on his knowledge of things and how he does things, and people come to him for class management, so he's the one that probably stands out in my mind the most. He's not as verbal and outgoing like I am, but he knows his stuff, so they can lead people to him when needed for that.

Ms. Williams discussed how other teachers are leaders beyond the classroom:

Beyond the classroom for Mr, Ray, I think he shares his knowledge if needed. He's not going to come out to you, but if you say hey, we need this teacher to talk to him about this, then he shares a lot with that. Steele is a good public relations person as far as let's try to see the other side of things, which I don't always do. Sometimes it's my way is the only way I think, so she brings the other balance of that of let's look at the other perspective and consider that. She's good about kind of bringing people together on the same page when we're not always like that.

She described them at greater length:

I think a lot of just being able to communicate. That's one thing we talk about with my teams. We talk about giving your best effort and then are you a good communicator. It's a challenge for kids these days, and even for adults just through the technology today. So, just being able to talk and then agree to disagree and see other viewpoints and understand that to them their class is the 
most important thing and so if I'm requesting something, how does it affect them? And then understand that both ways because some people get stuck in a rut mine's the most important and it's like, well, it's important, but we need to balance everything. I think just being able to communicate openly without creating rifts is best and then also being able to criticize in the right way to improve people without it being personal, like being demanding but not being demeaning, so not ridiculing them, but how can we improve this way? Or what's another way we could do this? That kind of stuff.

Ms. Weston discussed how her skills have been utilized by the administration: Previously I had been on like the TAC (Teacher Advisory Committee) committee, so we sit down and I've been on both for - superintendent for district wise and for two previous principals. So, bouncing ideas off of us, like trying this, do you think this will work? That kind of thing. And once again, I think it really just has to do with the fact that I can say I like that, I don't like that. Why would we do it that way? Why not this way? Okay, that makes sense. I'm just not going to be like no. There's a lot of times when people talk in meetings and I see all of these like red flashes. I don't like this. Oh, this is scary. And other things I'm like ok.

She gave examples of other teachers in leadership roles:

Well, my colleague next door. She's been here for two years, but she has been teaching for fifteen years. She is my co-chair for Professional Development, and the way that works is that we lead all of the professional development for the district. So we are the ones finding it, we are the ones teaching it, and we're the ones doing it. We're spending a lot of extra time together: free time, I mean like 
she has three kids, I have three kids. That's a lot of sacrifice for the betterment, I mean, yes ourselves, but the betterment of forty teachers that we have here. We're trying to figure out K-12, so we're even trying to figure out elementary, like what it is they want and what they need and all of that so that tends to be a little time consuming. She's definitely stepped up and has been like I will help you. What do you want to do? What do you need?

She discussed more about how these teachers are:

Not afraid to speak your mind. Whether it's against whoever's offering the idea or trying to better the idea, you might get backlash for it, too, but I think speaking your mind helps a lot and then you don't get walked over. Because that tends to happen in our field. You get pushed into doing things you don't want to do per se, but you say yes and then you smile anyway. And I learned a long time ago, I'm like ... Not that I want it to be like what's in it for me? Like for me right now I have three children, my husband is a marine, he's stationed in North Carolina. $\mathrm{He}$ does not live here. Like it's just me and my kids. And I have my mom. I have family around. We were talking about it the other day for renewals for next year, for like NHS and NJHS and I was like yes, I want to do it. I would do it without pay. It's not a ...I'm making a lot of money doing this sort of thing. I want the kids to get out and serve others so whether I'm getting paid or not I don't care. . . I think staying positive helps to go through all the negative. Lots of negatives. Everyday. Staying positive helps.

Ms. Robbins detailed how her skills have been used by the administration: 
Lots of UCM students come to observe, lots of UCM students being a student teacher, lots of students just doing their hours of observation. This last year we did a video, they would set up the video and they could see and hear everything going on in my classroom. But I could not see or hear them, so it was...there were three or four different teachers and they would set up a camera and so they could see everything going on in our classroom and they could flash between four different screens over at the college...we just saw the teacher do this, what was the intention? How did it turn out? Did she have to change anything or modify anything? So remote learning, I'm not sure what they called it...There weren't twenty people sitting in my room watching. So from the teachers at the college's point of view, oh, I've presented at the college before, different lessons. They've asked me to go over there and talk to some of their preservice teachers and teach them a lesson or show them how...just different things. Because as a college professor, it's been a few years. Since they've been engaged with real-life middle schoolers, real-life fourth graders, or that kind of thing. So I've taught some college classes, just one or two here or there, but so a lot of preservice teachers have come and watched and observed and have been under my supervision to student teach or plan lessons, so I think that's part of leading the next generation I guess you could say.

Ms. Robbins described other teacher leaders:

There are certain teachers that are electronic gurus and so if you have a problem working with your grade program or if you have a problem working with your website or getting an interactive thing to work for your classroom with your 
students, people will run to them and say, oh, can you help me with this or help me with that? So they are leaders. There are people that use a lot of technology, some younger people, and so as an older educator, it's like, can you show me how that works? Because the kids were excited and I liked that and I just need an extra practice run through with another person so I will feel more comfortable.

Everybody has their interests and their strengths, so there could be - depending on what you're wanting, you could go to a different person in our building and they are a leader in some way, some fashion. Some people are really good at relationship building, some people are really good at making behavior plans, and some people are really good at de-stressing children when they've gotten too wound up for whatever reason or too upset by whatever the environment and you might, sometimes just a fresh face also helps that. So I mean, the leaders are, they're good at something - there's this little niche. There's a little area of expertise. And they're comfortable doing it and they're willing to help, so they're helpers, they're leaders, they've got expertise in that area, and some are just the people that never say no. They will help you no matter what. I don't know what you're doing, I don't understand a word of it, but I will help you. And we have those people — the givers and they're needed, too.

Ms. Carpenter discussed how her leadership skills have been utilized:

I don't really know. Just recently I got my Google certification as an educator and I think again, that's just showing others, hey, you can do this. Our superintendent is kind of pushing for it, and so I am one of the first five to get it done and passed and everything, and I think just them being able to say because he sends out an 
email or whatever that says, hey, these people have passed, and it may be pushing forward and showing other teachers in the building that it's been done.

Next, Ms. Carpenter explained other teachers in leadership roles:

We have a couple of teachers here in the middle school that they have their master's degrees in specialized math and so they're taking on leadership, going out to other classrooms and kind of being an instructional coach so we have a couple of those here in the middle school. Again, I think it's just doing it. Going out and doing it and taking the leap of faith, a step ahead of everybody else just to show that it can be done. I think that's one of the things is just, you lead by example so, if you want to get it...if you want other people to do it you have to do it first so that they will follow. Well, obviously communication is key, so not only just going out and doing it, but hey, these are the problem's I've had or this is how you can solve this, things like that, so go-getter, communication, yeah.

Ms. Spalding discussed how her leadership skills have been used:

That's probably evolving a little bit. I know on the athletic side, our AD has encouraged me to speak up on hey, why don't you plan this, or why don't we host districts and you be kind of in charge, and so some of those athletic side of things, and then Mr. Munstermann in a meeting, like, hey, what do you think about that? And so like kind of pull and force me to speak up a little bit. And then this year is my first year on the PLC committee, which that kind of helps plan all of our PD and stuff and so, and like monitors our school's progress is like the PLC. I did my first faculty presentation at the beginning of this school year, and so starting to be more of a vocal person is challenging, but it's exciting to think about continuing 
on. And I'm working on my master's right now in administration, and (they, the administration) have been like hey, go for it, see what you learn. And if you need help or have questions...I feel very supported by my principal and our other administrators and so I think they want people to step up and do better.

Elizabeth described other teacher leaders:

I think within our department we have people you go to for certain strategies or certain...because my experience right now is more focused in the science department. And so we'll have Ms. Burnett who was my mentor teacher. If I'm wanting to do a lab or a walk through like okay, I want to do this, how can I get this to happen in my classroom? I feel like within each department there's somebody that you can go to that's not like the instructional person for that department. But you say like, "Hey, I'm trying to do this. How can I get this to happen?" I feel like there's people in every department or around the school that are encouraging like hey, I want to try this. Like go for it, you should do it. Or if you talk about like what you've been doing they're like, oh, that sounds super cool, let me know how that goes or like we just went around and grew bacteria from around the school and other teachers are like, yeah, come on in. Let's see what we're growing in here so I just think. I feel like other teachers are supportive of what you're doing for the most part. So we have people that we go to like instructionally. There's so many different committees and stuff that almost everybody has some kind of leadership position or role. The people that I'm drawn to are people that are supportive and want to know how they can help you, like if I ever need anything, Mr. M. is like, what do you need from me? And I 
think that's... if I were to ever be an administrator or if I were to ever be a department head, I'd be like what can I do to help you? I think that's the biggest thing I look for, that I would go to, and our AD's the same way. Like, what do you need from me? And he'll make it happen. Willing to work alongside people...I heard at a coaching conference that if service is below you then leadership is beyond you. So if you're not willing to serve, you shouldn't be in a position of power. And I feel like every administrator or person in a leadership position is willing to get down in the trenches right alongside. That's what I look for.

Ms. Stephens discussed how her skills have been utilized:

David definitely looks to me to schedule for us, I mean anything from just our basic daily schedule to our MAP testing to our benchmark testing to putting groups together for things, so I really feel like he definitely looks to me just to kind of take care of us down here.

She provided insight about teachers in leadership roles:

Well, when I think of academic leaders, I think of our two title teachers and they are so strong in their content. I mean, we just look to them like crazy for help and ideas. You know, because they can kind of see maybe how programs should be run from what's best for the student as opposed to, you know, administration has to see what works on paper, but you really look to those two ladies to see how does it really work for teachers and kids, so I definitely think of those two ladies for who we go to for that academic need, like what do I need to be doing with my kids or why isn't this program working? Where is the breakdown? It's those two, 
and they're both very, very bright. They're very conscientious, they have the utmost integrity. If they say they're going to do something, they do it. I mean, they're not ones that just give you the talk that you want to hear because a lot of us are good at the talk, but the really getting down and doing the work. Those two ladies, they do the work, and then they will help you in any way that they can, and they're very organized. You know, so they have those things, the organization. I don't think either one of them would be comfortable saying they're a leader. They don't want to be a leader, because that takes on a whole new monster in itself. But they, for sure, are our academic leaders.

Mr. Hawthorne discussed how the administration utilizes his leadership skills:

Well, yeah, the administration has in the last couple of years focused on then in the past on putting teachers together and having us work with each other in different roles. It's very, very easy for us to become like really compartmentalized, isolated, I don't know what science people do, you know? Even in this little building. They seem like they're really far away. So I think that the administration has been doing a good job of something that really....don't want to do necessarily, going and observing each other and making notes on that and so I think that's an area where the administration has utilized me and other people in the building — getting teachers into a situation where we're learning from each other. I would say, I don't know if the administration agrees, one of my strengths is like classroom management. We have a lot of classroom management problems and that's always a - like this really weird mysterious thing, just the art and the science of teaching and so I think that's on the art side. There's definitely 
scientific things you could do for classroom management, but there's a lot of the art in that. Sometimes it's really interesting to find out that we have a - I have students that I have never had a problem with that other teachers do. And maybe vise versa. You know, I've had a positive experience more than negative. And so the administration has done a good job of saying, look, you have a studentyou've never written this student up, sent them away, they're passing. They're totally, they're not making it in this other class. Can you talk to that teacher? Can they come into your room a little bit? Can they see and find out what you're doing? Share some strategies to get success across the board with the student? I think that is a way that is a lot of times just organic and not exactly part of a program or a plan, but one way that they've utilized me and other leaders in the building to try to do positive... It is something they've made a priority and they've found different ways to make that happen, and I think that that's positive impact for the school. I've gotten things out of it and I think other teachers have. That's one thing that comes to mind that I think administrators have positively used different leaders including me.

Mr. Hawthorne described other teacher leaders:

Leaders beyond the classroom...well, you know, for our district, and I'm sure it's the same for big districts, too, and actually just, by the way as a caviat, I've never actually worked at another district, so all my experience with other districts come indirectly from...I went to school in St. Louis... or where I student taught or whatever, but going back to that thing that I said, it feels in a district this size we take on a lot of different roles, we all have to wear a lot of hats...a lot of roles that 
have to be filled. So a lot of our teachers serve really important roles like in the PTO and the booster club and things like that. I'm sure it's like that in big districts, too, but are you looking for more like a specific example, or just general?

I think that this is going to sound pretty cliché or something like that, but the biggest characteristic is just the willingness to be devoted to the class. Obviously every school has the 7:30 to 3:15, I never...I don't want to be like jaded or sound negative or whatever, but you see people that leave and they're out at 3:15. They are right behind the students and I always think, how in the world do you pull that off? Sometimes it's like admiration, like how'd you do that? But usually it's like we have a lot of things here that could be done. So you feel like some people are picking up a lot of load and other people are the 9-5 thing, and this is not a 9-5 job and so I think that the biggest characteristic of other leaders that I admire the most is just the willingness to go all in, I guess. I landed in this district, loved it a lot, now I'm proud to say we bought property, a house, we live in the district now, we have a residence in the district. I have my kids in this district. My wife teaches at this district. Between the two of us we have about twenty jobs in this district because that aspect of this job that we love is that it's not just a job, I guess. You know what I mean?

That's the part of it that makes it, you know, like why would you do that? The pay, you know, and other things, even our public perception it feels like is low. So it's literally now kind of a thankless underpaid job as opposed to just an underpaid job. And so why do you do it? And I think that for us, the decision was it's more 
just our whole lives - our pride, our identity, our kids are here, and so this maybe sounds cliché, but the other leaders are the people that also do that. They're just here all the time. The kids know it. They know the ones that are here all the time. They know the ones that are also on the booster club and they go to the school board meetings and they come in hours early to sit on a scholarship committee. They did that last week. I was here late last night at a school board meeting. Your CTA's and all those different things. So I think that the number one characteristic I guess to sum it up is just who's going to show up and do all those things. Because they don't all pay, so who's willing to just do all that junk because somebody has to if it's going to get done.

And you just want your school to be the best. You want the experience for the kids to be the best. I don't know whether you'd call that dedication or whatever, but I think that's probably the primary. Every single one of us has something to offer. The English teacher here who was a former student of mine, you know, she came here and was like, we don't do speech. Why don't we do speech? When she was here she did speech, but the person that did speech retired and then nobody did speech, so now we don't do speech anymore. I didn't even really realize it...so why don't we do speech anymore? Mr. Graves left. I guess. So nobody did it. So now she does it. She's got a young lady going to regional speech championships. That just happened. Somebody just came in and made it happen, changed some kid's life, so. So that's really what I feel is the clearest answer I can give is who's going to be dedicated to put in those hours.

Ms. Wheatley shared how her skills have been utilized by the administration: 
They've actually given me the entire Google admin consult to manage. I also manage the website, so there are a lot of things underneath the surface that, you know it's not necessarily things that people see, but they're things that we have to have managed so that we can do what we do on a daily basis. And just as an example, the other day they brought me a massive binder and it was the entire school board policy and they said we need all this on the website - can you do it? And no we don't have it in electronic format, you know, and I said no problem. So there are a lot of times like that when there's something that they know needs to be done. And it's not necessarily that they don't have the time for it. They have so many things that they need to do. But I feel like they entrust me with a lot of that because they know that I'll take care of it and then I'll manage it.

Ms. Wheatley described other teachers in leadership roles:

Well, we have...you know, this is a small school. And there's not really what I would call teams in your traditional PLC type of a setting, but everybody here really works very hard for the same goal and everybody's very willing to step out of their comfort zone, you know, if somebody needs a little help with something here or there, everybody's very willing to do that. And we have a lot of people that feel very comfortable with a lot of the technology that we use.

So for example, something will come up in a meeting and we'll decide, okay, maybe we need to take a survey about this or we need to collect some data here and it is not uncommon for someone to say, hey, I'll create a form and I'll send it out to everybody. It's very...I think everybody feels comfortable and supported here, so they're very willing to do that and everybody's on a committee of some 
sort, so everybody has some sort of leadership role. It's awesome. It's so fun to work in that kind of an environment.

Let's see if I can come up with a good adjective. Definitely goal-oriented, but very determined and persistent. We've really stuck by our guns with everything that we've put in place this year as far as classroom management, behavioral procedures, positive behaviors enforced throughout the building, and we don't just necessarily rely on those committees to do that. Everybody will really stick with that. If they have to explain something to their students, they don't want the principal to do it - they take care of it.

Ms. Marigold explained how her administration has used her leadership skills:

This administration here is absolutely fantastic - I always say I don't work for him, I work with him. And he is so absolutely, that positivity that you see is not something that he fakes; it's truly who he is and the kids don't fear him, they respect him, and that's a huge difference. We hardly have any discipline issues here whatsoever because the kids respect him so much. When I was at another district, we would have multiple fights a day. Here, there's none of that. I mean, the biggest discipline would probably be tardies because, it's not that they're afraid of him or they're afraid of the consequences; they respect him enough not to want to disappoint him, so when you hear of someone getting in trouble, they are automatically almost ashamed of themselves because they know what he expects and so I think he fosters that attitude with his teachers. He plays no favorites, he is fair and equal with everyone and I think the teachers feel that, they know that, and he has an open door where he continually supports us and that has 
been a career changer for a lot of us. (I repeat question) I've led multiple conferences here, Socratic seminars, we have done, I'm in a pull-out right now with UMKC where we're talking about a book called Ship This where we're talking about mindsets, and we'll do a presentation soon, curriculum instructor. I just think in every way possible he utilizes all of us. Not just me, but he holds our staff to such a high degree. He's in our rooms all of the time but not checking on us, but just there to help, there to mentor, so many different things.

She provided further description of teacher leaders in the building:

Oh gosh, I think every single person here in our high school is a leader in their own right. And you can walk down the hallway at any given time and they are doing what they need to do. Again, it's not out of fear; it's out of respect. It's out of knowing that he has high expectations for us and so we follow that. Knowing that he expects for us to teach bell to bell, and it's not a you're in trouble situation, but more so in just out of respect.

He has people present all of the time when we have like our PD days, people are giving different things that work well in their classroom. We have a teacher of the month. He shines on us each month where we get to choose it, but he talks about our strengths. I just think for all of us he expects that we're mentors to the kids. Any principal could learn by coming and watching him just simply by walking down the hallway and watching how the kids react to him is such a joy. There's so many different ways even in your own individual classrooms. Even the teachers that don't have specific titles like instructional coach, they know that 
they have that expectation in their room every day to provide quality lessons to the kids and they rise to meet that challenge. So that's what I would say.

She provided further characteristics of teacher leaders:

Honesty, integrity, perseverance, diligence, and respect. We are such a big school on respect, and I think kids see that we have high standards, but they also see that we are grinding right next to them to meet those expectations. I mean this is, I loved my former district, I loved the kids, but I never really got it until I came here. And this school is so so big on the grind and the respect, and not respect given but respect earned. And I think that we are teaching our kids that it's a lifelong thing and not a right now thing.

Principal perceptions. Mr. Hall discussed the impact his teacher leader has had on the school:

Well, she's in charge of the BLT, she's also in charge of the morale committee and so she has had a positive impact on how people feel about the school, the school culture - she's almost directly in charge of that, or at least the BLT is. She's had a hand to play in improving that.

Mr. Garrison provided explained the impact his teacher leader has had:

Yeah, a perfect example for impact beyond the classroom is so my first year here when I very first started, one of our first PD's which I didn't set up or have anything to do with was we'd brought in three-dimensional coaching which is this coaching mantra. Basically there are three dimensions. And so like at the first dimension you're mostly just focused on the fundamentals and the game orientation and most coaches are only at this level, you know what I mean? And 
that's the reality of it because the second level would be like dealing with the individual needs and then that third level would be like promoting the individual needs as the team. And so like examples of coaches like that - I don't know if you're into sports or anything like that but when Dean Smith who is the coach at North Carolina passed away, like in his will he mailed a check to every basketball player who ever played for him - he's like take your families out to dinner. Remember the importance of, you know what I mean? And we see that and we understand that, and that's one of those things that's like she is an example of...she was instrumental in wanting to bring that here, wanting people to hear that message, and getting people to understand this is the impact that we have every day as teachers because you are the coach in the classroom. You know, it is different in a coaching relationship because you're seeing those kids and they're seeing a different side of you, but it's those elements, it's those pieces that take it beyond that because she sees it, she wants it to be like that, and you know, embodies that. So that would be an example of the impact that she has beyond.

Mr. Hyde discussed the impact of his teacher:

Really just making it a more positive learning environment. I mean, she does a lot of things in her classroom. But really, anytime you have a teacher that's willing to step out of their comfort zone - sometimes it's in their comfort zone, but just willing to take that initiative to positively impact kids you're going to see make a positive change in the school. She saw the blood drive; that was one thing that I did at my previous school that was kind of near and dear to my heart. I had a daughter that had an in-utero blood transfusion and so oddly enough, no matter 
how passionate I am about it, I throw up every time I get around a needle so even though I can't give blood myself, I still am very passionate about trying to organize people to give blood. Now in my position I don't have that ability and it was just something that I was talking about trying to revamp. She's taken it over, she sees a need in it as well, and we have had our largest blood drive. We almost doubled our blood drive in our first year, doubled the number of donations. In our first year that she had taken over in response to our previous year. Well, that just brings a positive vibe to our community, to our school, to our kids.

You know, she takes it upon herself to go around and decorate teachers' doors. It's a little thing, it's a minor thing. Is it necessarily quite as impactful as a blood drive? No, but she just takes the initiative to do it, and now as you walk around, all the teachers in the high school and middle school have their own unique positive saying on their door. Earlier in the year she did superhero themes, and so every teacher had a superhero theme on their door that correlated to their last name so if their last name started with an S they were Spiderman or Superman or depending on what they wanted. But then again it's a little thing of, it just kind of creates a better learning environment. We have a lot of power as an administrator, but really whenever it comes down to it, it's really the people that are making the things happen. We just have to give them the freedom to be able to do those things.

She just does a lot of little things that you know kind of just culminate into a bigger picture...new lockers, we used to have really, really janky, ugly, mismatched lockers and she's been fundraising for a long time, got the kids 
motivated because the middle school kids - she's in charge of NJHS. The kids didn't like their crappy lockers, okay, so let's fix it, let's come up with a solution. So they researched, you know, this is how much money we're going to have to have, they talked to the board and they said they would produce $50 \%$ of the money and so then they fundraised. Now we have nice new lockers so, again, kids are happier because their lockers aren't always jamming, look crappy, and all those sorts of things. But now whenever people walk through our halls, and through our middle school hall, they're not seeing forty-year-old, three-color because the paint's chipping off lockers. Again, it's not necessarily something that's going to make you go, oh my gosh, this is the greatest thing in the world, but it does positively impact the district.

Mr. Finnegan shared the impact his selected teacher leader has had:

Extremely positive impact, you know, she's also the science department chair and has guided us through the new standards, state informed upon what was going on. Science departments are always interesting at different places because they're naturalists, they're earthy. They all love their content more than anybody else's content, so to orchestrate that group to come together and move in the right direction on a daily basis is pretty cool to see. She does that with the whole building, too. She's a leader on her team in sixth grade. If we're having troubles with a seventh-grade student, we know we can send them down to her room to be shut down, let him not have an audience, because seventh graders aren't going to want to show off for sixth graders; they want to show off in for their own peers. 
She's got structure, she sees things black and white even though she knows there's a gray area, she does a great job.

You know, what I love about Cindy - I don't require teachers to come to things. We have dances they come to... I always tell staff your kids love to see you - at the music concert, at the band concert, at a basketball game. Even though she's a sixth grade teacher, those are still her kids because she had them in sixth grade. You see her at all of those different events whenever something's going on. She's going to be there. Now it could be because like me, all of her kids are grown. And so you have more free time; you don't have little kids at home, but she was that way even when her own kids were with her. She was at kids' events building those relationships with her. Others come with her and all I can say is I truly believe our staff views her as a leader. She's on a superintendent's advisory committee, reports back to our building, takes concerns to the superintendent that maybe are district concerns, not building concerns so yeah.

Ms. Chrisley discussed her teacher leader's impact:

Definitely within her sixth grade team she really, when it comes to technology, she pushes her other team members to try new things. It's been interesting because one of her teammates that is very timid - wonderful, wonderful teacher, but she's very timid amongst adults, but amazing with kids... she actually decided to go ahead and do her master's in technology education, which I hadn't seen that a lot from her but I think it's just she started seeing it grow and started seeing what was going on here and Carpenter was a big part of that push, letting people see - I don't know how to do it but we can try it and figure it out and be risk- 
takers. I think that's been the thing that people saw in Carpenter here at school is that she's a risk-taker. Even if it's not the most comfortable thing or she doesn't totally understand it, she's willing to figure it out and try it. And she's willing to, like we had two years of Kagan training, and she was one that she grabbed hold of one of the structures and just said I'm going to be great at this. So then she was able to get in there and teach the rest of the staff and give them some support in it and, you know, I can tell, there's just been several things I've been able to tell the other teachers when they come to me and say I'm not sure how to do this or that, go talk to Carpenter; she's your woman. So that's the impact she's made.

Mr. Munstermann elaborated on the impact his teacher leader has had on the school: Well, she's improved our department. I mean, I probably cheated a little bit. We have recently moved her into a building leadership role on one of our teams and I'm very curious to see how that progresses and she progresses with that. Because you know, there's a lot of like-minded folks having those very philosophical conversations, you know, and building improvement and so she's only been maybe to one of those meetings and so I think I was kind of let's sit back and we'll see the lay of the land. But I'm excited about that over the next couple of years. And that wasn't at my direction coming in. That was something we threw out knowing we had to fill a hole on that team and she was unanimously named by her peers that are on that team already. And none of those are in her department. Impact wise, there's a lot of people that listen.

Mr. Warren added: 
Before I got here, there was a pretty difficult culture on this side of the building. We had someone in this office, obviously before ... who was pretty rule with an iron fist. And then you did not sneeze unless you had permission, and if by chance you looked at her wrong, then she would scorn you for life. So when I was brought in, that culture was there. So when it got to the point to where that person no longer had middle school and I did, Alexandria is one of those people who dedicated that time, we know we're not under that reign anymore, so we're going to change culture around here. We're going to instill confidence, we're going to work hard for our kids, and we're going to make people understand that we are not the horrible people she made us out to be. So she stepped outside of that first and led that charge, and she has elevated us to incredible status. I believe we are the best school in this district, and because of her, that has happened. She is a teacher leader in the curriculum as well. That's just something that she does. She wants us to be the best and she wants our kids to be successful. And just the impact that she's had, I cannot quantify it. She is known for being just that person. Our school is known because of her. She's just awesome... Her mother was a teacher, I don't know if she shared that with you - she was in the school system as well. Great teacher, great educator, her family is well known in the district, very upstanding people but you would never know it. That's how they carry themselves. And that's how she carries herself, and in fact, she has shared that with her kids. And they're the same way. Talented young people, but you'd never know it. They just do what they need to do and they're happy to share that with others in a kind way. 
Mr. Quick discussed the impact his teacher has had on the school:

I'll try to sum that up. I think he does great in the classroom; the kids have a tremendous amount of respect for him and I think those go hand in hand. But then outside of the classroom he just builds those relationships with the kids and sometimes that's what they need just to get to school, so it affects more than just his class. And, you know, I ask students often, who's your favorite teacher? Who's the teacher that you can go to, you know those kind of questions. You know, if they don't have one, then most often they don't want to be there. And again, I don't know, chicken or the egg? Maybe they don't want to be there so they don't have one, but what I do know is that those two things are correlated. And if they do have somebody that they can trust that they can go to, then they usually don't mind being at school. They may still not be the biggest cheerleader, but at least they show up and they're not just in their own personal hell every day, so he does that for a lot of kids. And I think that's kind of natural, just natural to him. He also does student council and so I think that has - again, kind of a natural leader. He tries to get those students to be leaders, so I think he does a lot of those things that as far as the school, are positives that he does.

Principal Silvers shared,

I think just her impact with the community as well. She teaches flag corps competition and I think a lot of the people in the community wanted her back because of that reason. You know, they've seen her out and she's done an excellent job with them. They've won a lot of trophies - but it's not the winning 
of the trophies; it's the way the kids are learning from her. And I think that's what makes it really neat for me.

Mr. Shackles explained the impact Marie has had:

Well, at the school level, she was able to visit with me and convince me to start an honors program in English and that has a summer component, which most schools are okay with summer components. Many of your co-curricular activities will have summer components, you know. Band directors might write in $60 \%$ attendance at band camp or whatnot, but usually a summer component in my experience is usually relegated to more of your private and charter schools, especially heavily on the private. Well, we got to looking at a few things and read a little bit and you know, just kind of bounced ideas off of each other and well, let's do it. And I was pretty insistent that there would be a summer component, okay. I felt that that would be - I wanted something that would grasp everybody right up front, parents and kids and teachers, that this is different. It's a lot different. It's easy to tell parents and kids, hey, we're going to be faster moving and there won't be as many multiple choice. It's going to be more essay-based and critical thinking and strategic thinking and problem solving. I mean, we can say that until we're blue in the face and they'll go uh-huh, uh-huh, uh-huh, but they don't really understand it. But if you say, hey, there's a summer component, there's a reading list, and there's not quite what you would call a portfolio, but there are several things that are due the first day of school. Well, boom! That's concrete, they can grasp it, and they go, oh, this is a lot faster moving, this is more rigorous and that's concrete. 
And much like what you're used to, Odessa is a working community, a bluecollar community. We are, too. You've got to have a concrete component that they can grasp a hold of and they go, yeah, that really sets it apart, and I felt personally that that would really set it apart. And then, you know, maybe take out a little bit of the ones who really don't have the strong work ethic. I am not unhappy with the program, okay. It has...I'm not unhappy with anything about it. They do move fast. It is more rigorous. I actually had a couple of kids have asked to get in and we discussed letting them in at semester and I'm the principal, I guess I make the final call on everything, you know, and no. Wouldn't be fair. Not that we have to be fair. We have to be more just than fair, but... and some just want it to look good or it will look good on that resume I'm making for college. Recently, LA Times printed an article on, let's see the title of the article was...I'm paraphrasing obviously. What students in high school and college know that their instructors don't know. If you get a chance to read that article, I read it. It was about two weeks ago and I thought so much of it that I forwarded it to a bunch my teachers to read.

Principal Hall discussed other teacher leaders and their impact on the school:

Well, the ones that are evolving, you know, they continue to have an enthusiasm for improvement that drives them so, you know, they're driving that enthusiasm so as we go through the School Improvement Plan, they are the ones that really kind of keep it going, so...I just try to find people who are passionate about those changes... and kind of keeps us rolling along.

Mr. Hyde provided examples as well: 
I think a lot of it is just being positive. Because if your teacher leaders really want to see what's best for the kids and what's best for the school, it's always going to have a positive impact. It might completely fall on its face - whatever initiative or change - but in the end you're going to learn from it, you're going to grow from it and then the end result is you're going to have a positive. You may have a short term regress, but in the end you're going to see positive gains from it because you're going to learn from it. In all reality, whatever positive gains are going to put you past where you were before. I'll try to answer the beyond. Just getting kids excited about coming to school. That's the hardest thing, you know. Letting kids come to school and let them know that there is a variety of people that want to see you succeed. It's not just doing the things that you have to do. I'm not just coming to school and teaching you a lesson, but here are 100 different opportunities from twenty different staff members that all are trying to find ways to impact you and I would say that little piece I think kind of makes a difference. Principal Finnegan discussed other teacher leaders making an impact:

I'd say the practices of our school were developed by our teacher leaders through the years. I call it I think it's sustainable leadership. I read about it at some point. When I leave, it shouldn't change. It should stay the way it is. Change is good; don't get me wrong, but it should stay the way it is because it's not me that has pushed out, although I mean my philosophies are throughout this school, but the teacher leaders are the ones who are leading us in the direction that we need to be going. If you go to district committees on a regular basis, I cannot lie, I have subs in my building on those days. Because my teachers are the ones that they ask to 
lead that committee, to do this, to do that. And I don't take credit for that; I just think that they are naturally ingrained for that. Because yeah, Janet was a teacher leader before she came here; we've just harvested it more. I think probably most of those teacher leaders have a sense of leadership within them. Some are good with being a follower. And you need good followers, but it's a matter of giving them opportunities and saying hey, we might hold off on doing this. I think most of them will tell you I'm pretty good about saying let's wait a week or two. You've got to make sure that everybody's kind of going in the right direction. And then we can go ahead and implement something different.

Mr. Munstermann shared, I think if you talk to central office, the high school, I think with most districts it's the face of the district. We have started a lot of the initiatives that the district has taken on. The PLC - this was the first building to go the PLC route and we were that way several years before that became a district philosophy. And so I think that those teacher leaders have been the ones to implement the change process here that has gone district wide. Not just PLC, but the whole data team piece and everything else is that all originated with us here.

Mr. Warren explained the impact of other teacher leaders on the school:

Dana and I went through our specialist program together and... we've been pretty close. I think they understand that out of my core teachers I have nine core teachers in fifth through eighth. I think four of them are teacher leaders in the building, so as far as department leads, curriculum leads, program leads, after school extra-curricular leads...so I'm blessed to have that in the middle school. 
And we've been pretty intentional about who we hire and who we put in place, so I think we are the school people look at, the part of the building people look at. People don't know us a whole lot out there yet, but they will, because that's an issue I'm starting with our conference as far as sharing best practices, sharing curriculum. It's been a tough road, which I'm sure you're familiar with as well. But we're going to get there; however, people know that our school is a good school and they know that the middle school is a great place to be. It's a weird year because of all the transitions that we have with kids. They're so different between fifth through eighth. But I think inside of our building, people know. That's where eyes go and we push hard because of that and we're proud to take that on. Because then we want to model for K-4 and also best support 9-12. And I give our high school principal grief all the time. I say, listen, I'm sending you a great group of eighth graders. Be kind to them. Love them. Be okay with them. And just let them excel because they will...Also, some of our teachers are coaches as well in the middle school, so they not only lead us inside the classroom, but extracurricularly. And that's a big deal. We also lead science fair for the district at the middle school. So they understand the importance of it. And our kids appreciate that. And they see our teachers leading them outside of the regular classroom, they like to have their teachers come watch them compete or whatever it may be, but they also know we're supportive in every facet of their lives and we understand they are busy, busy young people. But if we can continue to have our hand in that in some way to guide, to love, to push, then that's what we're going to do and I have a group who's willing to do it. It's crazy good. Once 
again, it's about their strengths, and then who can I put in what position? And also give them the encouragement that you can't mess this up. It will be alright.

Mr. Quick discussed the impact his other teacher leaders have had:

As far as how does it relate outside the classroom, specifically we do strategic planning committees when you have teacher leadership teams. They are a part of that. You know, when I have any kind of advisory council, even if it's informal, and most of mine are informal. We don't have an official time where all of our teachers/staff gets together. We have five half-day professional developments throughout the year and some of those I get to use. Most of those I do not. The Professional Development Committee has stuff to do. So we have very little time that I put all of our teachers together in one room. It does not happen very often. Most of it is me individually going and finding a teacher during their plan period and talking with them like that or obviously some emails, those kinds of things, but getting input for the district, getting input for, you know, the high school building, just asking them. So that's really their impact here in our district. I say that, also, being as a small town, small community, they know, the community knows who those teacher leaders are - Mr. Hawthorne is very well respected in the community, same way. They've never had him in class, but they know. Again, you just kind of know, he just kind of has it. And obviously stories that they hear from their kids help as well. So you know, he does have an impact, then, with parents and with community members as well. Just as a trickle down kind of thing. . I think just her impact with the community as well. She teaches flag corps competition and I think a lot of the people in the community wanted 
her back because of that reason. You know, they've seen her out and she's done an excellent job with them. They've won a lot of trophies - but it's not the winning of the trophies; it's the way the kids are learning from her. And I think that's what makes it really neat for me.

Mr. Shackles weighed in on this topic as well:

Outside the classroom, well, there's a whole lot of different forms that can take. You know, can they lead the team? Can they lead in practice? Because generally, you have willing participants but not always. Can they hold kids accountable to the standards or the expectations? Whatever organization or group it is. I don't really look too hard outside of school activities to be honest with you. For instance, me. I've been doing this for ages. Coaching, plenty of Saturdays, plenty of late nights, blah blah blah. Right now for the last four or five years probably if I don't have a Friday night assignment, I disappear. I head for the woods, literally...I don't always look... because me, myself, I never ask any of them to do anything that I wouldn't do. For me being so public five days a week, they need their privacy...

\section{Administrative Support}

Teacher perceptions. When asked if the administration supports leadership endeavors, Ms. Carroll answered:

Yes, they do. It's more about having the ideas and presenting them knowing that you're not always going to get what you strive for and it's more so on the principal level than it is on a higher level so the superintendents or anybody above your main boss is not going to see it exactly the same way because they don't get to 
interact with you on a daily basis. But as leadership changes, with that collaborative reference continuously they'll bring up, we know that with multiple brains more things can be considered to achieve greatness. The way to get that is to hear out the individuals who are in the trenches of the experiences that we are trying to influence. For my experience the administration is definitely open to hearing the wishes of leadership members in general, anybody who wishes to go that route and their desires, their goals. It has to be really well planned out and presented and considered. There's got to be proof of this change for anything to really happen though. The opportunity to have your voice heard is always there though.

She gave another example:

Yeah, so I will just go back to the literacy reference actually because that one is easier as it was mentioned earlier and it's in my head. That initially stemmed from individuals who have read up on some research. That is one of the main things that can allow for students to be more successful on the academic path based off of the fact that they have to be able to understand text constantly and interpret text and all the other wonderful things about literacy, interpreting pictures and the like and that came from a few individuals on our leadership team with an ELA, a English Language Arts background. Then our principal also ended up researching it to follow it up because he felt like there was something there and then here we are now on year three of trying to incorporate more whatever literacy aspects into all classes. Another one would be PBIS (Positive Behavior Intervention System). It hasn't come so that's why I'm not quite certain about it. Somebody who had 
come from another school district saw that their relationship with the kids and how they dealt with behavior problems were more effective of keeping relationships and seeing positive changes in the behaviors using PBIS versus our current system at our school, BIST, (Behavior Intervention Support Team) and that person came to the principal saying this is something that I have seen and somebody else had said they had gone to a conference and support that. Then again the assistant principal in the situation looked into it some more and so here we are looking to next year to see if this is something that would fit our school. Ms. Williams discussed ways her administration is supportive of teacher leadership endeavors:

I definitely think so. You know, he has a lot of staff meetings. At first people were not receptive to because it was more open: hey, what do you think about this? And we might have a 45-minute discussion and not decide anything and so some of us were like, uh, we're wasting our time. Because we had come from the other extreme of a principal that we loved, but it was direct. He came in and said, "This is what we're going to do," and then did it and it worked great.

Steven is the other alternative, which is fine because it works, too. It just took people to realize why we do this. And, you know, there are some teachers that are old school of thought who don't go along with it and that's okay, but the majority of the people like the fact that their input is valued. And then you have a little more ownership on something instead of being told this is what you've got to do and you've just got to do it. And you jump through the hoops. A little more 
ownership of okay, this is what we want to do, or this is what we think is best, so let's make sure we do it, and then a lot better I guess accountability on that aspect. Ms. Weston discussed administrative support:

Yes. Here at our school it's very much like I want to try this. Okay, great. Myself and the FCCLA leader, we are going to start a clothes closet here at school. We were like, okay, we have an idea. We want to start a clothes closet and they were like, okay. And I was like where can we do it? And they were like, well, we have an extra classroom to do it in and we were like, great. We kind of had this idea and we don't really know and we'll send out emails. And we had this idea and we need some help and both our principal and our superintendent were like great idea! Let's use this or I've got some stuff we can use and so they're very much like what do you want to do? What do you need? Like the flexible seating this year, that was new for me this year. Like, do you want to try it? Sure! Well, we got some money, and I was like I did a fundraiser last year for social studies and I was like, well, I have some money, too, and it was like well, let's buy some couches ... or they normally sit at that table there and I have yoga mats that they lay on, too, on the floor. Or they sit on the yoga balls. We've been decorating doors...that's why I have like all the... all around my room. I went to the standing desk this year, like I don't have a traditional teacher's desk so I don't have a teacher's chair. I lecture depending on what we're doing, that kind of thing so then I'm just around the room. . It kind of reminds me of when I did subbing at a preschool ... and I was like I always have to wear comfy pants and sit on the floor...And the kids love it. Grade wise, my grades have gone up and I've had 
way less discipline issues because I'm like the instance you don't stop, you're moving. And the moving is you're going to sit at a table, in a chair, and then that will be it. And then it's instant. It's done.

Ms. Robbins shared:

I think so. I've never had an administrator - and I've taught for thirty years - if I have an idea and say, oh, I'm thinking about this and I explain it. They always say go for it. I've never had them say, no, that's a rotten idea, do not try that. They might say, let's put it in this form of a letter to educate the parents on why we're changing, you know, this philosophy or why you're trying this angle of it, or whatever, you know, just communicate clearly and I've always been supported and I've worked for four or five different principals. Either I have very calm ideas or...there's always a reason behind it, and if you explain, this is what I'm thinking, this is the desired outcome I want. Here's the challenge to get there. Okay, you know. Come back to me with what you've found out, come back to me with the results. Let's look at the data or let's look at, you know, how the children are doing and re-evaluate it, so I think we've been supported.

Ms. Carpenter also indicated administrative support:

You know, there have been many times where there's been a conference coming up, or something like that, you know, if you mention it, hey, I've seen this. They want you to go and learn those things so that you can come back and lead your teammates in the same way. That's one of the big things is just them supporting you and saying, yeah, go do this, go get this.

Ms. Spalding described administrative support at her school for teacher leadership: 
We almost have a hierarchy of administrators, leaders of the teacher leaders, teacher leaders and then like everybody else, which is not a whole lot of people, so you'll have like your administrators and they have like, I think they call them the asterisks. And it's like the leader of each team that we have, so we have like a data team and a PLC team and so on, and so, like those folks meet from time to time. And then all of our individual groups meet. And so like for the PLC team, we meet every Wednesday and then each group has their own, like data team meets on Tuesdays, and so like within that group they're giving out tasks, so like on the PLC team we have each teacher doing assessment capable learner assessment, little follow-up reflection type thing. So it's almost like a big pyramid. There's an overall idea. The administrators are kind of like facilitating some of it, but it's a lot..I feel like our teachers are mostly deciding the direction that we're wanting to go. And I'm sure that like our administrators have an idea, but like they're consulting with...so I feel like it's very teacher-friendly and like teachers are the ones making the big and like, we want to make our kids assessment-capable learners, so. I think that's cool and I'm sure it's not like that at every district, so it's a cool district to be a part of.

When asked if the administration supports leadership endeavors, Ms. Stephens shared: I think so. For sure. . Well, I mean our administration I feel like if you show the initiative and you show what you want to do, we have administrators that are so supportive of that. I mean, Todd sent me to the teacher academy last year and he sent two more this year just for teachers that, you know, just show the initiative. Anytime I've ever asked to go to any training, he sends me because he knows that 
I'm going to come back and share and use it in my classroom or whatever. They just never say no. It's kind of like I've earned their trust enough that if I say this is something that I want to do, they're going to encourage me to keep doing it. So, I mean, I couldn't ask for better administration in that respect, just so supportive. He's a very forward thinking principal, and like I said he's a big picture guy, too, so sometimes that gets him into a little bit of trouble because he just wants to jump headfirst into things and then the reality sets in like, okay, we haven't done these things first. No one else knows what your plan is, so we can't go there yet. We have a very supportive administration. If you just show them a little bit, they're going to let you run... We get a lot of opportunities for all teacher input, really. They send out Google forms all the time, surveys about, you know, what do you want your PD to look like next year, what's important for your insurance plan next year...We get a lot of those. We're small, though. We get a lot of opportunity. I don't know what I would do if I were not in a situation where we felt like we had a voice.

When asked if administrators support teacher leaders, Mr. Hawthorne answered: Yeah, I think my administration does. I'm pretty lucky here. You always hear horror stories about bad administration. And some administrators are even better than others, but I think our administration has been really supportive of you know, all sorts of teacher-driven endeavors. I think like the way that it looks...like is obviously from the administration standpoint finding out what they're teachers are good at, what they love, what they're passionate about, and then letting them, you know, being a problem solver to find solutions to put that teacher in a position to 
do that job. Our administration is really supportive of that; I've never really asked for anything and the answer just be like, no, we're not going to do that. Sometimes, obviously there's always logistical challenges or whatever, but they've always been really supportive of, like if you want to do it really bad and you can justify it with how it's going to meet goals, then you should do it and they've been pretty supportive of that, then you should do it. I think that, I remember when I was student teaching we had an administrator from a different school come and talk and he was pretty inspirational. He might have been retired. Anyway, he was talking about having been a principal in the building, and the number one thing that he looked for with teachers was people who are going to be powerful self-advocates, advocates for their own programs, and he wanted teachers that every teacher in this building he wanted them to think that what they were doing was the most important thing in the world. And I think that our administration gets that, like, if you are really passionate about it, it will work and so I think that they have supported that.

Mrs. Wheatley explained administrative support for teacher leadership: Well, if there's somebody that wants the opportunity to do something, they're going to make it happen, at least in my experience here. And anytime that anyone has been curious about or wanting to pursue some sort of additional certification or they want any kind of professional development, I've never seen anybody denied that. I mean, they see the benefit of it for, you know, the school and the individual so they try to make that happen. And like I said, there are so many opportunities around here for that to happen. Not only outside of our school, but 
we have time that, luckily our community and our school board have seen the benefit of and put it into our calendar, so we have every Friday where we'll be out at 1:15 and we'll be working together on anything that we need to tackle, and that also provides the opportunity for teachers to come into a leadership role where they can share the experiences that they've had or as part of PLC or positive behavior support, that's when they get to give all of us information. We get up and speak in front of each other all of the time in different capacities, and so it's supported in our school and outside. A lot of people don't understand how important that time is.

Ms. Marigold responded to different ways administration supports teacher leadership: Gosh, in so many different ways, from having freedom in your classroom to teach what you want. That is just so valuable. Our principal trusts us to make the right decision. He knows what's going on in our room. He knows what we are teaching, but the freedom to teach what we want, like if I want to teach Night he gives me that freedom to say, "I trust you. Run with it." He doesn't have us turn in lesson plans because he's in our rooms so often that he knows what's going on, but then again, he's not in our rooms as a threat. He's in our rooms as a support. I mean, he trusts us to go out into the community and represent ourselves well. He trusts our coaches with our athletes to take them to the next level. It's all about representing and letting our skills shine. The place where you find that is in the classroom where the teachers are given the respect and the freedom to do what is best for the kids. . . For example, we have a college prep class that I have next period where they write scholarships and like, rewarding them with little things 
like pizza, just anything or letting us take field trips - we read a book in my novels class and then it turned into a movie. He allowed me to get a bus and then I took those seven kids after school hours to the movies and we all watched the movie together and then we wrote an analysis paper comparing the book to the movie and the kids got to see how much more valuable it was to actually read the book than to simply just watch the movie. He's at all of our fundraising events. He has so much dedication to this district. And it's interesting to me because I went to high school here and he was my teacher at the time and then became my principal and he was a wonderful teacher and he still shows those characteristics as a principal because he understood what it was like to be in that classroom. So I just think that he is always preaching about integrity and respect inside and outside of the building and he showcases that himself, so we're required to do that. And required is not the right word. We feel thankful enough to be able to do that for him. . . We just had several teachers that went to Write-to-Learn, our band teacher just went down to Osage beach, he encouraged our book studies that we have where UMKC is coming in and observing us, he pulled out three different high school teachers to do that, so absolutely, yes, encouraging. He is all the time sending, we went to EOC, he is all the time encouraging, go out, find... And he sends us stuff. He sends us articles. He sends us PD different meetings to go to: ACT, EOC, Write-to-Learn, I mean, Math Interface, all of that. She discussed the principal supporting leadership by sending literature: He just sent us an article this week about higher expectations in the classroom and you know he's not doing it as an insult. He's doing it so that - he wants us to 
actually share it with our kids. And so it's like he's all the time doing things like that. And in our PD he'll talk about Lemov? And he'll talk about different instructional practices you can do. He actually came into my mythology class because he used to teach history - and he came in two days in a row to my mythology class and gave lessons. That's why I said I don't work for him; I work with him. It is extraordinary.

Principal perspective. Principals also discussed how they utilize teacher leaders, how these teachers evolve, and how they encourage and provide leadership opportunities for these teachers. Mr. Hall disclosed,

Well, I think my first year twelve years ago I was killing myself. I thought I had to be on every committee, I thought I had to do everything, you know, lead every situation. I quickly realized that I was going to die and so just the delegation of these teacher leaders who I trust allows me to focus on classroom instruction, developing teachers - especially new teachers - and so, just that delegation has helped me with my job and my priorities.

Um, you know, we don't have any, like, step by step process. You know, we look and see, you know, Denise was an exception. She took off right from the start. I've got another teacher who's been here eleven years and slowly but surely she started becoming a team leader. She didn't feel comfortable being in charge of anything, but I put her on some committees because I knew that she wanted to be involved. And then I talked her into getting her specialist degree in reading, and so once she got her specialist degree she feels more confident in leading now that she has something to say, and so now she's in charge of her leadership committee. 
So she wouldn't have done that eleven years ago; she wouldn't have felt strong enough to do that. I could tell that she just needed some time to develop. It really kind of depends on the teacher.

Well, the ones that are evolving, you know, they continue to have an enthusiasm for improvement that drives them so, you know, they're driving that enthusiasm so as we go through the School Improvement Plan, they are the ones that really kind of keep it going, so...I just try to find people who are passionate about those changes... and kind of keeps us rolling along.

Yeah, if I think a teacher is not stepping up to a leadership role and I feel like if they need to, I will go and talk to them personally. I'll assign them some type of leadership role. I know you can do this and let's give it a shot; I'll support you. ...I'll ask for volunteers...Sometimes it's just volunteering for something small like Route Committee or school dance or supervision at a basketball game. I'll see if someone will step up and do something outside their comfort zone. That tells me a lot about that person, ask for volunteers, you know, that's kind of the way we do it.

\section{Mr. Garrison responded:}

Yeah, so, sometimes I'm not always the best at this myself because I have a vision, I want to share my vision, and I usually do but sometimes it's hard. A lot of times I will have to go to these people and ask them, "So this is the message I want to convey, and it's very clear to me that it's not being conveyed in that fashion, you know what I mean? Like, I'm seeing something and I know that's not how people see it. That's not the message that I'm trying to send. This is the 
message that I'm trying to send." And so a lot of times I will use them in that capacity. Not necessarily as that, but also in that sense of I need input to understand what I need to change to make this maybe more palatable, more... how do we need to craft a plan here that's actually going to be successful. Because I tell them all the time the reality of it is if you don't have, like if we take an up or down vote on something, which we'll do sometimes in staff meetings. If we don't have $70 \%$ of the vote in favor, we never do it. Because then there's no point, because a $51 \%$ majority is not good enough for us. And so, a lot of times when we do those up or down votes and they come in short of $70 \%$, that's when you then turn to your teacher leaders and say, "Okay, I think this is really important. Obviously, either they don't understand what I'm thinking or they don't think this is important. Either way I need to know why and I need to know what I can do." You know, and so, you try not to have those discussions often, you try to have those discussions before the up or down vote fails.

You know, in my mind those are some of those examples and then like when you actually are in the process of doing the initiatives, you really try to empower those people to work. You know, for example, with Bonnie, I really want to change kind of the way we have curriculum set up, like in our weights department because we do weights really kind of like sport-driven basically, but we have nonathletes in there and it's like it's not necessarily fitness driven and that's one of the keys is like if our transfer goal for this is that kids will be able to make fitness decisions after high school - is what we're doing supporting that goal? And Bonnie's not my weights teacher, but I need that team to make a decision based 
on what's best for all the PE teachers in the district all the way down to the elementary. Well, I talked to each one about it, but I talked the most to Bonnie about it. Because I need Bonnie to be ...I need her to carry my torch into that arena and basically push for, because in the end I want it to be whatever they will have it and any progress is good, but I want the progress to obviously swing in the direction I want it to go in, so I mean, those would be examples of how I have tried to use them. Like I said, everybody can be better. I'm not sure if I do it well enough.

Okay, so yeah, a good example of this would be to kind of point to some of our other teacher leaders that we have who are...like my music teacher. She is very type A. She is great at basically setting high standards and high expectations but she sometimes struggles because she has the high expectations. She struggles to understand the people who don't have that. And so a lot of time is spent working on that viewpoint of cooperation and, you know, understanding other people's viewpoints because, you know, I understand her viewpoint. I am not that way. I get it. I get why that would drive you a little crazy. Because I am that way about some things, you know what I mean? But that's just not my everyday way of life. And for her, if she's ever really going to ascend to that level, then she needs to better understand how to operate and she has over time.

Because that's the thing is you do evolve. And a perfect example of that is some things you can't control and some things are just fortunate, you know, and one of the best things that happens to teachers like that is she had a kid. And you can't control them. And it frustrates you and then they craft their own personality and 
their own personality might clash with yours. And those things are great because out of those life lessons are how we all learn and so it's in those moments where you can kind of hopefully kind of be like understand this, like this situation, it does apply over here. This is more of an extension of this than you think because we have a tendency to -- this is my life at home. This is my life at school. And we don't like to think about how those two things interact, how you have changed as a person.

And we know that, a lot of it is just trying to ask the questions - asking the right questions in the right fashion where you don't piss somebody off, but you want them to actually think about what you're asking them. Because we all know...you talked about college professors...the number one thing that they used to always tell us is you have to be great at self-reflection if you ever want to be a great teacher and we all know that but at the same time, that's a skill unto itself. And the teacher leaders who evolve, they see that. They take the time to reflect. And we're all stubborn, but at a certain point you realize like I said, you don't want the up or down votes to fail. You know, if you're that sort of person - which I can respond to my basketball coach like that because coaches don't like failure. She gets that, you know what I mean? Whereas other people, her goals are more about expectations so it's not about failure.

It's about I want to meet the goal. Then you have to get people to evolve in different ways and so that's kind of the key is basically I'm a big believer in you don't put in what's not already there. The only time you ever do that is if it's going to cost somebody a job. If your deficiencies are so bad that I can't keep you 
employed, then we need to try to save you. Other than that, it's more about drawing more out of what you have in there. You just don’t see how to apply it, don't have a need to apply it, etc. And so that's really what you're looking for in the hopes that they do over time grow.

Garrison discussed how he provides opportunities for teachers in leadership roles: Yeah, we don't, I mean, we try to be kind of like a no BS, everybody's opinion is valued sort of set-up. Typically speaking, we don't have a lot of committee work. I mean, we do have some, our PDC and stuff, and we encourage people to take that on.

You know, one of the things that I felt like was when I was a teacher, I did a lot as is, you know what I mean? I sponsored a couple of activities, I was a coach, you know, and it was like when my principal comes to me and is like well, you want to be a principal someday, you need to do this, too. I didn't feel like helping me. And so we try really hard to encourage people if they want to take on things, absolutely, but I really try hard not to just craft a committee, you know what I mean? And the reality of it is sometimes even for a purpose, I mean, do we need a committee for this? Or can we hash this out together right now and I'll do the crap, or I'll be the one who has to go and be the research donkey and do that and — what would you prefer? You know, and then, within that meeting, like I said, you carry that in — who do you give the research to? You give that research to the teacher leaders. You know what I mean? I mean, if you want me to do the research that's fine, but I still need an advocate. So you go and you give it to them 
and so that way you don't overburden them but you still empower them. So I try to do things like that, like I said, on some things we could probably do better. Right now we're basically moving into a competency-based grading system over the course of like the next seven years, so we started it in the elementary and it's just going to grow to us. And so a lot of what we're doing right now is basically preparing teachers to understand the shifts in how you approach education. It's in these moments where, I mean, I definitely am going to need to use more of them than I am even right now. I mean because we're talking about major shifts in thinking and for some teachers who use it as a personal affront to using what I'm doing is bad, I think that what we've been doing hasn't changed in a long time.

Hyde discussed ways he has utilized teacher leaders as well as how they have evolved: Honestly just trying to get them to kind of get on board with some of the things that we are trying to do. The teacher leaders have the same philosophies as I do, you know, I might have a really good teacher leader. I'll use Cara as an example. But maybe the change that I am trying to make happen doesn't necessarily line up with her philosophy, and so philosophy is very hard to change. We're talking about something that's very large. It's not something that I can just come in and say this is something we're going to do. So trying to utilize those teacher leaders that I know maybe have the same philosophy and then trying to work them in a way to start making those changes happen. Because if I don't have buy-in from a certain percent of the teachers, it really doesn't matter. What initiatives I want to happen aren't going to happen. So you really just got to make certain that you have some of those teachers that are willing to kind of maybe help try to do those 
things. Another thing is there are a lot of things that...I used to think that principals just sat in their office with their feet up on the desks all day and I'm sure most of my teachers think that's all I do no matter how much you get in classes. But I'll go back to the blood drive. It doesn't matter how much I want to see it change. It's really not going to change unless I have a teacher leader that's willing to tackle it. You know our FACS program - it will probably never get back to her - and I'm not trying to undermine people who have been here in the past, but you know, if you don't just have a person that's willing to take initiative and drive, it doesn't really matter how much I really want that program to improve - it doesn't really matter. The ideas that we throw out there; if they're not willing to really just grab the bull by the horns and tackle the problem, they're never really going to see it. So just trying to figure out what teachers' strengths are and how I can utilize them to create things to happen in whatever capacity it is. I think it kind of goes back to the very beginning where your best teacher leaders are always going to be those that have a little bit more of a vocal drive, so yes, there are teachers that are a little bit more quiet. But really you're trying to figure out who has the desire and the will to see something get better and then just try to encourage them to maybe step outside and then kind of shine a little bit of light on themselves because really, that's the hardest first step for a lot of them is is I want to do better; there is something I could be doing for the kids or for a program, or whatever, but I'm kind of afraid to maybe put myself out there, and so the biggest part is is just trying to encourage those people. Like Cara has been here for twelve 
years, you know, so I know that she had a little bit of leadership. She kind of had some initiative before, but at the same time, we also had to build a relationship and she had to know - but we had to have a relationship to where she understood that I had trust and a little bit of faith in teachers getting outside their comfort zone. She's definitely a lot different now than she was my first year. My first year it was just kind of, she of did the things that she had to do. She would come to me with ideas every now and then. You know, I would take things to her but now it's just pretty much a working team. She knows that if she wants to do something, all she's got to do is ask and $99 \%$ of the time, you know, I'm just going to go ahead and give her the green light. So, I think it's just kind of about giving teachers the ability to just put themselves out there.

He discussed opportunities he provides for leadership:

It's hard and I don't think it's an exact science, but really I think just reiterating as many times as possible is I will let you do anything I am financially able to do. I generally don't like to say no. I have a few set guidelines as far as what I expect the kids need to be doing on a day-to-day basis. I'm not a big fan of field trips - I know that sounds awful getting kids out of school. Unless you can tie it to a career and college objective or a learning objective. You know, if you're going to miss school there really needs to be a legitimate point; it's not just to make the day like fun or exciting or whatever - let's make your classroom fun and exciting. And find ways to do that. I know that that's not always just being a teacher leader. That's kind of more educational things, but really just you can do whatever you want to do - in your program you're your classroom, with the kids, before or after 
school. I will just pretty much give you free reign. And if it fails it fails, that's great. You know, and then I think another thing I do is I'll talk about the things that I do that just completely fell on their face. We talked about in a faculty meeting. Hey, this sucked, it was awful, it was terrible. Okay, what can we do different? Is there a way to make this better? Then they see that I'm not just a bucket of answers. You know, I fail, too, and then we're all gonna grow from it, and so it's alright for me to do the same thing. Kind of answering your previous question, that hopefully trickles down and then the kids will see that teachers are putting themselves out there and it may not work and that's okay, and it's okay for them as well.

Principal Finnegan discussed how he has utilized teachers in leadership roles:

You try not to get your favorites. And every building will tell you that's one of his favorites. Well, why is it one of my favorites? Cause she stays late, she... there may be reasons that administrators have favorites, but I honestly have to say you can't go to the well too many times because you spread yourself too thin, so you've got to try to have those conversations with people in the hallways, about hey, have you ever thought about helping out with this? Helping out with that? Let me tell you pretty much everything I do I try to do by committee. We switched from BIST to PBIS this year. We're trying to marry the two together but I won't lie to you, there's a whole lot of PBIS and just a little bit of BIST with us still. So forming that committee to help lead us into that next phase of things. Grading practice. Have the teachers help develop it because I can tell you what to do, but I think until they have ownership in that... I don't want to say leadership 
by committee, but have those teacher leaders on committees to help guide the building in the right direction.

Principal's advisory - whatever it might be, put those people in place because they're the ones who aren't afraid to tell me what should be happening.

Mr. Finnegan discussed how teacher leaders evolve in his building:

I would say it's by getting involved. And then in those meetings you start to show those qualities that we're looking for. Staff looks to you for answers when things are going on. That's really I think the best way I can describe it. That's how we develop it. We try to get as many people involved in different things to have ownership, but how do you take advantage of that?

He also mentioned leadership opportunities he provides for these teachers:

I think the encouragement a lot of times is involving them in different things going on. Hey, let me pick your brain on the calendar, let me pick your brain on this. It's little conversations that are important to have with people. As a principal I have those people in the building, I'm thinking I've got Cindy Robbins here, but I've got a second year teacher here that I can see leadership with. I've got another second-year teacher that is our technology liaison and provides training to our staff. Good with technology, but I also see the leadership within this kid that I want to give him a bone so he doesn't go, I'm going to go to Blue Springs, because they're going to pay me $\$ 40,000$ and I'm serious about that. How do we keep this kid invested with us and not jumping ship so quickly, because I think if I was 26 or 27 years old today, I'd probably look to go to the city. When I was 26 , 
27 years old, nobody wanted to live in Kansas City. It was let's get out of the city, and now it's a pretty cool place to be.

You know, both spectrums and I'll even say this. I'm at the end of my career. I've got two, three years left. In a year I can retire, in two years I can fully retire with thirty. I love what I'm doing. I don't feel like I'm done with what I'm doing, but I also know there's a shelf life. When I look at Heather Smith, I'm like wow, what can she do differently in my building than what I'm currently doing? I think it will go a different direction. Just that young, excitement ...I have staff that ask when are you retiring? Good. That's how much longer I have. Because it's comfort for them. They know that here's where we're going, this is what we're doing. Michael does change ideas at the drop of a hat. In a good way usually. I've rambled for you, but really it's ... in my head now I'm really going I can tell I don't have that young YAY! That energy and I don't feel like I'm doing a disservice, I'm just saying...it's reality. It's good to have those younger administrators I'm sure. They're going to make more mistakes than I will. I promise you, you can ask me a question and I'd probably give you an answer on anything possible. I've done it for long enough. They haven't had those experiences but as far as the research that they're up on that I'm not up on.

Ms. Chrisley discussed how she has utilized teacher leaders and how they evolve: I guess another example would be with our parent teacher conferences. Really a lot of that, it started when I was teaching, we started doing student-led conferencing, and that really was something that teachers were very uncomfortable with, but the principal and I talked about it and I was like I'll try it, 
I don't know, let's see how it goes. And so I was the only one that did it the first year. And then worked with my team and got them convinced that we're going to do it as a team and then it grew a little bit, but it was me as the eighth grade class sponsor saying eighth grade team is going to take this and run with it. And it hadn't really hooked in, but now it's just expected that that's what we do.

And I don't do a ton with it. It really is--we'll start talking about it actually at our next faculty meeting. I'll just put it out there. What do you guys want to do? What have you been thinking? And the teachers all know they take it and they run and they just have to let me know. I'm not going to micromanage it; they just have to let me know how it's going to flow. What room is it going to be in? How are you going to have tables set up? What are parents going to pick up when they come in? They take it and run. Every grade level has a class sponsor that's also kind of the team leader.

We don't have nice neat clean teams; we're not quite large enough. We have four teachers that teach both seventh and eighth. But there is a class sponsor for each grade level. So basically the sixth grade, the leader of that team organizes them and reports back to me to tell me what's going on, and then the seventh and eighth grade, those two leaders are actually my two math specialist people and so they work together to get it all planned and it seems like every year they come up with something different. They'll say, we have this new reflection form that we tweaked from last year. We like it better and this is what we're going to do. Super! 
So then all I have to do is just walk around and make sure things are going well. But it does because it's those class sponsors that take on the leadership role and make sure it happens. They're the ones going to all of the other teachers and saying, now remember to get student artifacts in a folder and have those ready for the kids. They're the ones going to the teachers holding them accountable for practicing. Before we have conferences the students have to sit down and practice with a peer pretending like that's their parent. So they kind of run with it.

Ms. Chrisley discussed how these teachers evolve:

I think it depends on - you have to look at the individual person. The one that I'm really working on right now, where Carpenter was probably my last project, just being a female and she's more the elementary mindset and more the nurturer, and then the one that I'm really kind of working towards this now is a male coach, teaches primarily eighth grade, some seventh grade, just he's very serious about everything. So with him, it takes - one example last year we went to a middle school conference and I had asked people and said, "Hey, who wants to go with me? I'd love to take several teachers," and he hadn't said anything but I went to him and said, you know what? I'd like for you to be a part of this and when he came and had the opportunity to visit with these other teachers that he didn't normally talk with, just people we had taken from our school, he got really excited. He actually fed off of Carpenter, they had gone to a Brain-breaks workshop and got really excited about it. I got him then to present to the faculty meeting, so I needed other people - I needed him to buy in to middle school concept and then I needed other people to see him buying in. So anyway, and he's 
just a very, very respectful young man and just with the work ethic, I mean I guess that's just the key thing you look for is really somebody that's going to get things done and take it seriously whatever they do, but still be willing to have a little fun. So that's what we're working with on him is. It's okay to smile, it's okay to relax. So yeah, you just kind of have to look at their strengths and weaknesses and what needs to be worked on.

Ms. Chrisley also discussed how she encourages or provides teachers opportunities for teachers in leadership roles.

I'm just really big on encouraging them to lead professional development and to keep learning new things and to share the new things that they've learned and not just keep it in their classroom. Another example that is coming up in a few weeks and it's really scary but we're hosting a Missouri Middle School Association Regional workshop here at this district, and so I didn't really ask. I just picked a date that worked for me and I told my staff, I said, hey guys, this is what we're going to do. And then I told the MMSA Board, I said, hey guys, guess what we're going. Hope you can join me! Because we're not doing a state conference this year and I just found that to be sad so I said we're going to do this and so I went into faculty meeting and I said to them, this is what I want to do and I'm really excited about it. We're going to have teachers from all over the region coming to (name of school), see the new things we've got in the building, we've got a lot of improvements that have been made lately and I said you guys have great things to share. And again it comes back to encouragement. Really a lot of what we're doing is what everyone else is doing. I just said you guys are amazing, you have 
great, great things that you guys do in your classroom that other people need to know about, so let's share it. And I'm not getting quite the response I wanted to with the workshops, but I have a couple of bugs in some ears, so I said how about and they're nervous about presenting by themselves, so I've done a lot of, what if you guys got together and did this because you're really good at that and you're really good at that, so they're putting some things together, so it will be exciting. Mr. Munstermann discussed some of the best ways he has utilized teacher leaders: We are very - I hate the word shared leadership with decision making, but that's really what it is. Our PLC team, which you know, we just put Elizabeth in for obvious reasons. We have a data team that's all teachers. We have a literacy team that's all teacher-driven. Those are our three biggies. And then we have collaborative groups that all have their facilitators. And we do collaboration a little bit differently. It's not by department. We have a group working on technology, specifically Google, and we've incorporated Google drive and classroom and almost everybody has a Google classroom. Or is getting there. We have, you know, obviously the at-risk group. How can we help those kids? We have a group looking at poverty issues, which I guess falls into the at risk, so our collab's a little bit - I mean, where I came from PLC, our collabs were completely departmental. And you know and I hear people talking. They're like don't they do that in their departments? Well, ours are so cross-sectioned that we have no true departments in that regard. And even our data teams, they don't necessarily, we have a chemistry teacher and a social studies teacher working on data teams together and it's a lot of writing components that they share in class and they're 
tracking some of those skills. Instead of content it's very skill-based, which I think is highly appropriate.

And that's again, you have one of our up and coming teacher leaders - a young teacher in the game - but just full of ideas but yet, like Elizabeth, very realistic about the game that they're in, so to speak. And then he's paired with another teacher who is twenty plus years of teaching, and it's been good for both. It's reinvigorated the veteran teacher, but some lessons have been passed on to the younger teacher, so I consider both of those leaders in our building even though there's the experience discrepancy.

He also discussed how teacher leaders evolve in his building:

I hope very organically. You know, it's like anything else. I'm a firm believer in practicing what you're good at. I think that we spend a lot of time hearing about weaknesses and not focusing on strengths and I'm a little bit opposite of some of my peers in that regard. I think that's the old coach in me a little bit, too, and then the son of a coach - coaches actually. It's okay to work on what you're not good at, but it's still okay to really work on what you're good at. We have kind of stressed that as they do their growth plans as a building, so I think that you know, when I look at someone like Elizabeth, she embraces that, okay, I'm pretty good at this. How can I get even better? And that's not us pushing. They're giving some input in that. We give a lot of individual opportunities for PD. There's not much that we direct. We had an assessment-capable learner initiative this year, but then after teachers started on that, we gave them some fluidity and freedom to 
kind of create their own monitoring piece, if you will. So I'm hoping that when I say organic, it's not forced. It's just - it's a very natural progression and growth. Munstermann also discussed how he encourages or provides opportunities for teachers in leadership roles:

I think it's just encouraging them to express their freedoms and creativity. We don't want to put the ratchet on anybody. We want to allow them to grow. I think it's important to give feedback and I think that's probably one of the things I do the worst job at. You know, personally, I think that we often forget about our best teachers because we know they're going to be fine. Whitaker and some of the others will tell you you've got to spend time with your top people and that's true, but it's so easy to have your time sucked in by the teachers you're having to work with, but I also think, you know even for my own growth, spending time with those teachers allows them some different opportunities and tools to help some of our weaker teachers as well.

Mr. Warren shared how he has utilized teacher leaders and how they evolve:

(Laughing) Probably too much. Teacher leaders always put pressure upon themselves, and no matter what they do, they always feel like, like I said before, they need to get better. So I've been that person to say, hey, I'm trying to think about block schedule for next year, what do you think? Well, let me think about it. Two hours later she has a schedule made and she brings it to me, so that's ...I mean, that's just what she does. So, I throw a lot upon her, hey, let's talk about Writer's Workshop, what do you think about that? How about some PD? Yep, go. Comes back, implements it, done rock star status. What do you think about 
splitting up our kids into separate groups? We can have separate grouping? Done. Like I said, she just has that. Like I said, pressure she handles very well, but she knows that we need to be the best at what we do. So I utilize them a lot and also I know that their strengths are my weaknesses. So I'm very good about understanding that - I know myself pretty well. If you say Angie with the schedule or Desiree with curriculum, or if you say Jacqui at the front desk there to process and get people in and out of the building in an appropriate way, they do all that because I know I will struggle doing it...it's a hard lesson to learn... and I told them I will not micromanage you; I am not going to do that. I don't want it done so I'm not going to do it to you. I know what you're capable of - go for it. And I think most of them appreciate that...I have to trust. If I can't trust, then why are we here? And I don't want to stop you as a professional because that is ridiculous. We've all been through that. I don't want to live through that personally.

I think it starts with a mentoring process, .. who demonstrates by action and by voice, and then other people think, hey, it's okay if I do that. We do have way different teaching experiences in the middle school and levels of ability; however, we are always willing to share - I don't want to say a spotlight - but share a lead in something. If a brand new teacher like Grace has a new math initiative, yeah, go for it. Go do it. We'll support you every way we can, but just do it and we'll help you along the way. That's how it works in our building. We have a couple of teachers who may not be as boisterous or confident; however, once again, we know each other's strengths, so we will build you as we go. We want to instill that 
confidence and support you when you fail because we all will. Regardless, we all will. So to me, it's a deliberate mentoring process and our teacher leader next year will move to third grade; however, I know that she has instilled that in others who then now will take her place, be able to fill some gaps that we will have when she is gone. . Once again, it's about their strengths, and then who can I put in what position? And also give them the encouragement that you can't mess this up. It will be alright...

Principal Quick discussed how he utilizes teacher leaders and how they evolve:

Oh, not enough, that is actually a personal weakness of mine. I don't delegate well, I just, it's a - if you want it done right, do it yourself kind of thing and I try not to, I certainly don't want to. I have a tendency to not want to let go, or you know, I talked before about teacher leaders being overwhelmed already. I don't want to add one more thing to them. Hey, I have this thing I want to do, this project, whatever, who am I going to ask? Well, I'm going to ask my teacher leaders. I want to ask them, but I don't want to ask them because I know they're already doing a lot of stuff, so then I just end up doing it myself. Anyway, so how do you use them? I think probably one of the biggest best ways is just let them do their thing. You know, they are not successful because of me. You know, I didn't have anything to do with Mr. Hawthorne being a good teacher... That was not me. Certainly when you make decisions, good old Todd Whitaker, you make decisions based on your best teachers, and so I think often when I am making decisions I keep him in mind. I keep other of those rock star teachers in mind of, okay, how would they respond to this? But that can also get me in trouble 
sometimes, too, because of what I said earlier. Their assumption is that everybody is doing what they're doing, so sometimes that's not the case. So sometimes I have to - just like students - you have to meet them where they are and pull them up, so teachers are the same way. Sometimes I have to meet the teachers where they are and pull them up. I don't think any teachers intentionally come to school with our kids, they are usually doing the best way they know how - or are already frustrated with themselves for not doing better. And so they just need a little bit of help, little bit of guidance to maybe set some goals to accomplish what they already know they want to do, they just can't quite for whatever reason get it done.

But I think the biggest way I use teacher leaders is when I have an idea or when I have something that I need done, they're the ones I go to and ask, hey, what do you think about—and how can we, you know, would you mind, you know, and usually I try to get them to get a group of students to lead it. I try not to ask them to do it because I know they're busy, but hey, do you think you could get a group of kids together to make this flier? Do you think you could get a group of kids together at the next student council meeting, you know, what do you think about painting the ceiling tiles down the senior hallway? I think that'd be a great idea. Can you get student council to do that? So again, to get the teacher leaders to get student leaders to get them to then delegate and spread to - maybe there's a hidden, you know a hidden goal there, too, of if I can get them to delegate that to the kids, maybe they can delegate some other things to the kids to lessen their plate because they are always busy and sometimes they have a tendency then to 
not prioritize what the district prioritizes, so we need you to fill this whatever out. Well, that's silly because I already do whatever. Why would I need to fill that out? Well, because we need everybody to fill it out. You know, I understand. You know and so, then that thing kind of gets put on the back burner because it's not important to them, because they've already got a system in place that's working great. We need, though, a uniform thing for everybody and that means I have to not exclude you, so sometimes it's that kind of thing, too, and usually they just go along with it and do it. You know, personally, I could use them better. I could use them more efficiently. I think there are other teacher leaders in the building that I could use more effectively.

And I think the biggest need for them would be change. Like I said earlier, if we just stayed the same way. I heard a quote the other day, it said "Even if you're on the right track, if you're not moving, you're going to get run over". So I love that. Even if you're on the right track, you've got to be moving, and so you know, as good as we think we are, we've got to be looking for ways to improve. Which means change, plain and simple, that just means we're going to have to change something. Don't know what, and we're not going to change just to change, but there will have to be some kind of change and that's tough for a lot of people, teacher leaders included, but if I can get teacher leaders on board, or if I can even get their input on how to change, you know, whatever we're trying to change, I think that's the biggest necessity for those teacher leaders, so I think one, leave them alone, but the other is use them when I need them and try not to take advantage of them. I think it's very easy to always go back to that same two or 
three teachers in my building of sixteen. You know, go back to those same two or three over and over and over again, asking for all the things, when in reality what I should be doing is putting pressure on those teachers that maybe are not the teacher leaders that are just kind of hanging out in the corner and saying, hey, I need you to do something, too, you know? Mr. Hawthorne's tapped out. He's doing everything he can possibly do. I need you to take on something else. But that's an interesting mindset for myself to get in.

As far as how they evolve, Quick responded:

Well, certainly I think every teacher grows and improves, but you know, I think the more opportunities they get to learn, they're going to learn from them. You, know, that's again, one of the reasons they got to where they are is because they learned from those - whatever mistakes they had made in the past they continued to learn from that and continue to want to learn and improve. They're not satisfied doing the exact same thing over and over again either, and so I think they, again, are kind of natural improvers, they are natural -want to get better at whatever they are doing. So I think that's part of how they evolve.

As far as how does it relate outside the classroom, specifically we do strategic planning committees when you have teacher leadership teams. They are a part of that. You know, when I have any kind of advisory council, even if it's informal, and most of mine are informal. We don't have an official time where all of our teachers/staff gets together. We have five half-day professional developments throughout the year and some of those I get to use. Most of those I do not. 
The professional development committee has stuff to do. So we have very little time that I put all of our teachers together in one room. It does not happen very often. Most of it is me individually going and finding a teacher during their plan period and talking with them like that or obviously some emails, those kinds of things, but getting input for the district, getting input for, you know, the high school building, just asking them. So that's really their impact here in our district. I say that, also, being as a small town, small community, they know, the community knows who those teacher leaders are - Mr. Hawthorne is very well respected in the community, same way. They've never had him in class, but they know. Again, you just kind of know, he just kind of has it. And obviously stories that they hear from their kids help as well. So you know, he does have an impact, then, with parents and with community members as well. Just as a trickle down kind of thing.

Mr. Quick also relayed how he encourages and provides support for teachers in leadership roles:

Well, like I said I don't do a very good job of that, but I think that is something that needs to be done and most of those just come up with here's the idea, here's the thought. Sometimes it's a different teacher coming in with that thought. Hey, what do you think about if we, you know, start a school store this year? We kind of want to start a school store and we want to sell, you know, that has been a focus of mine since I got here was school pride. You have to be proud of where you come from, because if you're not, then what are you doing here? Are you just 
jumping through hoops, there's no above and beyond, there is no let me put in extra time.

People don't do that for things they are just doing, you know. They have to be proud of it and so it starts with that school pride which is I think a school equivalent of respect, you know, the building for the kids and the kids for the building. And so, let's start a school store. Well, that's an idea. Okay then, who's going to do it, because that's not an easy thing. So one teacher may have the idea and say, hey, you know what? You should go talk to Mr. Hawthorne because I think that he would really work well with you or again, some of my other teacher leaders. Or again, that's a great student council idea; why don't you talk with Mr. Hawthorne? So, try to get those ideas or those new ideas in the hands of the teacher that will do something about it.

Because I don't have time to do it myself; I couldn't do it myself, and honestly, I'd probably do less of a job than they will anyway, and so, you know, I think just realizing that and realizing each teacher leader's strength - they're not all the same. Realizing their strengths and trying to find things to play toward their strengths. You know, certainly there's always strengths and weaknesses, but I feel like it's more effective to focus on their strengths than their weaknesses. You know, he lectures all the time, I said that earlier. I could look at that as a weakness and say, you really need to expand your teaching strategies, you know, and we could do book studies or we could do whatever. In the meantime, though, if instead of spending all that time on his "weakness", if we could spend it on his strength of leadership and relationships and let him spend his time on that, and 
those just get exponentially better. That just makes sense to me that that's where he should spend his time and I should spend my time with him is on the strengths, not necessarily the weaknesses of those top tier teachers.

\section{Mr. Quick discussed professional development:}

Honestly, the teacher leaders that come to mind for me hate being out of the classroom. They hate it. He, you know, a kind of funny story about him, he does not like student teachers; he hates them. I could probably place a student teacher in his classroom every other semester and I think that student teacher would learn something. You know, would learn quite a bit. But he hates it. He says I'm a teacher because I like to teach. With a student teacher, I don't get to teach. He said I hate it. Anyway, he said I will do it once every few years because it's my duty as a teacher to do it, but I don't like it, and he's very, very vocal about that. There's a couple of other teacher leaders like I said that come to mind that have not been that vocal about it, but certainly are vocal about I hate being out of class. I don't like to be gone. It's more work being gone than it is to just be here, you know, those kind of comments. You know, or, hey, this is a really good opportunity for my kids. I'm sponsor of the FBLA club. It's a really good opportunity, it's a job shadowing thing, but I've already been out once this month and my daughter was sick, so I don't know if I should do this or not. They're almost weighing this great opportunity and almost not going to do it because they don't want to be gone. Because then they say well, I'm only taking ten on that trip - I've got another ninety back in the classroom that I'm leaving behind, and so, I 
mean you could argue both sides of that, but I think that is kind of a characteristic as well as they do not like to be out of class. They just dislike that.

Ms. Silvers shared how she utilizes teacher leaders:

Through PLC, through building our leadership team that way and then also changing to data decisions and trying to actually use data to drive instruction which we never have done before here. And so, getting them on vertical teams where they're working together, and it's hard in a little school to have a vertical team, so we've made kind of a math team and an English team and a science team. Watching them work together on those teams - because I wasn't sure how that would work — and they've come up with project to do. They have a weight loss challenge that they're doing with the teachers and the students where they're collecting data and using math and science together, so they've come up with some very interesting projects that are not just the same ole same ole. So that's been neat.

Utilize them going to conferences and coming back and sharing their ideas and just trying to think out of the box. We've had a lady ... she's with Central RPDC and PLC, she's just a really great person to have. And she's been in five times this year doing critical thinking with us and so just watching them embrace that has been good.

Silvers explained some things that come out of PLC with the teacher leaders:

The data making decisions, we do. Before we never did article studies, we never did book studies, those kinds of things so it's been nice to see the teachers embrace those and use those. Before, our Coach Limback, he's our PE teacher, 
he's one of our PE teachers at the high school, he's been here sixteen years, and the thing that he asked me back when all of this started was how is this program going to be anything different from anything we've done because we've tried all these things and we never stick with them. And I tried to explain to him that we were going to stick with this one and this one is different. You know, we're not going to let this one go. And I've seen changes in the way he taught, you know, worksheets and pre- and post-tests, he would never even have done anything like that. And when people see him using some of that, then they're like oh, well, it will be okay and we'll do this because I think between him and our librarian, they've been here the longest, so if they'll do it, you know, anybody will do it.

Silvers mentioned how teacher leaders evolve in her building:

That's still kind of being figured out right now since we've just started the process. In the PLC model they're supposed to cycle through on the committee and you bring in a new person and that kind of thing but since we're so small, we may just try and keep the people that we have for a while and let them continue to grow into leaders before we switch people off. But I would say, you know, just evolving in a way that went from nothing to now we're using data and now we're using pre- and post-tests.

To see what's next will be interesting because now the next step I think is to get them to really share what they're learning and what they're doing and that's why I think Anne is such a good leader in that respect because she just volunteers to do it. I don't have to go to her and say, "Can you do something on critical thinking or can you -" she wants to do that from anything she goes to and automatically just 
wants to share those things. I think our next step in this evolution is to get people to really work together even more and share things even more than they do now. Because it's different and it's been a rocky road and things haven't always worked and we've had to really...last year was a bad year. This year has been so great compared to last year. You know, the first year we're gung ho, we're getting into it, the second year, we're like, this isn't going to work, we get the ughhh and now this year it's like a light bulb came on and it's been an interesting — and what's next, I don't know, we'll see, but hopefully it will continue to grow. Silvers also discussed how she encourages and provides opportunities for teachers in leadership roles:

Conferences - if they want to go to professional development, we let them go. I try to seek out what I think is good professional development for them and ask them if they'd like to go. Our new English teacher, our high school English teacher - I've tried to get her. . I've really pushed her a lot this year to try to get her to go to things and they have been great about going to whatever I ask them to go to. Mr. Bond is very supportive with the money in allowing us to do what we need to do. We took nine to the PLC conference this year and that was really great. The ideas that they bring back and are willing to share - that is amazing. But I think just quality professional development really helps them and helps them see that we're not going to give up on the process. So I think that's one of the ways that we try to encourage that.

Silvers also stated these teachers sharing out at faculty meetings: 
We usually try to do our Fridays - at least part of our time is for that. And for what did you do this week that's great. We start every one with a celebration. Every Friday we try to start with a celebration-what went well and then do you have something to share that you're doing in your room, so we try to do that. Principal Shackles explained how he has utilized teacher leaders:

Have them lead the pack, get them on your side. Because generally if you have two of the teacher leaders, or I don't know, five regular teachers-I don't want to separate teachers that way-then you're probably headed in the right direction. I never shoot for $100 \%$. Just like you never want to tick off $100 \%$. I'm kind of that 90, 10 thing. I don't remember which coach told me that years ago. If you got $10 \%$ of the people mad at you, you're probably doing all right. $10 \%$ of the population - they're not in the same ballpark as the rest of us. So I'm like, okay, yeah. So I'm probably like that. One thing that I always tell everybody, no, I'm not the best at paperwork, never cared to be, never will be. But I will make decisions and I'll live with those decisions. And I think that's the big part about being a leader and so that would be another characteristic that I look for in my teachers. Can you make a call and live with the consequences? I'm not asking you to die on San Juan Hill or nothing, but take your lumps where it happens. If you were wrong, you were wrong. Take your lumps with it.

Shackles discussed how teacher leaders evolve in his building:

Well, I think from the support that I give them and they give each other and from the support that they get from the students and parents. I think it slowly evolves. I require every rookie and everybody new to me has to meet with me ten minutes a 
week generally during the plan time just to see how they're doing. When I feel comfortable like right now, we're in February. I'm probably ten minutes every two weeks with a couple of the rookies. So that begins the process and then how they interact with their data teams and how they interact in group settings with the whole group. Do they bring up questions? Do they answer questions? You know, things like that. Can they make the call? Are they already student leaders?

Shackles explained in greater detail how this leadership looks outside the classroom: Outside the classroom, well, there's a whole lot of different forms that can take. You know, can they lead the team? Can they lead in practice? Because generally, you have willing participants but not always, can they hold kids accountable to the standards or the expectations? Whatever organization or group it is. I don't really look too hard outside of school activities to be honest with you. For instance, me. I've been doing this for ages. Coaching, plenty of Saturdays, plenty of late nights, blah blah blah. Right now for the last four or five years probably if I don't have a Friday night assignment, I disappear. I head for the woods, literally. ... I don't always look... because me, myself, I never ask any of them to do anything that I wouldn't do. For me being so public five days a week, they need their privacy.

He gave examples of how he provides opportunities in leadership roles: I ask some to talk and then some are just naturally born talkers. If we pay for it (conference), they have to share. It doesn't have to be a long, giant thing. It can be - back in the old days the old timers used to say if you go to a conference and you learn one thing you can use pretty quickly and if there's another that you can 
use the following year, then it's been a successful conference. So you know, I usually say something along the lines of hey, what's that one thing? Can you talk about it? Don't do it all the time, sometimes my list, and this has been a big thing for the staff. They like it, and they actually tease the other principals about it. I believe my faculty meetings should be boom boom boom boom and we need to be done and with the kids.

\section{Advice for Discovering and Encouraging Future Teacher Leaders}

Teacher's Perspective. When asked what advice teacher leaders had for potential teacher leaders, there was a range of responses. Ms. Carroll stated:

It would be - one of the main things to start off with I think would be understanding social relationships and the social structure and knowing how to collaborate and coordinate with others of different backgrounds, of different beliefs, knowing that you are trying to achieve something on the same path, so of course you're all looking for something to become better or in the case of the school district situation, you are trying to do something to help improve experience for the kids and knowing how to communicate with people who think differently, act differently, believe in different stuff. That can really make or break you as a participant if you lack understanding of social relationships and how to share your opinions or hear others' opinions and not get to where it ends up being a personal dispute and stays on track. Everybody has an opportunity to do it. If they are perceptive of their own abilities and strive for that I think everybody has leadership somehow within them, it's finding out where that is, where that lies. What are your strengths that can be played on? So it comes down 
to looking into those opportunities and finding out if that fits you or where is your fit and where is your strength?

Ms. Williams shared,

I think the biggest thing for that is realize what your strengths are and what you're good at and then realize what you're not good at. And then you can try to improve those things, but just how can maybe you hide those as much. Instead of more bringing everything to where it's good. If you're great at two or three things, then maximize those. Because if you try to be good at everything I've found - and this is a lot from athletics, but if you try to be good at a lot, then we're just an okay team. But if we embrace the two, three things that we're really good at, then we can excel. So I think that's the biggest thing, and then just your positive perspective. I read a lot of John Gordan stuff about positive leadership, so it's just your perspective on how you look at things, and everything can be twisted to where focusing on what we can control and then go from there, so we talk a lot about control what you can control and I think when you realize that in your perspective, then you're able to make the most of every situation and then that leads to good things for your kids and your staff around. I think the biggest thing is, and I think it's the cliché of control what you can control. That's something I do with my teams a lot, with my kids and then also in my classroom because when people focus on that they become empowered because there's so much that happens that we can't control and dictate and so when we get caught up in those, we're just wasting our time and our energy and our efforts. So the big thing is focus on where you're at. My husband's football coach would say, "The big 
time's where you're at." So whether you're teaching at a small school or wherever you're at, make where you're at the big time. Give those kids everything you have to make them the best that they can be and then it trickles down.

Ms. Weston's advice for teachers with leadership potential:

Go out and try something new. Step outside your comfort zone. We have a lot of teachers. At the end of the year, we do like a fun day. We play a lot of games and everything and we have teachers who are like oh, I don't want to do that. I'm going to embarrass myself. You're just a grown-up kid. . . The kids laughing at you for a little while. . We need more of it. We need people to do more. Our whole committee of PD is six teachers, we have three from the elementary, three from the middle school/high school. And it's a stretch to get people on the committee and to go places. I'm like, well, you can go to one place and they will pay for it. And they're like well, how many places have you been to this year? And I'm like, well, I went to an MSTA conference, I went to a tech conference, I went to PLC, I'm going to a social studies conference, and I'm doing a summer conference. You know, and they're like well, how are you paying for that? Well, the one conference PD paid for... and the rest of it my husband and I are paying for. Getting people on the committee and getting people to go places...like, I'm just astounded by (it). When I first got here, I got put/pushed on the PD. They were like, well, you're new, here, be on this committee....and you're like, okay... Then I got off of it and it was like, well, we need volunteers. We didn't vote for me to be on the PD committee. I was the only one that volunteered for the position. It takes time. I don't get paid for it either but I'm just like, PD is one of 
those things that we get to lead as teachers for ourselves. So why would you not want to either help, be a part of, give input, you know, something. Staff wise there are 23 of us - there's not that many of us really, but there's a good majority of them that just don't care. They are interested in complaining a lot... But if I'm going to complain, I'm willing to say, okay to fix it. Because I don't like to complain just to complain...

Ms. Robbins indicated:

It's hard balancing the time, everything on your plate. That is the thing. That is the thing that holds most people back from I can do that or I can do this or I would love to help you. And those people who do jump up and do help and do work on that it's like, alright, it's six o'clock and I told my family I'd be home at five, oh, and they go but school got out at three. Yes, it did. And this is our reality, so and that's still something you do fight all the time is time management is the hardest thing, the balance, it's like, ugh! But it's like things you hear at other places if you're able to help somebody else. You get that little warm fuzzy, you know, feeling on the inside? Maybe it's just listening to another person and letting them bounce ideas off you or just listening to them and let them de-stress, you know, some of those little things as well, but -follow through. You have to balance it. You have to manage your time. If you say it, you have to do it. But the leader, you walk the walk, you do it.

Ms. Carpenter provided advice for potential teacher leaders:

I always come up with the same thing. Just doing it, just go ahead and take the leap and know that you may make mistakes, you know, in leading others or even 
in doing whatever it is that you're going to lead at and just not worry about necessarily that you might make mistakes but that's a part of learning. You're going to make mistakes but it's part of learning. So I think just telling them that they should go ahead and do it. Sometimes we're forced into the role. There's just been several times that I've been told, hey, you're going to do this, and then in the end, it's a good thing and you then prove your leadership through that.

Ms. Spalding's advice to potential teacher leaders:

I would say just like start to speak up. And like if you see - and that's something I'm getting more comfortable doing - it's usually like Mr. Munstermann would say, hey, "Mrs. Spalding, what do you think about that?" And if we're in like a meeting or something, "Hey, what do you think?" And I think encouraging other people to speak up but then if you have a good idea, then be confident and kind of go out there and put it out for everybody. That's still something I'm working on. I grew up in a family of teachers and so I think...I heard a lot about teachers that don't know what they're doing and they're talking a whole lot, and I don't want to be that teacher so if I'm like, I want to be really confident about what I'm doing so just step up and be the best and then...that's what I try is just be the best.

Ms. Stephens responded:

I guess for me, kind of the thing that I have the hardest time with is kind of seeing the both sides of it where, you know, I feel like I'm trusted among us, the teachers, so they feel comfortable, you know, complaining, maybe about administration and then in the same respect, I've earned a lot of trust with our administration, so I do often hear things about you know, staff that aren't doing 
what they're supposed to be doing, and that puts you in a really weird position because, you know, my loyalty is here, my loyalty is here so it's really hard to be in that position, so I guess advice to teacher leaders would be to keep your mouth shut, you know what I mean? You just have to keep it, you know, balanced and neutral, and just because your teachers are complaining about something doesn't mean you run and tell what they're complaining about because it doesn't always make it better - it just makes it look you look like the tattle tale. That's where I have a hard time, just stay balanced, stay neutral, stay out of it, just be professional, I don't have to be involved in it. Just, just sometimes you need to vent.

Mr. Hawthorne added, I think that, again, you know, in danger of sounding like a t-shirt or a bumper sticker or something, you literally have to find what it is that you have to offer and then tackle it because I think that the number one thing that I've learned about young people since I became a teacher is that they want to be inspired and pushed and challenged, as cliché as that sounds. Like when you look back, the teachers that inspired me didn't necessarily have amazing talents and skills; they were just really fired up about what they were doing and that's infectious, so I have no idea really what things I'm into that I'm only into because at some point I ran into some teacher who was really into it and that's the way that we impact people's lives. You don't have to be a genius or a, you know, whatever, some expert, you really just have to be really interested in it. We had one lady that came here at one point and was really interested in archery. And she started an archery club and 
there were all these kids that wanted to do it, because I guess like Hunger Games or something? So she had all of these kids staying after school, and there's not even like inter-school competitions or anything, so they weren't getting medals or trophies or anything. And it was drawing a lot of kids that maybe weren't in something else anyway. And she was like we're going to do archery. So now you've got kids just spending their time doing archery because she wanted to do archery, and I think that would be one of my number one things is like if the school doesn't have that club or whatever, make that club. Or if they don't have that activity, make that activity. And then the kids will follow. If you build it, they will come. When I started here they didn't really have a track program. I was doing the tour and the principal said I saw on your resume that you did track in high school. Would you be interested in starting a track program? And I was like, yeah, absolutely. And then we did the tour and I was like, where's your guys' track? And she was like we don't have a track. And I was like at that time it blew my mind. I was like how am I going to do a track program without a track? But we did if for twelve years; we ran on roads and then fields and literally everything else... and we ended up starting a cross country program. So now I coach cross country in the fall and track in the spring and the community just built us a $\$ 500,000$ all-weather track...yeah, we just started training on it this year. We have 40 kids... you know, like at the time my very first track team was six kids or whatever and now we have 40 and they have a track. And I was like I did that, but you just never know, that's the point. That was my biggest thing, I was like you 
have to be passionate about something and then everything will probably follow that. Passion is infectious...

Ms. Wheatley's advice for potential teacher leaders:

Well, you just can't hesitate; don't be afraid. Don't be afraid. The only way that you're going to learn is by making mistakes anyway so don't be afraid to make mistakes. And I listened to something recently on a Ted-talk and it was about, it was for my public speaking class that I teach and it was about body language and nonverbal communication and one of the things that she discussed was faking it until you make it. But she had an experience where she was in a car accident, had some brain damage. She had been a gifted student that had actually - the damage from it affected her intellectually and it took her a long time to get through college and she was talking about her experiences. Somebody had told her at one point that she felt like she didn't belong where she was and she said fake it until you make it. She said, well, I don't want to do that anymore; I want to fake it until I become it. You know, and I would never tell a teacher to fake it, but I'd tell them don't be afraid. I think that's the hesitation sometimes - I don't want to make a mistake. Well, the only way that you're going learn is to make a mistake. And there are so many opportunities within our state as far as professional development to go and learn what you need to do. And, you have to rely on your administration. You know, you have to express your concerns to them and they can even find leadership roles for you that will kind of ease you into it.

Ms. Marigold's advice to potential teacher leaders: 
Always have integrity. Make sure that you understand that it's not about collecting accolades; it's about staying true to what we started this profession for - why - we got into this to help kids and it doesn't matter what award you can put under your belt or what titles you can add to it - it still goes back to the core of you wanted kids to have those aha moments like you did when you were a learner. And so I think remembering that, remembering that we are a team, and that even if you are lucky enough or are honored enough to be put into a position where you have a title, learning that it's just that and it only carries as much value as you put into it. Does that make sense?

Teacher leaders also gave advice for identifying and engaging teacher leaders. Ms. Carroll said, I think there's a stigma towards leadership teams and thinking if I'm on this committee I am making decisions for people and so others see that as a negative thing. So finding a way to communicate to all staff that if you're in that situation you may find out it's not exactly that would be a major benefit so it's communicating the intentions of a leadership team or any leadership positions so it comes down to not assuming that they understand the process to get through that and again the intentions. I know for certain that some people I've met don't even know how to get on a committee or they don't know if being ignored per se, they might perceive it to be that way, Just not being asked to join means something about them as a leader or as an individual in their position, so they may be judging themselves. Basically they feel like their job is being judged too. Knowing how to let the staff know how to take the path to get to a position of 
leadership would be definitely helpful. And then again, what are those characteristics and attributes that are going to be perceived as better for implementing change? The whole point of the leadership team. What is it that we need to see, so, that's another thing. I mean, we're not looking for sedentary. We're not looking for walls being up. We are not looking for the negative all the time. We want those people who can see concern, but there has to be a way to present it so we need not the negative Nancys. We do need versions of it but not in that way. So to come to a leadership position I feel like those are three things that I think are pretty significant and then it may be also on the individual side reflecting on yourself in all of those positions as a professional, as the potential to be a leader farther than in the classroom to figure out what changes can you make about yourself in general that you think would better reflect a position in leadership. So it's mostly I would say from the perspective of administration for others to share that information how could you join? What do I need to know? Why would I want to? And then it's the individual looking back on the process, too. Is this for me? And if this is, what changes do I need to make for myself? Ms. Williams discussed how to identify and engage teacher leaders:

I think a lot of that starts with your leadership, like the administration. If they are a dictatorship, then it's hard because there's no room for it. So you're like why try? You know. But if there's more of an open... and you're seen as a peer, you know, I'll have the final say, but what do you think and I want to know your opinion, then that helps people express their voice more and then leads to 
leadership stuff, but if they're never given a chance to lead anything, then they're not going to develop at all.

Ms. Weston indicated:

I think the important thing is giving teachers some flexibility and some room. I've had previous admin that, when I did my student teaching with Reese, I did layered curriculum when I first got here it was like, yeah, sure, great, you can do that ...my third principal...I've been through a few principals...my third principal was like no, under no circumstance can you do that so then I had to change my whole teaching style. Literally, it was like first of August and he was like, well, I hear you do layered curriculum and I don't like that and so it was like, o...kay, so that was a real quick turnaround and I was like, oh, I'll do this instead. I think it really helps to let the teachers have their flexibility and space to make mistakes and correct mistakes and try again.

Try new things is the big thing. Cause it's a definite difference between....my previous principal before him was very much like you will do this, not this and like I'd get in trouble for making copies and they'd be like you're making too many copies. Now I have a lot more freedom. Last year we got really into the technology and I went to a tech conference and they were like, so do you want to try Chromebooks all the time in your room? What do you think? And I was like, sure! So a week later I had a whole set of Chromebooks for my kids. I've got eighteen Chromebooks in my room all the time and so it was like, well, let's just do it and see what happens. So the next week it was like Google Classroom, Google certified. It was like okay, let's just jump in and let's go! So it's been very 
nice to have that flexibility and that well, we'll just see how it goes. We'll just meet, and if it's going bad, let me know...How's it going? It's been really nice. This year all of the middle school classrooms have our own sets of Chromebooks. All four of the middle school classrooms do and then we have two mobile carts for the high school to use. But all of our dual credit kids - so half of our juniors and seniors have Chromebooks with them that they take home with them and that kind of thing. We still have an actual computer lab, too, and then our business still has a lab, too. But it has been a world of difference now. And with the flexible seating, my textbook is online, now, Google Classroom - it's amazing the amount of ...I don't get in trouble for making copies anymore. I hardly make copies. I make copies for kids who have a hard time adjusting to like, screens, that or my IEP kids, they need copies still... I don't print much...

The reason we went one to one in the middle school first is because we have some teachers - high school teachers - where it was going to be a little more difficult for them to switch over to begin with, so we started with the middle school to see how it goes. For me, I'm like I love it because I love Google, went to Google, so we have Google Classroom and all the apps. That's the best thing ever. We focus a lot of PD on tech because we have myself, Sandy next door, and we're Google certified kind of thing and I have some people that have a hard time remembering how to sign into their Google account. Because our computers have it all saved. You just get on, we log in, and then it's just there. When we get on the Chromebooks they're like we can't log in and I'm like, it's your email. It's a little bit of a challenge, but it is very nice to have that flexibility and just be like, well, 
try it. If it fails horribly, is it something you can change and will be better, or is it just never again, you know...

Ms. Robbins provided the following advice for identifying and engaging teacher leaders: I think it's kind of a natural thing that happens, but there are people that are good at things. They have a knack at things and they don't share. So I see the why are you, the little question. And some people are intimidated by large groups. I feel more comfortable with a smaller group than a large, large group. So maybe if an administrator or someone knows that a teacher has a strength in this area and could be a leader in that, they need to see what platform they're comfortable with sharing it at. Hey, I'm real comfortable sharing that with two people. I don't want to share with thirty people or 300 people, depending on the size of my district. See what level they're comfortable at.

We've just started - last year was the first one - kind of like an education camp. If there's something you're passionate about or you'd like to share what's going on in your classroom that's going really well, at the beginning of the year in August, we had a day at the high school and you could sign up for like four different mini courses, and then a teacher, being the leader, would take a little workshop approach and so for one whole day of our professional development we got to bop in to different teachers. You know, to me that's being a leader. You're presenting information, things that are working in your classroom, exciting children, keeping them motivated, interested in learning and sharing, so. So that's something we've just started. So I think that's a good way to get people, you're comfortable with your peers - sometimes. Here's a small group. You're comfortable with your 
peers, let's start that. And then if they feel comfortable with that they might get a friend or a buddy to present at a larger conference or a workshop or something. Which is a good way to develop more leaders by doing that. And if we would go ask, you know, I want to go to a conference or I want days off to go watch another teacher or I want this block off to go, or whatever, we can make that happen. If I went to my administrators, I really want third block off so I can go watch this teacher at this time, they will find a way to make it happen.

Ms. Carpenter explained:

I mean, I think everybody can be a teacher leader. And I also feel like if you can get the younger teachers involved in leadership positions, it's probably better because a lot of times when you're a veteran teacher you're kind of stuck and you don't like to venture out, so I think identifying the newbies coming in and seeing they're leadership potential is really good. And I know sometimes that's overwhelming, maybe, well for a new teacher it's overwhelming, but it's also overwhelming for a veteran teacher to have a new teacher come in and say, hey, this is what we're doing, or let's change this right away.

Ms. Spalding discussed how to identify and engage teacher leaders:

I think for me the biggest thing has been being given some opportunities and being put in some positions where I'm a little uncomfortable. And so, like, I did not want to present to the faculty this fall, and so my principal says you're standing in front of a group of eighty people, most of which are older than you and have way more experience, but to put me out there in that position made me like, well, holy cow, I can do this, and so afterwards, encouraging people, whether 
it went great or whether it went poorly, and so I presented, and before I had even gotten back to my classroom, Mr. Munstermann had sent me an email that said, hey, great job presenting today. That's a tough thing to do. Keep it up. And so, like, some of those little. . . and I know our assistant principals will leave little notes like that from time to time that it probably takes them 30 seconds, but it encourages and so like, "Hey, I walked in and saw your lesson, looked good today. Thanks for supporting our students that way or thanks for holding our students accountable." So I think giving people an opportunity to do something and then encouraging them to keep trying it or that it was good when they did it.

Ms. Stephens provided advice for identifying and engaging teacher leaders:

Well, I think it has to do maybe with just seeing how teachers operate in their classrooms and being present - if administrators are present when teams are meeting to see who can kind of keep the group at bay and keep them going. I think that their presence in those areas would kind of help other teachers come out as leaders.

Just being aware and taking an interest in who you have employed and what their strengths are and playing on them. Because like I said, you know, with my R2 Title teachers, they would never want to be pushed out there in the limelight and our administration knows that which is good, but they still go to them privately for advice or for help and then the principal knows that I'm not afraid to - here's what we need to do. So he knows that he can ask me and he can rely on me and I can do things that I'm stronger at and I think just playing on those strengths and getting people more confident, like those teachers that they see as leaders, just 
building their confidence but not singling them out necessarily. You can't single them out because then you get all those other feelings from teachers.

I think we have another teacher leader. She's just started at the district but she's taught before she started. She's the librarian. Her principal kind of started it out a little bit wrong where he made her seem like this God's gift or something...that has set people off a little bit, but she's been able to show, you know, just who she is, and people don't feel like that anymore. Being too, like, this is the greatest thing that ever happened, she's the greatest person, that's not the way to go. You have to very subtly encourage and lift those people up.

Mr. Hawthorne had advice for identifying and engaging teacher leaders:

I don't know... I think that one of the things that would be - I think this is probably a complaint in probably almost every organization that I've ever been a part of - is really been like the administration is seeking out your opinions on things, so I think that sometimes administrators are dead set on solving problems and I think that when it hasn't worked as well, is when they decide that they need to personally solve that problem.

Like specifically, we just went through scheduling. And they did a much better job this year of scheduling with coming to me and asking and making sure they got my input. And I don't want to sound petulant. It's not like I expect every single thing that I want to happen with scheduling to happen, but I do believe that at times in the past we have made mistakes in scheduling that could have been solved had I been consulted. So the scheduling became this thing that happened between the principal and the counselor and they didn't get correct input from me. 
And, you know, at this point in my career I felt pretty comfortable that I am the expert in the school on what social studies kids need, at least from 9-12, probably 7-12, but I feel pretty strongly that I know what needs to happen with the resources that we have available. And I feel like some times in the past they just didn't come and ask, and so we ended up with a schedule that didn't work out. And then we'll be complaining about it retroactively after the fact, and then I feel like you should have asked me because I could have told you that.

So I don't know if that sounds petulant or whatever, but I think that the number one thing is just to make sure that you're reaching out and getting as much information from the bottom - whether you take it or not, I think maybe they're like sometimes, well, what if I get $x$ ? They want things that I can't give them, but I think that there's a way to mine that pool of information and input from your teachers and subordinates across the board without running that risk.

Ms. Wheatley provided advice for schools identifying and engaging teacher leaders: Well, I think you have to give them the opportunity. You have to - it's one of those maybe this is a little gray area for you. It's something, you don't really know where to start, but it's just one of those things, you just have to jump in. And making the teachers responsible through committees, I've seen that, that's been a huge improvement, at least as far as our PLC and our PBIS committees here. Our administrators are part of it, but they don't run it. They're a part of the team; everybody does it together.

And so I think creating those opportunities, understanding and seeing the importance of teacher time to work together, to do things together, because the 
benefits are huge. And you don't see it right away; but you see it over time. I think they're on a three or four year process here, but they've seen a huge change in student behavior, in the way the teachers communicate with one another and you know, they just have to jump in and do it. Find somebody that's doing it well and model it after them.

Ms. Marigold responded:

Gosh, I think it all goes down to integrity and working with someone and not for someone and seeing that they're there beside you supporting you and not having that moment where they're trying to get you, but where they're trying to better you. Whole-hearted, that's what I believe.

Principal's Perspective. Principals shared pieces of advice they would give to other administrators in discovering and encouraging teacher leaders in their building. Hall advised:

Well, I've been working with my assistant principal, she's brand new this year and I talked to her about something similar. She's trying to do everything, like you need to find people you trust and you feel like they can support your vision. At this point we're looking at a new discipline policy and they can support your vision of discipline and also can do some of that stuff that you need to be done. You can't do everything, so...Just try to find those people when you are hiring when you're doing those hires, look on those resumes for leadership experience. Have they been in the military, have they had other jobs, have they been managers? Have they done anything in college that was a leadership role? Try to find those things. 


\section{Principal Garrison advised:}

I mean, in the end it all comes down to if you want teacher leaders, you show yourself as a leader yourself and when I say as a leader, not as an autocrat. You have to admit failure in front of your team. You have to demonstrate that you are willing to allow your ideas to be changed just like you're probably going to change their ideas, you know? And it's in that sense that, I mean, I've worked with people who are like that, I mean, I've worked with people who basically are like, I'm not the tenth smartest person in this room, but my job is to let the eleventh or twelfth smarter person in this room succeed and they made no qualms about that. And I respected that, you know what I mean? It's like these are the things I know, and these are the things I'm good at and these are the things I don't know and I'm not very good at and I'm going to lean on you, you know. Not only are you empowering teacher leaders, but you are empowering that concept of the team where everyone is valued and we're real with one another.

Because that's the number one issue with the team is when from a coaching standpoint when the one person is sitting over there thinking I should get the ball more often, it's like you shot $10 \%$ last season and it's like they shot $60 \%$. It's a no-brainer to the team, but if that one member of the team can't see that. You know, that's an issue. And that's where you need teacher leaders, but in order to get them, you have to be willing to take that on as well, and so when they're like, "Yeah, it sounded like a good idea, boss, but it was awful," you just have to be like I'm sorry that it was awful. I don't know what else to tell you and so to me, that's the number one thing - it's not about I'm going to put this person in charge 
of a committee - it's not about that, in my opinion. It's so much more just about look for people, see the value in the things that they do. I mean, some people might have all the attributes of a leader and never want to be a leader, and that's okay. You know, I mean, that's perfectly fine. Like I said, you try to put them in situations where you pull it out of them - some people don't want it pulled out. That's just kind of how I approach it, so...

Principal Hyde advised:

Get to know your teachers and know their strengths. Trying to figure out what is their positive attribute, you know, being in a small rural school, you know, I'll be very honest, we're not Lee's Summit West. We're not paying teachers $\$ 60,000$ a year, so we're probably not getting 120 applicants for every position. And I would say that it's going to be the same for every school district with the exception of the few: Clayton County, St. Louis, Grain Valley, and Lee's Summit, most school districts in the state of Missouri are struggling to find highly qualified staff. So if you really want teacher leaders you have to figure out what their strengths are, not focus on their weaknesses, but find out what their strengths are, and how those strengths can impact student learning and you know, kind of the school culture because you can kind of grow weaknesses and that's one aspect, or on the flip side, you can highlight their strengths and then hopefully their strengths will kind of mitigate whatever weaknesses they have and then once they kind of feel empowered, they feel like they have a say in what's going on, then it's a lot easier to identify those weaknesses and help them grow, because now they know what 
positives are available, and so let's fix these negatives as opposed to just kind of being, I don't want to say status quo, but. . .

Finnegan's advice for other administrators was:

Makes your job easier. You can't do it by yourself. You've got to have buy-in from your staff and those teacher leaders are the ones who are going to get it done for you. Seventy percent of your staff will end up following you just because they're like okay, it's the boss, I have to follow him. Others may not but the teacher leaders are the ones that have, to me, a lot of the impact on getting things done within our building, how we operate the culture within our building. The principal can't dominate the climate of the building. It really is the teachers who have that power to make it positive.

Chrisley advised:

I guess look for the positives. Because so often, I mean there's teachers and Ms. Carpenter would be an example of that. When she was at the elementary, things weren't going great, and you know, as principals we talked to each other and I just said, well, you know what? I'm willing to take a chance. Let's see if maybe she needs a different grade level. Let's move her up here and she'll be a part of a supportive team of teachers because she was kind of in the mix of some negative people. I said let's put her in the mix where she can have a more positive experience and then just started looking for those positives and then trying to grow them, so I mean I guess that's a big thing I would say. And then trust your teachers. I think that's one problem with a lot of administrators is they want to be in charge, which obviously, that's why you get 
the degree. You want to be the leader, but at the same time you don't have to do everything and I guess for me, I learned that really easily because I can't do everything, and I just - I'm one of those people that I want to do everything really really well, and it took me a couple of years to learn that in this job and especially a school this size, I can't. I have to really be okay with everything being mediocre and that sounds horrible but it's just the truth. Because I'm the 6-12 curriculum director, I'm the district safety coordinator, I go to conferences with all these other principals from larger districts and they say, well, this is where you would get your social worker involved ...that's me. Well, what about your instructional coach? Yep, that's me. We just don't have all those extra people and you have to juggle so much that you have to trust your teachers. If it's totally top down, you're just not going to get buy in. You have to let go...Every year there's something new that they're saying you have to make sure this gets done and not beat yourself up when it doesn't go perfectly.

Mustermann advised:

I think just trust them. Not everything is going to work. And I think we forget that when we go, not we, I think I forgot that when I went from the classroom to the administrator. It's like how many times do I fail and that's okay? You know, we're a failure is not an option school. That doesn't mean that we don't encourage our kids to fail. We just don't want them to be satisfied with that. And so we have tried to instill on our level that same concept with our teachers. It's okay for something to not work. Just because it sounded really good at a conference or in a book, it doesn't always work the way you want it to and I think that's what, you 
know, our teacher leader Elizabeth has kind of risen above that. Okay, it didn't work. Why? To me it's about that reflection and the teachers who truly reflect. But I grew up - my parents had the expectation that I reflect. I was always asked well, why? If I wanted it, it was always a why, why, why, why. Which is how I taught. That's something I don't even realize until I have one of these kind of conversations. That's how I was brought up....

Warren advised:

Identify them, celebrate them, let them take risks, let them be who they are meant to be - not only inside the classroom but outside the classroom - treat them like you would treat family, hopefully in a positive way. Understand they are human beings, they have families and lives of their own, and that comes first. If they're not okay, they're not going to be okay in the classroom, so if they need to bolt out of here at 1:30 to go do whatever, let it happen. It's all good. . . Don't be afraid to let go. I don't mind letting go. We have enough on our plate as it is. I have enough. I don't need to do everything, so let some of it go and let them do it and run with it. They will always surprise us in a positive way and they have the gift to be in school...that's why we hired them. Let them be who they're meant to be...I'm just blessed...Blessed to be in a good district in a good building around great people or I would not be here.

Quick advised:

Well, I think you've got to know who they are, for good or bad. I mean, you have to know who they are. If you don't know who your teacher leaders are or you think you have none, you know, this is my only job, so I can't - my only place, 
my only culture I've been involved in, my only district, but I think you'd be just absolutely wrong to say I don't have any teacher leaders. Maybe you don't have any positive ones, I guess, you could be put in a position where there are some negative teacher leaders, but then you still need to know who those are, too. You know, and I would always think that everything's relative so even in the worst of schools is going to have some teachers that are the highest level comparatively to everybody else, and you've got to find them and start with them. You've got to use them somehow. You've got to find out what their strengths are; you've got to use them. You've got to, if nothing else, ask their input. And I think you can ask everybody's input, but specifically and maybe more often, you ask those more intentionally.... And to add to that characteristic, often those teachers do that. They are intentional. They don't come - they don't fly by the seat of their pants very often. It's a going off on a tangent because a kid had a great question kind of moment or you know, they don't just show up and just teach - they've got a plan. It may not be the Madeline Hunter 13-step plan, but they've got a plan and they know what they want the kids to accomplish today.

Silvers advised:

I guess my advice would be to not give up because I think that we get bogged down and we listen to all the naysayers and we listen to this isn't working and this isn't working, and this isn't working and you just can't give up on it. You can't give up on the teachers, you can't give up on the kids and the moment you start to falter yourself is when they will see that and it's like a pack of dogs. They'll just 
zone in on that and say we're not going...we're going to let it go...they're going to feed on that. I think perseverance and not letting things go to the wayside. And identify those people that you know support you, and that's another thing. Watch your back, you know. And you know, that's unfortunate that you have to say that and I'm very fortunate here, but I've seen other principals where they think they've got a good thing going while in the background there's a little rough behind them that is working against them even though they, to your face, they...And I hate to be that way, that negativeness, but you have to surround yourself with like-minded people and people that want to see your school succeed. And that's hard advice to give, I guess, because you don't want to think ill of anybody or think that anybody would try to undermine someone else, but it's unfortunate that it happens.

So you've got to surround yourself with people that are - and it's all about kids....it boils down to. It's not about the adults in this building; it's about what's best for kids and I think we lose sight of that sometimes.

That would be my advice. I haven't been at this a super long time, but just in the short time I've learned a lot, and having Mr. Limback coming in and helping us...(talked about her mentor) listening to advice of other people. That would be another piece of advice I would give is find those guys and gals that have been in the trenches for a long time and listen to what they say because they have been through it all. Don't disregard them because they're the ones that have really been through it and you can't do it by yourself. You have to reach out and get help from other people. I think that's my biggest change between my first year and this 
year is that my first year I thought, you can do all of this. You can't. You can't. You have to let other people help.....and that's the biggest change between last year and this year with our leadership team. They're doing it. I'm not doing it. I just kind of sit back and watch them work, and the one person I haven't mentioned that I should is our counselor...

Shackles advised:

Be a people person. The advice I was given by my first super was, Chad, the paperwork is the least amount of the job. Your job is with kids and staff and parents. Concentrate on that and the paperwork - we'll do the bare minimum, do it after school or before school. Don't do it during school if you can help it. I mean, yes, there's a few forms during school you have to, but that day, your school day should be about people, not about paperwork. And I see too many young principals - they're more about research and reading and less about people. Don't get me wrong. Maybe that is the time we're moving into, but it's not the most important thing. Kids and the people we work with are the most important thing. I think a large part of what I do and how I do it has helped me in many different ways but it has made the school grow. 


\section{Appendix G}

\section{Themes}

Synchronous with qualitative research, responses from participants were captured by surveying the principals via email and with personal interviews of both principals and teachers. There was a total of ten principal surveys along with ten principal interviews and ten teacher leader interviews. The purpose of the study was contemplated as well as the guiding research questions, and survey responses and transcriptions from personal interviews were considered and analyzed for emerging patterns and trends. These trends were coded often as single-word or short phrase concepts. Upon further analysis, of the data, one overarching, comprehensive theme emerged: Let's go. Stemming from this prominent theme, four sub-themes emerged: 1) "I'm here for you", 2) "You can count on me”, 3) "Let's go together", and 4) "Let's keep our school moving forward". These personal statements capture the collective essence of the responses.

These selected themes were concurrent across the data and occurring in all participant responses: teachers and principals. It is important to remember the fact that all principals in the study selected a teacher leader, so they were, by nature, in support of this concept.

\section{Let's Go}

The prominent theme of "Let's go" was echoed throughout the research, cutting across all responses, indicating a level of support as well as a strong sense of motivation and enthusiasm for teacher leadership in general and in having the intiative to get things done. Ms. Carroll spoke of this sense of motivation and energy of teacher leaders: 
It's much like that teacher who comes out of school initially. They are motivated. They lean towards leadership somehow by nature. It could be that that's their-it's just the way that they are or in some instances I feel like there's others like me who realize when you are put in that position you have to step up. They're flexible, they are responsive, they are perceptive. . They are still active. They're not passive; they don't sit back. They communicate with you, but you can see that behind them is this energy that's visible in the hallways, in their classroom, in their interactions with their colleagues.

Ms. Carpenter shared:

I think I just jump in when there's something new. I jump in and get the hang of it and then ... if other teachers have questions or what not I'm ready to point them in the right direction... I think it's just doing it. Going out and doing it and taking the leap of faith, a step ahead of everybody else just to show that it can be done. I think that's one of the things is just, you lead by example.

When asked how Principal Hyde identified teacher leaders in his building, he claimed:

A lot of it just comes from initiative. I think being a leader you just have to have a little bit of self-motivation to want to do what's best for whatever the situation is, what's best for kids, best for the program, best for the district, whatever it is. There has to be a little bit of initiation there or motivation on the teacher's part. And other times I try to see, you know there may not be always people that are always putting themselves out in the front, but then through conversations they have a desire to maybe want to improve so then trying to find ways to see if they 
would be willing to take the next step and maybe put themselves out in front and take the initiative to make a difference.

Principal Quick explained:

I think being a self-starter helps. If you're motivated and a self-starter, you're probably gonna do things, you know, quote right. . .that's a pretty good identifier of who's going to be the leader in the building is the one that wants to step up and do it on their own.

Principal Silvers said, "First we start with looking for people who are just willing to step up and looking for some extra involvement." Principal Chrisley echoed this sentiment: “...we do have some really strong people in the middle school that are willing to jump in, be on the committees ...they like to jump in there and they do it with a positive voice." Ms. Williams mentioned:

I think it goes along with being a coach and being a leader for my girls. A lot of just able to give people direction on their purpose and what we're trying to achieve and then you, know, steps on how to get there and then motivating them along the way."

Ms. Stephens claimed:

I would say probably because I take initiative to kind of get things done... I really enjoy taking care of the details, so it just kind of started that way. When he first came it was, I think my second year here, and he would just kind of throw an idea out there and I would make it happen for us. . . 


\section{I'm Here for You}

Along with being motivated to action, the theme "I'm here for you" emerged.

This theme was detected over and over again in the research, and it addresses the components of meaningful relationships, involvement, and devotion, which were often used interchangeably within participant responses. When asked why she thought her principal named her as a prominent teacher leader, Ms. Williams explained this concept, “. . . I feel like I'm pretty good at connecting with relationships with the kids and then that leads to having a good purpose and then staying on the path for that." Mr. Hawthorne responded to the same question:

I feel like I'm probably involved in a lot of different aspects of the school. I coach two sports and I'm a curriculum leader, which we call department heads here since we're a smaller district. I am student council sponsor and we recently had a, we went through like a CSIP process. I was part of that.

When addressing characteristics of a teacher leader, Mr. Hawthorne spoke from experience:

The biggest characteristic is just the willingness to be devoted to the class. . . the biggest characteristic of other leaders that I admire the most is just the willingness to go all in, I guess. I landed in this district, loved it a lot, now I'm proud to say we bought property, a house, we live in the district now, we have a residence in the district. I have my kids in this district. My wife teaches at this district. . . our whole lives - our pride, our identity, our kids are here, and so this maybe sounds cliché, but the other leaders are the people that also do that.

They're just here all the time. The kids know it. They know the ones that are here 
all the time. They know the ones that are also on the booster club and they go to the school board meetings and they come in hours early to sit on a scholarship committee. So I think that the number one characteristic I guess to sum it up is just who's going to show up and do all those things.

Principal Hyde used his selected teacher leader as an example of someone willing to invest in relationships:

You know, she takes it upon herself to go around and decorate teachers' doors. It's a little thing, it's a minor thing. . .she just takes the initiative to do it, and now as you walk around, all the teachers in the high school and middle school have their own unique positive saying on their door. Earlier in the year she did superhero themes, and so every teacher had a superhero theme on their door that correlated to their last name so if their last name started with an S they were Spiderman or Superman or depending on what they wanted. But then again it's a little thing of, it just kind of creates a better learning environment.

Principal Chrisley also provided an example of how she encouraged her teacher in an intentional way:

With her, it really was she had been transferred from the elementary to the middle school. Things were okay down in the elementary, but she just kind of was struggling a little bit and she got up here and kind of just started to find a niche and so, I don't know. I just saw something in her that maybe she could be contributing more and I sat her down one day and said, "I believe in you. I think that you could be contributing a lot more and I think you are a leader." That's 
been about four years ago and she has run with it. . .I think you build those leaders by giving them encouragement and letting them know you do believe in them. Principal Hyde provided an example of how he supports his teachers by encouraging them in order to help build a foundation for leadership:

But really you're trying to figure out who has the desire and the will to see something get better and then just try to encourage them to maybe step outside and then kind of shine a little bit of light on themselves because really, that's the hardest first step for a lot of them is is I want to do better; there is something I could be doing for the kids or for a program, or whatever, but I'm kind of afraid to maybe put myself out there, and so the biggest part is is just trying to encourage those people. Like Ms. Weston has been here for twelve years, you know, so I know that she had a little bit of leadership. She kind of had some initiative before, but at the same time, we also had to build a relationship and she had to know - but we had to have a relationship to where she understood that I had trust and a little bit of faith in teachers getting outside their comfort zone.

Principal Garrison discussed teacher leaders and building relationships with students: Typically speaking from a teacher-leader standpoint, we're looking for the attributes, basically in a teacher especially, do they understand what the kids are going through? You know what I mean? Because that's basically what we as administrators are expected to do is make sure you remember what it was like to be a teacher, and so if you're the teacher, I really need somebody who remembers and understands what it's like to be a kid, and so that's one of the first things you're looking for. 
Mr. Hawthorne expressed the importance of building relationships within the community: I'll give you an example. You know, we have a Veteran's Day assembly. Schools are mandated to have some kind of Veteran's Day recognition assembly. When I first started, they had a real nice one and I was very impressed with it. The gentleman that ran it he moved on, he left. And so you know at that time I realized that when I first started at the district I thought that, I don't know, maybe every school does that, and maybe it's like a general format that all schools are doing. And I realized after he left that it was not. . . so when he left, you know how things are. Now you're in kind of danger of it going away, I had to step up and take that thing. So I kind of stepped into that role. I don't really know why. I'm in the military, so I guess it felt like the right thing to do. So they're like hey, will you do this Veteran's Day assembly thing? So I tackled that thing. Not alone - with a lot of help or whatever, obviously. You know, each year we try to make it even better and better and it's something that I'm really proud of. It's an opportunity for us to showcase the district, the whole community ...We've had a big focus on trying to get as many community members as possible. We also turned the experience into a fundraiser for veterans. We raised money for ShowMe Honor Flight through it and the last couple of years we raised a pretty good little hunk of money for Show-Me-Honor Flight. . .we really focused on having a key-note speaker here that could kind of deliver something to the student body and community that really mattered...

Ms. Williams also shared: 
As far as public relations stuff, community stuff, we do...we just got done with (a fundraiser). Her daughter, six, has cancer. We raised almost $\$ 6,000$ in the fall during homecoming week and we just did a basketball night where we raised over $\$ 3,000$ with another school. So we do a Hoops for Hope night, which was that night, and rally around people who currently have or had it, so kind of more of that aspect as far as the PR of good things happening and teaching our kids how to treat others so to speak, and so I'd say that would be more of where I am better as a leader is how our school as a whole is, so not just necessarily how we teach or anything like that but just being positive influences.

Ms, Carroll explained:

I am currently on a committee that is called Bright Futures where we try and have communal interactions, well, with the community that is, in making positive changes helpful to the kids involved so service learning activities, donations, giving back to the community.

\section{You Can Count on Me}

Support for principals. There were several cases where the principal counted on teacher leaders for support and ideas. Ms. Williams explained:

The decisions a lot of times he asks because I went to school here and then I left for seven years, so I was gone to another district and I came back, so I think he likes to check with me because I have a feel on what does work and doesn't work, and then I also like to challenge people a little bit. I like to challenge my teams to give their best. . And so I think he likes to do that also. He likes to have feedback on that. . he comes in for feedback. There's times in meetings when I'll answer 
his questions with my opinion even if it doesn't relate to PE. Just to be like why are we doing this? Just kind of feedback because you can tell he wants feedback from teachers and a lot of them are scared to give it. And I'm not because I know that he respects me and so, I know we might not always agree and we can always agree to disagree, but there's a respect there so I'm not afraid to say things. He might like it, he might not.

Principal Chrisley explained, in relation to the teacher leader she selected:

If I'm stumped on something in how we might make this work, especially if it relates to technology I can go to her and say, "Hey, what do you think? Do you have any ideas?" And she's very good at brainstorming and she's really receptive of just sitting down with me and just talking shop. She's a huge resource and it really comes down to mostly that she sees what needs to get done and she just gets out there and does it, without having to have a lot of direction.

Principal Quick added,

Hey, I have this thing I want to do, this project, whatever, who am I going to ask? Well, I'm going to ask my teacher leaders... They're the ones I go to and ask, hey — what do you think about, how can we, would you mind ...

Principal Garrison also relayed similar experiences where he relies on his teacher leaders: "I mean, those are the people that you can go to and you can say, 'Tell me what you think about this,' you know? Because they have the ear of the other teachers, they have the respect of the other teachers."

At times, principals rely on teacher leaders as liaisons to help them relay messages or new information. Principal Garrison attested to this: 
Sometimes I'm not always the best at this myself because I have a vision, I want to share my vision, and I usually do but sometimes it's hard. A lot of times I will have to go to these people and ask them, "So this is the message I want to convey, and it's very clear to me that it's not being conveyed in that fashion, you know what I mean? Like, I'm seeing something and I know that's not how people see it. That's not the message that I'm trying to send. This is the message that I'm trying to send." And so a lot of times I will use them in that capacity. Not necessarily as that, but also in that sense of I need input to understand what I need to change to make this maybe more palatable, more... how do we need to craft a plan here that's actually going to be successful.

Principal Chrisley also explained the liaison concept:

I think the teacher leaders are even maybe more important than the leadership of the principal, and that being, I really learned that because my unique experience was being here as a teacher, and I was that teacher leader, and I was the one that if I would say here's a great strategy; you should try this in your classroom and everybody would latch onto it and oh, Karla thought that was a good idea; let's try it. It was really good. We had some good stuff going on, and then when I moved to the principal's office I tried to do the same things but it didn't go over as good enough? Am I going to get a bad score? And they just were always wondering what I was up to....and I was like, no, I just want to help, I just like instruction and I want to keep helping you. So that's when I realized right away, okay, I have to get these people like I was. I pulled out of that mix, and we were left with not a lot of teacher leadership, I've got to start planting those seeds and get the people 
under me so I can give to them, hey, this is my idea, this is what I'm thinking, and let them take ownership and run with it. It's just better received from the teachers...And it was just interesting, because I am the same exact person I was three months ago...but it says "principal" over my door, so that changed things. And now, they've developed more trust and I'm kind of back, it's come full circle, but I mean, it's because of those teacher leaders; that's huge.

Support for other teachers. Teacher leaders also help to support other teachers.

Ms. Carpenter gave an example of other teachers viewed as leaders in the school playing a supporting role to other teachers:

We have a couple of teachers here in the middle school that they have their master's degrees in specialized math and so they're taking on leadership, going out to other classrooms and kind of being an instructional coach so we have a couple of those here in the middle school.

Ms. Spalding provided another example:

I think within our department we have people you go to for certain strategies or certain...because my experience right now is more focused in the science department. And so we'll have Ms. Barrett who was my mentor teacher. If I'm wanting to do a lab or a walk through like okay, I want to do this, how can I get this to happen in my classroom? I feel like within each department there's somebody that you can go to that's not like the instructional person for that department. But you say like, "Hey, I'm trying to do this. How can I get this to happen?". . . So we have people that we go to like instructionally.

Ms. Robbins mentioned teacher leaders supporting other teachers in a specialized area: 
There are certain teachers that are electronic gurus. And so if you have a problem working with your grade program or if you have a problem working with your website or getting an interactive thing to work for your classroom with your students, people will run to them and say, oh, can you help me with this or help me with that? So they are leaders. There are people that use a lot of technology, some younger people, and so as an older educator, it's like, can you show me how that works? Because the kids were excited and I liked that and I just need an extra practice run through with another person so I will feel more comfortable. . .So I mean, the leaders are, they're good at something - there's this little niche. There's a little area of expertise.

Principal Warren described this support as well:

I think it starts with a mentoring process . . .like an Alexandria Stephens, who demonstrates by action and by voice, and then other people think, hey, it's okay if I do that. . . We do have way different teaching experiences in the middle school and levels of ability; however, we are always willing to share ... a lead in something. . .We'll support you every way we can, but just do it and we'll help you along the way. That's how it works in our building. . . We want to instill that confidence and support you when you fail because we all will. Regardless, we all will.

Principal Munstermann gave the example of his teacher leader in a much needed mentoring role:

But I think, when we paired her, it naturally happened with common classes. We had a teacher that we were working quite hard with to improve some things and 
once they got paired up in a common curriculum, that other teacher, I mean, it was like a light switch went on. I mean, it was night and day the difference in the performance of that teacher in front of the classroom. I can't tell you what was said behind those closed doors or anything, I have no idea, but I know that individual relies on her, yet she has cut them loose a little bit but is always there. As a matter of fact, they're in a team right now together. But I think that is my Elizabeth story, if you will. Just because of the growth in one year's time that we saw in that other teacher. Because that's someone - we were seriously considering hey, this is not working and then now, they're a fantastic teacher, I mean holy smokes, I do attribute that to Elizabeth and her leadership.

Principal Chrisley provided examples of two other teacher leaders who regularly support other teachers:

I have a couple of other teachers who have gone and gotten their specialist degree in math instruction which is kind of a new thing that's just started in the last couple of years, so they're among the first ones at UCM to earn that degree. So they've been ones, then again, with tons of encouragement, and they support one another. I think that's been kind of a neat part of that is that they work really closely together and they push each other to be better and better all the time. So they're the ones that are always willing when I go to them and say I want you to present what I saw you doing at the faculty meeting. They're always willing to jump in and help other teachers. . . but they each have an extra hour when they can go down to the elementary and kind of do some instructional coaching informally. 
Support for the students. Teacher leaders support students in meaningful ways.

Ms. Marigold mentioned:

I am able to understand that teaching has so many different facets and there's not one correct way to teach or to bring instruction across. It has to be personal to the teacher, but they also have to differentiate to each student. So I think that was one of the aspects. Often times I'm a very good judge of character, but I'm also a very good judge of if a student is learning or not. I also think showing students leading through positivity. .. leading through respect is something that I'm able to show, and I think that has been a benefit for me as well. Also, just being resilient and showing that yes, you have bad days but the kids have bad days, too...

Mr. Hawthorne reported:

You literally have to find what it is that you have to offer and then tackle it because I think that the number one thing that I've learned about young people since I became a teacher is that they want to be inspired and pushed and challenged, as cliché as that sounds. Like when you look back, the teachers that inspired me didn't necessarily have amazing talents and skills, they were just really fired up about what they were doing and that's infectious, so I have no idea really what things I'm into that I'm only into because at some point I ran into some teacher who was really into it and that's the way that we impact people's lives. You don't have to be a genius or a, you know, whatever, some expert, you really just have to be really interested in it.

Ms. Robbins shared: 
You have to have good relationships with students and love what you do, you have to. The best teachers, if you think back, the ones that you either connected with or you just liked going to their class, you didn't know why, it was because they loved what they were teaching. They were excited about I get to be here, this is what I get to share with you, and I hope you love it as much as I do.

Principal Hyde claimed, in response to how his teacher leader has had an impact: Just getting kids excited about coming to school. That's the hardest thing, you know. Letting kids come to school and let them know that there is a variety of people that want to see you succeed. It's not just doing the things that you have to do. I'm not just coming to school and teaching you a lesson, but here are one hundred different opportunities from twenty different staff members that all are trying to find ways to impact you, and I would say that little piece I think kind of makes a difference.

Principal Warren elaborated upon one of the reasons why he selected his teacher leader: She has a God-given gift - to teach, and to be with kids, and to love them and nurture them and just, her content - I mean she's a master at it. Just five years teaching, she is a true master at it. She takes a concept, puts it in her class, and it is rock star stuff. But she just has that. You know, I can’t put my finger on it. Kids are drawn to her. She's specifically sixth grade for a reason because that's a major transition for us. And I'm sure you've been through this. Every year you hear, hey, this group is rough. Watch out for them. They're not going to be good. But she just has a way of bringing them in, making them feel comfortable, you will be okay, and get to know them. And so I could just mention a kid's name and she 
could tell me top to bottom, everything about that kid: not only academically but socially, all about their parents, everything. She just has that.

Principal Quick also spoke of his selected teacher's rapport with students:

I think he does great in the classroom; the kids have a tremendous amount of respect for him and I think those go hand in hand. But then outside of the classroom, he just builds those relationships with the kids and sometimes that's what they need just to get to school, so it affects more than just his class.

\section{Let's Go Together}

A theme of working together for a common purpose emerged from participant responses. These teacher leaders are willing to work alongside others and solve problems. They understand relationships and social structures, as well as how to motivate others to work together in order to accomplish tasks and make decisions. Ms. Carpenter recalled when it was expected for teachers to achieve a certification and she stepped forward and led the other teachers:

Just recently I got my google certification as an educator and I think again, that's just showing others, hey, you can do this. Our superintendent is kind of pushing for it, and so I am one of the first five to get it done and passed and everything, and I think just them being able to say because he sends out an email or whatever that says, hey, these people have passed, and it may be pushing forward and showing other teachers in the building that it's been done.

Mr. Hawthorne discussed himself in this role of leading others in collaboration: Well, yeah, the administration has in the last couple of years focused on putting teachers together and having us work with each other in different roles. It's very, 
very easy for us to become like really compartmentalized, isolated, I don't know what science people do, you know? Even in this little building. They seem like they're really far away. So I think that the administration has been doing a good job of something that really....don't want to do necessarily, going and observing each other and making notes on that and so I think that's an area where the administration has utilized me and other people in the building — getting teachers into a situation where we're learning from each other.

Ms. Robbins also divulged her experiences:

I've helped another teacher sponsor science Olympiad and they do competitions. I would just go out and help. Let me help you with that or help with this. . I have planned school-wide - we had a solar eclipse day and so I kind of got that started in a plan and then encouraged people to help plan that. We also have done crime scene investigation day. Just kind of take a little idea and bump it off a few people and if they agree it's a good idea say help me, so we've planned that.

Ms. Spalding shared:

Well, this year, I've started taking on more of a role, because we are a PLC and so I've started taking on more of a role in my individual collaboration group. I've started probably in the last two years I've really kind of co-led my instructional data team, the IDT group, and so we have a sophomore science small group that I've kind of helped pushed along.

In collaboration, as times teacher leaders help to mediate their peers, communicate clearly, and consider others' viewpoints. Ms. Williams voiced: 
She is a good public relations person as far as let's try to see the other side of things, which I don't always do. Sometimes it's my way is the only way I think, so she brings the other balance of that of let's look at the other perspective and consider that. She's good about kind of bringing people together on the same page when we're not always like that. . just being able to talk and then agree to disagree and see other viewpoints. . I think just being able to communicate openly without creating rifts is best and then also being able to criticize in the right way to improve people without it being personal, like being demanding but not being demeaning, so not ridiculing them...

Ms. Carroll conveyed the sentiment as well in encouraging teacher leaders: It would be - one of the main things to start off with I think would be understanding social relationships and the social structure and knowing how to collaborate and coordinate with others of different backgrounds, of different beliefs, knowing that you are trying to achieve something on the same path, so of course you're all looking for something to become better or in the case of the school district situation, you are trying to do something to help improve experience for the kids and knowing how to communicate with people who think differently, act differently, believe in different stuff. That can really make or break you as a participant if you lack understanding of social relationships and how to share your opinions or hear others' opinions and not get to where it ends up being a personal dispute and stays on track.

Principal Garrison discussed a teacher leader in the role of collaborator: 
Basically when somebody had a curriculum question, they would go to her because they knew that she would listen, they knew that she would work through them, they knew that they could find a solution for them because she wasn't the party line, so to speak, she was kind of the go-between, which is what all leaders should be. You know what I mean?

Principal Finnegan discussed the impact of teacher leader as a collaborator:

Extremely positive impact, you know, she's ... guided us through the new standards, state informed upon what was going on. Science departments are always interesting at different places because they're naturalists, they're earthy. They all love their content more than anybody else's content, so to orchestrate that group to come together and move in the right direction on a daily basis is pretty cool to see. She does that with the whole building, too.

Principals also reflected upon the value of shared leadership. Finnegan divulged: Makes your job easier. You can't do it by yourself. You've got to have buy-in from your staff and those teacher leaders are the ones who are going to get it done for you. Seventy percent of your staff will end up following you just because they're like okay, it's the boss, I have to follow him. Others may not but the teacher leaders are the ones that have, to me, a lot of the impact on getting things done within our building, how we operate the culture within our building. The principal can't dominate the climate of the building. It really is the teachers who have that power to make it positive.

Chrisley added, 
...trust your teachers. I think that's one problem with a lot of administrators is they want to be in charge, which obviously, that's why you get the degree. You want to be the leader, but at the same time you don't have to do everything and I guess for me, I learned that really easily because I can't do everything. . . it took me a couple of years to learn that in this job and especially a school this size, I can't. . . because I'm the 6-12 curriculum director, I'm the district safety coordinator, I go to conferences with all these other principals from larger districts and they say, well, this is where you would get your social worker involved ...that's me. Well, what about your instructional coach? Yep, that's me. We just don't have all those extra people and you have to juggle so much that you have to trust your teachers. If it's totally top down, you're just not going to get buy in. You have to let go...Every year there's something new that they're saying you have to make sure this gets done and not beat yourself up when it doesn't go perfectly.

Warren shared:

Don't be afraid to let go. I don't mind letting go. We have enough on our plate as it is. I have enough. I don't need to do everything, so let some of it go and let them do it and run with it. They will always surprise us in a positive way and they have the gift to be in school...that's why we hired them. Let them be who they're meant to be.

Silvers shared some words of wisdom and experience regarding sharing leadership: Identify those people that you know support you. . .you've got to surround yourself with those people. . find those guys and gals that have been in the 
trenches for a long time and listen to what they say because they have been through it all. Don't disregard them because they're the ones that have really been through it and you can't do it by yourself. You have to reach out and get help from other people. I think that's my biggest change between my first year and this year is that my first year I thought, you can do all of this. You can't. You can't. You have to let other people help.

\section{Let's Keep Our School Moving Forward}

Ensuring that progress is an ongoing consideration and mission surfaced as a prominent theme. Teacher leaders were involved in multiple capacities with growth and change. Ideas in this category include having a growth mindset and seeking improvement and change. A willingness to try new things and be innovative, as well as pushing and challenging both self and others are behaviors attributed to this theme.

Individual growth. Ms. Weston discussed the importance of professional growth: Try new things is the big thing. Last year we got really into the technology and I went to a tech conference and they were like, "So do you want to try Chromebooks all the time in your room? What do you think?” And I was like, "Sure!" So a week later I had a whole set of Chromebooks for my kids. I've got eighteen Chromebooks in my room all the time and so it was like, well, let's just do it and see what happens. So the next week it was like Google Classroom, Google certified. It was like okay, let's just jump in and let's go! So it's been very nice to have that flexibility and that well, we'll just see how it goes. This year all of the middle school classrooms have our own sets of Chromebooks. All four of the middle school classrooms do and then we have two mobile carts for the high 
school to use. But all of our dual credit kids - so half of our juniors and seniors have Chromebooks with them that they take home with them and that kind of thing. We still have an actual computer lab, too, and then our business still has a lab, too. But it has been a world of difference now. And with the flexible seating, my textbook is online, now, Google Classroom. . .

Ms. Spalding shared, "He talks a lot about that I try new things in the classroom so like new strategies and stuff; he says that I'll try anything in the classroom.” Ms. Weston encouraged, "Go out and try something new. Step outside your comfort zone." Mr. Hawthorne answered:

Different ways that I've been a leader. I think that probably one of the biggest ways is just being willing to step into a lot of these different roles. Certainly not all of them I would have described as within my comfort level first coming out of college. So I think that over the years it's like a general willingness to take on roles and projects that were not necessarily ones for which I was trained or even necessarily originally comfortable.

Principal Quick addressed how teacher leaders evolve in his building:

Well, certainly I think every teacher grows and improves, but you know, I think the more opportunities they get to learn, they're going to learn from them. You know, that's again, one of the reasons they got to where they are is because they learned from those - whatever mistakes they had made in the past they continued to learn from that and continue to want to learn and improve. They're not satisfied doing the exact same thing over and over again either, and so I think they, again, 
are kind of natural improvers, they are natural -want to get better at whatever they are doing. So I think that's part of how they evolve.

Principal Garrison elaborated on this same point:

Because that's the thing is you do evolve. . And we know that, a lot of it is just trying to ask the questions - asking the right questions in the right fashion where you don't piss somebody off, but you want them to actually think about what you're asking them. Because we all know... you talked about college professors...the number one thing that they used to always tell us is you have to be great at self-reflection if you ever want to be a great teacher and we all know that but at the same time, that's a skill unto itself. And the teacher leaders who evolve, they see that. They take the time to reflect. . . It's about I want to meet the goal. Then you have to get people to evolve in different ways and so that's kind of the key is basically I'm a big believer in you don't put in what's not already there. The only time you ever do that is if it's going to cost somebody a job. If your deficiencies are so bad that I can't keep you employed, then we need to try to save you. Other than that, it's more about drawing more out of what you have in there. You just don't see how to apply it, don't have a need to apply it, etc. And so that's really what you're looking for in the hopes that they do over time grow.

Principal Chrisley spoke of her teacher leader and growth through risk-taking:

Definitely within her sixth grade team she really, when it comes to technology, she pushes her other team members to try new things. It's been interesting because one of her teammates that is very timid - wonderful, wonderful teacher, but she's very timid amongst adults, but amazing with kids...she actually decided 
to go ahead and do her master's in technology education, which I hadn't seen that a lot from her, but I think it's just she started seeing it grow and started seeing what was going on here and Carpenter was a big part of that push, letting people see - I don't know how to do it but we can try it and figure it out and be risktakers. I think that's been the thing that people saw in Carpenter here at school is that she's a risk-taker. Even if it's not the most comfortable thing or she doesn't totally understand it, she's willing to figure it out and try it.

Principal Silvers also spoke of trying new things:

Well, with Anne that you're going to speak to, she is just willing to try anything new and she's willing to share her ideas so she's been to a couple of things and she's a very tech-savvy person anyway, but data. You know, people who are willing to use data to drive your decisions and willing to just put themselves out there and try something new. Those are the people that I really try to look for because you can't be stuck in a rut in education anymore. You have to be willing to change and try new things. . .those are the folks that I think make the biggest difference for our kids.

Professional Development. Seeking out, attending, and providing quality professional development was cited as something the teacher leaders are known for. Ms. Weston conveyed:

Well, my colleague next door. She's been here for two years, but she has been teaching for fifteen years. She is my co-chair for professional development, and the way that works is that we lead all of the professional development for the district. So we are the ones finding it, we are the ones teaching it, and we're the 
ones doing it. . We're trying to figure out K-12, so we're even trying to figure out elementary, like what it is they want and what they need and all of that so that tends to be a little time consuming.

Ms. Spalding explained her emerging role with professional development:

... Then this year is my first year on the PLC committee, which that kind of helps plan all of our PD and stuff and so, and like monitors our school's progress is like the PLC. I did my first faculty presentation at the beginning of this school year, and so starting to be more of a vocal person is challenging, but it's exciting to think about continuing on.

Ms. Stephens discussed her continuous role in professional development as well as administrative support for these endeavors:

Well, I mean our administration, I feel like if you show the initiative and you show what you want to do, we have administrators that are so supportive of that. I mean, Todd sent me to the teacher academy last year and he sent two more this year just for teachers that, you know, just show the initiative. Anytime I've ever asked to go to any training, he sends me because he knows that I've going to come back and share and use it in my classroom or whatever. They just never say no. It's kind of like I've earned their trust enough that if I say this is something that I want to do, they're going to encourage me to keep doing it. So, I mean, I couldn't ask for better administration in that respect, just so supportive.

Ms. Marigold also emphasized:

... he is fair and equal with everyone and I think the teachers feel that. They know that, and he has an open door where he continually supports us and that has 
been a career changer for a lot of us. I've led multiple conferences here, Socratic seminars we have done. I'm in a pull-out right now with UMKC where we're talking about a book called Ship This where we're talking about mindsets, and we'll do a presentation soon.

Ms. Wheatley also shared:

Well, at least within this school district they've done a lot of work with PLC which I actually had some experience with before I came here. So I kind of think I've been with PLC since the beginning and I know that they've made a lot of progress here, but there have been a lot of things at least particularly this year with data collection and understanding how to integrate technology with what they're doing and so I have some experience. And so they've been able to pick my brain a little bit but at the same time send me out to go learn some new things and then come back in and teach them to them and they even had me go to the consortium this year and do a whole technology session. It was so much fun. They know that that's a passion I have and so they allow me to work with them and to teach them and so that's been a great experience.

Yeah, a lot of those sessions that I try to do for everybody around here with professional development. I've even taken some big steps into learning more about data collection and then integration into what we're doing. I went to a huge conference in December...it was fantastic, and I would recommend it to anybody because there were professionals from all over the country. There was a contact that I made at Microsoft. It was phenomenal but at the same time thought wow, this his heavy... when I came back and tried to talk to everybody about it, I felt 
like it was incredibly overwhelming, but I narrowed it down to what I thought we needed to do here, and you know, everybody was really positive about okay, let's do something with this, so that was something that I really just kind of saw a need for and I said okay, how about I just do this because I think this is important and I think it will benefit us.

Teacher leaders providing motivational direction was discussed as a way of moving schools forward. Principal Hall said,

Well, the ones that are evolving, you know, they continue to have an enthusiasm for improvement that drives them so, you know, they're driving that enthusiasm so as we go through the School Improvement Plan, they are the ones that really kind of keep it going, so...I just try to find people who are passionate about those changes... and kind of keeps us rolling along.

Principal Hyde voiced:

... I can rely on her. Just the other day we had a fundraising idea - the elementary was doing it. My secretary caught wind and asked if we could hop on and I said yeah, but I know that I'm not going to be the best to get those kids kind of motivated and organized to do something and so I know that she is very effective in utilizing her resources, communicating with kids, kind of getting an idea across to them and getting things done. She's very organized, like I said, kind of going back to - any time there's something going on, whether it's professional development - if it's a teacher issue, if it's a student issue, hey, she has no problems with trying to find ways to improve, maybe she doesn't have the time, energy, or the ability to fix a problem but she at least recognizes the problem and 
maybe kind of direct other teachers to me and say, hey, we're all seeing this problem. . . so she does a very good job of you know, organizing, delegating there's a variety of things that she just does well. But she really just goes back to having that initiative and that desire.

Problem solving. Problem solving on the part of teachers as leaders was discussed as a way to continuously move forward. Mr. Hawthorne shared:

I think our administration has been really supportive of you know, all sorts of teacher-driven endeavors. . .finding out what their teachers are good at, what they love, what they're passionate about, and then letting them, you know, be a problem solver to find solutions to put that teacher in a position to do that job. Our administration is really supportive of that.

Ms. Robbins responded, in reference to problem solving:

There are certain teachers that are electronic gurus and so if you have a problem working with your grade program or if you have a problem working with your website or getting an interactive thing to work for your classroom with your students. People will run to them and say, "Oh, can you help me with this or help me with that?"

Principal Garrison mentioned this as well:

And so, you know, when you take the time to think about it like that and then one of your jobs as a leader is to develop leaders amongst you. .. and so you take those people - they are problem solvers, you know, they can take what you are saying, compute it, tell you the aspect, the viewpoint of, how this will be responded to and, you know, offer that back. So those are the things, like, to me, 
those are some of the characteristics I've seen that embody that person that really has the respect and the ear of the other teachers because they know that they can get things done.

Change Agents. Principals often rely on their teacher leaders to help implement new initiatives or to change current practices. Principal Garrison explained:

You know, in my mind those are some of those examples and then like when you actually are in the process of doing the initiatives, you really try to empower those people to work. You know, for example, with Bonnie, I really want to change kind of the way we have curriculum set up. . . I need her to carry my torch into that arena. .

Principal Hyde expressed:

We have a wonderful FACS teacher. Again, she just sees a need of how she can best suit kids. . . I would say that she's another good example of hey, I want to try this. I think it's going to be best for our kids and our school and she's really turned the program around that really didn't have a whole lot of participation last year, but just through her desire to kind of just want to take things on and face those challenges has led to...I mean we had the highest participation rate at the state conference this year for FCCLA. .

Principal Hyde provided another example:

Honestly just trying to get them to kind of get on board with some of the things that we are trying to do. . .trying to utilize those teacher leaders that I know maybe have the same philosophy and then trying to work them in a way to start making those changes happen. Because if I don't have buy-in from a certain 
percent of the teachers, it really doesn't matter. What initiatives I want to happen aren't going to happen. So you really just got to make certain that you have some of those teachers that are willing to kind of maybe help try to do those things. . It doesn't matter how much I want to see it change. It's really not going to change unless I have a teacher leader that's willing to tackle it. . You know, if you don't just have a person that's willing to take initiative and drive, it doesn't really matter how much I really want that program to improve - it doesn't really matter. The ideas that we throw out there; if they're not willing to really just grab the bull by the horns and tackle the problem, they're never really going to see it. So just trying to figure out what teachers' strengths are and how I can utilize them to create things to happen in whatever capacity it is.

Principal Finnegan gave another example of relying on his teacher leaders for change: The one you are going to interview is retiring this year. There's another one that's retiring this year. Both are teacher leaders - very different ways that I would say that they lead. But both are well respected by their peers. You know, as a principal, if I'm trying to implement something, I'm going to go talk to the two of them before I even try to do anything because I know that their influence will be helpful as far as things go. They're highly organized, they are tenacious, not in a mean way, but as in we're going to get this done... We aren't going to accept anything but getting it done. One of them is a talker; the other one is a listener. The one you're going to talk with is a listener. She hears and then she is able to go from there with it. 
Principal Finnegan also discussed the importance of teacher leaders with buy-in among the faculty:

Makes your job easier. You can't do it by yourself. You've got to have buy-in from your staff and those teacher leaders are the ones who are going to get it done for you. Seventy percent of your staff will end up following you just because they're like okay, it's the boss, I have to follow him. Others may not, but the teacher leaders are the ones that have, to me, a lot of the impact on getting things done within our building.

Teacher leaders are described as enhancing the school culture. Principal Finnegan relayed, "The teacher leaders are the ones that have, to me, a lot of the impact on ... how we operate the culture within our building." 


\section{Appendix H}

\section{Answering of the Research Questions}

The following questions are answered as a result of collecting and analyzing responses representing multiple perspectives from both teachers and principals in the Central RPDC region in the state of Missouri. These responses were captured in the form of principal surveys as well as principal and teacher interviews. Teachers interviewed were specifically selected as teacher leaders by the principals.

\section{Research Question One}

Research question one of this study was "How are teacher leaders identified and utilized in school districts?" Teacher leaders are identified in various ways. Often times, these individuals rise to the top on their own or inevitably show themselves in many different scenarios, which Northouse (2016) termed "emergent leadership". Principal Warren indicated,

The way I identify them is basically how they model for other teachers, their willingness to help others, their constant drive to get better in the classroom, and the fact that they're always looking at ways to make their environment better and instruction better. So that's how I identify them and usually it doesn't take a whole lot of prodding. They will rise to the top, and you'll find them pretty darn quick. So those are quick and easies for me to figure out who they are.

Principal Hall shared the following about his selected teacher leader:

Well, I know a couple like Ms. Carroll, for example, would be one, that, you know, she is an art teacher. She impressed us obviously to hire her. She was a 
very impressive person. But just in her desire to improve herself is what really drove me to her and so we started working together on the leadership team. Other times, the principal will see leadership traits or potential in certain teachers and will question or encourage them to take on leadership roles. Elizabeth indicated that this was the case with her leadership as a teacher:

I think for me the biggest thing has been being given some opportunities and being put in some positions where I'm a little uncomfortable. And so, like, I did not want to present to the faculty this fall, and so my principal says you're standing in front of a group of 80 people, most of which are older than you and have way more experience, but to put me out there in that position made me like, well, holy cow, I can do this, and so afterwards, encouraging people, whether it went great or whether it went poorly, and so I presented, and before I had even gotten back to my classroom, Mr. Munstermann had sent me an email that said, "Hey, great job presenting today. That's a tough thing to do. Keep it up. . " So I think giving people an opportunity to do something and then encouraging them to keep trying it or that it was good when they did it.

These people are the activators and initiators. They step up and take an active role. They are highly motivated, take on challenges, are problem solvers, and actively seek out opportunities to improve themselves and the school, all for the greater good. They lead by example, and they serve students, teachers, and administrative personnel as an invaluable resource. Principal Hyde mentioned such characteristics:

A variety of things, but honestly I think it just goes back to the initiative piece. I think the real teacher leaders are the ones that are just constantly almost to the 
point of bugging I think at times just because they see that there is a need here and they want to move forward and they want to make a change, you know. And it may not be a drastic change, it just may be a tweak, it may be a minor thing, but they just see a need and they would like to attack it. And they know how to get people on board to kind of make those changes.

Alexandria discussed her own motivation and responsibility as a teacher leader: I would say yes, with the getting things done. I'm kind of the one that will start the email, like here's what's coming up next month and what we need to get going, just the proactiveness of it because I don't want to wait until the last minute. And then we have to throw something together. I don't know. That's just how I am. Luckily, they all are okay with it. . .I am the department head for ELA for the school, so we are taking on some curriculum writing, so I've had to go to some summer trainings and then tomorrow during our early out is the day when ELA is meeting to kind of vertically reassess and make sure we're all on the same page of what grade level is doing what. So but again, I think it just takes just the motivation and the organization to put that together and that's just where I think I kind of thrive on that kind of stuff.

Teacher leaders are involved in a plethora of different roles and contribute in many different areas; they are multi-talented and multi-faceted individuals. They collaborate well with others, and those with whom they are directly involved, such as students, teachers, and principals, and these people gravitate towards them. Principal Quick contended, "Those are more just the teachers that other teachers want to follow. . .and "they are teacher leaders by students ... .kid magnets. . .students are flocking to them and 
want to be around them and yet still learn ..." They act as a voice for both teachers and principals, often serving as a powerful liaison for both. As principal, Garrison spoke of this meaningful role of teacher leaders:

But you see a lot of things differently when you move into administration because you're just viewing all the systems at the same time. And so things look so different. And sometimes you want to impress that on people, but it's hard for you to impress that because you are different. And so, to have that person who is the teacher leader, that person can step in and basically, like I said, they can take the message and they can translate it. And when I say translate, I mean it's nothing different. It's nothing amazing, it's nothing new. It's just they trust that perspective of that person because they're respected as the leader.

They are receptive to input and feedback from the principal and other teachers, and they reciprocate this interaction by providing valuable input to both parties in return. They are instrumental in carrying out the articulated mission and in leading the school in a desired direction. Principal Finnegan articulated,

I'd say the practices of our school were developed by our teacher leaders through the years. I think it's sustainable leadership . . .my philosophies are throughout this school, but the teacher leaders are the ones who are leading us in the direction that we need to be going.

These are ways they show themselves or are identified by principals.

Teacher leaders are utilized in so many different ways and fulfill vital roles. One such role is that of mentor, both to students and teachers. These mentors go above and 
beyond, and they are on a personal mission to help others. They are instructional leaders and effective strategists. Principal Warren discussed:

I think it starts with a mentoring process, like a teacher who demonstrates by action and by voice, and then other people think, hey, it's okay if I do that. We do have way different teaching experiences in the middle school and levels of ability, however, we are always willing to share - I don't want to say a spotlight - but share a lead in something.

Ms. Carpenter spoke of these teacher mentors:

We have a couple of teachers here in the middle school that they have their master's degrees in specialized math and so they're taking on leadership, going out to other classrooms and kind of being an instructional coach so we have a couple of those here in the middle school. . .Again I think it's just doing it. Going out and doing it and taking the leap of faith, a step ahead of everybody else just to show that it can be done. I think that's one of the things is just, you lead by example so, if you want to get it...if you want other people to do it you have to do it first so that they will follow.

Another important way these teachers are utilized is through professional development. They not only lead professional development, but they also seek out professional development, both for themselves and others as well as for the district. These pursuits are often self-driven. Principal Chrisley elaborated on the topic of professional development and teacher leaders:

Confident but willing to follow as much as they are to lead. They're a good team player. So they listen to other people's opinions... not a know-it-all because they 
have to be respected by others so it's got to be somebody with a good work ethic and someone who values professional development and learning and wants to grow as an educator so we need them to be a model to other teachers.

Ms. Weston provided information about her own involvement with leading professional development:

Well, my colleague next door. She's been here for two years, but she has been teaching for fifteen years. She is my co-chair for professional development, and the way that works is that we lead all of the professional development for the district. So we are the ones finding it, we are the ones teaching it, and we're the ones doing it. We're spending a lot of extra time together . . . for the betterment, I mean, yes ourselves, but the betterment of forty teachers that we have here. We're trying to figure out K-12, so we're even trying to figure out elementary, like what it is they want and what they need and all of that so that tends to be a little time consuming.

Principals also rely on these teacher leaders to relay important messages, to rally support and teacher buy-in for upcoming initiatives, and to help solve important problems. Principal Garrison shared his experience with relying on teacher leaders for such matters: And so we try really hard to encourage people if they want to take on things, absolutely, but I really try hard not to just craft a committee, you know what I mean ... You know, and then, within that meeting, like I said, you carry that in who do you give the research to? You give that research to the teacher leaders. You know what I mean? I mean, if you want me to do the research that's fine, but I still need an advocate. So you go and you give it to them and so that way you 
don't overburden them but you still empower them ... Right now we're basically moving into a competency-based grading system over the course of like the next seven years, so we started it in the elementary and it's just going to grow to us. And so a lot of what we're doing right now is basically preparing teachers to understand the shifts in how you approach education. It's in these moments where, I mean, I definitely am going to need to use more of them than I am even right now. I mean because we're talking about major shifts in thinking and for some teachers who use it as a personal affront to using what I'm doing is bad, I think that what we've been doing hasn't changed in a long time.

Several principals indicated a need for teachers to help with such messages being relayed to staff, explaining that the role of teacher leader makes this transition smoother.

\section{Research Question Two}

Research Question Two of this study was "How are teacher leaders perceived by teachers and principals?" Both teachers and principals perceive these teacher leaders as having initiative or an innate desire to lead. Ms. Carpenter expressed this desire:

You know, at one point we had done RTI (Response to Intervention) and I was on the team for that so figuring out what interventions would work best and how do we go about doing that and so I think part of it is that, just stepping forward and taking that initiative and then like I said, anytime there's something new just jumping in and doing it and then being able to lead others in the process.

Principal Hyde spoke of this initiative as well:

A lot of it just comes from initiative. I think being a leader you just have to have a little bit of self-motivation to want to do what's best for whatever the situation is, 
what's best for kids, best for the program, best for the district, whatever it is. There has to be a little bit of initiation there or motivation on the teacher's part...to take the next step and maybe put themselves out in front and take the initiative to make a difference.

These teacher leaders are passionate about their work; they have a strong sense of pride and a vested interest for the culture of the school and the community in which it resides. Mr. Hawthorne illuminated this idea:

And you just want your school to be the best. You want the experience for the kids to be the best. I don't know whether you'd call that dedication or whatever, but I think that's probably the primary. Every single one of us has something to offer. The English teacher here who was a former student of mine, you know, she came here and was like, we don't do speech. Why don't we do speech? When she was here she did speech, but the person that did speech retired and then nobody did speech, so now we don’t do speech anymore. I didn’t even really realize it...so why don't we do speech anymore? That teacher left. I guess. So nobody did it. So now she does it. She's got a young lady going to regional speech championships. That just happened. Somebody just came in and made it happen, changed some kid's life. So that's really what I feel is the clearest answer I can give is who's going to be dedicated to put in those hours.

These teacher leaders are perceived as having integrity. Ms. Marigold reflected upon her own profession:

Always have integrity. Make sure that you understand that it's not about collecting accolades; it's about staying true to what we started this profession for, 
why we got into this to help kids and it doesn't matter what award you can put under your belt or what titles you can add to it - it still goes back to the core of you wanted kids to have those aha moments like you did when you were a learner. And so I think remembering that, remembering that we are a team, and that even if you are lucky enough or are honored enough to be put into a position where you have a title, learning that it's just that and it only carries as much value as you put into it.

They are conscientious, and this is often seen through their high expectations and a constant desire for betterment and growth.

These teacher leaders are highly knowledgeable in their content. They are intelligent critical thinkers and teaching strategy specialists, and they are viewed as experts in their fields. They are often described as "informal instructional coaches," and they collaborate with others. They are often sought out for practical advice. Principal Chrisley declared:

I have a couple of other teachers who have gone and gotten their specialist degree in math instruction which is kind of a new thing that's just started in the last couple of years, so they're among the first ones at UCM to earn that degree. So they've been ones, then again, with tons of encouragement, and they support one another. I think that's been kind of a neat part of that is that they work really closely together and they push each other to be better and better all the time. So they're the ones that are always willing when I go to them and say I want you to present what I saw you doing at the faculty meeting. They're always willing to jump in and help other teachers. We worked it out this year that each one of them 
can have an extra hour-it's different hours, different quarters, but they each have an extra hour when they can go down to the elementary and kind of do some instructional coaching - informally. Nothing super formal, but that's been really well received, so they just kind of hung their hat on a passion and we just keep encouraging it and they keep growing and growing.

These teacher leaders have meaningful interactions with others. They are described as caring and compassionate. They not only help others, but they are known for their level of effort and engagement. Principal Hyde voiced:

But again it's kind of that desire inside to want to see a change and see something positive for our kids. Some of my other teacher leaders, like Cara . . .but her desire to always want to do what's best and try to evaluate what's going on is probably stronger so than my other staff members. You've got to have a sense of compassion and caring because if you didn't care, then obviously you're not wanting to see things get better; you're okay with the status quo. Then again, just going back to a little bit of initiative and being able to grab the reins and go with it.

Teacher leaders follow through with their words, and they work alongside both teachers and principals to see that things come to fruition. Ms. Robbins indicated:

There's a little area of expertise. And they're comfortable doing it and they're willing to help, so they're helpers, they're leaders, they've got expertise in that area, and some are just the people that never say no. They will help you no matter what. I don't know what you're doing, I don't understand a word of it, but I will help you. 
They are listeners and learners themselves. They are results-driven and detail-oriented. They are problem solvers and mediators. Williams shared about a co-worker:

She is a good public relations person as far as let's try to see the other side of things, which I don't always do. Sometimes it's my way is the only way I think, so she brings the other balance of that of let's look at the other perspective and consider that. She's good about kind of bringing people together on the same page when we're not always like that.

Another perception of teacher leaders is they are innovative. They are unafraid to try new things and take risks, often stepping outside their comfort zone. These new undertakings are researched and well-planned - the aim is to revise and improve teaching strategies and to enhance learning. In both success and failure, reflection is seen as a compulsory part of this process in order for these teacher leaders to evolve and advance. Principal Munstermann spoke of his teacher leaders:

You know, I think that it's so hard to answer, but I think you see teachers who are very innovative, not afraid to try things, who question and ask others what works, what doesn't work, how can I get better? And I think people are naturally drawn to those inquisitive people. And I think that just kind of sets that whole thing in motion. And we see that, when something new comes down the pike, who do teachers gravitate towards? She's relatively young in the game, but they flock her direction right now. I think that it's almost courage to try something and to fail and then I think the reflection piece is huge on that, whether it's internal, or just bouncing things off. 


\section{Research Question Three}

Research Question Three of this study was "What types/characteristics of leadership are exhibited by teacher leaders?" Specific types of leadership that emerged from the data were servant leaders and transformative leaders (Northouse, 2016). Principal Warren shared of servant leadership:

Someone who's willing to put themselves out in front, someone who understands what it means to be a servant leader, and I think that's most important. And here in (name of school) we're blessed with a lot of people who come back and are alumni from here, Stephens being one of them. Just the fact that they have pride in the school, especially the school district, and they know what the school did for them and so they want to come back and give in return. And so that to me, definition of servant leader. I love it. They want to serve our community and serve our kids and that's awesome.

Principal Finnegan also noted:

You know that they are - when I am leaving here at 4:30 and we dismiss at 2:30, their car is still around back because they are doing that much more. They are the ones who, when asked to serve, serve, and other times they volunteer to serve. And those teacher leaders aren't power hungry; they are just wanting to make the place better.

Principal Munstermann spoke of transformative leadership in response to characteristics of teacher leaders:

Gosh, almost transformative. And by that I think just bringing other people along with them, maybe even unintentionally. If I look at Ms. Sparlding, she has people 
follow her that she probably doesn't even realize. And I think that's okay. But I think that, I know that there's some that sit back and watch what she does and things that she says. She makes us better every time she presents something or questions something. Right now they're in data teams and she has really kind of taken a lead role with her data team. I think, you know, specifically in terms of her, and I think that's probably broad and global, she makes others better just through the natural conversations they have. Nothing fake about it - just genuine concern for how do we make this a better place for our kids. I don't know if I can quantify that. I'm not aware of any words per se, but when I think transformative, that's what I think of.

Major leadership traits that surfaced, as outlined by Northouse (2016) were: sociability, integrity, and confidence. Principal Chrisley reported:

And we do have some really strong people in the middle school that are willing to jump in, be on the committees, be on the PD committee, help out with the superintendent's advisory council, they do like to jump in there and they do it with a positive voice. What I have heard is when they are in those committees, they're not there to complain, they're not there to say this is really messed up and I'm here to make a change; they come into it with a positive attitude. And I think that's huge. They have a growth mindset, I guess, and they know we are doing great but we can do better, and I think that attitude is a little bit contagious throughout the district. They learn a lot from each other being this close together. 
Based on interview responses of both teachers and principals, other characteristics of leadership exhibited by teacher leaders that arose were: influential, inspiring, guiding, positive, determined, and confident.

\section{Research Question Four}

Research Question Four of this study was "How can schools more effectively identify and engage teacher leaders?” As indicated by both teachers and principals, discovering who the teacher leaders are is paramount, and this happens by being present. Spending time in classrooms and in meetings is helpful, especially when teachers are engaged in collaboration such as in focus groups or leadership team meetings. This way the principal can see who emerges as a leader. Ms. Stephens reflected on the importance of this presence:

Well, I think it has to do maybe with just seeing how teachers operate in their classrooms and being present - if administrators are present when teams are meeting to see who can kind of keep the group at bay and keep them going. I think that their presence in those areas would kind of help other teachers come out as leaders.

Another important part of this identification process is in getting to know each individual teacher so that principals can become better aware of his/her strengths. This happens through personal conversations with teachers. Ms. Stephens elaborated:

Just being aware and taking an interest in who you have employed and what their strengths are and playing on them. Because like I said, you know, with my R2 Title teachers, they would never want to be pushed out there in the limelight and our administration knows that which is good, but they still go to them privately 
for advice or for help and then the principal knows that I'm not afraid to - here's what we need to do. So he knows that he can ask me and he can rely on me and I can do things that I'm stronger at and I think just playing on those strengths and getting people more confident, like those teachers that they see as leaders, just building their confidence. . .

Principal Quick also discussed the importance of identifying teacher leaders and of having these conversations:

Well, I think you've got to know who they are, for good or bad. I mean, you have to know who they are. If you don't know who your teacher leaders are or you think you have none, you know. . . I think you'd be just absolutely wrong to say I don't have any teacher leaders. Maybe you don't have any positive ones, I guess, you could be put in a position where there are some negative teacher leaders, but then you still need to know who those are, too. You know, and I would always think that everything's relative so even in the worst of schools is going to have some teachers that are the highest level comparatively to everybody else, and you've got to find them and start with them. You've got to use them somehow. You've got to find out what their strengths are; you've got to use them.

Principals often look for teachers who show initiative, share and collaborate well with others, are willing to present professional development before their peers. Principal Shackles verbalized this sentiment in relation to the teacher leader he chose:

Willingness to get in front of their peers.... I mean, there's plenty that would like to say yes, I'm a leader. Plenty that you think would be a leader, but it's fewer when you go hey, would you put a 15-minute presentation together or a 1-hour 
presentation at our next PD day on a certain instructional strategy or whatever. The ones who are willing to do that, well, you've found a leader. If they're not willing to do it then you go, well, you're all right. But you're not going to be the leader of the pack. The young lady that you interviewed before me, Ms. Marigold, she had not been here more than 60 days - it might have been less than that when I talked to her, but I asked her to put on at our first PD day of the fall ... I asked her to put on a half hour to one hour demo of the Socratic seminar method running a discussion and debate. I was going to do it with her, but then my wife fell down so I couldn't do it with her, but she went ahead and did it on her own. Which, you know, that's kinda cool.

These teacher leaders understand social relationships and social structures. They are not afraid of disagreement and they see the value in providing diverse perspectives and in moving forward and even collaborating and learning from people who think differently than they do.

Ms. Carroll described her experiences:

I am most often acknowledged by the few people that I've talked to personally and on some of the stuff that we do on the leadership teams when we do evaluations is that I hear people out and I'm not quick to make a statement about a particular movement we're trying or change we are trying to implement. I'm not quick to shoot it down or say let's go for it. I perceive multiple sides and I'm one of those people who sits back first to hear it all before making any decisions. Principal Garrison conveyed: 
I'll just kind of give you an anecdote. The other day I was having a discussion with another staff member about relationships within the building and I was just like, I go, "I think we all know that Ms. Williams is the ultimate team player. And she's from here, she played basketball here, she's our basketball coach now, but it's so much more than just an athletic mindset. . She's the team player because in meetings, she's the one who's going to stand up and say, 'We need to hear that person's opinion because all of our opinions matter because when you're truly the ultimate team player, everybody's voice on the team should be heard,"' you know, and when you're the ultimate team player, you stand up for other people's opinions because you want your own opinions to be stood up for as well and there should be value in the collective. And so she truly embodies that ... Several principals indicated that often times teacher leaders emerge organically, as a natural progression. Finding willing participants is quite important in the process. These individuals are driven by high expectations and have their focus on success. Principal Garrison emphasized, "And the teachers who evolve, they see that. They take the time to reflect. . . her goals are more about expectations so it's not about failure." As far as engaging these teachers, principals indicated that often happens in increments. Principal Hall communicated:

I've got another teacher who's been here eleven years and slowly but surely she started becoming a team leader. She didn't feel comfortable being in charge of anything but I put her on some committees because I knew that she wanted to be involved. And then I talked her into getting her specialist degree in reading, and so once she got her specialist degree she feels more confident in leading now that 
she has something to say, and so now she's in charge of her leadership committee. So she wouldn't have done that eleven years ago; she wouldn't have felt strong enough to do that. I could tell that she just needed some time to develop. It really kind of depends on the teacher.

Principals engage these teacher leaders by encouraging and providing opportunities for leadership through decision-making, committee involvement, and collaboration.

Ms. Silvers claimed:

Well, I think you have to give them the opportunity. You have to-you just have to jump in. And making the teachers responsible through committees, I've seen that, that's been a huge improvement, at least as far as our PLC and our PBIS committees here. Our administrators are part of it, but they don't run it. They're a part of the team; everybody does it together. And so I think creating those opportunities, understanding and seeing the importance of teacher time to work together, to do things together, because the benefits are huge. And you don't see it right away; but you see it over time. I think they're on a three or four year process here, but they've seen a huge change in student behavior, in the way the teachers communicate with one another and you know, they just have to jump in and do it. They often enlist the teachers to make important decisions that impact many. They present professional development to the building and even school wide. These teachers are often included to help share the vision of the school and the principal. Principal Garrison explained,

Yeah, so, sometimes I'm not always the best at this myself because I have a vision, I want to share my vision, and I usually do but sometimes it's hard. A lot 
of times I will have to go to these people and ask them, "So this is the message I want to convey, and it's very clear to me that it's not being conveyed in that fashion, you know what I mean? Like, I'm seeing something and I know that's not how people see it. That's not the message that I'm trying to send. This is the message that I'm trying to send." And so a lot of times I will use them in that capacity. Not necessarily as that, but also in that sense of I need input to understand what I need to change to make this maybe more palatable, more... how do we need to craft a plan here that's actually going to be successful? Principal Hall claimed, “. . . You need to find people you trust and you feel like they can support your vision."

Principals also delegate responsibilities to these teachers. Ms. Stephens shared: Todd definitely looks to me to schedule for us, I mean anything from just our basic daily schedule to our MAP testing to our benchmark testing to putting groups together for things, so I really feel like he definitely looks to me just to kind of take care of us down here.

Ms. Carroll mentioned:

Mostly the only ways in which I have influence is in that leadership committee with others and it's ultimately making decisions together. . .I am currently the facilitator of the group, so there is a responsibility there that has been offered to me in that position, an accountability piece, that I think is used to keep others accountable ...I'm keeping my colleagues accountable in there. . . so when we are initiating change, for example, a focus on literacy across the building, I can share what it may look like within this classroom and other performance-based 
classes where individuals who don't necessarily have that built into the curriculum as quickly as others may or as easily as others may. So it would be ultimately just be being a voice for those who don't have a voice on a normal dayto-day basis when we meet with him.

Ms. Spalding claimed:

... this year is my first year on the PLC committee, which that kind of helps plan all of our PD and stuff and so, and like monitors our school's progress is like the PLC. I did my first faculty presentation at the beginning of this school year, and so starting to be more of a vocal person is challenging, but it's exciting to think about continuing on. . .And if you need help or have questions...I feel very supported by Mr. Munstermann and our other administrators, and so I think they want people to step up and do better.

Mr. Hawthorne also mentioned:

I think that's an area where the administration has utilized me and other people in the building — getting teachers into a situation where we're learning from each other. I would say, I don't know if the administration agrees, one of my strengths is like classroom management. I have students that I have never had a problem with that other teachers do. And maybe vise versa. You know, I've had a positive experience more than negative. And so the administration has done a good job of saying, "Look, you have a student - you've never written this student up, sent them away, they're passing. They're totally, they're not making it in this other class. Can you talk to that teacher? Can they come into your room a little bit? Can they see and find out what you're doing? Share some strategies to get success 
across the board with the student?' I think that is a way that is a lot of times just organic and not exactly part of a program or a plan, but one way that they've utilized me and other leaders in the building to try to do positive...It is something they've made a priority and they've found different ways to make that happen, and I think that that's positive impact for the school. I've gotten things out of it and I think other teachers have. That's one thing that comes to mind that I think administrators have positively used different leaders including me.

Principal Hall answered, "If I think a teacher is not stepping up to a leadership role and I feel they need to, I will go and talk to them personally. I'll assign them some type of leadership role."

Another significant way the principals rely on the teacher leaders is to help implement initiatives or change. They are instrumental in rallying support and teacher buy-in during such times, making the transition smoother and more effective. Principal Munstermann indicated:

I think if you talk to central office, the high school, I think with most districts it's the face of the district. We have started a lot of the initiatives that the district has taken on. The PLC - this was the first building to go the PLC route and we were that way several years before that became a district philosophy. And so I think that those teacher leaders have been the ones to implement the change process here that has gone district wide. Not just PLC, but the whole data team piece and everything else is that all originated with us here.

Principal Finnegan relayed-- 
... both are well-respected by their peers. You know, as a principal, if I'm trying to implement something, I'm going to talk to the two of them before I even try to do anything because I know that their influence will be helpful as far as things go. Principal Hyde felt similarly:

...It's not something that I can just come in and say this is something we're going to do. So trying to utilize those teacher leaders that I know maybe have the same philosophy and then trying to work them in a way to start making those changes happen. Because if I don't have buy-in from a certain percent of the teachers, it really doesn't matter. What initiatives I want to happen aren't going to happen. So you really just got to make certain that you have some of those teachers that are willing to kind of maybe help try to do those things ... It's really not going to change unless I have a teacher leader that's willing to tackle it. . . if you don't just have a person that's willing to take initiative and drive, it doesn't really matter how much I really want that program to improve—it doesn't really matter. The ideas that we throw out there; if they're not willing to really just grab the bull by the horns and tackle the problem, they're never really going to see it. So just trying to figure out what teachers' strengths are and how I can utilize them to create things to happen in whatever capacity it is.

\section{Research Question Five}

Research Question Five of this study was "How is teacher leadership encouraged by teachers and principals?" Teachers encourage leadership by example, primarily by modeling their own leadership behaviors for other teachers.

Ms. Stephens expressed: 
Everybody just kind of has their own niche ... and mine is the voice of reason. I don't really know why, but we've got a lot of personalities in our group and some are more likely to have big opinions really quickly, and, you know what I mean? And there are some negatives and some that are really just hyper and it's just like somebody has to be that voice, okay, but here's what we need to do. Here's what our goal is. I don't know. I've just always been like that. I don't have a lot of patience in a meeting when we're not talking about what we're supposed to be talking about because we've all got stuff to do and so I just kind of lead things in that way.

Principal Chrisley described how both she and her teacher leader encouraged leadership development in a different teacher who was not very involved but had leadership potential:

Last year we went to a middle school conference and I had asked people and said, "Hey, who wants to go with me? I'd love to take several teachers," and he hadn't said anything but I went to him and said, "You know what? I'd like for you to be a part of this," and when he came and had the opportunity to visit with these other teachers that he didn't normally talk with, just people we had taken from our school, he got really excited. He actually fed off of Ms. Carpenter, and ... they, they had gone to a brain-breaks workshop and got really excited about it. I got him then to present to the faculty meeting, so I needed other people - I needed him to buy in to middle school concept and then I needed other people to see him buying in. So anyway, and he's just a very, very respectful young man and just with the work ethic, I mean I guess that's just the key thing you look for is really 
somebody that's going to get things done and take it seriously whatever they do, but still be willing to have a little fun.

On leadership teams, teacher leaders encourage other teachers to step up, take initiative, and self-advocate. Teacher leaders play a supporting role, especially when it comes to problem solving, brainstorming for ideas, or helping with the day-to-day profession of teaching. This process is welcomed by both principals and teachers, and it helps to create an environment that is rich in support and resources. Teacher leaders are often active listeners, inviting the confidence of both principals and teachers. They hear multiple, often diverse perspectives which may later become helpful components used to gather ideas, handle issues, or offer solutions. In this way, teacher leaders are seen as a voice for others. This process is encouraging to teacher leaders, as they are encouraged to take ownership by supporting and promoting individual members' needs as a part of the team.

An important aspect of encouraging teacher leadership, as noted by several principals, is to first build relationships with faculty members by getting to know them through personal conversations. The teachers will feel as though what they have to say as well as what they do matters. Principal Quick discussed:

You've got to, if nothing else, ask their input. And I think you can ask everybody's input, but specifically and maybe more often, you ask those (teacher leaders) more intentionally.... And to add to that characteristic, often those teachers do that. They are intentional. They don't come - they don't fly by the seat of their pants very often ... .they've got a plan ... you've got to find those teacher leaders - you've got to ask the advice. You should. . .base your decisions 
on what they would say more often than not and use them. Just put them to work. I think continue to praise them for what they do because they need to know that not everybody is doing that.

Principal Hall commented:

...you just get to know teachers. You are looking for anybody that's really going to be a good teacher in the classroom is where we start having those conversations. Find people who have a niche for something like RTI, or organization, or after school programs and then try to connect their passion to that need, so ...that's how we kind of do it here.

Through relationships that are built and opportunities for leadership, principals better know who their most effective teacher leaders are, and they will then be able to encourage them in more direct, personal ways, maximizing their strengths, deliberately working compatibly with their passions and interests, while building confidence along the way. This focus on communication helps to create a positive school culture, which is encouraging to teachers. Principal Quick shared, "Hey, I have this thing I want to do, this project, whatever, who am I going to ask? Well, I'm going to ask my teacher leaders. . .I think it's a culture thing - and a relationship between the principal and the teacher."

Both principals and teachers emphasized the importance of providing opportunities for these teacher leaders to exercise leadership roles as well as to grow as leaders. Teachers underscored that awareness of these opportunities is key, as well as clearly articulating the purpose and intentions of the teacher leaders acting in leadership roles to help diminish effects of the stigma of teachers in leadership roles. Ms. Stephens, when mentioning other teacher leaders, mentioned the issue: "I don't think either one of 
them would be comfortable saying they're a leader. They don't want to be a leader, because that takes on a whole new monster in itself." Ms. Carroll also helped to clarify this point:

I think there's a stigma towards leadership teams and thinking if I'm on this committee I am making decisions for people and so others see that as a negative thing. So finding a way to communicate to all staff that if you're in that situation you may find out it's not exactly that would be a major benefit so it's communicating the intentions of a leadership team or any leadership positions so it comes down to not assuming that they understand the process to get through that and again the intentions. . Knowing how to let the staff know how to take the path to get to a position of leadership would be definitely helpful.

As teachers try out new leadership endeavors, flexibility and openness on the part of the principal was cited as critical for improvement and growth. Room for making mistakes was a necessary ingredient for these teachers' success. Principals who show vulnerability and admit their own mistakes was also encouraging to the teachers, showing them that this is not only acceptable, but a necessary part of growth. Ms. Carpenter shared:

Just doing it, just go ahead and take the leap and know that you may make mistakes, you know, in leading others or even in doing whatever it is that you're going to lead at and just not worry about necessarily that you might make mistakes but that's a part of learning. So I think just telling them that they should go ahead and do it. 
Ms. Weston revealed, "I think the important thing is giving teachers some flexibility and some room. . .I think it really helps to let the teachers have their flexibility and space to make mistakes and correct mistakes and try again." Trust was also an essential component in this process; the teacher trusted that the principal would provide support and back up while in the role as leader, and the principal trusted that the teacher would be a conscientious leader.

Several principals indicated a tendency to go to the same teacher leaders time and time again, but this was often viewed as a personal shortcoming on their own parts, in that these teachers may become burned out because it is likely that they apply additional pressure to themselves given their strong work ethic and level of involvement and because so many people are potentially using them as resources. Because of these occurrences, the importance of rotating teacher leadership and giving many individuals the chance at leadership opportunities was verbalized. This decision of involving many helps to boost morale and cultivates a climate of leadership and professionalism. Principal Finnegan discussed this:

You try not to get your favorites. And every building will tell you that's one of his favorites. Well, why is it one of my favorites? Cause she stays late, she... there may be reasons that administrators have favorites, but I honestly have to say you can't go to the well too many times because you spread yourself too thin, so you've got to try to have those conversations with people in the hallways, about hey, have you ever thought about helping out with this? Helping out with that? Let me tell you pretty much everything I do I try to do by committee. We switched from BIST to PBIS this year. We're trying to marry the two 
together...so forming that committee to help lead us into that next phase of things. Grading practice. Have the teachers help develop it because I can tell you what to do, but I think until they have ownership in that... I don't want to say leadership by committee, but have those teacher leaders on committees to help guide the building in the right direction.

Ms. Spalding also elucidated:

We almost have a hierarchy of administrators, leaders of the teacher leaders, teacher leaders, and then like everybody else, which is not a whole lot of people . . And it's like the leader of each team that we have, so we have like a data team and a PLC team and so on ... and then all of our individual groups meet. . .So it's almost like a big pyramid. There's an overall idea. The administrators are kind of like facilitating some of it, but it's a lot ... I feel like our teachers are mostly deciding the direction that we're wanting to go. And I'm sure that like our administrators have an idea, but like they're consulting with... I feel like it's very teacher-friendly ... so. I think that's cool and I'm sure it's not like that at every district, so it's a cool district to be a part of.

Another important part to growing teachers as leaders is to never lose sight of the personal aspect of the individual who is the leader. This will support the process of teacher growth by empowering the teacher as an individual and celebrating the personal strengths and aspects of each teacher. Principal Munstermann illuminated, "I think it's just encouraging them to express their freedoms and creativity. We don't want to put the ratchet on anybody. We want to allow them to grow." Principal Warren shared, "Identify 
them, celebrate them, let them take risks, let them be who they are meant to be - not only inside the classroom but outside the classroom."

\section{Research Question Six}

Research Question Six of this study was "How are elements of distributed leadership exhibited by principals and teachers?" In order for distributed leadership to occur, that is, principals sharing leadership with other individuals, principals feel that they must relinquish some control and get help from the abundant resource of leadership that is all around them every day: teachers. Teacher leaders are seen as trusted advisors to the principal, and there are many situations in which leadership is shared. Principal Chrisley echoed this sentiment:

I think the teacher leaders are even maybe more important than the leadership of the principal, and that being, I really learned that because my unique experience was being here as a teacher, and I was that teacher leader, and I was the one that if I would say here's a great strategy; you should try this in your classroom and everybody would latch onto it and oh, Karla thought that was a good idea; let's try it. It was really good. We had some good stuff going on, and then when I moved to the principal's office I tried to do the same things but it didn't go over as good enough? Am I going to get a bad score? And they just were always wondering what I was up to... and I was like, no, I just want to help, I just like instruction and I want to keep helping you. So that's when I realized right away, okay, I have to get these people like I was. I pulled out of that mix, and we were left with not a lot of teacher leadership, I've got to start planting those seeds and get the people under me so I can give to them, hey, this is my idea, this is what I'm thinking, and 
let them take ownership and run with it. It's just better received from the teachers. And it was just interesting, because I am the same exact person I was three months ago...but it says "principal" over my door, so that changed things. And now, they've developed more trust and I'm kind of back, it's come full circle, but I mean it's because of those teacher leaders; that's huge. . . Trust your teachers. I think that's one problem with a lot of administrators is they want to be in charge, which obviously, that's why you get the degree. You want to be the leader, but at the same time, you don't have to do everything ., ,

Principal Warren attested to this point:

Don't be afraid to let go. I don't mind letting go. We have enough on our plate as it is. I have enough. I don't need to do everything, so let some of it go and let them do it and run with it. They will always surprise us in a positive way and they have the gift to be in school...that's why we hired them.

One way leadership is shared is through problem solving and decision making. Principals often rely on teacher leaders to help them solve important problems that affect many people. By considering this trusted teacher's opinion, the principal is able to better understand different viewpoints among the faculty and make more well-informed decisions that more people will embrace and be able to implement. Ms. Wheatley shared some of her experiences with problem solving:

I've even taken some big steps into learning more about data collection and then integration into what we're doing ... so far we've kind of narrowed it down to our reading and math. We've got to figure out what our foundational issues are within those two areas. So I'm starting on the high school end, trying to figure out 
why the certain kids that we have keep landing in our DI all the time and we're trying to figure out if this is a can we do this and just not want to, or do we really not understand what we're learning, so that's kind of where we're starting.

Principal Garrison also relayed information about getting help with problem solving: You have to demonstrate that you are willing to allow your ideas to be changed just like you're probably going to change their ideas, you know? And it's in that sense that, I mean, I've worked with people who are like that, I mean, I've worked with people who basically are like, I'm not the $10^{\text {th }}$ smartest person in this room, but my job is to let the $11^{\text {th }}$ or $12^{\text {th }}$ smarter person in this room succeed and they made no qualms about that. And I respected that, you know what I mean? It's like these are the things I know, and these are the things I'm good at, and these are the things I don't know and I'm not very good at, and I'm going to lean on you, you know.

Related to decisions implemented, principals rely on teachers to help them begin new initiatives for improvement or to help enforce change. These teacher leaders are seen as instrumental at bringing improvement or change, especially in helping with teacher buy-in. Principal Quick emphasized:

And I think the biggest need for them would be change. Even if you're on the right track, you've got to be moving, and so you know, as good as we think we are, we've got to be looking for ways to improve. Which means change, plain and simple, that just means we're going to have to change something. Don't know what, and we're not going to change just to change, but there will have to be some kind of change and that's tough for a lot of people, teacher leaders included, but if 
I can get teacher leaders on board, or if I can even get their input on how to change, you know, whatever we're trying to change, I think that's the biggest necessity for those teacher leaders.

Principals who share leadership often rely on teacher leaders as a resource for instruction, given that these teachers are viewed as experts in their content field. In this way, these teachers are academic leaders. These teacher leaders are provided opportunities to lead other teachers through data teams, research, professional development, leadership committees, strategic planning committees, and in other ways. These teachers often guide, direct, and mediate their peers, as well as aid the principal in holding them accountable. They are also effective in encouraging, challenging, and pushing teachers beyond the status quo and to higher standards. Principal Munstermann spoke of his selected teacher leader in this role:

When we paired her it naturally happened with common classes. We had a teacher that we were working quite hard with to improve some things and once they got paired up in a common curriculum, that other teacher, I mean it was like a light switch went on. I mean, it was night and day the difference in the performance of that teacher in front of the classroom. I can't tell you what was said behind those closed doors or anything, I have no idea, but I know that individual relies on her, yet she has cut them loose a little bit but is always there. As a matter of fact, they're in a team right now together. But I think that is my Ms. Spalding story, if you will. Just because of the growth in one year's time that we saw in that other teacher. Because that's someone - we were seriously considering hey, this is not 
working and then now, they're a fantastic teacher, I mean holy smokes, I do attribute that to Ms. Spalding and her leadership.

This process of distributed leadership enriches and empowers the team concept and dynamic. By sharing leadership roles and delegating responsibility, principals recognize the value in the collective, and in the words of teacher leader Ms. Carroll, "With multiple brains more things can be considered to achieve greatness." This increased sense of ownership benefits both the school and the individual. Principal Garrison added, "Not only are you empowering teacher leaders, but you are empowering that concept of the team where everyone is valued and we're real with one another." 
VITA

Julie Ann (Smith) Carter was born in San Antonio, Texas, on August 18, 1971, where her father was stationed at Lackland Air Force Base. Julie, her father, and her mother were relocated to Fairbanks, Alaska, in 1972. The Air Force would move the Smith family one last time to Knob Noster, Missouri, in 1974. Julie attended kindergarten at Whiteman Air Force Base, and then her family moved to Warrensburg. Julie graduated from Warrensburg High School in May of 1989.

Julie received her Bachelor of Science degree in English Education (with grades 7-12 certification) from Central Missouri State University in December of 1993 after completing student teaching requirements in Chilhowee, Missouri. She was employed at La Monte R-IV School District in the fall of 1994, where she taught middle school and high school English for seven years. Julie earned her Master of Science in Education degree from the Central Missouri State University in May of 2001. As a result of her husband's employment relocation, the family moved to Poplar Bluff, Missouri, where she commuted to Ellsinore, Missouri, and taught high school English in Ellsinore, Missouri, at East Carter County R-II for two years. Then, Julie and her family moved back to Warrensburg where Julie began teaching at Crest Ridge Middle School. She taught middle school English in this district for two years. Next, a friend and former co-worker convinced her to transfer to Odessa High School in Odessa, Missouri, where she has taught for thirteen years and was still working at the time of this study.

Julie has always been passionate about teaching, and she finds the profession rewarding and inspiring. She works to have a special connection with her students. She has facilitated student council, yearbook, creative writing club, and book club at several 
different schools over the years. She thrives on integrating drama and hands-on activities in different ways into the classroom to engage students.

Julie's future goals are to retire from teaching public school in five years (to complete twenty-nine years) and afterwards to pursue a career in higher education, possibly as a professor of education, teaching future teachers. Her options are open, however, for the right position to come along. 